


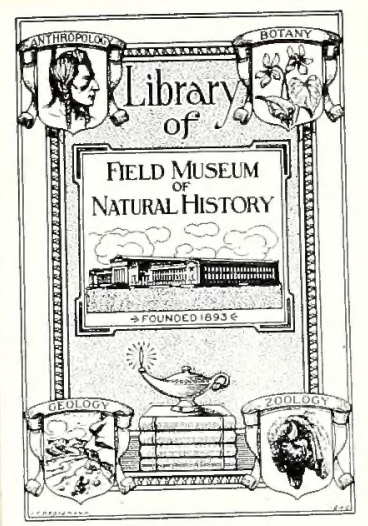





\section{ICONES PLANTARUM}

IN

FLORA CUBANA

DESCRIPTARUM 


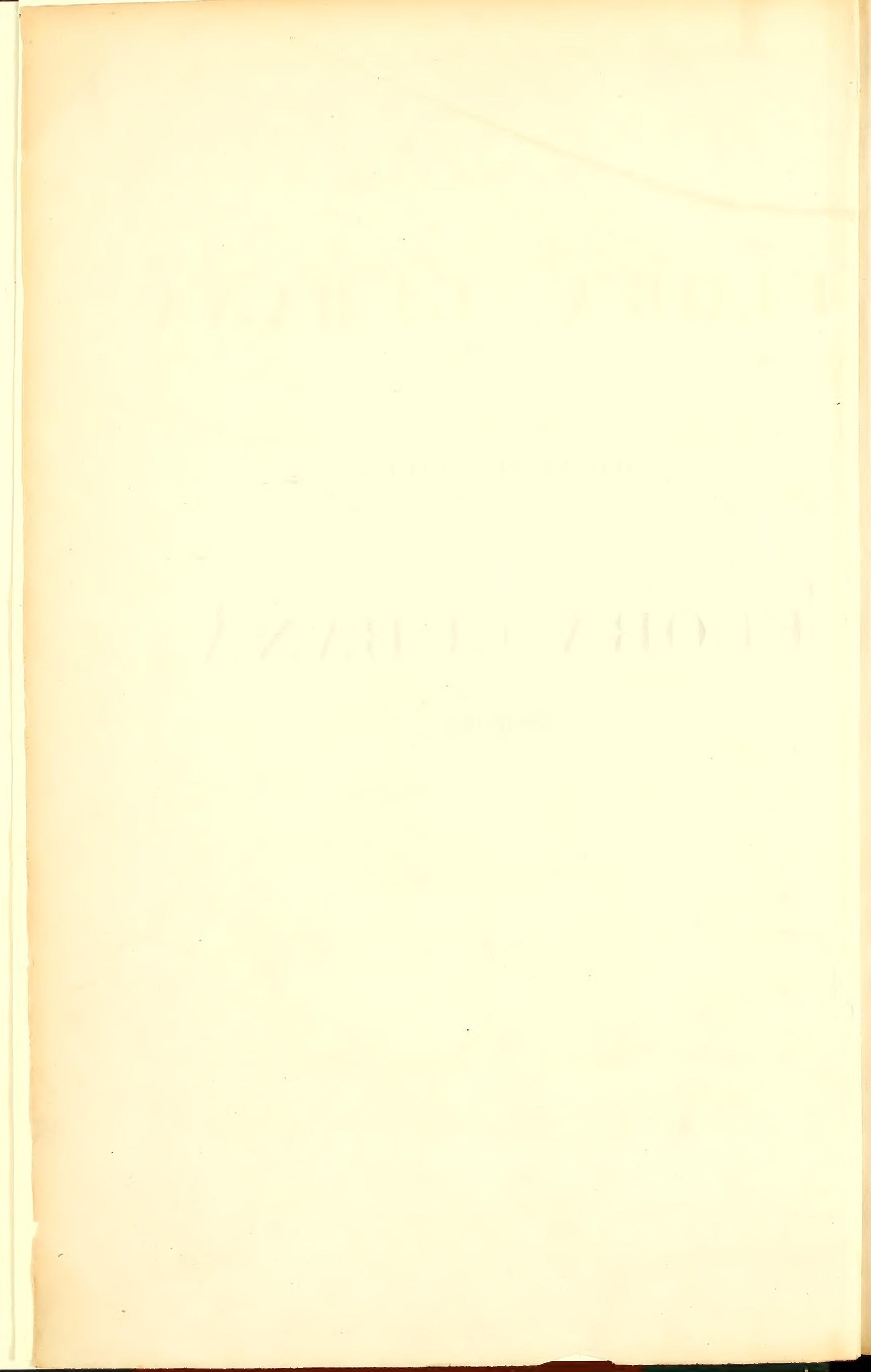




\section{ICONES PLANTARUM}

IN

\section{FLOR I \\ CUBA N A}

DESGRIPTARUM

EX HISTORIA PHYSIGA, POLITIGA ET MATLRALI

A RAMON DE LA SAGRA

Ex-direclore Horti botanici Habanensis, Instituti Impcriali Gatlici socio exlero

EDTA EXCERPTA

INTRODUCTIO IN FLORA GUBANA

HATON DE HA SARA

CR YPTOGAMIA

20 Tabul:Fe.

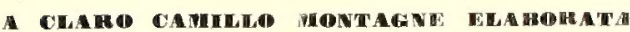

PHANEROGAMIA

(102 TABU(F).

C CLARO A. HECHARID ELABOHATA

PARISIIS

18498

J.-B. BAILLIERE ET FILIIS, BIBLIOPOLIS ACADEMIE IMPERIALA MEDICIN E Via vulgo dicta Hauteferille, 19

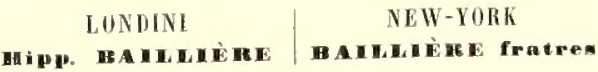

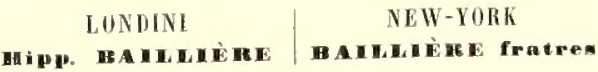

MADR 19, C. BAIT,I, Y-BALLLEERT:

MVCGCLXIII 
OVERSIZE

QK

227

524

1863

3

$$
2043:
$$

117526 


\section{INDEX ICONUM CRYPTOGAMIA}

1. - Sargassum polyceratizm. Montag.

II. - Fig. 1. Ceramium clavulatum var, crispulum. Montag.

Syn. Centroras crispulum. Montag ad kütg.

- 2. Scytonema byssoideum. Ag

- 3. Caulerpa fastigiaza. Montag. Syn. Herpochæta fastigiata. Hon tag. Syllog.

III. - Fig. 1. Sphærococcus Ciorallopsis. Montig.

- 2. Bryopsis ramulosa. Montag.

- 3. Haliseris plagiogramma. Montag.

- 4. Sphærococcus radicans. Bory, Syn. Gelidium radicans. Monlag. Sylloge.

IV. - Fig. 1. Rhodomela calamistrata. Montag Syn. Bostrychia calamistrata. Montag. Syllog.

- 2. Conferva brachyclados. Montag. Syn. Cladophora brachyclatos. Külzg.

v. - Fig. 1. Thammophoræ frondis et fructu structura.

- 2. Polysiphonia secunda. Montag

Havanensis. Montag.

- 4. Callithamnion repens.

VI, - Fig. 1. Collema chloromelum. Ach.

- 2. Leptogium marginellum. Ach.

- 3. Parmelia gossypina. Monteg.

VII. - Fig. 1. Strigula Feei. Honlag.

- 2. - mitida. Mon

-. 3. - complanata. Honlag.

- 4. Pyxine sorediata. Fries.

VIII. - F Fig. 1. Parmelia applanata. Fée Syn. Parmelia picia. Ach.

- 2. Thelotrema Auberianum. Montag.

- 3, Parmelia Domiagensis. Montag. non Ach.

Physcia erisya. P. Uran ex Nyl.

IX. - Fig. 1. Opegrapha flicina. Montag.

- 2. Bialora vestita. Montag.

- 3. Parnelia rictu. Ach. - deil P. viridis. Montag Sylloge.

X. - Fig. 1, Graphis Leprevostii. Monlag.

- 2. Bialora pusilla, Montag.
XI. - Fig 1. Puccinia plaqiopus. Montas.

2. Zygosporium oscheoides. Moutng.

- 3. Stilbum cimeduarinum. Montag.

- 4. Tulostoma cxasperatum. Montag.

XII. - Fig. 1. Hypocrea cirrine frucus Montaly.

- 2. Neliola Amphirricha. Monlag.

3. Hypoxylon Bomba. Montag.

Sagrcanzm. Montag. dein Phylacia.

- 5. - poculiforme. Montag.

- 6. Micropellis applanata. Montag.

XIII. - Fig. 1. Hypoxylon Cubense. Monlag.

- 2. - OEdimes. Montag.

- 3 - dichotomum. Hontag.

XIV. - Fig. 1. Thelephora auratianca. Pers.

- 2. Favolus cucullatus. Mlontag.

- 3. Hexagonia polygramma. Hontag.

- 4. Diedalea repanda. Pers,

$\mathrm{XV}$ - Fig. 1. Glacoporus enchoides. Montag.

- 2. Polyporus Flabellum. Montag.

- 3. - byrsinus. Monlag.

- t - Valenzuelianus. Montar

XVI. - Fig. 1. - Auberimus. Monfag.

- 2. - lichoides. Montag.

- 3. - Cubersis, Montag.

XYl - L. Sagracamus, Houtag

XVII. - Fiy. 1. Polyportus tricholoma. Montag.

- 2. Lontinus engrammus, Montag.

- 3. - velutimus. Fries.

- 4. Marasmius hematocephahus. Mont.

- 5. l’olyporus mioromegas, Mlontag.

XVIII - Fig. 1. Phragmicoma Sagroura. Montag.

- 2, Iejeunia Cubonsis, Montag.

- 3. - semlata. Monlag.

- 4. - cardiocarpa. Montag

XIX - Fiy, 1 - Auberiance. Hontag.

- 2. - unidentata. L, et $\mathbf{L}$

- 3. Fimbriaria Cubanensis. Lehm.

- 4. Cyathodium cavernarm, Kunzo.

XX. - Fig. 1. Hypnum Mortagnet. Schimaper:

2. Torlula latifolid. Montag

3. Hypnum litiputiamm Monlig. 


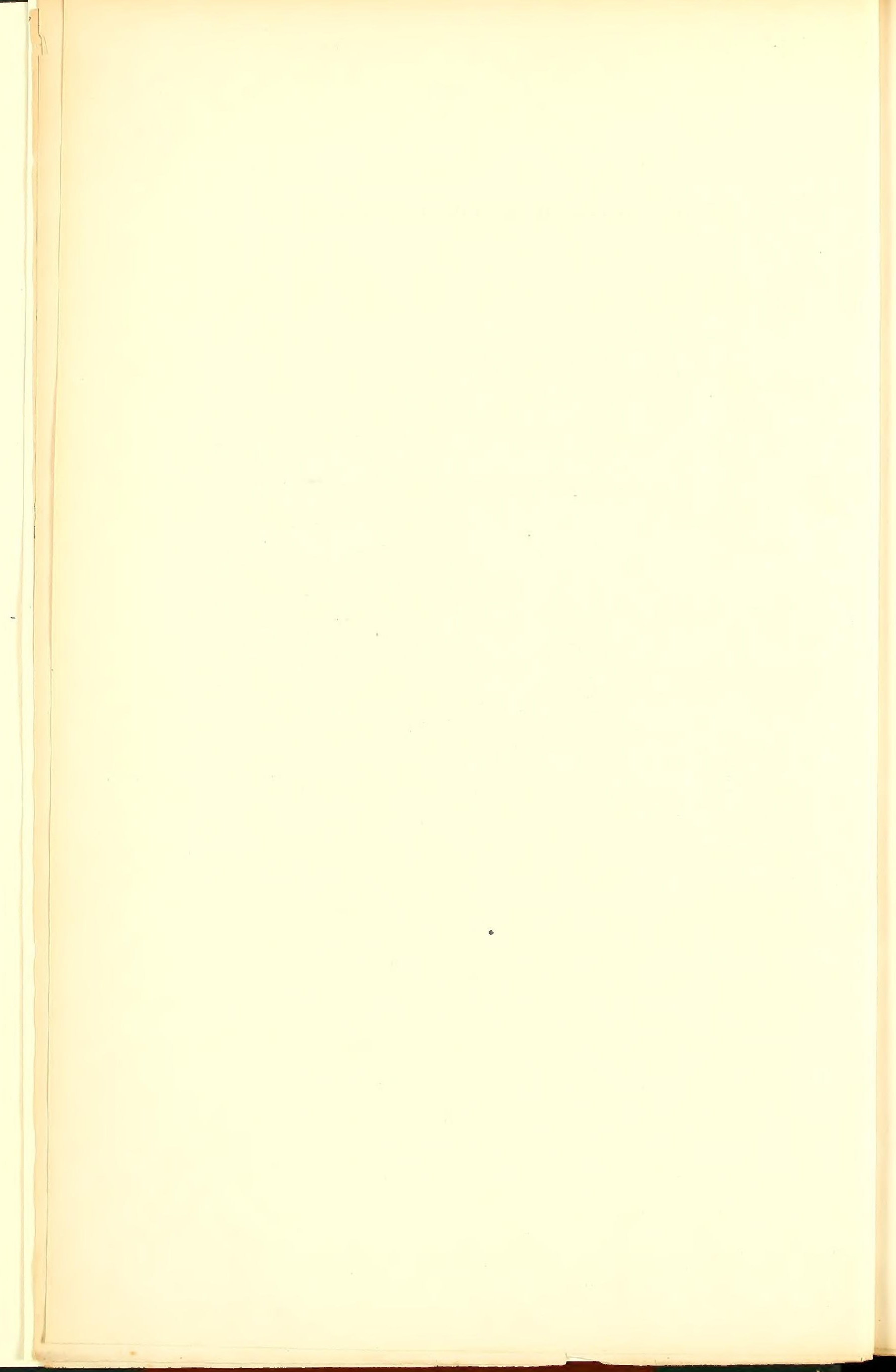




\section{INDEX ICONUM PHANEROGAMIA}

TAB.

1. Clematis Havanensis............ Kunth

2. Davilla Sagreana............. Rich

3. - ciliata. ............. -

4. Tetracera Pappigiand.......... Schlect

5. Anona bullata................... Rich.

6. Xylopia Cubensis............. -

7. - obiusifolia........... -

8. Oxandra laurifolia . ........... -

9. Capparis emarginata.......... -

10. Lætia longifolia

11. - crenata

12. Zuelania lcetioides.

12 bis. Polygala neduncularis

13. Pavonia linearis.

14. Malvaviscus Sagrcanu

16. - trincatus.......... -

17. Abutilon trichodum ............ -

18. Helicteres trapezifolia.......... -

19. - furfuracea..........-

20. Pachira emarginala.

21. Triumphetla grossularicfolia..... -

22. Belotia grevicefolia.

23. Luchea platypetala.

24. Prockia tomentosa.......

25. Ternstromia obovalis

26. Laplacea Curtyana.

27. Erythroxylum affine.

28. Stigmaphyllom Sagrcanum ...... A. de Joss.

28 bis. Byrsonia lucida ........... Kunth.

29. Schmidelia nervosa............ Rich.

30. - macrocarpa......... -

31. Gupania multiyuga........... -

2. - oppositifolid..........

33. Trichilia minor ................ -

34. Zanhoxylum coriaccum

3. $\quad$ - bombacifolium

36. Monteverdia buxifolia.

36 bis. Pieramnia pentranda........ Swartz

37. Icico copal ................. Rich.

38. Myrospermum Toluiferm ...... -

38 bis. Lonchocarpus latifolius....... Kumth
39. Poppigia excelsa .............. Rich.

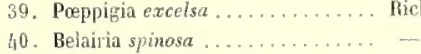

40 bis. Cerasus occidentalis.......... Loiselenr.

141. Cynumetra Cubensis............ Rich.

1,2. Swartia mulliyuga.

43. Chicharronia intemedia

44. Calycogonium Cubense.

44: Naudinia argyrophylle.

$44^{2}$. Triceralia biyonioides.
4/4. Stegnosperma Cubense.......... Mich

45. Siderodendrum floriburun

46. Guettarda calyptrata ........... -

47. Gátesbaea machranta

47 bis. lichinodendrum camparulat

48. Exôstemma Valenzuela...........

$19 \mathrm{bis}$. fonianthes Lindleniana . . . . . -

50. Eupatorium aromatisais........ D. C

51. Thibaudia Cubensis,.......... Rich.

52. Lencothoe latifolia. ......

53. Gostoea Cubensis.

54. Diplocalyx crysonhulloides.

5 h bis. Dipholis salicifolia .......... Alph, D. C.

54 ter. Bunelia rubra............ Rich

55. Dyospyros larrifolia .

(5).

57. Melastelma linearifolim.

58. Lisianthus glandulosus.

59. Bignonia lepidophylla

$59^{1}$, Coritie gerascanthoides......... Kurth.

60. Cordia anqiocarpa ............. Rich.

61. Ehretia callophylla....

62. Solanum Sagreapum

63. Calonyclion megalocarpum

64. Vilex ilicifolia.

65. Espadea amcrna.

66. Brunsfelsia sinuata. .

68. Bonania Crebana

69. Stillingia Inurifolia.

70. Phyllanthus laurifolius.

72. Ficus Jacquiniafolia, ........... -

73. Ouercus Cubana

7h. Pleurothallis pachyrachis.

75. Epidendrum Sogræanum

76. - fucatum......... Lindl.

77. - $\quad$ hircinum......... liisk.

78. - ochranhum........ -

79 - nematocaulon.......

80. - oblongarum........

82. Lalia Lindlemit.............. Lind!

82. Laelia Lindlenit.............. Bint

84. Oncidium Guibertianum -

85. Rhynchadenia Cubensis......... -

86. Habenaria replicata............ -

87. Ponthieva lancifolia............ -

98. Physurus sagreameus......... -

89. Andromvela Cubensis............ - 



\section{FLORA CUBANA}

\section{INTRODUCCION}

Al presentar al público terminada, la parte descriptiva de la Seccion botánica de la Historia Natural Cubana, nos parece conveniente y oportuno el consignar en una Introduccion, varias reflexiones sobre el orígen de este trabajo y las causas que nos han precisado á reducirle dentro de límites extremadamente estrechos. En efeeto, y conforme al plan primitivo de la presente obra, la descripcion botánica de las plantas que hemos reunido durante nuestra larga residencia de doce años en la isla de Cuba, debia constituir solo una Seccion, en el conjunto de observaciones relativas á la vegetacion, pues tal fué el modo como la comprendimos, desde que en nuestra juventud pisamos el suelo privilegiado de la rica Antilla.

Aunque una reunion de causas secundarias, nos decidieron mas tarde a $\mathrm{cm}$ prender la reunion de todo género de producciones y de salir de la esfera puramente científica, para abrazar tambien la económica y administrativa, la primordial mision que en el año de $\mathbf{1 8 2 2}$ debimos al Gobierno de nuestra patria y al buen criterio de las autoridades cubanas, se limitaba á la enseñanza de la Botánica aplicada á la agricultura, por las utilidades que la Isla podia obtener, de fundar en los principios de la ciencia la práctica del cultivo y de estender la esfera de este á un gran número de plantas ya indigenas ya exóticas, dignas de ser en él comprendidas.

Bien considerado, este plan, aunque simple en apariencia, no podia menos de resultar complexo por los medios que para realizarle requiera; sobre todo si se reflexiona en la carencia absoluta de datos y de observaciones, preliminares indispensables para el fin que el mismo suponia. - En efecto, mejorar las prácticas de la agricullura y enriquecerla con nuevos cultivos, constituian dos inmensos próblemas para aquel pais nuevo, donde eran aun desconocidas las condiciones Botanica. 
climatológicas, las leyes de la vegetacion y los obstáculos que la misma fecundidad de esta debia oponer á la introduccion de las reglas cientílicas descubiertas y solo aplicables en las regiones templadas y frias de la Europa. - Aunque entonces, el estado aun juvenil de nuestra inteligencia, no nos permitiese abrazar, con la perspicaz y profunda mirada de la edad adulta, toda la complicacion del próblema, el recuerdo del plan que formamos nos confirma ahora en la idea de que ya le considerabamos bajo su verdadero punto de vista. En efecto, se verá que la série de observaciones que desde luego emprendimos, y las que sucesivamente formulamos ó recomendamos, abrazaban las principales séries que deben preceder á la constitucion de una agricultura científica, bajo el cielo de los trópicos, y de las cuales vamos á dar una ligera y sucinta idea.

Las primeras condiciones para plantear, digamoslo así, los próblemas fisiológicos y agronómicos á que nos referimos, eran : $1^{\circ}$ el conocimiento del clima y de la vegetacion; $2^{\circ}$ el del territorio rural; $3^{\circ}$ el de sus producciones espontáneas y agrícolas. - Como estos tres órdenes de estudios tenian una estrecha y mutua dependencia, nos fué preciso emprenderlos á la vez, aunque no con la esperanza de que ni pronto ni con regularidad, nos procurasen útiles resultados. Por otra parte, la diversa naturaleza de estas observaciones y la imposibilidad de desempeñarlas todas por nosotros mismos, hicieron preciso el confiarlas á corresponsales activos é inteligentes, naturales del pais, prácticos en los hechos á que muchas se referian y en posicion social adecuada para reunir los datos que debian servirles de base. En cuanto á las que dependian de nuestra propia actividad, organizamos desde luego su centro en el Jardin botánico de la Habana, desgraciadamente poco análogo por su posicion urbana, lo reducido y uniforme de su superficie y la naturaleza de su terreno, para establecer en él los planteles de estudio y de futuros y ventajosos cultivos.

De lo que venimos de decir resultan ya dos divisiones en la série de tareas, relativas á la vegetacion, que nos ocuparon en la Isla de Cuba. - La una, que tẹnia su centro en el Jardin botánico ; la otra, que se ramificaba por todos los puntos de la Isla, donde nos fué posible ó hacer excursiones ó hallar colaboradores celosos.

Vamos á enumerar sencillamente las unas y las otras, antes de exponer algunos de los resultados que obtuvimos.

Las tareas que emprendimos sucesivamente en el Jardin botánico de la Habana, á parte de su direccion material y de la enseñanza que nos estaba confiada, se refirieron á las séries siguientes :

$1^{\circ}$ Observaciones meteorológicas diurnas, mensuales y anuales, comprensivas de 1a temperatura, la humedad y la presion atmosférica, los vientos, las lluvias y el aspecto del cielo; 
$2^{\circ}$ Experiencias sobre la germinacion de las plantas, ya indigenas ya exóticas, y sobre los fenómenos de la floracion y de la fruclificacion;

$3 \circ$ Escuela botánica ó sea la reunion melódica y el cultivo de las especies cubanas, por familias naturales;

$4^{\circ}$ Escuelas agrícola, médica é industrial, ó sea la reunion metódica de las plantas cubanas, de aplicacion á los diversos usos de la vida, y conforme á ellos;

$5^{\circ}$ Correspondancia científica, que abrazaba la relativa al interior de la Isla de Cuba, y la estrangera acompañando plantas en herbario y semillas, para que fuesen debidamente estudiadas por los profesores europeos, poseedores de todos los recursos necesarios para determinar las especies nuevas;

$6^{\circ}$ Formacion de una estadística de la topografía vegetal y agronómica de los partidos de la Isla de Cuba, enviando interrogatorios y estados en blanco y enumeradas las cuestiones que deseábamos resolver;

$7^{\circ}$ Reunion de noticias concernientes á la vegetacion ya de los bosques, ya de los llanos que sirven para pasto de animales; comprendiendo en ellas todas las relativas á las maderas y demas productos forestales, sus aplicaciones y usos; y en cuanto á los ganados, la enumeracion de todas las plantas anuales, hojas y fiutas de las perennes y arbóreas que les sirven de alimento en las dos estaciones de las lluvias y de la seca, en que se divide naturalmente el año en la Isla de Cuba ;

$8^{\circ}$ Trabajos preliminares para una Instilucion agrónoma;

9० Publicaciones ya elementales, ya periódicas, ya sueltas, para facilitar la enseñanza á los alumnos, tener el público al corriente de las tareas del Jardin y de los principales adelantos modernos que pudiesen interesarle, y tratar las cuestiones de importancia local en los momentos oportunos.

$10^{\circ}$ Formacion de un numeroso herbario de plantas cubanas, ya por medio de excursiones propias, ya por la cooperacion de algunos corresponsales que conseguimos formar para este género de trabajo, que desde luego destinábamos á la redaccion de la presente Flora cubana.

La exposicion, aunque sencilla, del precedente programa, puede dar idea, sin embargo, de su latitud é importancia, así como de lo insuficientes que debian ser las fuerzas de un solo individuo, mal secundado y constantemente contrariado, para llevarle á cabo. El grado de la dificultad é insuficiencia resultaba todavía mayor, considerando que todo lo que venimos de enumerar, refiriéndose soloá la vegetacion y á las plantas, no formaba mas que una parte del programa general, que la actividad inexperta de la juventud, nos decidióá emprender en la Isla de Cuba.

En efecto (y como se puede juzgar por las materias reunidas en la presente obra, y por las que tratamos desde nuestra llegada á aquel pais, en otras anteriores), nos propusimos estudiarle bajo todos sus aspectos, es decir, tanto en su administracion 
interior, como en sus condiciones naturales del clima y de las producciones, y en las economías de su agricultura, su industria y su comercio (").

Este plan era tanto mas vasto y difícil de llenar, cuanto eran aun escasos los materiales reunidos sobre todas y cada una de las materias que comprendia; pues si en la parte económico-política, no existian mas que las observaciones reunidas por el Señor Baron de llumboldt, consignadas en su Ensayo político sobre la Isla de Cuba, dado á luz poco despues de nuestra llegada á aquel suelo, en la parte de Historia natural se carecia de toda guia, pues sobre la Zoología no habia mas libro que el del portugués Parra, y sobre la Botánica el sucincto indicatorio ó Florula, que insertó al fin de su obra el citado ilustre viajero. Decimos esto, no para encomiar el mérito de nuestro trabajo, sino para disculpar sus imperfecciones y obtener la indulgencia del público hácia el resultado incompleto (que ofrecemos en la presenteobra que toca ya á su finz) de un plan muy vasto emprendido con mayor entusiasmo que criterio de nuestras débiles fuerzas.

Pasaremos ahora á decir algo de los resultados que hemos conseguido, y que, como debe imaginarse, dejarán aun un inmenso campo que explorar á los hombres laboriosos que nos sucedan en la vastísima empresa que comenzamos hace treinte y cuatro años. Para la debida claridad en la succinta relacion que vamos á hacer, y en la imposibilidad de publicar en esta Introduccion todos los datos que hemos reunido, seguiremos el mismo órden de la enumeracion precedente; y en ella nos referiremos á las varias publicaciones sueltas donde hemos consignado algunos de aquellos. Un trabajo completo sobre esta parte, aun inedita, de nuestras tareas, haria precisa la publicacion, cuando menos, de un tomo mas en la Seccion botánica de la Historia Natural de la Isla de Cuba.

RAMON DE LA SAGRA.

Paris, $1^{\circ}$ de abril de 1856.

\footnotetext{
- A la Seccion económica precedió la publicacion que hicimos en la Habana en el año de 1831, de muchos de los datos y obsergresos en la poblacion, la agricultura el comería de listoria éonómivo politiva y estadistica de la isla de Cuba, ó sea de sus pro* En el momento públicas. - Un tomo en $4^{\circ}$.

faltaba, con el cual, la presente Introductas lineas, se halla ya muy adelantada la impresion del tomo vil, intermedio que sicion metódica de nuestras taress en
} 


\title{
EXPOSIGION SUCINTA
}

DEL

\begin{abstract}
RESULTADO DE LAS PRINCIPALES OBSERVACTONES CONCERNIENTES A LA VEGETACION GUBANA
Y A SUS VARIADAS PRODUCGIONES,
\end{abstract}

no COMPRENdidas en la parte deschiptiva de ellas.

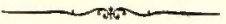

\section{I. - Circunstaneias elimatológiens.}

En el capítulo referente al clima, de la primera parte de esta obra, hemos expuesto detalladamente el resultado de nuestros estudios sobre el de la isla de Cuba, dedueido del analísis de algunas observaciones allí hechas antes de nuestra llegada y de las mas constantes y generales á que pudimos consagrarnos durante nuestra residencia. Por lo tanto y con el fin, por una parte, de evitar repeticiones inútiles en una misma obra, y por otra, con el de poner á la vista de los que solo consulten esta Seccion botánica, todos los datos nece. sarios para apreciar el conjunto de las indicaciones en ella consignadas, vamos á extractar solo los resúmenes del mencionado capítulo, en la forma concisa y elara que nos parece mas conveniente.

Los caractéres distintivos de la zona feraz donde se halla la isla de Cuba, resultan no tanto de la elevada temperatura de su latitud geográfica, sino y mas particularmente de la constancia de unos mistnos grados de calor y de una excesiva humedad atmosférica, en largos periodos del año. Esta unida á la influeneia de la vecindad del mar, por la estremada estrechez de la isla de Cuba, y á la de los vientos aliseos durante los meses mas rigorosos del estio, moderan la accion de aquella y procuran tanto á la vida animal como á la vegetal, condiciones mucho mas propicias de las que podian esperarse bajo una zona trópical. Para que se pueda juzgar, con datos mas fijos, de los efectos de estas varias y beneficiosas influencias, presentamos el resúmen de nuestras observaciones sobre los principales fenómenos de que dependen :

\begin{tabular}{|c|c|c|c|c|c|c|}
\hline \multirow{2}{*}{ MESES. } & \multirow[b]{2}{*}{ TEMPERATUHA. } & \multirow[b]{2}{*}{ HUMEDAD. } & \multirow[b]{2}{*}{ DAAS DE LLEYTA. } & \multirow[b]{2}{*}{ AGUA LLOVIDA. } & \multicolumn{2}{|c|}{ ASPECTO DEL CIELO } \\
\hline & & & & & diks sodudoos. & DIAS \\
\hline Enero........... & $21^{\circ} 87$ & $82^{\circ} 0$ & 8 & 64 & 5 & 26 \\
\hline Febrero........... & $23^{\circ} 35$ & $84^{\circ} 0$ & 7 & 53 & 8 & 20 \\
\hline Marzo......... & $23^{\circ} 37$ & $82^{\circ} 8$ & 6 & 61 & 7 & 24 \\
\hline Abril............. & $24^{\circ} 79$ & $82^{\circ} 4$ & 4 & 31 & 5 & 25 \\
\hline Mayo.............. & $25^{\circ} 74$ & $85^{\circ} 4$ & 8 & 97 & 8 & 23 \\
\hline Junio............. & $27^{\circ} 22$ & $85^{\circ} 0$ & 10 & 128 & 6 & 24 \\
\hline Julio .............. & $27^{\circ} 47$ & $87^{\circ} 6$ & 12 & 139 & 6 & 25 \\
\hline Agosto............ & $27^{\circ} 54$ & $88^{\circ} 2$ & 12 & 116 & 6 & 25 \\
\hline Setiembre......... & $26^{\circ} 87$ & $88^{\circ} 2$ & 14 & 147 & 7 & 23 \\
\hline Octubre........... & $26^{\circ} 03$ & $85^{\circ} 2$ & 9 & 79 & 7 & 24 \\
\hline Noviembre......... & $23^{\circ} 96$ & $86^{\circ} 2$ & 8 & 83 & 8 & 22 \\
\hline Diciembre......... & $22^{\circ} 05$ & $84^{\circ} 8$ & 6 & 31 & 7 & 24 \\
\hline Medias y totales.. & $25^{\circ} 05$ & $85^{\circ} 15$ & 104 & 1,029 & 80 & 285 \\
\hline
\end{tabular}

NoтA. - Termómelro centigrado. - Higrómelro de Saussure, - Miltmetros de agua llovida. Botanica. 
Para comprender bien, por el solo dato de las temperaturas medias mensuales, la intensidad de los calores que las producen, debe lênerše pressefite la esceala tèrnionétríca que recorre el mercurio, sea durante cada dia sea durante cada mes. - Del exámen de este dato, que al intento consignamos en un estado especial, puede inferirse cuan aproximados son los grados máximos y mínimos dentro de los cuales oscila la columna del líquido metálico, puesto que no exeede de $8^{0}, 5$ durante un dia, ni de $12^{\circ}, 4$ durante un mes.

\section{Osćilaciones del termómelro y del higromelro en la llabana.}

\begin{tabular}{|c|c|c|c|}
\hline & TEP & Ro. & HIGRONETRO. \\
\hline Enero ............ & $12^{\circ} 3$ & $6^{\circ} 8$ & $25^{\circ} 4$ \\
\hline Febrero.......... & $10^{\circ} 3$ & $6^{\circ} 9$ & $22^{\circ} 7$ \\
\hline Marzo ............. & $12^{\circ} 4$ & $6^{\circ} 8$ & $24^{\circ} 0$ \\
\hline Abril ............. & $9^{\circ} 8$ & $6 \circ 5$ & $26^{\circ} 0$ \\
\hline Mayo............. & $10^{\circ} 2$ & $7^{\circ} 1$ & $23^{\circ} 2$ \\
\hline Junio.............. & $6^{\circ} 7$ & $5^{\circ} 6$ & $22^{\circ} 2$ \\
\hline Julio ............. & $6^{\circ} 2$ & $5^{\circ} 6$ & $18^{\circ} 7$ \\
\hline Agosto................. & $6^{\circ} 1$ & $5^{\circ} 0$ & $18^{\circ} 5$ \\
\hline Setiembre......... & $6^{\circ} 8$ & $5^{\circ} 1$ & $17^{\circ} 0$ \\
\hline Octubre........... & $8^{\circ} 4$ & $5^{\circ} 0$ & $20^{\circ} 4$ \\
\hline Noviembre......... & $9^{\circ} 8$ & $6^{\circ} 7$ & $20^{\circ} 2$ \\
\hline Diçiembre.......... & $11^{\circ} 0$ & $8^{\circ} 5$ & $21^{\circ} 3$ \\
\hline
\end{tabular}

Como ya dijinos en otra parte, la mayor variacion diurna que hemos observado fué de $\mathbf{9}$ grados en algunos dias de los meses de diciembre, y la menor de 4 grados, durante algunos dias del mes de agosto. - Las mayores variaciones mensuales, direetamente observadas, fueron de 14 y 1 ğ grados en los meses de enero, febrero y marzo, y las menores, tambien mensuales, de 5 á 6 grados en los meses de julio, agosto y setiembre.

Los datos extremes anuales presentan el mismo carácter de proximidad, puesto que, en los doce años de nuestra residencia en la Habana, solo una vez hemos visto subir el mercurio á $32^{\circ}, 3$ y solo en otra le vimos bajar á 10 grados sobre cero.

En el interior de là iśă, sin embargo, a la vecindad de los bosques, durante los cambios súbitos que suelen ocurrir en la estacion seca del año, por los vientos que descienden de làs regiones septentrionales, el termómétro baja algunas veces á cero; pero este fenómeno es accidental, de cortísima duracion y sín efecto alguno en las leyes constantes de la vegetacion.

El higrómetro ofrece tambien en su marcha diurna y mensual fenómenos semejantes á los del termómetro ếalmente càracterísticos del climà cubano, á saber : oscilacion casi constante dentro de reducidos límítes, los cuales, en este instrumento, son los mas elevados de su escala. Tratando detenidamente de la humedad atmosférica, dijimos ya y repetimos ahora, porque es esenciăl, que el grado mas bajo ên que hemos visto la ahuja del higrómetro de Saussure, lia sido el 66 , y el mas alto y frecuentísimo 100 ; lo cual da 34 á la máxima extension recorrila ó á la mayor oscilacion observada. La frecuencia del grado 100, ó máximo de la humedad atmosférica, se observa casi siempre en las horas tempranas de la mañana. La marcha mas ordi* haria es entre 84 y 100 grados, pasando de este máximo á aquel mínimo en las horas intermedias entre el amanecer y las tres de la tarde, hora en que baja tambien la temperatura.

La humedad media de algunos meses es, como vimos, superior a 88 grados, y durante ellos la saturacion atmosférica llega frecuentemente á 99 y 100 grados. Las epocas de mayor sequedad son aquellas en que caen durante la noche $y$ al amanecer abundantes rocios. El descenso de la temperatura atmosférica hace 


\section{INTRODUCCION}

perder al aire una parte de su facultad disolvente, y entónces el agua de los vapores condensados se deposita sobre los cuerpos.

La abundancia de estos rocios, en la estacion seca del año, es sumamente favorable para la vegetacion de las plantas herbáceas, pues ellos con la humedad disuelta constantemente en la atmóslera, suplen hasta cierto punto, á la fálta de lluvís en la estacion invernal del año.

En el estado de la págína š se vé que los grados medios de la humedad mensual, difieren muy poco en los diversos meses del año, y en cuanto á los diurnos se puede ver tambien, que no es grande la diferencia que ofrecen de un mes á otro. Sin embargo las diferencias son menores durante los meses de julio, agosto y setiembre, es decir, prineipalmente en los meses mas húmedos del año.

Puede notarse tambien una relacion regular y constante entre las temperaturas mensuales, el estado higrométrico del aire y la cantidad de agua lluvida, tres fenómenos que en Europa no ofrecen una coordinacion semejante. Pero en lá Isla de Cuba es constante la simultaneidad de los tres fenómenos indicados, en sus manifestaciones así mảximas como mínimas. Las primeras, á saber, la elevada temperatura de los meses, la excesiva humedad atmosférica y la frecuencia de las llavias, constituy en y caracterizan la estacion que lleva este nombre, y que dura ordinariamente desde mayo ó junio liasta fin de seliembre; las segundas, es decir la temperatura moderada entre $\mathbf{2 2}$ y $\mathbf{2 8}$ grados, la menor bumedad atmosférica, la escasez ó falta alssoluta de las lluvias, distinguen la otra estacion que lleva el nombre de la seca.

Habiendo notado tambien en nuestro diario, las épocas del dia en que las lluvias acaecian, hemos deducido qué en el total anual de ellas, mas de la milad se verifican despues del medio dia, y solo un cuarto de ellas por la mañaná. Esta particularidad contribuye mueho á moderar los calores de la estacion, para el hombre, y á favorecer el desarrollo de la vegetacion, en una atmósfera saturada al máximum de humedad.

A las condiciones mencionadas, que la son eminentemente favorables, deben agregarse las de la electricidad por la frecuencia de las tempestades y de otros fenómenos que la manifiestan. Pero aunque nuestras observaciones comprenden tambien la enumeracion de dichas perturbaciones atmosféricas, no hemos podido medir su intensidad y su influéncia, sea en el océano aereo, sea en la capa terrestre, conforma deberia hacérse para apreciar su accion sobre la vida y el desarrollo de las plantas. Esta parte de la física del globo, sumamente imperfecta aun, lo era mucho mas cuando nos ocupamos de observar los fenémenos meteorologicos cubanos, por lo eual no debe extraũarse que nosotros participásemos tambien del general atraso, que fué causa de nuestro descuido, que ahora deploramos.

Los datos que acabamos de presentar como resultado de nuestras observaciones, no son bastante numerosos y precisos para resolver los próblemas que la vegetacion ofrece, lo cual depende principalmente, de que las termométricas fueron hechas del modo ordinario, es decir con los termómetros á la sombra, guarecidos de la accion poderosa de los cambios que ocurren én las corrientes aereas y en la lumedad de las capas atmosféricas. Las observaciones de temperatura y de humedad, para ser eficazmente aplieables á la vegeta* cion y al cultivo, deberan hacerse en lo sucesivo de un modo diferente que hasta aquí y con instrumentos masadecuados, ó mejor dicho, mas fieles indicadores de las influencias climatológicas y nieteorológicas en la vida de las plantas. Tal vez se formulen pronto nuevas reglas y nuevos medios, partiendo de las importantes reflexiones a que dió lugar, el mes de dielembre úlimo $(\mathbf{1 8 5 5})$ en la Acallemia imperial de ciencias de Paris, el proyecto del Gobierno de establecer olservatorios meteorológicos en la colonia de Argelia.

Sin embargo, aunque imperfectos comó todos los reunidos hasta ahora (segun confesion de los primeros sábios que tomaron parte en la discusion académica á que aludimos), los datos de la climatologia cubana, con las indicaciones oportumas que presta el hecho de la vida de las plantas al aire libre y á la exposicion directa de los rayos solares y de las corrientes atmosférieas, pueden servirnos para deducir unalogías impor* tantes entre las leyes de la temperntura y de la lumedad y las de la vegetacion cubana. listo es lo que nos propusimos hacer en las otras séries de observaciones que vamos á referir. 


\section{II. - Experiencias sobre los fenómenos de la vegetaelom.}

Procurando determinar las condiciones climatológicas bajo las cuales viven las plantas en la isla de Cuba, solo desempeñabamos la tarea preliminar de un estudio mucho mas vasto y complicado, cual era el de observar la influencia de los agentes atmosféricos, tales como el calor, la humedad, la luz y la electricidad en los fenómenos de aquella. Pero en esto como en todo lo que emprendimos en la interesante Antilla, el plan fué mucho mas vasto que satisfactorio el resultado; y no podia menos de ser así, considerando de una parte la escasez de nuestras fuerzas y recursos y de la otra la falta casi absoluta de trabajos precedentes y la duracion que exigian los que por primera vez emprendimos. Realmente, en todos ellos, no hicimos mas que iniciar en la isla de Cuba, una série de estudios científicos que hasta entónces habia sido del todo desconocida, lo cual, como se puede conocer, aumentaba en otro tanto la dificultad inherente á ellos mismos.

Los fenómenos á cuya observacion procuramos aplicar los datos climatológicos que sucesivamente reuniamos, se referian á la germinacion de las semillas, al desarrollo anual de las especies perennes y á los períodos de la floracion y de la fruetificacion de todas las que podiamos observar.

En los ensayos de germinacion comprendimos tambien algunas especies exóticas, por que nos pareció interesante averiguar la influencia que las condiciones climatológicas tropicales ejercian, en la duracion del primer periodo de la vida de las plantas europeas, allí transporladas.

Para obtener los datos que buscabamos, recurrimos á dos medios, á saber: las experiencias directas y la correspondencia con individuos zelosos que habitaban diversos districtos de vegetacion rica y lozana. Empleamos esclusivamente el primer medio para los fenómenos de la germinacion, y el segundo nos procuró muchos datos sobre los otros. En los estados en blanco que circulamos al interior de la Isla, destinados á las noticias relativas á la vida de los árboles, habia columnas para inscribir en ellas la altura y el diámetro que alcanzaban, en una edad dada, y las épocas en que florecian y fructificaban.

Nuestras herborizaciones nos procuraron tambien gran número de datos relativos á estos fenómenos, pues naturalmente tomábamos notas de todo; ademas el estado de la rama conservada en el herbario, certificaba la época en que el fenómeno de la floracion ó de la fructificacion tenia lugar en cada especie. Pero desgraciadamente, una omision que cometimos fué la primera causa de la perdida de muchas de las noticias que nuestro herbario podia haber suministrado. Descuidamos el anotar, en una tarjeta para cada planta, la fecha en que la habíamos cogido, que nos limitábamos á inscribir solo en el exterior de los paquetes referentes á cada herborizacion. Esta omision tuvo generalmente lugar en todas las muestras de plantas que no conocíamos y de las cuales tampoco podíamos averiguar el nombre vulgar. Esperando saberlo mas tarde, así como la determinacion botánica, nos proponiannos tomar entónces, de la indicacion de la fecha inseripta en el paquete, el dato de la floracion y de la fructificacion en que habiamos cogido la rama. Por efecto de otra fatal inadvertencia (padecida durante nuestra ausencia de Paris en los años de 1838, 1839 y 1840, á que nos obligo el desempeño de un cargo politico en nuestra patria), el distinguido profesor Richard, eneargado de clasificar y de determinar las plantas fanerogámicas de nuestro herbario, deshizo lodos los paqueles para ordonar las especies por el sistema de familias naturales, en cuyo órden debian ser publicadas. Como nue stros cuadernos de las herborizaciones solo expresaban las especies que nos eran conocidas, 6 botanicamente 0 por los solos nombres vulgares, se perdieron, con la alteracion de los paquetes, las indicaciones de localidad, floracion y fructificacion de todas las otras, y que solo podian deducirse de la fecha inscripta en el esterior de aquellos. Luego veremos que no fué esta sola la confusion y la perdida de datos que ha ocasionado el cambio, en nuestros paquetes, del órden que llamaremos topográfico y cronológico, en el puramente sistemático para la clasificacion; pues se perdieron igualmente, con las indicaciones de muchas localidades, las que pudieron haberse deducido de las diferencias en las épocas ó períodos de la vegetacion segun aquellas, y sobre todo las relativas á las asociaciones naturales y espontáneas de que hablaremos mas adelante. Estas perdidas son tanto mas sensibles cuanto era fácil el haberlas evitado, por medio de la union de targetas á cada muestra, antes de haber deshecho los paquetes, consignando en ellas la indicacion de la localidad y de la fecha de la herborizacion.

El resultado de nuestras experiencias directas sobre la germinacion, consta en los diarios que hemos seguido y de los cuales publicamos algunos en la Habana, que fueron reproducidos entónces en varios 
periódicos y obras europeas. Formando parte de un trabajo especial sobre la vegetacion Cubana, no nos es dada insertarlos aqui, y por esto los conservamos aun ineditos, mientras que no podemos consiguarlos con la extension requerida y unidos á todos los demas de los diversos períodos de la vida vegetal, que formabán parte de la misma seccion de esperiencias que vamos simplemente refiriendo.

Como la duracion de la germinacion, la época en que se operó, asi como la en que tienen lugar la floracion y la fructiticacion de las plantas, dependen de las condiciones vitales de cada especie y de las constitutivas del elima y de los períodos atmosféricos, nos proponíamos formar, de la reunion de todos los datos que sobre tales fenómenos buscabamos, un alnanaque vegetal, donde apareciesen, distribuidas en los doce meses del año, las germinaciones, las floraciones y las fructificaciones que en cada uno se verificaban. Esta serie, retratando las manifestaciones de la vida vegetal en la Isla de Cuba, serviria tambien para completar el mas general de la vida general de los seres en ella, cuando la otra série de observaciones zoológicas que habíamos emprendido, sobre el nacimiento ó aparicion de las aves y de los insectos, las épocas de las enigraciones y de las inmigraciones de las primeras, y de la metamórfosis en los segundos, nos suministrasen todo el conjunto variado de noticias que el tal almanaque natural requeria.

No era posible que pudiésemos completar estas séries; pero si reunimos muchos elementos, casi en totalidad ineditos, y de los cuales vamos á extractar algunos nombres de las espeeies que nos han ofrecido, en su floracion, indicaciones mas constantes.

Antes de presentar este ensayo de Calendario de Flora, debemos exponer una reflexion relativa al fenómeno de la floracion bajo el cieto de los trópicos, donde las estaciones europeas ó de los elimas frios y templados, se hallan sostituidas por las dos épocas, de la lluvia y de la seca, que indicamos antes, y en cada una de las cuales la regetacion ostenta una igual lozanía. Los dos agentes mas conocidos de la vida vegetal, á saber el calor y la humedad, obran, como hemos dicho, simúltaneamente durante lo estacion á época ardorosa del estío. Al comenzar aquella, las dos causas reunidas producen la grande, uniforme y simultánea manifestacion de aquella vida, y en la cual, como dijimos ya en otra parte de esta obra, la naturaleza se desentraña en flores. En la siguiente estacion, bajan la temperatura y la humedad atmosféricas, y tal vez el descenso de la segunda seria suficiente para detener en todas las plantas cubanas las expansiones aereas de la vegetacion, que algunas esperimentan, si la accion aun vigorosa de un sol de cuarenta grados y su lua vivificadora, no estimulasen el organismo vegetal para operar nuevas floraciones en el mes de octubre, constituyendo en los bosques cubanos una segunda y bellisima primavera. Este fenó. meno es la causa de la repeticion de algunos nombres de plantas en las indicaciones mensuales del siguiente calendario, que al intento liemos dejado para llamar la atencion de los observadores y suministrar elementos de estudio álos fisiólogos.

Hubiéramos deseado presentar tambien algunos rlatos, en suficiente número y debidamente comprobados, sobre la evolucion de las hojas y de las lores, en los distintos períodos del dia y de la noche, suministrando así los elementos para un Reloj de Flora, á semejanza del que formó el célebre Linneo, para el clima de Upsal. El profesor Martius nos invitó en el año de $\mathbf{1 8 2 6}$ a hacer este género de esperiencias sobre la floracion diurna, la direccion de los tallos volubles y el sueño de las plantas, con tanto mayor interés cuanto se sospechaba entónces que alguaos de estos fenómenos ofreeian, bajo el cielo de los trópicos, diferencias y anomalías con los observados en Europa, - La mulitud de nuestras ocupaciones no nos permitió fijarnos en estos fenómenos, con la regularidad y la constancia requeridas, y por esto no damos valor al corto número de observaciones exactas que pudiéramos consignar aqui. - Solo diremos, que siendo sumamente intensa la accion de la luz y del calor solares, deste que el astro del dia aparece en el orizonte, los periodos de la evolucion floral no nos han parecido tan bien marcados ni tan listnntes en las diversas especies, como en Europa.

Sobre el cambio de color de la corola, durante la succesion del dia, hemos observado que no era efecto de la luz solar sino de la temperatura, puesto que vimos prolongarse, hasta el dia siguiente, dicho cambio en el Hibiscus mutabilis, por efecto de un descenso anormal en aquella ${ }^{1}$.

Por último, sobre el sueño de las plantas, fenómeno producido por la ausencia de la laz, diremos que es idéntico al observado en Europa, en todas las plantas leguninosas de hojas compuestas.

- Esta obserfación fué publicada en la Biblióteca de Ginebra del mes de mayo de 1827, y en la Fisiología zegelal de Candolle. Botanica. 


\title{
ENSAYO DE UN CALENDARIO DE FLORA
}

\author{
PARA LA ISLA DE CUBA
}

Caracteruzado POR VARIAS PLANTAS QUE FLORECEN EN LOS DIVERSOS MESES DEL AÑo.

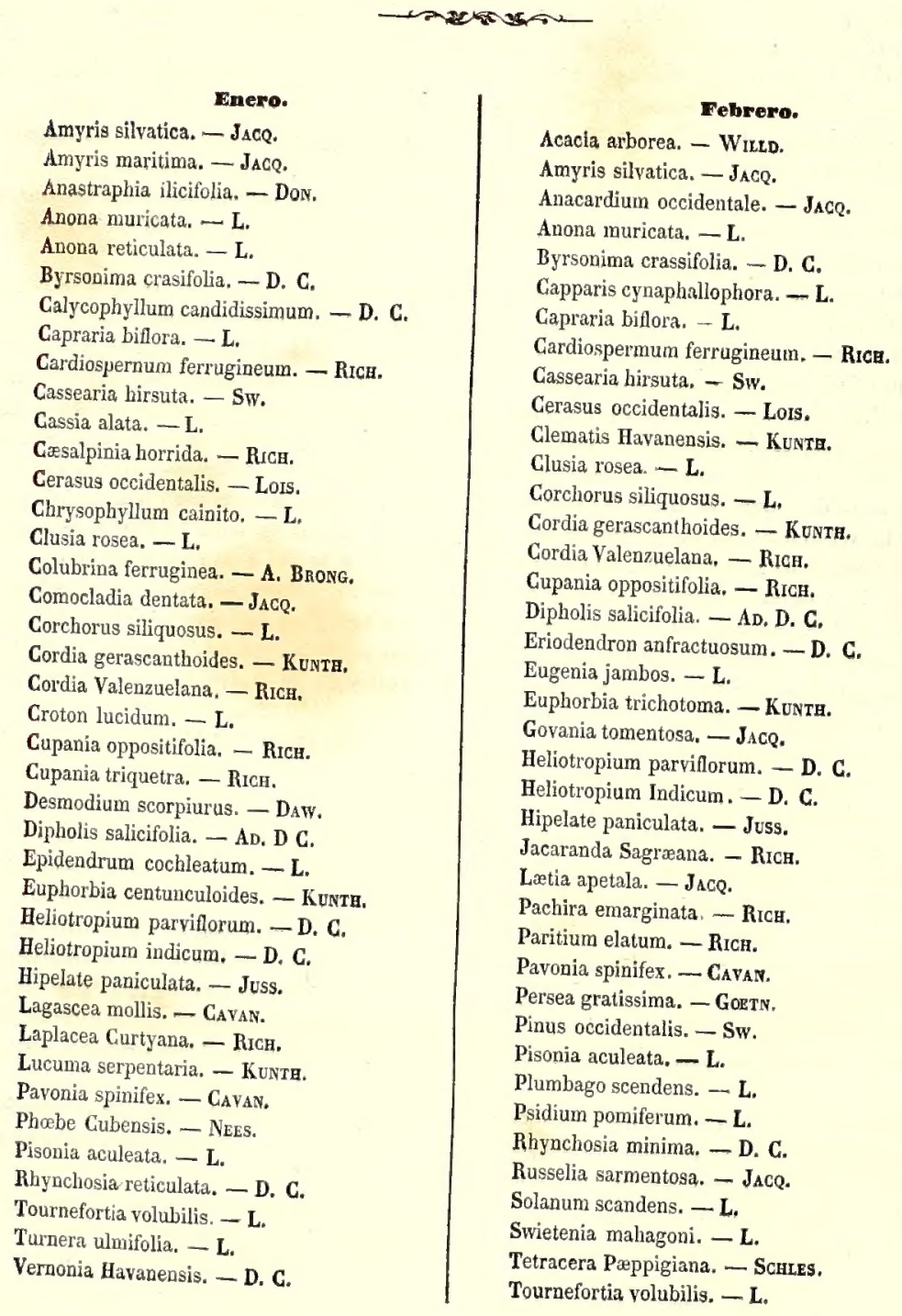


Tribulus cistoides, - Liv.

Triumfetta heterophylla. - LAM.

Zornia Havanensis. - Ricu.

\section{MIIavzo.}

Acacia arborea. - WiLld.

Egiphylla Martinicensis, - L.

Amyris maritima, $-J_{A C Q}$.

Ammania sagittata, - D, C,

Ammania sanguinolenta, - Sw.

Andira inermis. - Kunta.

Anona muricata. - L.

Anona reticulata. - L.

Ardisia Cubana, - ALp. D. C.

Belotia greviæfolia, - Rich.

Brya ebenus, - D. C.

Bucida buceras, - L.

Bucida capitata, - VAHL.

Bumelia nigra. - $\mathrm{Sw}$.

Byrsonima crassifolia, - D. C.

Cakile maritima, $\rightarrow$ Scopoli.

Callophyllum calaba, - JACQ.

Calycophyllum candidissimum. - D. C.

Cameraria latifolia. - JAGQ.

Canella alba. - Munnax.

Canna indica. - Roscole.

Capparis cynaphallophora, - L.

Cassearia hirsuta. - Sw.

Cassearia alba. - Rice.

Cassearia silvestris. - Sw.

Cassia fistula. - L.

Cæsalpinịa bijuga. - Sw.

Celastrus parviflorus. - Rich.

Cerasus occidentalís, - Lors.

Chicharronia intermedia. - Rich.

Clematis Havanensis, - KunTH,

Clematis pallida. - RieH.

Cleome Cubensis. - RicH.

Cleome pentaphylla. - L

Clusia rosea. - L

Coccoloba uvifera. - JACQ.

Copaifera hymenæfolia. - Monic.

Corchorus siliquosus. - L

Cordia gerascanthoides. - Kuntr.

Cordia Valenzuelana, - Rrch.

Cordia speciosa. - Roem. Sca.

Crescentia cujete. - L

Groton lucidum, - L.

Cupania oppositifolia. - RicH.

Cupania tomentosa. - Sw.

Cuphea Swartiana. - Spr.

Curatella Americana, - L

Trichilia spondioides. $-\boldsymbol{J}_{\mathbf{A C Q}}$.
Cynometra Gubensis, - Rich.

Diospyros laurifolia. - Rrch.

Drypetes alba. - Port.

Drypetes glauca. - Vart.

Echites littorea, - KunTH.

Ehretia tinifolia. - L.

Elreodendron attenuatum, - Rrcu.

Eriodendron anfractuosum. - D. C.

Erythroxylum obtusum, - D. C.

Erythroxylum Havanense. - JACQ.

Erythroxylum brevipes. - D. C.

Eugenia phyllireæfolia. - Rich.

Eugenia rigidifolia. - Rıсн.

Eugenia jambos. - L

Gomphrena decumbens. - J $\mathbf{A} \mathbf{C Q}$.

Guarea trichilioides، - L.

Guilandina bonduc. - AIr.

Hibiscus Cubensis, - Rich.

Hypericum styphelioides. - RıcH.

Icica copal. - Rich.

Jacaranda Sagræana. - Rıсн.

Lætia apetala. - $\mathbf{J}_{\mathbf{A} C Q}$.

Laplacea Curtyana. - RIcH.

Lippia dulcis. - Tnev.

Lippia canescens. - KunTH.

Lonchocarpus latifolium. - Kunta.

Malanea lucida. - Rrce.

Miconia piramidalis. - D. C.

Momordica balsamina. - L

Nectandra cigua. - RicH.

Nicotiana repanda. - WiLLD

Oreodaphne alba. - Ricr.

Pachira emarginata. - RicH.

Panax undulata. - Aurt.

Persea gratissima. - Gokts.

Persea silvestris, - RicH.

Petiveria alliacea. - WiLı.

Phytolaca decandra. - L.

Plumbago scandens, - L.

Pœppigia excelsa. - Rucr.

Psidium pomiferum. - L

Quercus Cubana. - Rich.

Rhynchosia minima, - D. C.

Serjania paniculata. - KuNTH.

Serjania Ossana - D. C.

Sesuvium portulacastrum. - L.

Simarouba glauca. - D. C.

Smilax Havanensis. - RicH.

Spondias lutea. - L.

Spondias purpurea. - $\mathbf{L}$.

Stigmaphyllon reticulatum. - $\mathbf{A D .}$ DE Jusstev.

Sideroxylon pallidum, - SPHENG.,

Teucrium Cubense. - L.

Tournefortia volubilis, - L 
Trichilia spondioides. $-J_{A C Q}$

Trichilia Havanensis. - JACQ.

Trichostigma rivinoides, - RicH

Waltheria Ainericana. - L.

Xylopia obtusifolia. - Rich.

Xylopia Cubensis, - RucH.

Abril.

Acacia formosa. - KUNTH,

Anona palustris. - L.

Anona muricata. $-L$.

Asclepias Curasavica. - L.

Asclepias nivea. - L.

Avicennia tomentosa. - JACO

Bursera gummifera. -- J J $\mathrm{JCQ}_{\text {. }}$

Byrsonima crassifolia. - D. C.

Callicarpa reticulata. $-\mathrm{Sw}$.

Cameraria latifolia. -JACQ.

Capparis cynaphallophora. - L.

Cæsalpinia cristata. - L.

Celastrus parviflorus. - Ricr.

Chamissoa altissima. - Kuntr

Cleome Cubensis. - Rica.

Clethra Cubensis. - Ricr.

Clusia rosea. $-\mathbf{L}$.

Cordia gerascanthoides. - KUNזr.

Cordia Valenzuelana. - RıcH.

Cordia speciosa. - ScH.

Echites littorea. - KunTH.

Ehretia bourreria. - L.

Epidendrum Bøothianum. - Lisd.

Eriodendron anfractuosum. - D. C.

Erythroxylum obtusum. - D. C.

Erythroxylum Havanense. $-\mathbf{J}_{A C Q}$

Erythroxylum brevipes. - D. C.

Eugenia jambos. - L

Guarea trichilioides. - L.

Helicteres furfuracea. - Ricr.

Hydrocotyle ranunculoides, $-\mathbf{L}$.

Icica copal. - Ruch.

Lætia apetala. - $\mathrm{J}_{\mathrm{ACQ}}$

Lonchocarpus sericeus. - KunTH.

Lonchocarpus latifolium. - KUNTH

Myrospermum Toluiferum. - Rich.

Nectandra cigua. - Ric日.

Prockia crucis. - L.

Rajania hastata. $-\mathbf{L}$.

Spondias Iutea. - L.

Tournefortia volubilis, - L.

Verbesina alata. - $\mathbf{L}$.

Zanthrixylum lanceolatum. - Porrex.

Zanthoxylum juglandifolium. - WiLL.

\section{INTRODUCGION.}

Mayo.

Adenanthera pavonia. - L Asclepias Curasavica. - L. Asclepias nivea, - $\mathbf{L}$.

Avicennia tomentosa. - JACQ. Byrsonima crassifolia. - D. C. Capparis cynaphallophora. - L. Catesbeca latifolia. - Lind. Cæsalpinia cristata. - L.

Centrosema pascuorum. - Mart.

Clusia rosea. - L.

Conocarpus erecta. - Kunth.

Gordia Galeotiana, - Rıcr.

Groton lucidum. - L.

Echites littorea, - Kuvtr.

Elretia bourreria. - L.

Govamia tomentosa., - J JCQ.

Guarea trichilioides. - L.

Hippocratea integrifolia, - Rrck.

Icica copal. - RucH.

Lætia crenata. - Rich.

Lepidium Virginium, - $\mathbf{L}$.

Myгospermum Toluiferum. - Rica.

Rajania hastata, - L.

Rhizophora mangle. - L.

Tecoma stans. - Juss.

Tournefortia volubilis. - L

Tournefortia angustifolia. - RUIz Ex Pavon.

Trichilia spondioides. - JACQ.

Verbesina alata. - L.

Uvaria neglecta. - RicH.

Yucca alofolia. - L

Zantoxylum lanceolatum. - Pork.

Jumio.

Allopectus cristatus. - MART.

Anona palustris. - L.

Bocconia frutescens, - L.

Bursera gummifera. - JACQ.

Byrsonima crassifolia. - D. C.

Byrsonima lucida. - KunTH.

Callophyllum calaba. - JAce.

Calonyetion speciosum. - CHorsy.

Capparis cynaphallophora. - L.

Capparis emarginata. - RucH.

Cleome pentaphylla, - L.

Comocladia dentata. - J $\mathbf{A C Q}$.

Ehretia cassinefolia. - Rich.

Eugenia beterophylla. - Ricu.

Gouphia ilicifolia. - D. C.

Guarea trichilioides. - L.

Hippocratea integrifolia. - RIсн.

Icica copal. - Rich.

Jussiæa Sagræana. - Rich. 
Jatropha fragrans. - KuvTH.

Lætia crenata. - Rich.

Lepidium virginium. - $\mathbf{L}$.

Malpighia urens. - L

Mouriria Valenzuelana. - Ricн.

Picramnia pentandra. - Sw.

Tournefor tia volubilis. - $\mathrm{L}$.

Uvaria neglecta. - Rich.

Wedelia reticulata. - D. C.

Xylopia Cubensis. - Rich.

\section{Jullio.}

Eschinomene Americana. - L

Anona palustris. - $-\mathbf{L}$.

Bucida angustifolia. - D. C.

Calophyllum calaba. - Jace.

Calyptranthes chytraculia. - Sw.

Cassia cuneata. - D. C.

Catesbea macrantha. - RIcH.

Cedrela odorata, $-\mathbf{L}$.

Echites umbellata. - Jaco.

Echites ferruginea. - Rich.

Echites crassipes. - Rich.

Echites suberecta. - JACQ.

Exhretia spinifex. - Roвm. Scr.

Gardenia Sagreæna. - Rich.

Guayacum verticale. - ORTEgA.

Guettarda resinosa. - PERs.

Icica copal. - Rich.

Metastelma Cubense. - DeGaIsN.

Odontostigma Galeottianum. - RicH.

Neurocarpum angustifolium. - KunTH.

Picramnia pentandra. - Sw.

Teucrium Cubense. - L.

Tournefortia volubilis. - L

Tribulus cistoides. -. Liv.

Trianthema monogyna. - L

Vernonia gnaphalifolia. - Rice

Viscum buxifolium. - LaM.

Volkameria aculeata. - L.

Yuca alæofolia. $-\mathbf{L}$.

\section{Agosto.}

Echinomene Americana. - L.

Ginoria Americana. - JACQ.

Picramnia pentandra, - Sw.

Solanum scandens, - $\mathbf{L}$.

Trianthema monogyna. $-\mathbf{L}$.

\section{Setienabe.}

Achinomene Americana, - L.

Angræum Lindenii. - Lind.

Cæsalpinia bijuga. - Sw.

Ciococca racemosa. - JACO.

Colubrina Cubensis. - A. Brone. Bonnica.
Colubrina reclinata. - A. BRong.

Conradia humilis. - MART.

Cynometra Cubensis. - Rici.

Helicteres furfuracens. - RicH

Lagetta Valenzuelana. - RicH.

Lonchocarpus latifolius. - Kuntr.

Mimosa pudica. $-\mathrm{L}$.

Morinda rojoc. - L.

Poinciana pulcherrima., - LIN.

Rajania hastata. - L.

Schmidelia nervosa. - Ruch.

Smilax Havanensis. - RicH.

Xylopia Cubensis. - Rich.

\section{Cetulbre.}

Acacia litorolis, - Ruch.

Achinomene Americana. - L.

Amyris silvatica, - JACQ.

Batatas quinquefolia. - Cногs.

Bauhinia heterophylla. - KunTH.

Bryonia racemosa. - $\mathrm{Sw}$.

Crsalpinia bijuga. - $\mathrm{Sw}$.

Colubrina reclinata. - A. Brong.

Colubrina ferruginea. - A. BRoNG.

Conocarpus erecta. - KunTH.

Desmodium glabellum, - D, C.

Erytroxylon brevipes, - D. C.

Exostema parviflorum. - L.

Exostema floribundrum. - RoEm. ScB.

Hamelia patens. - Jaco.

Helicteres trapezifolia. - Rich.

Pavonia spinifex, - Gavan.

Pectis postrata. - Cavan.

Sarcostemma clausum. - RoEM. ScH.

Schmidelia nervosa. - Rich.

Sida pilosa. - Cavas.

Stylosanthes humilis. - KUNTH.

Swartia multijuga. - Rich.

Tribulus cistoides. - LIN.

\section{Noviembre.}

Acacia lentiscifolia. - Rrch,

Anyris silvatica. - JACQ.

Anona hastata. - Cay.

Barbiera polyphylla. - D. C.

Boerhavia polymorpha. - L.

Boerhaavia paniculata. - L.

Bryonia racemosa. - Sw.

Cassia alata. - L

Cæsalpinia cristata. - L.

Corchorus siliquosus. - L.

Ecastaphyllum Brownei. - Pers.

Govania tomentosa. - JACQ.

Inga hixtris. - Rich.

Malpighia coccifera. - L. 
14

\author{
Passillora pedata. $-\boldsymbol{L}$. \\ Pavonia spinifex, - Cayan. \\ Solanum Bahamense, $\mathbf{-}$. \\ Trichilia Havanensis. - JACQ \\ Ximenia Americana. - L.
}

\section{Diciembre.}

Acacia lentiscifolia, - Ric日.

Aristolochia tigrichna. $-\mathbf{R}$.

Barbiera polyphylla. - D. C

Cassia alata. - L.

\section{INTRODUCCION.}

\author{
Cresalpinia cristata, - $\mathbf{L}$. \\ Clidemia Valenzuelana. - Rron. \\ Convolvulus Jamaicensis. - JAGQ \\ Convolvulus ruderarius. - KuNTH. \\ Ecartaphyllum Brownei. - PBRs \\ Eugenia Valenzuelana - RicH. \\ Euphorbia glabrata. - Sw. \\ Ipomea sidæfolia. - Chors. \\ Luhæa platypetala. - Rich, \\ Malpighia coccifera. - L. \\ Zanthoxylum juglandifolium. -. WILLD.
}

No presentamos el estado precedento más que como un ensayo de lo que puede sucesivamente observarse, pues seria preciso para completarlo, agregar todas las demas floraciones de las plantas cubanas, que no hemos podido determinar con exactitud. - Ademas, convendria redactar varios estados completos anuales, antes de formar el almanaque medio, pues segun varian las épocas de las aguas y de la seca, ya anticipándose ya retardándose y de consiguiente variando cada una en su duracion, así tambien las floraciones de los mismos meses, son mas ó menos abundantes en diferentes años.

No obstante estas reflexiones críticas sobre nuestro propio trabajo, si se le considera de un modo absoluto, ofrece relativamente al número reducido de las especies que comprende, algunos resultados que merecen meditarse, y que indicaremos ligeramente.

La época de la menor floracion aparece ser el mes de agosto, lo cual procede, no de que las circunstancias atmosféricas no sean propicias para operai dicho fenómeno, sino porque habiéndose ya operado en los meses precedentes, resulta el maximum de las fructificaciones en el de agosto. Desde dicho mes, crecen rápidamente las floraciones pôr el doble efecto de las plantas que florecen únicamente en los meses de octubre y noviembre, y de las dobles floraciones de varias que lo hicieron ya en marzo y abril. A no ser esta segunda causa, las floraciones de la época de los nortes, serian mucho menores que las de los meses de lluvias; pero ya dijimos que la vida vegetal se reanima en muchas especies, presentando dobles floraciones en el mismo año. - La fuerza vegetativa es tal, que varias especies se encuentran en flor casi todo el año.

Examinando las familias de las plantas designadas en el precedente calendario, se puede notar que hay grande floracion de Terebintaceas en marzo, abril y junio, de Leguminosas en marzo, abril y mayo, y luego seliembre, octubre y noviembre; de Cardiaceas, durante los cinco primeros meses del año; se puede notar tambien, que las $S$ apindaceas parecen florecer de preferencia en enero, febrero y marzo, las Apocymeas en julio, las Capparideas, desde marzo á junio, las Samydaceas, casi exclusivamente en marzo, y las Convolvudaceas al fin del año, lo cual hizo dar á varias especies, el nombre vulgar y expresivo de aguinaldos.

La repeticion, que puede notarse, de la floracion de unas mismas plantas en distintós meses del año, procede de diversas causas, á saber : de la desigualdad que presentaron las floraciones de distintos años, de la constancia de la floracion de la misma planta durante varios meses consecutivos, y de la repeticion del fenómeno en los dos periodos mas ó menos distantes, pero las mas veces equidistantes, que presentan muchas especies.

No nos extenderemos mas á deducir consecuencias absolutas de las observaciones que hemos presentado, porque no son suficientes para dar á conocer la ley constante, que probablemente no existe. - Cuando se posean datos completos de la floracion mensual de todas las zonas terrestres, ya geográficas ya en altura sobre el nivel del mar, se podrá apreciar mejor la sucesion periódica de la vida de las plantas relativamente al periodo de una rotacion anual de la tierra, y entónces se verá probablemente, que no es de igual duracion el año vegetal, para todas las especies de plantas, ni en todas las latitudes ó zonas de vegetacion. 


\section{S III. - Escuela Botánica.}

Este trabajo era á la vez un preliminar para la enseñanza que nos estaba confiada y un plantel indispensable para nuestros futuros estudios. Pero, debiendo ser al mismo tiempo que un medio para la enseñanza y el adelanto, un resultado de nuevas investigaciones, fué para nosotros tambien la tarea mas difícil por el apremio que nos imponia.

Los botánicos saben bien, cuanta es la dificultad que presenta hoy dia la determinacion científica de las especies desconocidas, y que esta difieultad llega á ser un imposible, cuando no se tienen á mano todos los materiales indispensables, á saber: libros, periódicos científicos y herbarios. Nosotros careciamos de todo esto en los primeros años de residencia, y ademas, nuestra inexperiencia y escasa práctica del conocimiento de las plantas tropicales, hacia mas embarazosas nuestras incipientes investigaciones sobre las cubanas. Confiando nuestras dudas á algunos distinguidos profesores de Europa, y particularmente al recomendabílisimo Decandolle, que desde los primeros años nos honró con su correspondeneia, nos respondian que no nos fatigásemos esterilmente en determinar especies, cuyos nombres ó lugar en la clasificacion botánica no nos seria posible hallar con exactitud, careciendo de los materiales para ello; que nos concretásemos pues, á recolectar, á anotar circunstancias y á remitir muestras en herbario á Eur opa, donde fácilmente serian clasificadas. El distinguido profesor de Ginebra, que entónces habia ya comen zado la publicacion de su Prodromus del Reino vegetal, nos ofreció que no se retardaria la determinacion de las especies que le enviásemos, y que sucesivamente serian insertadas en aquella obra ; como efectivamente lo hizó para las que le enviamos correspondientes á las familias que luego vieron la luz pública.

Estos consejos y estas promesas eran ciertamente oportunisimos y ace eptables bajo todos aspectos; pero no ra menos oportuna y ademas apremiante la nzcezidad do poseer en el Jardin de la Habana una Escuela botánica suficientemente provista de especies cubanas exactamente elasificadas. Asi fué que nos dedicamos con ahinco á plantearla, y que ya en el año de 1824 se ballaba organizada, contando en ella las principales familias vegetales, representadas por muchos géneros y especies, mas ó ménos exactamente determinadas; como se puede deducir de la comparacion del catáloge que entónces publicamos, con las clasificaciones hechas despues por M. Richard.

Tenemos la mayor satisfaccion en manifestar aqui, que las primeras indicaciones que obtuvimos en la Habana de correspondencias científicas á varios nombres vulgares de plantas cubanas, las debimos á unas notas manuscritas que dejó un antiguo naturalista, D. Mariano Espinosa, y á las comunicaciones verbales y escritas de D. José de la Osa, que habiéndonos precedido en el Jardin botánico, se habia ocupado muchos años del estudio de la botánica y hecho excursiones en el interior de la isla. Estas dos fuentes y la Florula de plantas cubanas que publicó el Señor Baron de Humboldt en su Ensayo políico sobre la Isla de Cuba, fueron los elementos que nos sirvieron para verificar á la plantacion de la Escuela práetica de Botánica en el Jardin, y para las citas de especies cubanas, en el Tratado elemental de fisiología vegetal y botánica agricola, que tuvimos que redactar inmediatamente para la enseñanza.

Debiendo mas adelanta presentar algunos reflexiones sobre el conjunto de las especies que hemos reunido en la Isla de Cuba, y que se hallan descritas en la Flora ya impresa, no nos estenderemos ahora á enumerar las 800 especies con que entónces comenzamos la Escuela botánica, que fué el princípio de la presente Flora; pero referiremos, por parecernos característica, la noticia que imprimimos en la Habana en el año de 1825, y que no es conocida aun en Europa. Ella dará una idea de la primera reunion sistenática de plantas, que creemos se haya hecho, bajo el cielo de los trópicos.

- Comienza la Escuela, decíamos, por la familia de los Helechos, de útiles aplicaciones en la medicina, a cuyo fin se hallan las Zamiss y las Crcas, modernamente separadas de los primeros y de las cuales la revoluta suministra una hárina análoga al Sagú. Las Malangas y las Gxperacess terminan esta hilera de plantas curiosas. Las utilísimas Gramineas llenan toda la segunda, y no contuviera esta familia en la isla de Cuba mas planta que la caña de azúcar, bastára sin embargo para distinguirse entre todas, por el engrandecimiento que á su cultivo debe; pero reune tambien un gran número de especies cuya importancia no se conocerá bien, interin no se plauteen los prados artíiciales. El cultivo del trigo, introducido ya ea várias comarcas del interior; el del maiz tan generalizado como productivo, y el del arroz, que para recompensar ampliamente las fatigas del labrador, solo requiere la introduccion de los molinos del norte para limpiarle, 
ofrecerán con el tiempo á la industria cubana, en el ramo de cereales, un grado de interés desconocido ahora.

« Las Palmas comienzan ya á extender sus gentiles ramas sobre este cuadro de estudio, y aunque no poseemos todas las especies indigenas, se la ba conservado su lugar como á naturales del pais. Cuando el viagero europeo recorra en lo sucesivo la Escuela del Jardin de la Habana, á la sombra de las palmas y bambues, entre hileras de graciosas bignonias, de curiosos nopales, de movibles acacias, de magnificas pasionarias, no podrá contener su gozo contemplando al aire libre, las variadas producciones de este suelo, que habrá visto en los invernaculos de Madrid, de Paris ó de Lóndres, bajo bóvedas de cristal, al calor de las estufas y entre la atmósfera punzante del tanino ".

«Despues de varias familias de plantas, unas en descredito médico, desprues del alto concepto que merecieron, como la Zarzaparilla y la Raiz de China ${ }^{2}$, otras de azucarado y refrigerante jugo, como la $\boldsymbol{P}$ iña (Bromelia ananas), aparecen los Magueyes (Agave) de aplicaciones en la cordeleria y uno de ellos cultivado en grande en Nueva España, con el objeto de obtener el licor fermentado que alli llaman pulque, de un consumo general entre la clase pobre. Sigue la hermosa familia de las Nancisas ; entre ellas ostenta sus flores la linda Alstroemeria tan lozana en este suelo como aparecia en los jardines de Motezuma. A su lado se eleva el productivo Platano ese benefico don del cielo, que por sus ricos y abundantes frutos no le es comparable planta alguna. Acompañante varias otras plantas de raices aromáticas, como las Thalas y MaranTHas, una de ellas (M. indica) mas apreciada de los médicos ingléses por la especie de Sagú que contienen en abundancia sus raices, y que ofrece al comercio entre Jamaica y Lóndres uno de los ramos de mayor importancia.

"La fecula conocida con el nombre de Salep 6 Salap y que del Oriente se introducia en Europa, es un producto de las raices de Orouneas, que se encuentran al fin de esta línea, de cuyas propiedades no hay lugar aun de hablar, ni cuyas lindas flores deben recomendarse para los jardines, cuando se descuida entre nosotros el cultivo de una de ellas, de la aromática Vainilla, de precio tan subido en los mercados de Europa y espontánea en muchas costas de la isla.

“ Al llegar á esta parte de la Escuela, no puede menos de notarse la diversa estructura que las plantas anteriores ofrecen comparadas á las que siguen. Tallos herbaceos y efimeros, ó troncos cilindricos; ningun canal medular en su interior, ni capas concéntricas de madera, ni una verdadera corteza. El aspecto comun de estas plantas sin ramas ó divisiones subalternas del tallo, como las ofrecen todas las que las siguen hasta el fin de este cuadro, son carácteres que marean bien la conclusion de la clase de vegetales cilíndricos (MovocoTYLenones) y el principio de los vegetales cónicos (Drcotyledones); division capital debida al célebre Desfontaines y $\tan$ esencial para el estudio del botánico como del fisiólogo y del agricultor.

"Las copas en forma de parasol, del primer árbol que se presenta en esta clase, distinguen al Almendro de la India (Terminalia Catappa) cuyos frutos se sirven en las mesas mas delicadas de aquel pais y que vegeta perfectamente en la isla de Cuba, recomendándose por sí solo para hermosear las alamedas. Un frutal de la familia de los laureles, el frondoso Aguacate (Pensea gratisima), un gran número de plantas, de vistosas flores, como los Amaranthos, las Celosias y las Gompherenas; toda la familia de los Nictagos, poco apreciada ya desde que se ha descubierto que la jalapa no se obtiene de la Maravilla (Mirabisis jalapa), pero á cuyo lado las humildes Boerhavias recuerdan el sabio y distinguido médico cuyo nombre llevan; el oloroso grupo de los jasmines, cuya esencia es mas apreciada para el tocador de las bellas que en los anales de la medicina; $y$ las varias Verienas, la linda Callicarpa y las menudas y fragantas Filigranas (LANTana) anteceden al grupo medicinal de las Labiadas tan empleadas en los usos domésticos y en algunas de las cuales el célebre Proust halló el alcanfor en cantidad capaz de poder heneficiarse.

"Aparecen luego las sospechosas Solaneas, entre ellas el Estramonio con el cual se procuran los orientales una especie de delirio voluptuoso que momentaneamente los alivia del peso de la servidumbre y de una vida insoportable por la esclavitud. Generalmente son venenosas las plantas de esta familia, pero no obstante el temor que inspiran muchos de sus generos, basta para recomendarla la Patata, producto del suelo

'Esta prediccion que llenos de júbilo y de esperanza haciamos en la Habana hace treinte y un año, no se realizará cierta-
mente, pues un decreto de la autoridad loca hizo mente, pues un decreto de la autoridad local hizo talar y arrasar en un solo dia, todas las plantas de aquel Jardin botánico,
como explicaremos luego.

- Véase la flora del Diecionario de ciencias médicas publicado en Paris. 
americano, mas útil que todo el oro de sus minas, y tambien el Tabaco que, por la primacia del de la Isla, merecia cultivarse con mas generalidad y reclama la introduccion de las maquinas francesas para elaborar el rapé, á fin de obtener todas las utilidades de que es susceptible este ramo de la agricultura cubana.

"La Baria (Conda gerarcanthos), el Roble negro (ERHETra bourrevia) y el Vomitel (Condia sebestena) constituyen no menos útiles por sus maderas, que gratos á la vista por la frondosidad de sus ramos y la belleza de sus flores, los grupos de las Cordis que anteceden á las Tounnefortias, dedicadas al ilustre botánico frances que ha establecido los géneros. Ricas con todas las galas del colorido la hermosa tribu de trepadoras Ipomeas y Convotyulus, desespera la atencion del botánico, ansioso de fijar esta inmensa diversidad de formas y matices en descripeiones precisas. Citados alguuos en los tratados de Materia médica, por la virtud purgante de sus raices, el dulce Boniato (Convolvolus balalas) ofrece sin embargo una excepcion que no desagrada á los gastrónomos. La familia de las Bıgnonias, numerosísima en especies bajo el cielo feliz de estas regiones y conservadas con esmero en los invernáculos de Europa, da principio en la Escuela para la Jacaranda cerulea ${ }^{1}$, del mas gracioso aspecto. Nada ciertamente puede igualar á la delicadeza y verde amenísimo de sus hojas y al apacible color de sus grandes racimos de flores, sino la vistosa inflores. cencia del Jasmin amarillo (Tecoma stans) que vegeta á su lado. Cuando estos hermosos árboles alcanzan toda su lozanía, ofrecen sus flores en los bosques los contrastes mas primorosos, para ejercitar la mano del pintor y la imaginacion del poeta.

“ El género Vinca, á la cabeza de las Apocineas, recuerda aquel pasaje de la vida de un hombre sensible ( $J_{-}-J$. Rousseau), cuando extasiado á la vista de una mata de la especie comun en Europa, experimentaba todo el placer de las memorias infantiles en la triste edad de los pesares. Las Plumerias tan áridas en la estacion de los Nortes como verdosas y floridas en los calores del estio; las Asccepias de singulares flores los vistosos Echites, las olorosas Adelfas (varias especies del género Neniuv) y la Cerbera de hojas lineares, hermosean esta linea que tambien ofrece en la Camenaria latifolia y la Tabernadontana arcuata, dos árboles frondosos para las alamedas y de los cuales el primero, conocido aqui con el nombre de Maboa, no se desprecia para la construccion.

“El Mamey colorado (Achras mammosa), el Canisté (Sapota elongata), el Caimito (Chrysophyllum Cainito), el Caimitillo (CH. microphyllum) y el Sapote (AcHras sapota) constituyen la riqueza frutal de la familia que lleva este nombre. Merece verificarse la observacion becha sobre el último, de que llegando á la vejez no da scmilla, á fin de fijar por medio del ingerto esta variedad mas apreciable que la comun, no solo por el aumento de la pulpa, que reemplaza á las pepitas, sino tambien por su gusto mas esquisito. Las diversas especies de Achras, Lucuma, Syderoxroon y Bumela que ofrece esta familia en la isla de Cuba, son muy recomendables como maderas duras.

"Sigue la bella y numerosa tribu de las Compuestas donde se ballan muchas aromáticas de uso en la medicina : la familia de las Rubraceas, que reune el aromático Café, cuyo cultivo ocupará en la historia cubana, las felices páginas de su mayor prosperidad y riqueza, y el Dagame ${ }^{2}$ y la Jagua ${ }^{z}$ empleados en diversas construcciones y del mas bello aspecto para alamedas, con especialidad el primero, cuya multitud de flores, de un blanco amarillento, le hacen parecer una pirámide de cera. Las Uruecadas y las Adormideras, las Cruciferas, de tanto uso en la economía doméstica como en la medicina, por sus virtudes anti-escorbúticas, las lindas Paulinias, la afriana Akersia, que merece cultivarse por la belleza de sus frutos, las graciosas Malpighas, entre las cuales el Cerezo del pais (Malpighia punicifolia) brinda sus bayas para agradables confituras, y las trepadoras Banistenias que hermosean lasta los peñascos donde vegetan, preceden en las últimas hileras del primer cuadro, á la apreciable familia que ofrece el magnifico Mamey de Santo Domingo (Mave a Americana), el precioso árbol del Balsamo de María y la carnosa Cuessia cuyas hojas pueden conservar, mejor que las cortezas, los tiernos votos de los amantes.

a Los bosques de la Isla de Cuba escitarán la envidia europea interin ofrezcan los corpulentos y olorosos Cedros y las robustas Caobas, maderas no menos buscadas para la construccion naval; ambos generos pertenecen á la misma familia en que se halla el bello arbol del Paraiso (Melua alzedarach), la Canela blanca y el Yamáo (Guarea trichiloides). La que le sigue, poco numerosa en este suelo, ofrece sin embargo una

\footnotetext{
'Es la J. Sagreana de D. C

- Calscophitlum equdidissimum, D. C
}

Botanica. 
especie de $V$ id indigena, muy propia para suministrar, por medio del ingerto, el vigor que la caracteriza y que las especies traidas de Europa necesitan.

“Con una corpulencia y lozanía desconocidas en aquellos climas, vegetan en este las MaLvacess, grupo natural que no solo llama la atencion del médico sino tambien del fabricante que encuentra en la Majagua ${ }^{\prime}$ y en la Malva-rosa ${ }^{2}$, una substancia para hacer euerdas de suma fortaleza, y en el Algodon la materia primera que, manufacturada por las manos de la India, produce esos tejidos preciosos, que la sagaz industria inglésa en vano intenta imitar recurriendo á míquinas delieadas : hablo de las sutiles muselinas de la India, mas apreciadas por su lucimiento que los olanes y las batistas y objeto hoy dia en la Habana, del lujo mas refinado. - Esta útil familia reune en la Escuela, plantas de adorno para los jardines, como los matizados Hibiscos y las rubicundas Pavonias dedicadas al sabio español que hizo conocer en Europa los tesoros vegetales de la America ${ }^{\circ}$. En la misma línea se encuentra un pequeño Boabab, árbol formidable en el Senagal, cuya extraordinaria ancianidad precisa á contemplarle como el viviente mas antiguo de nuestro planeta. Adanson, que midió algunos de 70 piés de circunferencia, opina que tienen de edad mas de 6,000 años.

- El Anon, el Mamon y la Chirimoya, son frutales demasiado conocidos para que sea preciso indicar sus utilidades; pero se puede conseguir mucho mas de estas especies, por medio de ingertos mutuos que mejorarán las cualidades de algunas ó facilitarán la vegetacion de las que son delicadas en terrenos humedos. Al hacer esta advertencia no creo de mas el decir que, el Laurel de Cuabal ${ }^{i}$ pertenece al mismo género y que puede quizas servir de patron vigoroso á alguna de las otras especies.

- La Bixa brinda en abundancia la materia colorante que rodea la semilla para los tintes; y al lado del exótico clavel, una mata de Lino muestra á los habitantes de la Isla, los debiles tallos donde estriba la riqueza de miles de familias, que en sus diversas preparaciones se ocupan, antes de pasar á los ingeniosos telares donde la industria europea los transforma en las delicadisimas telas que cubren los miembros de las bellezas de la zona torrida, cuyo clima abrasador hace tan apreciables los vestidos de hilo. - A continuacion una planta curiosa (Bryophrlum calycimum), que semejante al Pólipo se reproduce en cada fraceion de sus hojas, es mirada por algunas personas como la morada de un reptil venenoso; cuya preocupacion ha acarreado á este vegetal hermoso é inocente, la pena de destierro de los jardines donde se cultivaba. - A la extremidad de este primer cuadro y sobre un cantero de la tierra que la es propia, se eleva en columnas verdes y espinosas y en artículos aplanados, la extraña familia de los Nopales. El raro aspecto de estos vegetales de las aridas sabanas, el aroma exquisito que exhalan las nocturnas flores de algunos, y la esperanza de ver un dia introducido el cullivo de la cochinilla en varias localidades de la Isla, hacen contemplar con gozo este grupo de plantas singulares.

“Comienzan el segundo cuadro varios vegetales de aplicaciones muy conocidas, como la Guayaba ${ }^{5}$, la Poma-rosa ${ }^{6}$, el Granado, el Mirto olorisimo. Bajo la denominacion de Salicarias, está la hermosísima Lagerstroemia con sus magníficos racimos de curiosas flores, indudablemente la mas bella adquisicion que ban hecho los jardines de la Habana; y á su lado la vistosa Ginonia que reclama todo el esmero que merece para lucir las suyas, de un morado suave, á la par de la linda exótica indiana.

a Despues de los rosales y otros géneros de la misma familia, sigue la rica y variada de las Leguminosas. Vegetales comestibles por una parte, algunos de aplicacion en los tintes, como el Palo de Campeche y el Añil; otros para la construccion y la ebanistcria, como la Yaba ${ }^{7}$ y el Granadillo ${ }^{8}$ y muchos en la medicina, como el Balsamo del Perú, la Caña-fistola, la Cassu Marylandica, el Tamarindo y el árbol que suministra el aceite de Ben, que no se enrancia jamas, constituyen este grupo uno de los mas útiles que ofrece la Escuela. Entre los vegelales resinoses se reunen, bajo la misma tablilla, el Anacardio ó Marañon, recomendado en la antigüedad para dar talento y memoria, el jugoso y anti-escorbútico Mango ${ }^{\circ}$, el funesto

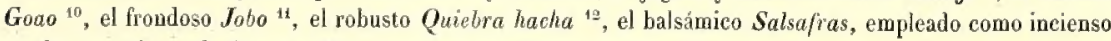
en algunos paises, el Almacigo ${ }^{13}$ y otros cuyo estudio aun está por hacer en la parte de los usos que puedan

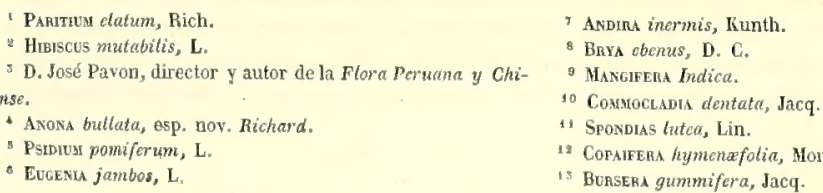


tener los jugos que fluyen de sus cortezas. En la venenosa familia de las Eurorias se hallan las Yueas", una comestible y otra de que se hace el pan de casabe de tanto recurso en el interior. El Jardin ofrece tambien en este sospechoso grupo vegetales comestibles, cuando el embrion se ha desecado ${ }^{2}$, como son $\mathrm{tl}$ Avellano de las Antillas ${ }^{5}$ y el Nogal de la India. Este último y algunos mas que presenta la Escuela en la misma línea, son árboles bellísimos para alamedas por la frondosidad de sus copas.

a Antes de finalizar este cuadro, una hilera completa de Pasionarias le hermosea, y la familia que lleva la denominacion de Ortigas reune plantas de la mayor utilidad en la eeonomía y en las artes : solo citaré algunas. El verdadero Arbol del pan ${ }^{4}$ que no es mas que la variedad sin semilla del exótico que ya vegeta lozanamente en este suelo y que tambien posee el Jardin, suministra con sus frutos el principal alimento á los muchos pueblos que habitan las islas del mar del Sur y el archipiélago de la India; es decir, casi toda esa quinta parte del mundo conocida en la geografía moderna con el nombre de Oceania. El Moral, del cual espera conseguir la industria en Francia, la seda directamente por la maceracion, sin recurrir al intermedio de los gusanos ${ }^{5}$; el Moral del papel ${ }^{6}$, del cual hacen en la China el papel lustroso que viene al comercio eon sus manufacturas de seda y que ya se cultiva en Francia para un objeto análogo; y por último, el Ule ${ }^{7}$ ó arbol de la Goma elástica del Perú, que lo mismo que varias plantas de la familia de las Euforens, produce esa sustancia particular y bien conocida ". D

Hemos reproducido aquí la precedente descripcion, mas bien que por la novedad de las indicaciones hechas hace tanto tiempo, para dar idea del modo como ya entónces considerabamos la utilidad local de la enseñanza y de las tareas que nos estaban confiadas. Por esto insistíamos tanto en las aplicaciones así agricolas como industriales y medicinales; por esto aludímos a las mejoras futuras; por esto enfin procurabamos escitar y transmitir á nuestros jóvenes oyentes, el entusiasmo cientifico que nos animaba, y que juzgándolo entónces como ahora, indispensable para lanzarse, bajo el cielo ardiente de los trópicos, á las asiduas tareas del estudio de la naturaleza, nos dietó la exhortacion poética que les dirijimos lace treinta y dos años, y que ahora desde Europa repetimos á los hijos de nuestros antiguos alumnos: « ${ }_{j} N_{0}$ desmayeis! La divinidad que eantó Lucrecio no es avara de sus bienes ni esquiva con sus favores. Amable y encantadora con los que la siguen, prodiga sus gracias y recompensa las penas con la dulce posesion. - Estas regiones venturosas os brindan con sus mas preciosos areanos. Aqui es donde esa prodiga madre de cuanto existe, se muestra con el aparato de magnificencia y lozanía de su edad primera. Bajo este cielo feliz, la naturaleza ostenta un brillo y magestad que deslumbran al viajero europeo. En estos campos de perenne primavera, en estos bosques de eterno verdor, es donde podeis sorprenderla en su hermosa desuudez, sin los ridículos atavíos con que el hombre la afea en los jardines. Alli poseedores de sus secretos, de sus variados y sabrosos favores, vereis como el éxito corresponde á la esperanza, la recompensa á las fatigas ${ }^{9}$. ”

A estas exhortaciones tendriamos hoy dia otras mas que dirigirles, fundándonos en el porvenir que la Isla de Cuba espera de la laboriosidad y de la perseverancia de sus hijos; pero tal no es en este momento, el fin de Cuba espera de hemos propuesto, que hallará su oportuno lugar en otro escríto que simultáneamente redactamos ${ }^{40}$. Debiendo concretarnos á la relacion sucinta de las tareas que, relativamente á las plantas y sus aplicaciones nos ocuparon, continuaremos exponiendo las que se refieren á los demas planteles de estudio, verificados en el Jardin de la Habana.

El que venimos de descrihir, aunque esclusivamente destinado á la enseñanza elemental, nos sirvió de anxiliar poderoso para todos los demas trabajos que dependian de la clasificacion eientífica. En cuanto á la enseñanza, fácil es comprender la utilidad que nos reportaria el tener á la mano, para las lecciones, ejemplos de plantas cubanas con que sostituir las citas de plantas europeas que hacen las obras, y el poder redactar. 4 estos elementos indigenas, los de la Organografía y Fisiología vegetal, que dimos muy pronto á luz, como preliminar indispensable de la Botánica aplicada.

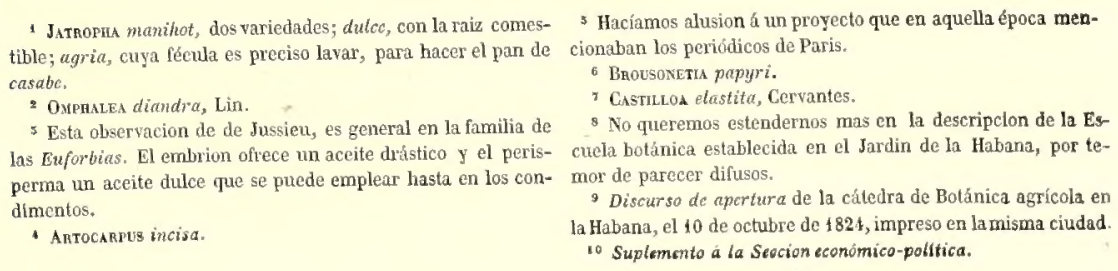




\section{Escuelas agricola, Industuriall y médícn.}

La Escuela botanica estaba exclusivamente destinada á facilitar la enseñanza de los elementos de la botánica; pero siendo nuestro eneargo el presentar esta ciencia en sus aplicaciones útiles, era preciso plantear en el Jardin los cuadros de exposicion y de estudio relativos á ellas. Tal fué pues el motivo de las tres Escuelas ó plantaciones que venimos de nombrar, y que desgraciadamente no pudimos llevar á cabo como deseabamos, porque la reducida extension del terreno y su mala naturaleza, presentaban dos obstáculos insuperables. - Mas tarde, é ya en los últimos años de nuestra residencia en la Habana, la aprobacion que el Gobierno supremo se dignó prestar á nuestro proyecto de Institucion agrónoma. y la asignacion de un terreno algo mas espacioso y adecuado que el del Jardin botánico, á las faldas del Castillo del príncipe, nos permitieron comenzar la planteacion de las Escuelas prácticas que desde un principio habiamos concebido y ensayado, como auxiliares indispensables para la enseñanza que estaba á nuestro cargo. Cuando lleguemos á referir las tareas emprendidas para la mencionada Institucion agrónoma, lo haremos de lo que á aquellas se refiere. Por ahora consignaremos tan solo, que el plan de lo que debian contener las dos prineipales, que eran la agricola y la industrial, le publicamos en un número de las Memorias que, sobre el proyectado establecimiento, dimos á luz en la Habana en el año de $\mathbf{1 8 3 4 .}$

En cuanto á la Eseuela médica, el Jardin botánico de la Habana presentó siempre en abundancia las especies mas usuales de plantas útiles bajo este aspecto bumanitario, las cuales eran constantemente dadas á la puerta del establecimiento, á todas las personas que las solicitaban. Esta parte del servicio público se hubiera extendido y completado en lo sucesivo, cuando los plantíos hechos en el otro terreno y la adquísicion de muchas especies silvestres del interior de la Isla, lo hubiesen permitido. - Luego diremos, que la publicacion especial de una Flora médica, formó parte tambien de nuestros trabajos. Todas las especies cubanas, y algunas exóticas, mencionadas en ella, debian hallarse expuestas vivas en el terreno, en el mismo órden de clasificacion que habiamos adoptado en la indicada obra. De este modo, el médico y el farmaceútico, sacarian tambien partido de la enseñanza que suministraba el Jardin botánico de la Habana.

Uno de nuestros objetos al ocuparnos de las plantas medicinales indigenas, era el reunir materiales exactos para la formacion de una Materia médica vesetal cubana, que remplazase con inmensas ventajas á la europea, en la cual las indicaciones se refieren muchos veces á especies que llegan á las Antillas alteradas por el tiempo ó adulteradas por el fraude, y hacen tributario aqquel pais de sustancias, las mas veces ineficaces, cuando la Isla abunda en especies preciosas dotadas de mayor energía y eficacia, á parte de otras muchas desconocidas en Europa, que indudablemente serán algun dia solicitadas.

Ademas de este fin trascendental, llevabamos otro en la plantificacion de la Escuela médica, y era el de evitar muchos errores á que podia dar orígen en la práctica, la equivocada introduccion de nombres vulgares de plantas de España, dados á especies cubanas enteramente diversas en sus propiedades. Clasificadas y presentadas estas, en la Escuela médica, con los nombres científicos al lado de los vulgares, los médicos y los farmaceúticos que deseasen hallar sucedaneos á las especies medicinales de Europa, y que por ejemplo se propusiesen emplear una rosacea, no echarian mano de la Agrimonia, que en la isla de Cuba es una lahiada, el Teucrium Cubense, ni tampoco si solicitasen una planta de esta familia, echarian mano del Dictamo, que alli es una peligrosa Euғoris.

Este ramo importantisimo de la botánica aplicada, merece ser estudiado con detencion, y no abandonamos el proyecto, ahora que la parte deseriptiva de las plantas cubanas se laalla terminada, de reunir en una memoria especial, las indicaciones que sobre las medicinales hemos reunido, con la mira de llamar la atencion hácia este nuevo y utilisimo campo de aplicaciones saludables. Tenemos la íntima conviccion de que el exámen imparcial de las plantas medicinales de las regiones intertropicales del globo, donde la accion de los agentes atmosféricos es tan poderosa, suministrará interesantísimas sustaneias, tanto ó mas preciosas que las ya debidas á aquella admirable zona. Pero este estudio requiere, ademas de los productos en perfecto estado de conservacion, la determinacion botánica de las especies, para lo cual sirven los herbarios y las Floras locales. 


\section{Correspondeneia cienthea}

Con la mira de reunir datos sobre los interesantes puntos que venimos de indicar, y con la de ilustrarnos sobre los mismos objetos que reuníamos, nos pusimos en comunicacion constante, ya con hombres prácticos del país, ya con hacendados distinguidos por su patriotismo y su inteligencia, ya con profesores célebres, con academias sabias y establecimientos científicos de Luropa y de los Estados Unidos. Todo esto era necesario para conducir regularmente y llevar á término el vastísimo plan que nos habian decidido á emprender. el entusiasmo de la edad juvenil y la seductora novedad del pais que habitabamos.

No enumeraremos ahora los diversos puntos que abrazaba esta correspondencia, pues tendremos ocasion oportuna de hacerlo mas adelante; bastará por el momento decir, que las relaciones que nos procuramos en lo interior de la Isla, nos proporcionaban noticias y objetos naturales para el estudio, y que las comunicaciones con la Europa y la América, tenian por objeto el pedir allí la determinacion de los segundos, que no nos era dado hacer con exactitud por nosotros mismos. Las personas que cultivan las ciencias naturales saben bien, que en el estado actual de estas, inmensamente ricas de objetos descubiertos continuamente en todas las partes del mundo, es de todo punto imposible, á un profesor aislado, el abrazar la determinacion de todos los que le presenta un país nuevo como la Isla de Cuba. Ademas de la imposibilidad ofrecida por la magnitud de la ciencia, exisle otra para la determinacion de los objetco de un solo ramo 0 sea de parte de ella, cuando no se habita en centros científicos ecmo los europeos; porque faltan los elementos indispensables para hacer aquella, que son las bibliótecas, los museos, las publicaciones periódicas y sobre todo los hombres especiales que cultivan cada seccion de la Historia natural. Tal era nuestra situacion en la isla de Cuba. - El tiempo que allí residimos, no hubiera sido suficiente para reunir noticias y objetos, conservarlos y coordenarlos convenientemente, para bacer luego su exámen y determinacion científica en Europa. A esto deberia haberse coneretado nuestra tarea de exploracion; pero debíamos desempeñar al mismo tiempo la de la enseñanza de la ciencia y las del estudio difícil de sus aplicaciones á las necesidades agricolas ể industriales del país. Esta segunda parte de nuestros deberes, y que realmente constituian los oficiales de nuestro destino, exigia simultáneamente el conocimiento ó sea la determinacion cientifica de los objetos del país, que como hemos dicho y demonstrado, era de todo punto imposible verificar por nosotros mismos. Este fué el motivo por el cual recurrimos á la correspondencia europea y norte americana, remitiendo herbarios y notas á diversos profesores distinguidos, que luvieron la bondad de ayudarnos, así como á muchas sociedades cientílicas, donde, desde luego, se dió cuenta de las investigaciones que nos ccupaban.

Seria muy larga aqui la enumeracion de todas las corporaciones cientificas de Europa y de los Estados Unidos, y de profesores célebres de estos paises, con las evales y con quienes entramos en frecuentes y activas relaciones. En los Informes á la Sociedad patriótica de la Habana, que se publicaron allí, se encuentran sucesivamente consignadas estas útiles relaciones del Jardin botánico, cuya direccion nos estaba confiada. Pero, no debemos omitir aqui la meneion especial del ilustre de Candolle y de sus colaboradores Mercier y Moricand, quienes fijando una atencion perentoria y especial en las especies cubanas, qque desde los primeros años de nuestra residencia en la Habana les remitimos, consignaron las determinaciones en las obras curopeas y con particularilad en el Probromus del reino vegetal, que entónces daba á luz el célebre profesor de Ginebra. Gracias á esta cooperacion activa é inteligente, tuvimos la satisfaccion de ver desde luego incorporadas en la ciencia, muchas de las plantas nuevas que hallabamos en la isla de Cuba, y la ventaja de tenerlas ya determinadas, para las tareas que nos ocupaban.

Hemos creido oportuno y conveniente el dar aquí cstos pormenores, ya para satisfacer una deuda de gratitud á los sabios que nos han ayudado, ya para explicar los fundamentos de esta importante cooperacion : lo cual servirá ademas de respuesta á las críticas ocultas que se han solido hacer, por personas extrañas á la ciencia, quienes creyendo forzoso que poseésemos la universalidad de conocimientos que hasta el dia no ho reunido hombre alguno, encontraron defectuoso y censurable el que hubiésemos confiado la determinacion cientifica de los minerales, de las plantas y de los animales que reunimos en la Isla de Cuba, á profesores eminentes, que sabiendo infinitamente mas que nosotros, en cada una de las especialidades que cultivan, Botanica. 
contribuyeron á la perfeccion de una obra, que no podia obtenerla de nuestros únicos conocimientos" En cuanto á nuestros corresponsales en el interior de la Isla de Cuba, sus noticias y frecuentes remesas de objetos, nos fueron sumamente útiles, pues han contribuido con las unas á aumentar el caudal de elementos preciosos para nuestros estudios, y con las otras á enriquecer la Historia natural cubana. Mas adelante, y despues qua hayamos expuesto todo el cuadro de nuestras investigaciones económico-agricolas y botánicas en la reina de las Antillas, mencionaremos los nombres de nuestros bondadosos y activos colaboradores.

\section{Formacion de una estadística de In topografia vegetal y agromómica de la Isla de Cuba.}

Ya hemos dicho que el plan de nuestras tareas abrazaba á la vez las investigaciones científicas y las aplicaciones que de ellas pudieran hacerse á la mejora de la agricultura cubana; por esto nos era preciso reunir todos los datos necesarios para coustituir con ellos mas tarde, un sistema comple to de reglas aplicables á un país que aun no las tenia. Tratándose en efecto de mejorar los cultivos y las prácticas agrónomas en la Isla de Cuba, para obtener constantes y variadas cosechas y forzar los terrenos á que adnitiesen todas aquellas plantas que podian sostener, en consideracion á sus cualidades físicas y químicas y á su posicion topogrática, hubiera sido importantísimo, como lo dijimos en la Habana en público ${ }^{2}$, emprender un viaje general por todo el país, y en su consecuencia trazar una carta física y los perfiles necesarios para manifestar la calidad de las tierras, su posicion con respecto á las aguas corrientes, á los vientos dominantes y al nivel del mar. De esta suerte se poseeria un dato estadístico muy precioso, á saber : el de la extension de las tierras cultivables en general y de las peculiares para eada cultivo.

Con la mira de reunir algunos datos sobre estas interesantisimas cuestiones, preliminares á la obra que venimos de indicar, solicitamos varias noticias de nuestros corresponsales del interior de la Isla, relativas ála topografia vegetal y agrónoma de los distritos que lrabitaban. En una circular impresa en 1826, se comprendian las principales, referentes á la calidad de los terrenos y sus circunstancias topográficas, á la duracion de las épocas de las aguas y de la seca, los vientos dominantes, las cantidades de la produccion media anual de los frutos cubanos sobre una extension dada de tierra, los árboles conocidos en el distrito, con ex. presion de los nombres vulgares y usos económicos y medicinales, las yerbas y plantas de pasto y las hojas y frutos de los árboles que comen los ganados, y otros datos que no es preciso repetir aquí. Sin embargo diremos, que la série de tales preguntas, sugeria á nuestros corresponsales vasto campo para extenderse en indicaciones y reflexiones importantes, sobre el estado de la agricultura en el distrito que habitaban, la urgeneia de las mejoras que reclamaban, los recursos que el pais poseia, los que aun pedia de la administracion y de los propietarios poderosos, y otro gran número de avisos, dignos de ser conocidos y meditados con detenimiento, para fundar en ellos el plan de reorganizacion á que tantas veces hemos aludido.

La simple indicacion del interrogatorio que circulamos, da á conocer los fines á que lo destinabamos. Al mismo tiempo manifiesta que nuestra empresa era larga y que por muy numerosos que fueran los resultados que obtuviésemos, habíamos de dejar aun mucho mas que reunir y coordinar á los que nos siguiesen en este género de investigaciones. Esta es la razon por la cual las consignamos en esta introduccion, y no con la mira de darlas á conocer, pues de unas ya lo hemos hecho en la Habana ${ }^{3}$ y las demas requieren una revision completa de la correspondencia que seguimos entónces con nuestros laboriosos corresponsales; trabajo que no corresponde al plan de la presente obra. Nuestro fin, al referir los pormenores del plan que en ellas hemos seguido, es el de que sean continuadas, porque las creemos esenciales para verificar con acierto la gran reforma que reclama la agricultura cubana, de la cual hemos hablado en el capitulo especial de nuestra obra y probablemente tendremos que decir algo mas en el Suplemento que redaclamos ahora.

\footnotetext{
'Lo absurdo de las críticas á que aludimos llegó al punto de afirmar que habiamos inventado varios de los animates y de las plantas descritas en nuestra obra. La asercion no hubiera pasado de ridicula, si desgraciadamente las personas que las hicieron no ejerciesen un influjo demasiado directo en las opiniones de la administracion oficial, de la cual despendia la proteccion acordada por el Gobierno.

"Discurso de aberfura al curso de 1830, pág. 3.

sanales de ciencias, agricultura, etc.; Habana.
} 
VII. Reunion de noticiag concernienteg á In vegetacion de los bovques y de las sabanas, los usos y las aplicaelones de los úrboles y de las yerbas, ete.

Ademas de las noticias relativas á la topografia vegetal y agrícola, necesitabamos, para llenar, poco á poco y sucesivamente, el vasto cuadro de nuestras investigaeiones, otras todavía mas detalladas y si es dable decirlo así, locales, concernientes á dos grandes ramos de riqueza, que yacen casi vírgenes en la Isla de Cuba; y son la explotacion de los bosques y la crianza de los ganados. Para ambos era preciso comenzar por conocer bien los elementos ó medios que el país poseia, y á este fin, redactamos, imprimimos circulamos á todos los Partidos rurales, donde teníamos relaciones, estados en blanco divididos en colunas donde era fácil inscribir, con órden y claridad, las indicaciones que solicitabamos; a saber, sobre las especies arbóreas, sus nombres vulgares, las dimenciones en una edad probable, las localidades, la clase de terreno, la época de la floracion y de la fructificacion, los usos de las maderas, de las raices, de las cortezas, de las gomas, de las resinas, ete., y sobre las especies herbáceas y arborescentes, la indicacion de si eran vivaces ó anuales, los terrenos en que vegetaban, las especies de animales que las comian, la preferencia que les daban, el efecto que en ellos producia su alimento, etc.

Los mas celosos de nuestros corresponsales nos remitieron, con los estados llenos, colecciones de troncos, muestras de gomas y resinas, y ramas secas en herbario, y algunos nos enviaron tambien muestras de los terrenos de cultivo, particularmente de las afamadas vegas de tabaco de la Vuelta de abajo, cuyo análisis hicimos y publicamos en la seccion correspondiente de la Historia física (Tomo 1º, página 75 ).

Si hubiésemos conseguido reuni todas las noticias pedidas á todas las comareas de la isla, seria fácil redactar una Silvia cubana completa, para la cual sin embargo tenemos muchos materiales ordenados. Desde luego, poseemos los de la determinacion botánica de muchos árboles útiles, que antes de nuestro viaje solo eran conocidos por los nombres vulgares; poseemos tambien una numerosa coleccion de maderas de los mismos, cuyo duplicado remitimos hace años al Jardí botánico de Madrid, y es la misma que, con un catálogo especial que publicamos, de las denominaciones eientíficos y vulgares, fue presentada por disposicion del Gobierno en la Exposicion universal de Lóndres. Poseemos en fin, un gran número de noticias sobre las propiedades físicas y las aplicaciones económicas é industriales del mayor número de dichas maderas, así como de los usos medicinales á que se apliean en la Isla, muchos productos naturales obtenidos de los árboles.

No es menos rico el catálogo que conseguimos formar de las plantas herbáceas y de las hojas y frutos de las arbóreas y arborescentes que comen los ganados; de cuyas séries publicamos en la Habana una lista bastante numerosa ${ }^{1}$ que nos contentaremos con reproducir, muy mejorada, al fin de esta introduccion ; ya que no podemos, por falta de suficientes recursos, publicar un tomo mas bajo el mismo título de Plantas usuales de los cubanos, que dimos entónces á nuestro coneiso catálogo. Esta obra seria tanto mas necesaria, cuanto es incompleta en indicaciones usuales la presente Flora Cubana; defecto que debe atribuirse, ademas de la estrechez de límites (que lubimos de fijar á nuestro sabio colaborador M. Richard, para redactar la deseripeion de cerca de 1,500 especies de plantas, muchas de ellas nuevas) los accidentes que experimentó nuestro herbario, y á los cuales antes aludimos de paso.

\section{Trahajos preliminares para una Institucion agrónoma.}

Desde que comenzamos nuestras investigaciones en la Isla de Cuba, nos convencimos de que su agricultura carecia, por una parte, del variado número de procedimientos que en otros paises facilitaban las tareas rurales, de las máquinas y utensilios modernos que las simplifican, y de las prácticas melódicas que aseguran el éxito de los cultivos, y por otra, reconocimos que se hallaba demasiado limilada la esfera de estos, tanto que no pasaban de doce las especies vegetales que daban ocupacion al labrador cubano ${ }^{2}$. Los grandes cultivos, aquellos que sirven de base al comercio, se resentian de esa falta de pribcipios fijos que economizan

1 Memorias de la Institucion agrónoma de la Habena, $n^{\circ}$ XVIII del Apéndice; Habana, 1834 .

* Esta observacion la consignamos ya en la Habana en el mes de agosto de 1829 (Anales de ciencias, elc, tomo III, pág. 30) 
gastos y ammentan los productos del suelo, al misno tiempo que un exceso de produccion indiscreta, en nno de ellos (el café), habia ocasionado bajas en los precios, por la concurrencia que los frutos de la Isla hallaban en los mercados de Europa. Estas razones y otras varias que sucintamente índicamos en el capítulo consagrado á la agricultura en la presente obra (y que probablemente tendremos ocasion de desenvolver mas en el Suplemento que actualmente redactamos), nos decidieron á recomendar al Gobierno supremo, varias medidas fundamentales para elevar la agricultura cubana al rango científico que necesitaba para hacer grandes y trascendentales progresos. Entre ellas, mencionamos las Instituciones agrónomas, donde á la buena doctrina acompañase el ejemplo práctico, transmitido á jóvenes exentos de las preocupaciones rutineras, que en todas partes se oponen á aquellos.

Dos eran las grandes secciones que proponíamos para el futuro Instituto: $1^{\circ}$ el cultivo, destinando a de cada plania útil, el lugar que mereciese, y ensayando los instrumentos, los procedimientos y las prácticas agrarias consignadas por la experiencia en otros paises; 2a la enseñanza elemental y metódica, á los jóvenes destinados á la carrera agrícola, de los fundamentos y de las prácticas del cultivo, del regimen económico de las fincas y de todo lo demas que requeria la profesion de labrador en Ia Isia de Cuba.

La indieacion de estas bases esenciales para la reforma agrónoma de aquel país fué perfectamente apreciada y bien acogida por el distinguido Ministro de hacienda ", bajo cuya Cependencia se hallaba entóncese Jardin botánico de la Habana. La real órden expedida el 22 de abril de 1829, es un modelo de inteligencia y de prevision, que merece ser seguido aun en el dia, con tanto mas motive, cuanto que fué malogrado el primer proyecto emanado de ella.

En efecto, dicha providencia comprendia los trabajos agronómicos que debian verificarse en la Institucion agrónoma, bajo el doble aspecto de utilidad para la Isla y para la Península; pues haciéndose cargo de st insigne posicion geográfica, la consideraba como ventajosa para constituit en ella un centro de aclimatacion de vegetales de otras regiones, los cuales pasando despues y sucesivamente á los jardines de aclimatacion intermedios de las Islas Canarias y costa de Andalueía, Hegasen un dia á conaturalizarse en las comarcas meridionales de España.

Esta idea no era nueva, pues hacia algunos años que la Isla de Cuba se presentaba á la imaginacion de los botánicos como el suelo mas apropósito para servir de primera escala de aclimatacion, con respecto á las plantas de las regiones ecuatoriales de la América y del Asia; y ya, antes de la guerra de la independencia, el Gobierno español decretando la creacion de un jardin de aclimatacion en San Lucar de Barrameda, habia dado principio al plan general que venimos de indicar. Pero la real órden citada, comprendia ademas los otros puntos de interés inmediato para la Isla de Cuba, pues refiriéndose á la Institucion decia : "Qué siendo una de las principales causas del atraso de todos los ramos de su agricultura, la falta de su enseñanza de un modo práctico, que convenza de la necesidad de adoptar y de propagar los conocimientos útiles, deberá enseñarse la agricultura y ramos agrarios de manera que sea el plantel donde se formen sujetos que difundan por toda la Isla las prácticas ventajosas, abrazando una extension de terreno considerable que contenga toda la diversidad posible de sitios agrónomos, para que se veriliquen el mayor número de experimentos que pide la industria rural. $\gg$

Como se vé, el plan era tan vasto como las circunstancias poco propicias para establecerle de una vez; así fué que, destinando para principiar algunas tareas de cultivo, á las cuales el terreno del Jardin botánico no se prestaba, una finea que la Real hacienda poseia á las inmediaciones de la Habana, pudimos introducir desde luego varios nuevos cultivos y ensayos de nuevas industrias rurales, así como la práctica de los instrumentos y máquinas de la agricultura perfeccionada. Al mismo ticmpo, redactamos las hases del futuro Instituto de enseñanza, el reglamento interior y todo lo demas que debia concurrir al complemento y al éxito del proyecto del Gobierno.

En el corto tiempo que dirijimos aquellos trabajos, tuvimos ocasion de reconocer la necesidad del auxilio de otros profesores y de un vasto terreno para los ensayos de cultivo de las muchas plantas económicas é industriales, que en nuestro sentir debian ser comprendidas mas tarde en la Cartilla rústica cubana. Por esta razon y con esta mira, contestamos extemamente al Exmo. Sr. Conde de Villanueva, sobre el modo de llevar á cabo la Institucion decretada. Creemos oportuno abora insertar aquí algunos párrafos de ella, con

\footnotetext{
' El Ermo. Señor D, Luis Lopez Ballesteros, varon activísimo y celoso, que duxante su larga carkera no desinintió un solo momento, las elevadas cualidades que le distinguian.
} 
la esperanza de que algun dia seran tomadas en consideracion las ideas que expresabamos entonces, y que de modo alguno han envejecido ó caducado :

* La idea de fundar cerca de la Habana una Institucion agrónoma, que reuna á la enseñanza de la agricultura y ciencias naturales accesorias, el cultivo de las plantas análogas al clima de la Isla, en la cual ademas se hagan ensayos de aclimatacion y de mejoras en los cultivos, se introduzcan los nuevos instrumentos que diariamente pone la iudustria en manos del labrador, se perfeccionen los métodos y se generalizen las prácticas rurales; esta idea tan fundamental del bien, tan filantrópica é ilustrada, y cuyas ventajas son tan evidentes y trascendentales que no necesitan ser demostradas; reune la circunstancia de poder realizarse á poco costo, ó mejor dicho, de exigir tan solo la anticipacion de un capital, reembolsable dentro de cierto número de años. Pero antes de manifestar los medios de conseguirlo, juzgo necesario hacer algunas observaciones sobre las primeras medidas que deben tomarse para asegurar el éxito, economizar tiempo empleándole bien, y para establecer los primeros cimientos del grande edificio agrónomo que se proyecta, de manera que llegue a produeir todas las utilidades de que es susceptible y para las cuales le destina la muniticencia paternal de un monarca ilustrado.

- Cuando las dos colporaciones económicas de esta ciudad, han puesto bajo mi direccion este Jardin botánico, establecido por el celoso é ilustrado antecesor de V. E. el Sr. V. Alejandro Ramirez, se propusieron un plan que podia considerarse como una miniatura del que abora lecomienda el Rey nuestro Señor. Efectivamente, se puso á uni cargo la enseñanza de los principios fundamentales de la agricultura y se considero el Jardin como una pequeña escuela de ella, no obstante su extencion limitadisima para semejante objeto. Sin embargo, en poco tiempo y con una escasez de recursos extraordinaria, se han visto en sus cuadros nuevos cultivos, nuevas especies exóticas para ser generalizadas, y la prảctica de nuevos métodos, en cuan to lo ha permitido el corto espacio del Jardin y la delgada capa de su lieira vegetal anegadiza. Posteriormente S. M. ha vuelto á recomendar el establecimiento de un vivero para surtir al Real Jardin de la Córte, y este nuevo objeto ha dado mayor amplitud á las tareas que con tanta satisfaccion me ocupan.

- En medio de ellas, tengo el sentimiento de ver que las utilidades que obtiene la agricultura de la Isla, del Jardin botánico, no son tan prontas ni tan en grandes, como el atraso de aquella exige; y esto proviene de que el establecimiento es muy reducido, mal situado para grandes cultivos, y mas que todo, por la escasez de fondos de la corporacion á cuyo cargo se halla. De esto procede tambien, que muchas ideas beneficiosas, como la del cultivo del añil, que solo necesitaban de fomento para producir el bien, han quedado paralizadas; que la vasta correspondencia que he establecido con las primeras sociedades de agricultura é instituciones agrónomas de Europa, no reporta las ventajas que podian obtenerse, y en fin que el Jardin, por falta de medios, se halla como estacionario sin ofrecer mas recursos que aquellos que permite el limitado círculo en que se le tiene, pudiendo ser, con un ligero impulso, el primer plantel de la agricultura cubana. Pero, en vano es la introduccion de nuevas plantas, sino se continua su cultivo demostrando palpamente el método mas ventajoso y la utilidad y facilidad de introducirlas en la grande agricultura. Esto solo puede hacerse en una Institucion ag̣ónoma, cual la recomienda el Rey nuestro Señor, y el Jardin botánico pudiera considerarse en tal caso, como el plantel para los semilleros, el depósito de las plantas que deben venir del estrangero, y como el lugar mas á propósito, por su inmediacion á la ciudad, para dar la enseñanza teórica y práctica de los frineipios, euya vasta aplieacion se veria en la Hacienda modelo.

a Estas observaciones manifiestan, que el Jardin botánico, por los trabajos que ya ha emprendido, debe ser considerado como la base de la Institucion agrónoma; y aun cuando á los principios exigirá algun aumento en los gastos, estos disminuirán desde que se establezea la Hacienda y en lo sucesivo ella misma proveeráal sostenimiento de ambos, como demostraré luego.

a Al examinar la agricultura de la Isla de Cuba, con los ojos de la despreocupacion y de la ciencia, se conoce que no solo está atrasada, por el corto número de plantas y lo mal que se cultivan, sino que todo el sistema agrónomo es vicioso, y de consiguiente que la reforma debe ser radical, si se quiere que la agricultura continue siendo la base de la prosperidad del pais y la única fuente de su riqueza. Los adelantos que ha hecho esta ciencia en Europa, hijos de la desgracia, de la esperiencia y de la aplicacion de muchos siglos, han demostrado que no puede haber continuas y abundantes cosechas, sin una sabia sucesion en ellas, cou el uso de los abonos, abonos sin animales, y animales sin pastos. Pero en la Isla de Cuba, los pastos, los animales, los abonos y la sucesion de cosechas es lo que menos se considera, y lo que en ninguna hacienda Botanica. 
se práctica como doctrina fundamental. De aquí ha resultado el abandono de tierras, llamadas viejas y estenuadas á los quince ó veinte años de cultivo, la escasez de carnes, de productos vegetales para el alimento, y por consiguiente de los medios mas poderosos de aumentar la poblacion, que son las subsistencias. Si de estas consideraciones se pasa á otras, sobre la pobreza del comercio interior, la nulidad de la industria rural, la enorme masa de importaciones de efectos, comestibles, etc., se conocerá fácilmente que, la carestía de los jornales rechazando la industria fabril, la escasez de poblacion, el desnivel en el valor de nuestras transacciones comerciales y la calamidad que amenaza á la Isla de Cuba, por la baja de sus frutos y la minoracion de los pedidos de Europa, proceden del atraso de la agricultura, considerada en la totalidad del sistema, resultante del corto número de cultivos y de lo vicioso de los métodos seguidos.

- La Institucion agrónoma que el Rey nuestro Señor recomienda para la Habana debe ofrecer, y las palabras mismas de S. M. lo expresan : a Las prácticas confirmadas por la experiencia, combatiendo así por la "cilustracion la ignorancia, la rutina y las preocupaciones ". La exposicion de los cultivos, el órden de ellos, la formacion de los abonos, la cria de animales, el establecimiento de pastos, el método económico en los pormenores, la unilad en la accion y marcha de la Hacienda, deben ser tan perfectos como lo permiten los adelantos del dia, de manera que los cultivadores y hacendados encuentren demostradas en ella, por la práctica, las reglas fijas que eximan á unos de la duda tan perjudicial para los progresos del arte, y á otros les ahorre los gastos infructuosos de ensayos mal meditados ó de innovaciones irreflexivas.

- Durante mucho tiempo se creyó, dice un sabio agrónomo moderno, que el arte de cultivar los campos era la cosa mas fácil del mundo; y este error, que es un obstáculo para los progresos, tiene su origen en la indiferencia con que aquel se ha mirado. $\$$ - En la Isla de Cuba, donde la feracidad del suelo y la benignidad del clima dispensan al labrador de muchas tareas penosísimas en Europa, la ciencia del cultivo se halla limitada á las dos operaciones de sembrar y coger, abandonando despues la tierra apenas cultivada. No se ha considerado que la agricultura estaba destinada en este país, á alimentar á sus individuos, á aumentar la poblacion, á cubrir el monto de las importaciones del estrangero, al sostenimiento del Estado, y á suplir en fin, á todos los adelantos del lujo y de la civilizacion de un gran pueblo. Tampoco se ha considerado que los mismos elementos de facilidad para las cosechas, los reunen en mayor número otros pueblos mas sobrios y con menos necesidad que el nuestro; que en los climas rigidos, los esfuerzos de la industria han logrado contrarrestar la natural fertilidad de las regiones privilegindas, y que donde quiera el hombre aplieado saca recursos de sí propio para producir y prosperar, en medio de los obstáculos y de las privaciones. Asi el labrador de la Isla de Cuba, encantado de ver la casi espontánea produccion de sus opimos campos, ignoró los progresos de la ind ustria europea, y al empezar ahora á salir de su embelezo, se espanta del coloso que aquella ha levantado y con el eual amenaza á su existencia política é individual.

- Convendria pues, recorrer las fuentes de esa misma industria europea para beber en ellas los elementos de vida y prosperidad que han de resuscitar el abatido everpo de nuestra agricultura ; examinar el estado de esta en las naciones que consiguieron elevarla al primer grado de esplendor; ver alli la accion combinada de las ciencias y de la aplicacion práctica; de los talentos del sabio y de la constancia del agricultor; la série de operaciones que constituyen la nueva teoría racional del cultivo; la cooperacion que le prestan, la policia urbana y la economía doméstica; el enlace de todos los ramos de produccion; el sistema del órden y de la economía; los progresos de ciertos cultivos; el pormenor y los efectos de nuevos instrumentos y máquinas, y en fin, todo cuanto pueda interesar á nuestro estado presente, para apliearlo despues con constancia y vigor á la mejora de nuestros campos, tan bellos por naturaleza, pero tan necesitados de industria. Este viaje por Europa, no puede menos de ser de la mayor trascendencia en el bien futuro de este país. Considerando que diariamente se verifican por cuenta de gobiernos, que parece nada tienen que imitar; cuando se reflexiona que el inglés estudia los cultivos de la Bélgica, que el francés recorre las ricas haciendas de Escocia y que el holandés imita los primores de los jardines ingléses, es fácil concebir cuantos modelos de imitacion, cuantas reformas, cuantas máquinas é instrumentos nuevos constituirian la preciosa conquista obtenida á favor de la agricultura cubana y peninsular, por fruto de un viaje con el esclusivo objeto de examinar el estado de esta cieneia en las primeras naciones de Europa. El tiempo destinado á él, que no debe pasar de dos años, léjos de retardar aceleraria estraordinariamente el progreso de la Inslitucion rural que el Rey nuestro Señor recomienda, y por el eontrario fuera incompleto el plan de establecerla, sin contar con todas las mejoras y perfecciones que desde el primer año puede ofrecer y que, sin el viaje espuesto, solo serán 
el resultado de numerosos ensayos y de infinitas consultas por medio de una correspondencia cuya lentitud evitaria fácilmente la inspeccion ocular de los establecimientos. En cuanto al costo del viaje, no merece ser considerado atendida su utilidad, y si se recuerda que, para objetos muchos menores, acaba de costear uno el Real Consulado. Los gastos puede reducirlos estraordinariamente un hombre que, por fin de sus viajes, se propone el estudio y la observacion; y la carestía de la Habana hace la vida sedentaria de un profesor en ella, tan costosa como su existencia en Europa recorriendo los principales focos de la agricultura y de Ia industria. Por otra parte, el establecimiento de la Institteion agrónoma en la Isla, supone la adquisicion de un habil cultivador, esto es, de un hombre instruido y educado en los invernáculos templados y calientes de los jardines de Europa, para confarle aquí el cuidado que exigen los diversos eultivos tropieales, el arreglo de las remesas á la Península, y toda la parte material de semilleros, trasplantes, podas, ingertos, etc. Estos hombres no los hay en la Isla de Cuba, y es muy arriesgado pedirlos, no conociendo íntimamente lo establecimientos agrónomos donde se hallan; porque no deben hacerse contratos anticipados con personas de cuyas costumbres, actividad y conocimientos no hay mas pruebas que simples recomendaciones parciales ó imperitas. Pero examinando los jardines y las haciendas modelos de Europa, es fácil contratar verajosamente y sin exposiciones funestas, con uno ó dos hombres capaces de tomar á su cargo, desde e. aorrento de la llegada á la Isla, el cultivo del terreno y el cuidado de las primeras siembras. Se procuraria al mismo tiempo, el elegirlos de establecimientos análogos al que se trata de crear, para que les fuese familiar el órden y los procederes del método que en todos ellos, con uniformidad se observa s. - (Extracto del oficio de 2 de setiembre de 1829 .

Nuestro informe continuaba exponiendo las condiciones que debia reunir el terreno que se destinase para la Institucion, las grandes utilidades ya agrónomas, ya industriales, ya sociales que debia producir, ete.

En otras comunicaciones que redactamos en la misma época, trazamos el plan interior del establecimiento y de la enseñanza, y todo lo demas que pudiese conducir al éxito de una Institucion que cossiderabamos y continuamos considerando, como necesaria y fundamental para el progreso de la agricultura cubana.

\section{Publieaciones varias.}

Todos los trabajos que venimos de indicar y cuyos resultados convenia dar á conocer al público, exigieron frecuentes publicaciones, de las cuales daremos aquí una sucinta idea.

En la relacion que dejamos hecha, citamos varias veces algunas de las publicaciones donde hemos consignado varios resultados de nuestras tareas, durante nuestra residencia en la Habana. Como aquellas circularon casi exelusivamente en la isla, y solo fueron conocidas en Europa por los sucintos extractos que dieron de algunas los periódicos cientificos y las actas de Sociedades europeas, nos ha parecido conveniente consignar aquí los títulos y los objetos respectivos de ellas, para que puedan ser buscadas por los profesores que deseen tener á la vista muchos pormenores no comprendidos en nuestra obra general.

Las obras que publicamos en la Habana fueron unas elementales para la enseñanza, otras periódicas y varios folletos sueltos. Las primeras quedan ya en parte citadas en los párrafos precedentes y no contienen por lo general mas que doctrina elemental y noticias de usos medicinales, para la Flora médica que proyectabamos. Las publicaciones periódicas que hicimos fueron dos, á saber : los Anales de ciencias, agricultura, comercio y artes, que redactamos durante cuatro años (desde 1827 hasta dieiembre de 1831), y las Mcmorias de la Institucion agrónoma de la Habana, que dimos á luz en el penúltimo año de nuestra mansion en la isla. El primero de dichos periódicos no era especial de nuestras tareas como el segundo; su plan mas vasto, era tener al público cubano en general y á los hacendados y profesores en particular, al corriente de los adelantos que se hacian en Europa y América sobre los ramos que mas interesaban al país; discutir las cuestiones agrícolas y económicas, á que daban lugar de una parte los mencionados adelantos exteriores, y de la otra los interiores de la produccion cubana. Relativamente á las tareas especiales que nos ocupaban, los Anales contienen, ademas de los Informes anuales relativos á ellas, los estados meusuales de las observaciones meterológicas que haciamos, otros relativos á la germinacion de las semillas ya indigenas ya exóticas, pormenores sobre varias plantas útiles y las noticias de topografia vegetal y agricola que nos enviaban nuestros corresponsales.

Las Memorias de la institucion agrénoma, correspondian á su título exclusivo, presentando la historia de 
nquel naciente establecimiento, el plan de enseñanza y de los culivos que debia ofrecer, los resultados de los varios ensayos que indicamos en el precedente artículo, relativos á la fabricacion del añil por el método de la hoja seca y de consiguiente por simple infusion; de crianza de gusanos de la seda, que por primera vez introducimos en la Isla de Cuba con la Morera multicaulis, que les sirvió de alimento y cuyas hojas fueron despues preciosas para el alimento de los ganados en las sequias; de varias plantas textiles y aceitosas como el Hibiscus carnabinus, la Moninda pterigosperma, la Aleuntes triloba, etc., y enfin consignamos en aquel periódico, la descripcion, las láminas y el uso, que introducimos en aquella finca, de los instrumentos de cultivo y máquinas aratorias de Roville y de los Estados Unidos. Como estas tareas son mas bien agronómicas que botánicas, no pueden hallar hueco oportuno aquí, mas que de un modo incidental y pasajero, y como simple indicacion para que las personas que en la Isla ó fuera de ella, se ocupen de trabajos semejantes, sepan donde se hallan impresos los resultados de los que iniciamos durante nuestra mansion en ella.

Concretándonos á los exclusivos de la botánica, objeto especial de la presente seccion de nuestra obra, vamos á referir, con algun mayor detenimiento, los que en ella van consignados, en su mayor parte resultado del estudio del herbario y de las notas que reunimos.

\section{X. - Formacion de herbrio. - Flora. - Iden de la vegetacion Cubana.}

Como dejamos dicho, la recoleccion de muestras de plantas cubanas y su conservacion en herbario, fué una de las tareas á que con mas asiduidad no hemos dedicado durante nuestra mansion en la Isla de Cuba; pero nuestras ocupaciones diarias en los trabajos del Jardin, la enseñanza, la reunion de noticias estadisticas en los archivos y oficinas, el diario meteorológico, la correspondencia cubana y estrangera, ete., nos impidieron hacer las excursiones lejanos continuas, de un verdadero viajero. Procuramos suplir esta falta, pidiendo á nuestros corresponsales en el interior, muestras de todas las plantas de sus respectivas comarcas, enviándoles instrucciones adecuadas ó explicándoles verbal y práeticamente el modo de formar los herbarios. Los profesores de la ciencia comprenderáa bien, cuantas dificultades experimentariamos antes de conseguir algun resultado; dificultades que nacian, mas aun que del aprendizage, de la indiferencia con que era, por lo general, mirado este trabajo por muchas de las personas á quienes se lo recomendabamos. No podian figurarse que tuviesen el menor interés ni importancia, ramas secas de árboles comunisimos, de yerbas inútiles, de bejucos (enredaderas) insignifieantes, de curujeyes (orquideas parasitas) sin aplicacion, de muzgos, de likenes y de hongos, en fin, de todo punto despreciables para las gentes del país. Quizas perjudicaba á nuestros encargos, la misma importaneia que les dabamos y el carácter de generalidad con que los recomendabamos. Recoja $V d$. y envie de todas cuantas plantas encuentre en flor ó en fruto; era la frase que constantemente repetíanos. Agréguese á esto, que nuestra edad entónces daba poquisima importancia á nuestros encargos, y así era preciso que los apoyásemos con largas explicaciones sobre las utilidades que debian resultar de la determinacion y del conocimiento exacto de los vegetales cubanos. De todas maneras, por mucbas de las respuestas que recibimos de personas que al fin no nos secundaron, nos convenciamos tristemente que no podian comprender que fuesen desconocidos en la ciencia, los árboles que tenian diariamente á la vista, y cuyos nombres y usos comunes, sabian ellos por antigua y constante tradicion. Nuestra posicion era efectivamente dificil, pues si bien solicitabamos el envio de lo que era allí de todos conocido (lo cual podia, hasta cierto punto, halagar el amor propio de aquellos vecinos), teniamos que darles á entender que su conocimiento no era el científico y que habia mucho mas que saber y que investigar en la variada vegetacion que los rodeaba; y esto los mortificaba.

Pero si de muchos corresponsales recibimos respuestas desanimadoras, otros nos comprendieron y secundaron con amor, con celo, con actividad, con patriotismo. - D. José Maria Valenzuela, á quien son debidas las hermosas, nuevas é interesantes especies de la $\boldsymbol{V}$ uelta de abajo; D. Antonio Reynoso, de Guanimar; D. Manuel Avarez y el Licenciado D. Luis de Lima, de Pinal del Rio; el Presbítero D. Manuel Donoso y el Licenciado D. Luis José Espinosa, del Guanabo; el Presbitero D. Juan José Baff y el Bacliller D. Francisco Gutierrez Jaquez, del partido de las Pozas ; el Presbítero D. José Ramon de la Paz y Morejon, de los partidos de Hanabana y Yaguaramas; el Doctor $D$. Juan Josè Oliver, del partido de Alquizar; D. Jose Maria Palacios, de Villa Clara; el Licenciado D. Manuel de Monteverde, de Pucrto Principe; D. Hilario 
de Cisneros Saco, de Santiago de Cuba, y otros varios, nos secundaron de ina manera eficaz, el primero, como queda dicho, remitiéndonos numerosas muestras en herbario, y los demas varios productos vegetales, como troncos, cortezas, gomas, resinas, noticias detalladas sobre las épocas de la floracion y fructificacion de las plantas, las propiedades y los usos.

Ademas de estos zelosos corresponsales, merecen aquí una mencion especialísima, cinco amigos que franca y decididamente nos ayudaron durante nuestra residencia en la Isla de Cuba. Fueron estos $D$. José Antonio de la Osa, primitivo Director del Jardin botánico de la Habana, en la época de su creacion por el benemérito Superintendente D. Alejandro Ramirez; D. Alejo Helvecio Lanier, D. Sebastian Bonani, D. Felipe Poey y D. Pedro Auber. A nuestra partida de la Isla en $\mathbf{1 8 3 5}$, este último quedó eneargado de suplimos en la enseñanza; el Sr. Bonani lo fué tambien de entretener y cuidax las plantaciones comenzadas en el terreno de los Molinos del Rey, de las cuales hablamos en el artículo VIII, y ambos continuaron, en los años siguientes, hasta su fallecimiento, enviándonos á Europa los objetos naturales que recogian y que fueron consignados, con la justa mencion que les era debida, en las respectivas secciones de esta obra. Al Sr. Lanier, en fin, debe esta, todas las plantas de la Isla de Pinos, de la cual imprimió una descripcion geográfica especial ${ }^{4}$, y nos remitió tambien muchas conchas que fueron igualmente comprendidas en la seccion de los moluscos.

Mencionamos tambien entre nuestros compañeros de investigacion cubana, al sabio y laboriosísimo D. Felipe'Poey, aun cuando sus tareas se refiriesen mas á la zoología que á la botánica, porque enriqueció notablemente la Historia natural de la Isla y nos acompañaba con frecuencia en nuestras exploraciones. Su nombre se halla citado con frecuencia y consignado en muchas especies de moluscos y de insectos de la presente obra. Tambien lo están las interesantísimas Memorias que ha comenzado á publicar en la Habana, continuando así, con-gloria y honor para su país, la noble carrera de investigaciones naturales, en las cuales le acompañará y seguirá su digno hijo $D$. Andres $P$ oey, distinguido ya en las ciencias físicas.

De los cinco amigos que durante un largo periodo recorrimos juntos los bosques y las sabanas de la Isla de Cuba, tres han fallecido ya ; á nosotros nos compete abora, consignar la memoria de sus tareas en la obra cientifica á que contribuyeron. Los que la consulten sabran perdonarnos esta digresion amistosa, con la cual deseamos pagar una deuda de profunda gratitud.

Los colaboradores citados nos ayudaron tambien á reunir denominaciones vulgares de plantas cubanas; tarea mas difícil de lo que á primera vista parece, y que nos era precisa como preliminar de nuestras futuras adquisiciones, así como para facilitar la difusion de las ideas cientificas en el país que habitabamos. Cuando llegamos á él, no existia mas que de un catálogo ó lista de los mencionados nombres, referente á $\mathbf{2 8 7}$ especies de los principales árboles de la Isla de Cuba, formado por D. Antonio Parra é impreso en Madrid en 1799, al fin de una Memoria ${ }^{2}$. En 1828, se publicó en el $\mathbf{n}^{0} \mathbf{4 1}$, del $\mathbf{1}^{\circ}$ de mayo, de las Memorias da la Sociedad económica de la Habana, otra lista de 106 nombres de maderas que se crian en los montes de la Isla de Cuba. Al año siguiente, se insertó en el Mensagero semanal de Nueva York una relacion de $\mathbf{4 7}$ maderas cubanas, con expresion de sus nombres, calidad, color, usos comunes y, en el ramo de artillería, altura y grueso reyular de sus troneos, su fuerza ó resistancia, y el peso de una pulgada cübica de cada una de estas maderas. Este trabajo fué debido al teniente coronel de artillería, D. José María Calleja, que le tuvo inedito desde el año de 1818 que hizo las experiencias. El coronel de ingenieros D. Juan Pio de la Cruz, le enriqueció con las indicaciones del peso específico. Pero, en ninguna de estas relaciones se hallaban las correspondencias botánicas de los nombres vulgares.

Hablando en otra ocasion ${ }^{3}$ de las plantas cubanas, hemos dicho las dificultades que ofrecia la averiguacion de las correspondencias vulgares, porque los hombres del eampo dan muchas veces el mismo nombréa vegetales diversos en la realidad, aunque semejantes en las hojas, en la madera y en carcatéres de segundo órden; otras veces distinguen con denominaciones extrañas plantas idénticas; las mas confunden y alteran, cambian y corrompen los tales nombres, y en algunas no saben el nombre vulgar ó realmente no le tienen las plantas.

Por todas estas causas resulta dificilísima su averiguacion 6 es realmente imposible, como hemos reconocido en muchas de las especies que determinamos y que carecen de nombre vulgar en la Isla de Cuba.

- Geografia de la Isla de Pinos, ó Notas hidrográficas, topográficas, etc., que acompañaron la Carta de dicha Isla. Habana, 1836. 2 Discurso sobre los medios de conaturalizar y propagar en España los cedros de la Habana y otros arbotes ast de construccion como de maderas curiosits y frutales.

3 Nímero go de los Anales de ciencias, agricultura, comercio y artes. - Habana.

Botanica. 
Ademas de estos inconvenientes, la comparacion de las listas de maderas que nos remitieron de Cuba, de Baracoa, de Holguin, de Nuevitas, etc., con los trozos y tabletas de nuestra coleccion, nos dieron á conocer que muchas, siendo idénticas, llevan en aquellos distritos nombres absolutamente diversos que en la jurisdiccion de la Habana, y que al mismo tiempo faltaban en las listas muchos de los nombres usuales en esta.

El primero Catálogo que ba salido á luz de plantas eubanas con las correspondancias botánicas, fué el que redactamos é insertamos en el citado $\mathbf{n}^{\circ} 9^{\circ}$ de los Anales de Ciencias. Siete años despues, é ya mas enriquecidos con las comunicaciones de nuestros corresponsales de la Isla de Cuba y de Europa, dimos á luz en el $n^{\circ}$ XVIII del Apéndice á las Memorias de la Institucion agrónoma de la Habana, y bajo el título de Plantas usuales de los cudanos, un eatálogo mucho mas numeroso, comprensivo de mas de $\mathbf{4 0 0}$ especies distribuidas en secciones, segun los usos de las plantas ${ }^{1}$. Pero en él no insertamos mas que las conocidas con denominaciones botánicas. Resta aun por averiguar si todos los demas nombres vulgares que hemos reunido, y de los cuales insertamos algunos al fin de nuestra lista de 1827, se refieren 0 no á especies diferentes.

Refiriéndonos ahora al herbario que, por todos estos medios reunimos, ya dijimos en la página 8, que se hallaba distribuido en paquetes referentes á las diversas herborizaciones que hicimos. Ahora añadiremos, que támbien habia paquetes duplieados de todas las remesas que habiamos dirigido á M. de Candolle, y por último, otros muchos de los diversos envios de la Vuelta de abajo y de las comarcas del interior, que no hemos visitado. Todo esto hacia tres órdenes de colecciones, cuyas notas se hallaban, con referencia á nú. meros, en los diarios de nuestras excursiones, en la correspondencia con los Señores de Candolle, Mercier y Moricand, y en las cartas de nuestros colaboradores cubanos. Esta distribucion debia suministrarnos, en lo sucesivo, ámplia materia para reflexiones y eomparaciones importantes sobre los fenómenos de la vegetacion cubana, y la aclaracion de muchas dudas y la rectificacion de las determinaciones hechas, muchas veces con demasiada premura en Ginebra, con la idea de enriquecer el Podromus con las especies nuevas que remitiamos. Todo esto hubiera sido muy fácil, pues las cartas mencionaban las plantas por los números que llevaban las muestras, lo cual permitia, en todo tiempo, comparar las frases especificas publicadas en Europa con los tipos dobles que habíamos conservado. Pero ya indicamos, en la misma citada página, que la malhadada idea de destruir todos nuestros primítivos paquetes, para formar una sola série conforme al sistema de familias, introduciendo una gran confusion en los numeros de las muestras, hizo perder todo el fruto que esperabamos sácar de nuestras notas y correspondencia.

La coleccion de herbario que hemos traido, fué despues aumentada con varias especies criptogamicas que nos remitió el laborioso D. Pedro Auber, con las especies halladas por los Señores Pæppig y Lindley en la parte oriental de la Isla de Cuba, y que tuvieron la bondad de comunicar á nuestro colaborador M. Richard, y en fin con varias orquideas vivas remitidas de la Habana al mismo, por su amigo el doctor Belot, y que florecieron en el jardin de la Facultad de Medicina de Paris.

Al confiar nuestro herbario de Faneroganas á M. Richard, encargándole absolutamente de la clasificacion y descripcion, le entregamos tambien gran número de nuestras notas sobre las localidades, las propiedades y aplicaciones.

Nuestras frecuentes ausencias de Paris ${ }^{2}$ para desempeñar diversas misiones de nuestro país y de nuestro Gohierno, nos impidieron estar á la mira, ya para evitar, en la nueva distribucion de las muestras en familias, la confusion de números que deploramos, ya para aclarar las dudas que, por esta causa, ocurian á cada momento á nuestro amigo, para referir á aquellas las notas que le habíamos dado. Esto unido á la estrechez de los límites en que era preciso concentrar las descripeiones botánicas, produjó la omision de muchas de aquellas noticias que hubieran debido hallar su sitio al fin de las descripciones. De todos modos, la série de plantas que en la presente obra forman la Flora Cubana conocida, es ya bastante interesante, como se puede juzgar por el siguiente :

1. Algunos escritores cubanos publicaron, despues de nosotros, catálogos de plantas Cubanas con correspondencias botánicas, omitiendo citar la fuente de donde tomaban ó reproducian semejantes listas.

2 Estas ausencias y viajes continuos nos impidieron tambien yigilar la traduecion del texto frances al espanol, y corrigur gran numero de erratas de imprenta que desgraciadamente lieva la presente seccion. 


\section{EPITOME DE LA FLORA CUBANA.}

-caras

\section{FANEROGAVIA}

RANUNCULACEA

CLEMATIS havanensis. - Kunth.

- pallida, - Rich. (nob.)

- Catesbyana. - Pursh.

- Dominica. - Lam.

\section{DILLENIACE $A$.}

DAVILLA Sagræana, - Rich. (nob.)

- ciliata. - Rich. (nob.)

CURATELLA americana. - L.

TetraGera Poppigiana. - Schlech.

\section{ANONACEAE}

ANONA muricata. - L

- palustris. - L.

- squamosa. - L.

- bulata. - Rich. (nob.)

- cherimolia. - Mill

- reticulata. - L

- glabra. - L

XILOPIA Gubensis. - Rich. (nob.)

- obtusifolia. - Rich. (nob.

UVARIA neglecta. - Rich. (nob.)

OXANDRA laurifolia. - Rich. (nob.)

- virgata. - Rich. (nob.)

CISS AMPELOS caapeba. - L

NYMPHAACEA

NYMPHEA ampla. - D C.

PAPA VERACE E.

ARGEMONE Mexicana, - L. BOCCONIA frutescens. - $\mathrm{L}$.

\section{GRUCIFERE.}

CAKILE maritima. - Rich.

LEPIDIUM Virginicum. - L

\section{CAPPARIDE. $\mathrm{E}$.}

CLEOME pentaphylla. - L

- Cubensis. - Rich. (nob.)
CAPPARIS cynophallophora. - L.

- emarginata. - Rich. (nob.)

\section{FLACOURTIAN EA.}

BIXA orellana, - $\mathbf{L}$.

LETIA apetala. - Jacq.

- longifolia. - Rich. (nob.)

- crenata. - Rich. (nob.)

ZUELANIA lætioides, - Rich. (nob.)

VIOLARIE $A$.

HYBANTHUS Havanensis. - Jacq.

DROSERACEA.

DROSERA incisa, - Rich. (nob.)

POLYGALEA.

POLYGALA paniculata. - L

- stellera. - DC.

- peduncularis. - Rich. (nob.)

SECURIDACA volubilis. - L

- virgata. - Sw.

FRANKENLCE $A$

SAUVAGESIA erecta. - L.

CARYOPHYLLE $A$.

MOLLUGO bellidifolia. - Sering. ARENARIA serpens, - Knnth.

\section{MALVACE $E$.}

MALVA Americana. - I

- tricuspidata, - Aiton.

- leprosa. - Ortega.

MALAGHRA capitata, - L

$$
\text { - ciliata - Poiret. }
$$

URENA sinnata, - L.

- Swartii. - DC.

PAVONIA spinfex. - Cav.

- typhalæa. - Gav.

- linearis. - Rich. (nob.) 
- intermedia. - Rich. (nob.)

- racemosa. - Sw.

MALVAVISGUS Sagræanus. - Rich. (nob.)

- pulvinatus. - Rich. (nob.)

HIBISCUS pentaspermum. Bertero.Var lobata. - Rich. (nob.)

- Syriacus, - L.

- costatus. - Rich. (nob.)

- Cubensis. - Rich. (nob.)

- esculentus. - L.

- cryptocarpus, - Rich. (nob.)

- mutabilis. - L.

- Phœniceus. - L.

- truncatus. - Rich. (nob.)

PARITIUM elatum, - Rich. (nob.)

GossipIUM. Sp. var.

ANODA hastata. - Cay.

ABUTILON periplocæfolium. - Rich. (nob.)

- triquetrum. - Rich. (nob.)

- lignosum. - Rich. (nob.)

- confertiflorum. - Rich. (nob.)

- hirtum. - Rich. (nob.)

- trichodum. - Rich. (nob.)

GAYA affinis, - Rich. (nob.)

BASTARDIA viscosa. - Kunth.

SIDA spinosa. - L.

- lanceolata. - Rich. (nob.)

- obtusa, - Rich. (nob.)

- carpinifolia. - L.

- involucrata - Rich. (nob.)

- rhombifolia. - L.

- dumosa.-Sw.

- urens. - L

- glutinosa. - Cav.

- multiflora. - Cav

- paniculata. - L.

- pilosa. - Cav.

- hederæfolia. Cav.

BOMBACEA

HELICTERES trapezifolia. - Rich. (nob.) - furfuracea. - Rich. (nob.)

PACHIRA emarginata. - Rich. (nob.)

- aquatica. - Aublet.

ERIODENDRON anfractuosum. - DC.

OCHROMA lagopus. - Sw.

BUTTNERIACE $\boldsymbol{A}$.

THEOBRoMA Cacao, - L.

GUAZUMA tomentosa. - Kunth.

- parvifolia. - Rich. (nob.)

MELOCHIA pyramidata. - L.

- nodiflora, - Sw.

- hirsuta. - Cavan.
- depresa. - L.

W ALTHERI A Americana. - L

PENTAPETES Phœnicea. - L.

TILLIACE $A$.

GORCHORUS siliquosus.

TRIUMPHET A heterophylla. - Lam.

- rhomboidea. - Jacq.

- hispida. - Rich. (nob.)

- grossulariæfolia.-Rich. (nob.)

BELOTIA greviæfolia - Rich. (nob.)

LUHEA platypetala. - Rich. (nob.)

PROCKIA erucis, - L.

- tomentosa. - Rich. (nob.)

TERNSTROEVIACEA.

TERNSTROEMIA peduncularis. - DC.

- obovalis. - Rich. (nob.)

LAPLACEA Curtyana. — Rich. (nob.)

OLACINEA.

XIMENIA Americana. - L.

AURANTLACE $/$.

GLYCOSMIS heterophylla. - Rich. (nob.) CITRUS limonum. - Risso.

- vulgaris. - Risso.

HVP RICLNEA

HYPERICUM styphelioides

$$
\begin{aligned}
& \text { - arenarioides. - Rich. (nob.) } \\
& \text { - galioides. - Lam. }
\end{aligned}
$$

CLUSIA rosea. - L.

- alba. - L.

MAMMEA Americana. - L.

GALOPHYLLUM calaba. - Jacq.

\section{CANELLACEA.}

CANELLA alba. - Murray.

MARGGRA VIACE/E.

MARCGRAVIA umbellata. - L.

HUPPQCRATEACEA.

HIPPOCRATEA integrifolia. - Rich. (nob.)

ERYTHROXYLACEAE.

ERYTROXYLUM brevipes. - DC.

$$
\begin{array}{ll}
\text { - } & \text { spinescens. - Rich. }(n o b .) \\
\text { - } & \text { alaternifolium. - Rich. }(n .) \\
\text { - } & \text { Havanense. - Jacq. } \\
\text { - } & \text { obtusum. - DC. } \\
\text { - } & \text { rufum. - Cay. } \\
\text { - } & \text { affine. - Rich. (nob.) }
\end{array}
$$


MALPIGHIACE E.

TRIOPTERIS rigida. $-\mathrm{S} w$.

HLTEROPTERIS laurifolia, — Ad. de Juss.

BANIS'CERIA pauciflora. - Kunth.

STIGMAPHYLLON Sagræanum. - Ad. de Juss. (nob.) reticulatum. - Ad. de Juss. (nob.) diversifolium. - Kunth.

SPACHEA parviflora. - Ad. de Juss. (nob.)

Ossana. - Ad. de Juss. (nob.)

BYRSONIMA crassifolia, - DC.

- cinerea. - DC.

- Cubensis. _Ad, de Juss. (nob.

- lucida. - Kunth

MALPIGHIA urens. $-\mathbf{L}$.

- glabra. $-\mathbf{L}$.

- coccifera. - L.

\section{SAPINDACE $\mathbb{E}$.}

CARDIOSPERMUM ferrugineum. - Rich. (n.) SERJANIA paniculata. - Kunth.

- Ossana. - DC.

SAPINDUS saponaria. - L.

SCHMIDELIA nervosa. - Rich. (nob.)

- macrocarpa. - Rich. (nob.)

- cominia. - Sw.

CUPANIA glabra. - Sw.

- multijuga. - Rich. (nob.)

- tomentosa. - Sw

- triquetra. - Rich. (nob.)

- juglandifolia. - Rich. (nob.)

- macrophylla. - Rich. (nob.)

- oppositifolia. - Rich. (nob.)

HYPELATE paniculata - Cambess.

MELICOCGA bijuga - $\mathrm{L}$.

VALENTINIA ilicifolia. - $\mathrm{S} w$.

\section{MELIACEA.}

TRICHILIA spondioides. -- Jacq

- Havanensis. - Jacq.

- minor. - Rich. (nob.)

GUAREA trichiloides. - L.

SWIETENIA mahogoni. -. L.

CEDRELA odorata. - $\mathrm{L}$.

\section{AMPELIDE $E$}

CISsuS sicyoides. - L.

- intermedia. - Rich. (nob.)

VITIS Caribæa. - DG.

AMPELOPSIS quinquefolia. - Rich.

Botanica.

\section{OXALIDACE E.}

OXALIS corniculata, - L

- intermedia, - Rich. (nob.).

- violacea - L.

\section{RUTACE $A$.}

TRIBULUS maximus. - $\mathrm{L}$

-. cistoides, $-\mathrm{L}$.

GUALACUM officinale, - L

- verticale. - Ortega.

GALIPEA Ossana. - DC.

LEMONIA spectabilis, — Lindley.

ZANTHOXYLUM coriaceum. - Rich. (nob.)

$$
\begin{array}{ll}
- & \text { bombacifolium, - Rich.(n.) } \\
- & \text { dumosum - Rich. }(\text { nob. }) \\
\text { - } & \text { ternatum. - Sw. } \\
\text { - } & \text { tediosum. - Rich. (nob) } \\
- & \text { pterota. - Kunth. } \\
- & \text { lanceolatum. - Poiret. } \\
\text { - } & \text { juglandifolium. - Wild. } \\
& \text { SIMARUBE } \text { E. }
\end{array}
$$

SIMARUBA glauca. - DC.

\section{OCHNACEA.}

GOMPHIA ilicifolia. - DC.

- acuminata. DC.

- alaternifolia. - Rich. (nob. $)$

- elliptica. - Rich. (nob.)

ELADENDRON attenuatum. - Rich. (nob.) MYGINDA uragoga. - Jacq.

- ilicifolia. - Lam.

MONTEVERDI buxifolia. - Rich. (nob.)

CELASTRUS parviflorus. - Rich. (nob.)

ILEX cassine. - Aiton.

- minutiflora. - Rich. (nob.)

\section{RHAMNE E.}

ZIZIPHUS spina Christi. - Wild.

- Havanensis. - Kunth.

COLUBRINA ferruginea. - Ad. Brong.

- reclinata. - Ad. Brong.

- Cubensis. - Ad. Brong.

GOUANIA Dominguensis. - L.

-. tomentosa. - Jacq.

\section{SAMTDE $A$.}

CASEARIA spinosa. - Wild.

- ramiflora. - Vahl.

- alba. - Rich. (nob)

- sylvestris. - Sw.

- parviflora. - Wild.

- hirsuta. - Sw. 
TEREBINTHACE E.

ANACARDIUM Occidentale. - Jacq. MANGIFERA Indica - L. COMMOCLADIA dentata. - Jacq. PICRAMNIA pentandra. - Sw. RHUS metopium. - L. SPONDIAS purpurea. - $\mathrm{L}$.

$$
\text { - lutea. - L. }
$$

ICICA copal. - Rich. (nob.)

- Edwigia. - Rich. (nob.)

BURSERA gummifera. - Jacq.

AMYRIS maritima. - Jacq

- silvatica. - Jacq.

\section{LEGUMINOS $\boldsymbol{A}$.}

SOPHORA tomentosa. - L

MYROSPERNUM Toluiferum. — Rich. CROTALARIA retusa, - L

- litoralis. - Kunth

- pumila. - Ortega.

- incana. - L.

INDIGOFERA argentea. - L

$$
\begin{array}{ll}
- & \text { Añil. - L. } \\
\text { - } & \text { tinctoria. - L. } \\
\text { - } & \text { cytisoides. - Thunb. } \\
\text { - } & \text { ternatea. - L. }
\end{array}
$$

CLITORIA.

CENTROSEMa Plumieri. - Benth.

- Virginianum. - Benth.

- intermedium - Rich. (nob.)

- ferrugineum. - Rich. (nob.)

- pascuorum. - Mart.

NEUROCARPUM angustifolium. - Kunth.

GALACTIA Cubensis, - Kunth.

- parvifolia. - Rich.(nob.)

BARBIERA polyphylla. - DC.

DALEA mutabilis. - Wild.

TEPHROSIA cinerea - Pers.

LONCHOCARPUS sericeus. - Kunth.

$$
\text { - latifolius. - Kunth. }
$$$$
\text { - maculatus. - DC. }
$$

SESBANIA Occidentalis. - Pers.

AGATI grandiflora. - Desv.

ZORNIA Havanensis. - Rich. (nob.)

STYLOSANTHES viscosa. - Sw. humilis. - Kunth.

ASCHINOMENE Americana, - L. sensitiva. - Sw.

DESMODIUM glabellum. - DC.

- incanum. - DC

- tortuosum. - DC.

- scorpiurus. - Desw.

- triflorum. $-\mathrm{DC}$.
ABRUS præcatorius. - L.

RHYNCHOSIA minima. - DC.

$$
\text { - phaseoloides. - DG. }
$$$$
\text { - reticulata. }-\mathrm{DC}
$$

PHASEOLUS crotalaroides. - Martius.

$$
\text { - tuberosus. - Lour. }
$$

DOLICHOS sesquipedalis. - L.

VIGNA villosa. - Savi.

- vexillata. - Rich. (nob.)

LABLAD vulgaris. - Savi.

PACHYRHIZUS angulatus. - Rich.

STENOLOBIUM cæruleum. - Bentham.

CANAVALIA obtusifolia. - DC.

$$
\text { - ensiformis. - DC. }
$$

MUCUNA urens. - DC.

$$
\text { - pruriens. DC. }
$$

CAJANUS bicolor. - DG.

ERYTHRINA corallodendron. - L.

$$
\text { - umbrosa. - Kunth. }
$$$$
\text { - crista-galli, - L. }
$$

ARACHIS hypogæa, - $\mathbf{L}$

ECASTAPHYLLUM Brownei. - Pers.

PTEROCARPUS gummifer. - Bertero.

BRYA ebenus. - DC.

SWARTIA multijuga. - Rich. (nob.)

MIMOSA pudica. - L.

ADENANTHER A pavonia. - L.

ACACIA pauciflora. - Rich. (nob.)

- cornigera. - Wild.

- Valenzuelana. - Rich. (nob.)

- formosa. - Kunth.

- insularis. - Rich. (nob.)

- arborea. - Wild.

- lebbek. - Wild.

- propinqua. - Rich. (nob.)

- littoralis. - Rich. (nob.)

- leucocephala. - Link.

- lentiscifolia. - Rich. (nob.)

- microcephala. -- Rich. (nob.)

INGA hixtris. - Rich. (nob.)

- unguis-cati. - Will.

- obovalis. - Rich. (nob.)

ENTADA gigalobium. - DC.

DESMANTHUS strictus. - Bertol.

- comosus. - Rich. (nob.)

ANDIRA inermis. - Kunth.

MORINGA pterygosperma. - Goetn.

GUILANDINA bonduc. - Ait.

CESALPINIA bijuga. - Sw.

$$
\text { - horrida. - Rich. (nob.) }
$$

$$
\text { - crista - L. }
$$

POEPPIGIA excelsa. - Rich. (nob.)

POINCIANA pulcherrima. - L. 
HEMATOXYLUM Campechianum. - L. PARKINSONIA aculeata. - L.

TAMARINDUS Indica. - L. CASSIA fistula. $-\mathrm{L}$.

- Brasiliana. - Lam.

- grisea. - Rich. (nob.)

- bicapsularis. $-\mathbf{L}$.

- alata. - L.

- Occidentalis. - L.

- tora. - L.

- sericea. $-\mathrm{Sw}$.

- chrysotriche. - Colladon.

- biflora. - I.

- chrysophylla. - Rich. (nob.)

- hispida. - Colladon.

- rotundifolia. - Pers.

- cuneata. - DC.

- grammica. - Spreng.

- chamærista. - L.

- patelaria. - DC.

COPAIFERA bymenæfolia. - Moric. BAUHINIA heterophylla. - Kunth. HYMENALA Courbaril. - L.

CYNOMETRA Cubensis, - Rich. (nob.) BELAIRIA spinosa. - Rich. (nob.)

\section{ROSACE $\mathbb{E}$.}

CHRYSOBALANUS Icaco, - L. HIRTELLA nitida. - Wild. CERASUS Occidentalis. - Loiseleur.

\section{COMBRETACE $\mathbb{E}$.}

BUCIDA bucerus. - L.

- angustifolia. - DC.

- capitata. - Vahl.

TERMINALIA catappa. - L.

- eriostachia. - Rich. (nob.)

CONOGARPUS erecta, - Kunth.

LAGUNCULARIA racemosa. - Goet.

POIVRE eriopetala. - DC.

CHICHARRONIA intermedia. - Rich.(nob.)

\section{ONAGRARIA.}

JUSSIFA peploides - Kunth.

- ramulosa. - DC.

- Sagræana. - Rich. (nob.)

- octonervia. - Lam.

- octofolia. - DC.

- hirta. -. Vahl.

ISNARDIA repens. - DC.

OENOTHERA rosea. - A tion.

RHYOPHOREA.

RHIZOPHORA mangle. - L.

\section{LYTHRARIE $A$}

AMMANIA sagittata. - DC.

- sanguinolenta. - S S. .

LYTHRUM hyssopifolia. - L

CUPHEA Swartzana. - Spreng.

GINORI Americana. - Jacq.

\section{MELASTOMACEA.}

CHETOGASTRA Hayanensis. - DC. ARthrostevma Gubense. - Rich. (nob.) CLIDEMI Valenzuelana, - Rich, (nob.)

- crenata. - DC.

- lanata. - DG.

- spiccata. - DC.

CALYGOGONIUM Cubense. - Rich. (nob.)

CONOSTEGIA subhirsuta, - DC.

$$
\text { - semicrenata. - Sering. }
$$

- acutidentata. - Rich. (nob.)

PaChy AnthUS Gubensis, - Rich. (nob.)

NAUDINIA argyrophylla. - Rich. (nob.)

- chrysophylla. - Rich. (nob.)

MICONIA prramidalis. - DC.

- delicatula. - Rich. (nob.)

- elata. - DC.

- impetiolaris. - Don.

- auricalata. - DC

\section{MYRTAGE E}

MOURIRIA myrtilloides. - Poiret.

- Valenzuelana. - Rich. (nob.)

CALYPTRANTHES syzygium, - Sw.

PSIDIUM pyriferum. - L

$$
\text { - chytraculia. - Sw. }
$$

- pomiferum. $-\mathrm{L}$.

- guayabita. - Rich. (nob.)

EUGENI ligustrina. - Wild.

- brevipes. - Rich. (nob.)

- microphylla. - Rich. (nob.)

- rigidifolia. - Rich. (nob.)

- phyllirexfolia. - Rich. (nob.)

- heterophylla. - Rich. (nob.)

- tuberculata. - DC.

- sessiliflora. - DC.

- farameoides. - Rich. (nob.)

- verrucosa. - Rich. (nob.)

- baruensis. - Jacq.

- guayabillo. - Rich. (nob.)

- ferruginea - Rich. (nob.)

- jambos. - L.

- pimenta. - DC.

- Valenzuelana. - Rich. (nob.)

PASSIFLOREN.

PASSIFLORA holosericea. - L. 
PASSIFLORA minima. - L.

$$
\begin{array}{ll}
\text { - } & \text { multiflora, - L. } \\
\text { - } & \text { pubescens. - Kanth. } \\
\text { - } & \text { rubra. - L. } \\
\text { - } & \text { coriacea. - Rich. }(n o b .) \\
-\quad & \text { quadrangularis. - L. } \\
-\quad & \text { incarnata. - L. } \\
-\quad & \text { pedata. - L. } \\
\text { - } & \text { ciliata. - Ait. } \\
& \text { TURNERACEA. }
\end{array}
$$

\section{TURNERACEA.}

TURNERA ulmifolia. $-\mathrm{L}$. PIRIQUETA jonidioides, - Rich. (nob.)

\section{GUGuRbitace $\boldsymbol{A}$.}

LUFFA acutangula. - Sering. BRYONIA Americana. - Lam.

- racemosa. $-\mathrm{Sw}$.

MOMORDICA balsamina. - L.

SECHIUM edule. - $\mathrm{Sw}$.

TRICERATIA bryonioides. - Rich. (nob.)

\section{PORTULACE $\boldsymbol{A}$}

TRIANTHEMA monogyna. - $\mathbf{L}$. PORTULACA microphylla. Rich. (nob.) SESUVIUM portulacastrum. - L.

- revolutifolium. - Ortega.

- microphyllum. - Wild.

TALINUM patens. - Wild.

CLAYTONIA perfoliata. - Dou.

\section{PHYTOLACE $\mathbb{E}$.}

RIVINA humilis. - $\mathbf{L}$.

TRICHOSTIGMA rivinoides. - Rich. (nob.) PETIVERIA alliacea. - Wild.

PHYTOLACGA decandra. $-\mathrm{L}$.

STEGNOSPERMA Cubense, -- Rich. (nob.)

\section{CACTE $/$ E.}

PERESKIA aculeata. - Haworth. portulacæfolia. - Haw.

RIPSALIS cassytha - Gœtn.

\section{UMBELLIFER $\boldsymbol{E}$.}

HYDROCOTYLE umbellata. - L.

$$
\text { - leptostachya. - Rich. }
$$

LRYNGIUM foetidum. - L ranunculoides. - L.

\section{ARALIACE}

PANAX undulata. - Aublet. HEDERA arborea. - Sw.

\section{LORANTHACEE.}

VISCUM buxifolium. - Lam.

- tereticaule, - DC.

- tetragonum. - DG.

LORANTHUS uniflorus. - Jacq.

\section{RUBIACE E.}

HILLIA longiflora. - Sw.

EXOSTEMA Caribæum. - Rœm. et Sch.

- longiflorum. - - Ræm. et Sch.

- parviflorum. - Rich.

- floribundum. - Rem.

-- nerifolium. - Rich. (nob.)

MANETIA Havanensis. - Kanth.

GALYCOPHYLLUM candidissimun. - DC.

AMAIOVA fagifolia. - Desf.

TOCOYENA Havanensis. - Rich. (nob.)

GENIPA Americana. - L.

- pubescens. -DC.

CASASIA calophylla. - Rich. (nob.)

GARDENIA Sagræeana - Rich. (nob.)

GONIANTHES Lindeniana. - Rich. (nob.)

$$
\text { - Sagræana. - Rich. (nob.) }
$$

CoccocypsiluM repens. - Sw.

CATESB EA latifolia, - Lindley.

- longispina. - Rich. (nob.)

- macrantha. - Rich. (nob.)

RONDELETIA odorata. - Jacq.

$$
\text { - Americana. }-\mathbf{L} \text {. }
$$

- microdon. - DC.

- $\quad$ alaternoides. - Rich. (nob.)

- lævigata. - Ait.

- Lindeniana. - Rich. (nob.)

- peduncularis. - Rich. (nob.)

- Berteriana. - DC.

- leptacantha. - DC.

HEDYOTIS glomerata. - Ellis.

RACHICALLIS rupestris. - DC.

GONZALEA spicata. - DG.

- brachyantha. - Rich. (nob.)

- leptantba. - Rich, (nob.)

HAMELIA patens. - Jacq.

- chrysantha. - Sw.

- brevillora. - Rich. (nob.)

ALIBERTIA edulis, - Rich.

ECHINODENDRUM campanulatum, - Rich. $(n o b$.)

MORINDA rojoc. - L.

- ferruginea. - Rich. (nob.)

GUETTARDA Havanensis. -- DC.

- ambigua. - DC.

- odorata. - Lam.

- Valenzuelana. - Rich. (uob.) 
GULTTARDA Lindeniana. - Rich. (nob.)

- $\quad$ rigida, - Rich. (nob.)

- calyptrata. - Rich. (nob.)

- resinosa. - Pers.

MELANEA lucida. - Rich.

- dichotoma. - Rich. (nob.)

CHIONE Cubensis. - Rich. (nob.)

ERITHALIS fruticosa. - L.

- angustifolia. - DC.

- pentagona. - DC.

SIDEROXYLUM floribundum. - Rich. (nob.)

CIOCOCCA racemosa. - Jacr.

FARAMEA occidentalis. - Rich.

COFFEA Arabica, - L

RONABEA didymocarpos. $-\Lambda$. Rich.

PSYCOTRIA chimarroides, - DC.

- Brawnei. - Spreng.

- floribunda. -. Kunth.

- glaucescens. - Kunth.

- pubescens. - Sw.

- Berteriana. - DC

- involucrata, - Rich. (nob.)

- obovalis. - Rich. (nob.)

- tubulosa. - Rich. (nob.)

herbacea. - L

PALICUREA crocea. - DG.

CEPH ELIS muscosa, - Sw.

SPERMACOGE tenuior. $-\mathrm{L}$.

- Portoricensis. - Balbis.

- tetraquetra. - Rich. (nob.)

- microcephala. - Rich. (nob.)

- regida. - Kunth.

- obscura - DC.

CRUSEA rubra. - Cham. et Sch. Richarosonia Cubensis. - Rich. (nob). MITRACARPUM Sagræanum. - DC.

$$
\begin{array}{ll}
\text { - } & \text { linearifolium. - Rich. (nob.) } \\
\text { - } & \text { diodioides. - Rich. }\left(n \circ b_{.}\right) \\
\text {- } & \text { crassifolium. - Rich. }(n o b .)
\end{array}
$$

\section{SYNANTHER $A$.}

SPARGANOPHORUS Vaillantii. - Gœetn. VERNONIA Hayanensis, - DC.

- menthæfolia. - Lessing.

- Sagræana. -DG.

- Valenzuana, - Rich. (nob.)

- gnaphalifolia. - Rich. (nob.)

LACHNORHIZA piloselloides. 一 Rich. (nob.

ELEPHANTOPUS mollis - Kunth.

DISTREPTUS spicatus. - Gass.

LAGASCEA mollis. - Gay.

PECTIS prostrata. - Gavan.

- Noribunda, - Rich, (nob.) Botanica.
PECTIS ciliaris. - L.

LORENTEA Cubensis, - Rich. (nob.)

AGERATUM conyzoides. $-\mathrm{L}$.

- matricarioides. - Lessing.

PHANIA multicaulis. - DC arbutifolia. - DC.

KUHNIA rosmarinifolia. - Vent.

CRITONIA pseudodalea. - DC.

HEBLECLINUM macrophyllum. - DC.

EUPATORIUM odoratum. - L

$$
\begin{aligned}
& \text { - heterophyllum. - Rich. (nob.) } \\
& \text { - reticulatum. - Rich. (nob) } \\
& \text { - conyzoides. - Vahl. } \\
& \text { - Ossceanum. - DG. } \\
& \text { - repandum. - Wild. } \\
& \text { - ivæfolicum. - L. } \\
& \text { - aromatisans. - DC } \\
& \text { - trichosanthum. - Rich. (nob.) } \\
& \text { - nudiflorum. - Rich. (nob.) } \\
& \text { - villosum. - Rv. } \\
& \text { - Cubense. - DC. } \\
& \text { - cynanchifolium. - DC. } \\
& \text { - Havanense. - Kunth. } \\
& \text { - cæltidifolium. - Lamarck. } \\
& \text { - Lindenianum, - Rich. (nob.) } \\
& \text { - coronopifolium. - Wild. } \\
& \text { - glumaceum. - DC. } \\
& \text { - Poppigii. - Spreng. }
\end{aligned}
$$

TRIPOLIUM augustum. - Lindl.

ERIGERON Canadense, - $\mathbf{L}$.

SOLIDAGO Lindeniana - Rich. (nob.)

GRANGEA Maderaspatana. - Poir.

CONYZA obtusa. - Kunth.

BACCARIS halimifolia. - $\mathbf{L}$.

PLUCHEA glabrata. - DC.

- odorata. - Cass

- purpuracens. - DC.

BORPICHIA arborescens. - DC

$$
\text { - argentea. - DC. }
$$

ECLIPTA erecta. - $\mathbf{L}$

LLVIRA biflora. - DC. 
CLIB ADIUM Havanense, - DC. PARTHENIUM hysterophorus. -5 XANTHIUM macrocarpum. - DC AMBROSIA cristhmifolia. - DG. - paniculata. - Rich. PINILLOSIA tetranthoides. $-\mathrm{DC}$ IVA cheiranthifolia. - Kunth. WEDELIA carnosa. - Rich.

- gracilis. - Rich.

- veronicifolia. - Rich. (nob.)

- reticulata -DC.

- acuminata. - DC

- serrata. - Rich.

MELANANTHER A hastata. - Rich.

- deltoidea - Rich.

- angustifolia.-Rich. (nob.)

WULFIA Havanensis. - DC.

VIGUIERA belianthoides. - Kunth.

- microdine. - DC. BIDEUS rubifolia. - Kunth.

- cynapifolia. - Kunth.

cosmos caudatus. - Kunth.

VERBESINA alata. $-\mathrm{L}$.

- serrata - Cav.

SPILANTHES oleracea. - Jacq.

- insipida - Jacq

XIMENESIA encelioides. - Cav.

SYNEDRELIA nodiflora. - Gretn.

GHRYSANTELLUM procumbens. - Rich.

FLAVERIA contraherba. - Pers.

- linearis. - Lag.

LEBETINIA cancellata. - Cass.

TETRACANTHUS linearifolius. - - Rich. (nob.)

POROPHYLLUM elipticum. - Cass.

$$
\text { - ruderale. - Cass. }
$$

TRIDAX procumbens. $-\mathbf{L}$.

EGLETES viscosa. - Lessing.

NEUROLENA lobata. - -R. Brown.

ERECHITES hieracifolia. - DC.

SENECIO discolor. - DC.

ANARTRAPHIA Licifolia. - Dow.

LERIA leiocarpa. - DC.

TRIXU Hayanensis, - Spreng.

\section{LOBIBIAC E.}

SIPHOCAMPYLUS Cubensis. - Rich. (nob.) LOBELIA cliffortiana. - Wild.

salvifolia. - Rich. (nob.)

ISOTOMA longiflora. - Presl.

\section{GOODENOVIACEA.}

ScoEvola Plumieri. - Vahl.
GESNERIACE E.

RYTIDOPHYLLUM crenulatum. - DC.

CONRADIA humilis. - Mart.

BESLERIA pulchella. - Don.

ALLOPLECTUS cristatus. - Mart.

COLUMNEA scaudens. $-\mathbf{L}$

\section{VACGINIACE}

THIBAUdia Cubensis. - Rich. (nob).

\section{ERIACEE.}

LEUCOTHOE myrsinefolia. - Rich. (nob.)

$$
\begin{aligned}
& -\quad \text { affinis. - Rich. (nob.) } \\
& \text { - } \quad \text { glandulosa. - Rich. (nob.) } \\
& \text { - latifolia. - Rich. (nob.) }
\end{aligned}
$$

CLETRA Cubensis. - Rich. (nob.)

CYRILLA Antillana. - Rich.

JASMINACE $E$.

CHIONANTHUS compacta. - Sw.

\section{MYRSINEACE E.}

MYRSINE Cubana. - Alp. DC.

- coriacea. - Rom. et Sch.

ARDISIA Cubana. - Alp. DC

ICACOREA dentata. - Alp. DG.

WALLENIA laurifolia. - Sw.

\section{THEOPHRASTACE $A$.}

JACQUINIA Berterii. - Spreng.

$$
\begin{aligned}
& \text { - linearis. - Jacq. } \\
& \text { - } \quad \text { ruscifolia. - Jacq. } \\
& \text { SAPO'T } \mathbf{A C E} \text { TL. }
\end{aligned}
$$

CHRYSOPHYLLUM Cainito. - L.

$$
\text { - } \quad \text { microphyllum. - DC. }
$$

DIPLOCALYX chrysophylloides. - Bich.

$$
\text { (nob.) }
$$

LUCUMA serpentaria. - Kunth.

- nervosa. - DC.

- mammosa, - Goetn.

- Valenzuelana. - Rich. (nob.)

SAPOTA achras. - Mill.

SIDEROXYLON pallidum. - Spreng.

BUMELIA nigra. $-\mathrm{S} w$.

- parvifolia. - DC.

DIPHOLIS salicifolia, - Alp. DC.

EBENACE.E.

DYOSPYROS laurifolia. - Rích.

APOCYNACE $/$.

ALLAMANDA cathartica. - L 
ODONTOSTIGMA Galeotianum. - Rich. $(n$. RAWOLFIA nitida. - L

$$
\begin{aligned}
& \text { - Cubana. - DC. } \\
& \text { - parvifolia. - Spreng. } \\
& \text { - canescens. - L. }
\end{aligned}
$$

THEVETIA nerifolia, - DC. TABERNAEMONTANA citrifolia. - L. PLUMERIA alba. - L.

MALONETIA Cubana. - DC.

VINCA rosea. - L

GAMERARIA latifolia. - Jacq.

FORSTERONIA corymbosa, - Meyer.

ECHITES umbellata. - Jacq.

- littorea. - Kunth.

- crassipes. - Rich. (nob.)

- repens, - Jacq.

- rosea. - DC.

- ferruginea. - $\mathbf{R}$.

- Sagræi. - DC.

- biflora. - Jacq.

- suberecta, -- Jacq.

- Valenzuelana. - Rich. (nob.)

- cinerea. - Rich. (nob.)

- calycosa. - Rich. (nob.)

- macrocarpa. - Rich. (nob.)

\section{ASCLEPIADACE $F$.}

ASTEPHANUS Cubensis. - Kunth.

$$
\text { - ovalifolius, - Rich. (nob.) }
$$

METASTELMA parviflorum, - Brown.

$$
\text { - Cubensis. - Decaisne. }
$$$$
\text { - linearifolium, - Rich. (nob.) }
$$

SARCOSTEMMA clausum. - Rœm. et Sch. ASCLEPIAS curasavica. - L.

$$
\text { - nivea. - L. }
$$

OXYPETALUM riparium. - Kunth.

GONOLOBUS Cubensis. - Rich. (nob.)

IB ATIA maritina. - Jacq.

FISCHERIA scandens. - DC.

$$
\text { - Havanensis. - Dne. }
$$

MARSDENIA agglomerata. Dne.

$$
\begin{aligned}
& \text { - affinis. - Rich. }(n o b .) \\
& -\quad \text { elliptica. - Dne. } \\
& \text { - } \quad \text { longiflora. - Rich. }\left(n o b_{.}\right) \\
& \text {- } \\
& \text { satureiæfolia. - Rich. }\left(n o b_{.}\right) \\
& \text {GENTIANNACE.E. }
\end{aligned}
$$

\section{GENTIANNACE.E.}

EUSTOMA exaltatum. - Lamk.

ERYTRAA ramosissima. - Pers.

SCHULTESIA stenophylla. - Mart.

LISIANTHUS glandulosus. - Rich. (nob.)

VOYRIA uniflora. - Lamark.

LIMNANTHENUM Humboldtianum.-Griseb.

\section{BIGNONHAEA.}

BIGNONIA simplex - Rich. (nob.)

- lepidophylla. - Rich. (nob.)

- microphylla. - Lam.

- Sagræana. - DC.

- gnaphalanthia. - Rich. (nob.)

PITHECOCTENIUM hexagonum, - DC.

SPATHODEA podopogon. - D. C.

TECOMA heptaphylla. - Martius.

- leucoxylon. - Mart.

- Lepidota. - DC

- stans. - Juss.

JACARANDA Sagraana, - DG.

CRESCENTIA cujete. - L.

- acuminata. - Kunth.

CORDIAE E.

CORDIA gerascanthoides. - Kunth.

- bracteata. -DC.

- speciosa. - Rom, et Schr.

- Galeottiana. - Rich. (nob.)

- angiocarpa. - Rich. (nob.)

- rariflora. - Rich. (nob.

- Valenzuelana. - R.

- adnata. - DC.

- ulmifolia. - Juss. v. lineata. D. G.

- cineracea. - DC.

- bullata. - L.

ERHETLA tinifolia. - L.

- Guatimalensis. - DC

- calophylla. - Rich. (nob.)

- bourreria. - L.

- divaricata. - D. C.

- cassinefolia. - Rich. (nob.)

- spinifex. - Roem. et Sch.

TOURNEFORTIA gnaphaloides. - Brown.

$$
\begin{array}{cl}
- & \text { scabra. - Lam. } \\
\text { - } & \text { hirsutissima. - L. } \\
\text { - } & \text { fotidissima. - L. } \\
- & \text { angustiflora. - Ruiz et } \\
\text { Pavon. } & \text { lævigata. - Lam. } \\
- & \text { Sagræana. - DC. } \\
- & \text { laurifolia. - Vent. } \\
\text { - } & \text { polyochros. - Spreng. } \\
\text { - } & \text { volubilis. - L. } \\
\text { - } & \text { inundatum. - Sw. } \\
\text { - } & \text { cinereum. - Kunth. } \\
\text { - } & \text { humifusum. - Kunth. } \\
\text { - } & \text { fruticosum. - Kunth. } \\
\text { - } & \text { parviflorum. - DC }
\end{array}
$$


SOLANACEA.

NICOTIANA tabacum. - L

- repanda. - Wild

DATURA stramonium. - L.

- metel. - L

- ceratocaula. - Ortega

SOLANDRA nitida. - Zucchar

PHYSALIS pubescens. - $\mathrm{L}$.

CAPSICUH conoides. - Mill.

- pendulum. - Wild.

SOLANUM tuberosum. - L.

- scandens. - L.

- pterocaulum. - Dunal.

- indecorum. - Rich. (nob.)

- radula. - Vahl

- verbascifolium. - L

- Havanense. - Jacq.

- nudum. - Dunal.

- lentum. - Dunal.

-. Bahamense. - L.

- aquartia. - Dunal.

- Jamaicense. - Sw.

- cuneifolium. - Dunal.

- melongena. - $\mathbf{L}$.

- torvum. - Sw.

- latifolium. - Poir

- Sagræanum. - Rich. (nob.)

CESTRCM diurnum. - L L

- nocturnum. - L'Herit.

- laurifolium. - L'Herit.

- ferrugineum. - Rich. (nob.)

\section{CONVOLVULACEA.}

QUAMOCLIT coccinia. - Mœnch.

$$
\text { - hederæfolia. - Choisy. }
$$

BATATAS littoralis. - Choisy.

- edulis. - Choisy.

- cissoides. - Choisy.

- pentaphylla. - Choisy.

- quinquefolia. - Choisy.

PHARBITIS calycosa. — Rich. (nob.)

- hispida. - Choisy.

- nil. - Choisy.

- heterophylla. - Choisy.

GALONYGTION speciosum. - Choisy.

- megalocarpum. - Rich. (nob.)

EXOGONIUM arenarium. - Choisy.

- repandum. - Choisy.

IPOM EA pescaprre. - Choisy.

- serpillifolia. - Choisy.

- argentifolia. - Rich. (nob.)

JACQUEMONTIA violacea. - Choisy.
CONVOLVULUS Valenzuelanus. -Rich. (nob.) - micranthus. - Rom. et Sch.

IPOMEA sinuata. - Ortega.

- tuberosa. - L.

- tamnifolia. - L.

- Havanensis. - Choisy.

- sidæfolia. - Choisy.

- umbellata. - Meyer.

- Ramoni. Choisy.

- commutata. - Rom. et Sch.

- triloba. - L.

JACOUEMONTIA violacea. - Choisy.

GONVOLVULUS micranthus. - Rœm. etSch

- ruderarius. - Kunth

- Valenzuelanus. - Rich. (nob.)

- Jamaicensis. - Jacq.

EVOLVUluS arbuscula. - Poir.

$$
\begin{aligned}
& \text { - incanus. - Pers. } \\
& \text { - } \quad \text { argenteus. }- \text { Pursh. } \\
& \text { - } \quad \text { nummularis. }-\mathbf{L} .
\end{aligned}
$$

CUSGUTA Americana. - L.

\section{HYDROLEACE $/$.}

HYDROLEA spinosa. - L

NAMA Jamaicensis, - $\mathbf{L}$.

\section{VERBENACEA.}

TAMONEA verbenacea. - Sw.

PRIVA echinata. - Juss.

VERBENA urticæfolia. - L.

officinalis, - L

BOUCHEA Ehrenbergï. - Cham.

STACHYTARPHETA Jamaicensis. - Vahl - mutabilis. - Vahl.

$$
\text { - } \quad \text { orubica. - Vahl. }
$$

LIPPIA strchadifolia. - Kunth

- canescens. - Kunth.

- nodiflora. - Rich.

- dulcis. - Trev.

LANTANA camara, - L

- trifolia. - L

- involucrata. - L.

- microcephala. - Rich. (nob.)

- reticulata. - Pers.

CITHAREXYLUM villosum. - Jacq.

$$
\begin{aligned}
& \text { - } \quad \text { subserratum. - Sw. } \\
& \text { - } \quad \text { caudatum. - L. } \\
& \text { - } \quad \text { quadrangulare.- Jacq. }
\end{aligned}
$$

DURANTA Plumieri. - Jacq.

PETREA volubilis, - Jacq.

PETETEA Pœppigii. - Schaner.

CALLICARPA reticulata. - $\mathrm{Sw}$.

- ferruginea, - Sw 
CALLICARPA fulva. - Rich. (nob.)

- cinerea. - Rich. (nob.)

EGIPHYLLA Martinicensis, - L.

- macropbylla. - Kunth.

VOLKAMERIA aculeata. - L.

GLERODENDRON Cubense. - Schau.

- Sagrai. - Schauer.

- tuberculatum. - Rích. (nob.)

- Lindenianum. - Rich. (nob.)

ESPADÆA amcna. - Rich, (nob.)

VITEX ilicifolia. - Rich. (nob.)

- divaricata. - Sw.

- avicennioides. - Rich. (nob.)

AVICENNIA nitida, -Jacq.

- tomentosa. - Jacq.

\section{SCROPHULARIACE $/$ E.}

SCHWENKIA Americana. - L.

BRUNSFELSIA cestroides. - Rich. (nob.)

- simuata. - Rich. (nob.)

- nitida. ? - Benth.

- parvifolia. - Rich. (nob.)

ANGELONIA salicariæfolia. - Humb. et Bonp.

MAURANDIA antirrhiniflora. - Wild.

RUSSELIA sarmentosa. - Jacq.

STEMODIA maritima. - L.

- durantifolia. - Sw.

HERPESTIS chamædryoides. - Kunth.

- monnieria. - Kunth.

- obovata. - Popp.

CAPRARIA biflora.

SCOPARIA dulcis, - L

BUDDLEIA Americana. - L.

BUCHNER A Americana. - L.

\section{LABIAT E.}

HYPTIS capitata. - Jacq.

- criocauloides. - Rich. (nob.)

- pectinata. - Port.

SALVIA microphylla. - Kunth.

- occidentalis. - Sw.

- micrantha. - Vahl.

- serotina. - L.

SCUTELlaRIA Cubensis. - Rich. (nob.)

LEONURUS Sibericus. - L.

LEONITIS nepetæfolia. - Brown.

TUNGRIUM Cubense. - L.

\section{ACANTHACER.}

GALOPHANES Cubensis. - Rich. (nob.) DIPTERACANTHUS nanus, - Nees.

. Botanica.
GRYPHIAGANTHUS Barbadensis. - Nees.

BARLERIA Solanifolia. - L.

STENANDRIUM droseroides. - Nees.

GRAPTOPHYLLUM hortense. - Nees.

RHYTIGLOSA Havanensis, - Nees.

$$
\text { - Sagræana. - Rich. (nob.) }
$$

ADHATODA vasica. - Nees.

ANTHACANTHUS microphyllus. - Nees.

BLECTUM Brownei. - Juss.

DICLIPTERA sexangularis. - Juss.

- Vahliana. - Nees.

PRUMULACE $/$.

SAMOLUS Valerandi. - L.

- ebracteatus. - Kunth.

LEXTIBULARIACE $A$.

UTRICULARIA obtusa. - Sw.

PLUMBAGINACE.E.

PLUMBAGO scandens. - L.

\section{NICTAGINACE $A$ E.}

NICTAGO hortensis. - Juss.

PISONIA aculeata. - L.

- obtusa. - Sw.

BOERHAAVIA paniculata. - L.

$$
\begin{aligned}
& \text { - } \quad \text { polymorpha. - Rich. } \\
& \text { - viscosa. - Lagas. } \\
& \text { - } \quad \text { scandens. - L. }
\end{aligned}
$$

\section{AMARANTHACEA.}

CELOSIA paniculata. - L.

- virgata. - Jacq.

$$
\text { - } \quad \text { argentea. - Moquin.-'Г. }
$$

CHAMISOA altissima. - Kunth.

AMARANTHUS paniculatus. - Moq.

$$
\text { - spinosus. - L. }
$$

AMBLOGYNA polygonoides, - Rafin. EULOXUS caudatus. - Moquin.-T.

ACHYRANTHES fruticosa. - Moquin-T.

- nirtiflora. - Rich. (nob.)

IRESINE vermicularis, - Moquin.-T.

- crassifolia, - Moquin.-T.

- aggregata. - Moquin.-T.

- elatior. - Richard.

- gracilis. - Martins et Galeotti.

- Mutisii. - Kunth.

- parvillora. - Kunth.

- Havanensis. - Kunth.

- obtusifolia. - Kunth.

- ? gossypiantha. - Rich. (nob.)

ALTERNANTHERA spinosa, - Rœm. et Sch.

TELANTHERA polygonoides. - Moquin.

GOMPHRENA decumbens, - Jacq. 


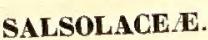

CHENOPODIUM album. - Moquin.-T.

- ambrosioides. - L.

CHENOPODINA maritima, - Moquin.-T.

CRYPTOCARPUS globosus. - Kunth.

OBIONE cristata. - Moquin. T.

SALICORNIA fruticosa, - L

AUREDERA spiccata. - Pers.

\section{POLYGonace E.}

POLYGONUM truncatum. - Rich. (nob.) michranthum. Rich. (nob.)

RUMEX acutus. - L

COCCOLOBA uvifera. - Jacq.

- coriacea. - Rich. (nob.)

\section{LAURACE $F$.}

PHOEBE Cubensis. - Nees.

- Valenzuelana. $\rightarrow$ Rich. (nob.)

- bypoleuca. - Rich. (nob.)

PERSEA gratissima. - Gœtn.

- silvestris. - Rich. (nob.)

- cinnamomifolia - Kunth.

AYDENDRON? Cubense. - Rich. (nob.)

NECTANDRA cigua, - Rich. (nob.)

- boniato. - Rich.

- ? longifolia. - Rich. (nob.)

- 8 magnoliæfolia.-Rich. (nob.) OREODAPHNE'? obovata. - Rich. (nob.)

- Lindeniana. - Rich. (nob.)

- ? alba. - R.

SYMPHYSODAPHNE Cubensis. -Rich. (nob.) CASSYTA Americana.-Nees.

\section{DAPHACEA.}

LAGETTA lintearia، - Lam.

- Valenzuelana, - Rich. (nob.)

HARGASSERIA Cubana. - Rich. (nob.)

ARISTOLOCHIACE E.

ARISTOLOCHIA tigrina, - Rich. (nob.)

\section{- pentandra? - Jacq. \\ - passifloræfolia,-Rich. (n.)}

EUPHORBLACE $A$.

PEDILANTHUS tithymaloides. - Poit. EUPHORBIA tríchotoma. - Kunth.

$\begin{array}{ll}\text { - } & \text { glabrata. - Sw. } \\ \text { - } & \text { buxifolia. - Kunth. } \\ \text { - } & \text { centunculoides. - Kunth. } \\ \text { - } & \text { callitrichoides. - Kunth. } \\ \text { - } & \text { Lindeniana. - Rich. (nob.) } \\ \text { - } & \text { heterophylla. - L. }\end{array}$

EUPHORBIA trachyphylla. - Rich. (nob.)

- dumosa. - Rich. (nob.)

- pedunculosa. - Rich. (nob.)

- hypericifolia. - L.

- Berteriana. - Balbis.

DELECHAMPIA scandens, - L.

EXCACARIA lucida. - Sw.

HURA crepitans. - L

HIPPOMANE mancinella. - L.

BONANIA Cubana. - Rich. (nob.)

STILLINGIA sebifera, - Rich.

- laurifolia. - Rich. (nob.)

- eglandulosa. - Rich. (nob.)

MIGROSTACHYS Vahlii. - Rich. (nob.)

TRAGIA volubilis, - L.

- urens, - L.

ACALYPHA corchorifolia. - Wild

$$
\begin{aligned}
& \text { - } \quad \text { setosa. - Rich. (nob.) } \\
& \text { - alopecuroidea. - Jacq. } \\
& \text { - membranacea. - Rich. (nob.) } \\
& \text { - leptostachya. - Kunth. } \\
& \text { - glechonæfolia. - Rich. (nob.) } \\
& \text { - pygmæa. - Rich. (nob.) }
\end{aligned}
$$

OMPHALEA diandra. - L

ALEURITES triloba. - Jorst.

JATROPHA panduræfolia. - Andrews.

- gossypifolia. - L.

- multifida. - L.

- fragrans. - Kunth.

CURCAS indica, - Rich. (nob.)

MANIHOT edule. - Rich. (nob.)

RICINUS communis, - - L.

ADELIA microphylla. - Rich. (nob.)

- pedunculosa. - Rich. (nob.)

CROTON cascarilla. - L

- lucidum. - L.

- penicillatum. - Vent.

- nummulariæfolium. - Rich. (nob.)

- vaccinioides. - Rich. (nob)

- hippophaleoides. - Rich. (nob.)

- Lindenianum. - Rich. (nob.)

- ellipticun. - Rich. (nob.)

- fulvum. - Rich. (nob.)

- Domingense. - Valh.

CAPERONIA castaneæfolia. - Aug. St-Hil.

$$
\text { - nervosa. - Rich. (nob.) }
$$

GEISLERIA glandulosa. - Klotsch. ASTR EA lobata. - Klotsch.

ARGYTHAMNLA caudicans. - Sw.

PHYLLANTHUS falcatus. - Sw.

$$
\begin{aligned}
& \text { - } \quad \text { Carolinensis. - Rich. } \\
& \text { - } \left.\quad \text { micranthus. - Rich. }{ }^{n} \boldsymbol{n}^{\circ} \text {. }\right) \\
& \text { - } \quad \text { orbicularis. - Kunth. } \\
& \text { - } \quad \text { pruinosus. - Pœppig. }
\end{aligned}
$$


PHYLLANTHUS laurifolius, - Rich. (nob.)

- pubigerus. - Rich. (nob.)

TRICERA Cubana. - Rich. (nob.)

DRYPETES alba. - Poiteau.

- glauca. - Vahl.

\section{URTICACEA.}

CELTIS micrantha, - Sw.

- parvifolia. - Rich. (nob.)

MERTENSIA lævigata. - Kunth.

BROUSSONETIA tinctoria. - Kunth, FICUS populnea, - Wild.

- pertusa. - L.

- trigona. - K. fil.

- venusta. - Kunth.

- jacquiniæfolia. - Rich. (nob.)

- radula. - Wild.

CEGROPIA peltata. - Wild.

TROPHIS Americana. - L.

URTIGA nemorosa. - Kunth.

- baccifera. - L.

- cuneata. - Rich. (nob.)

- ciliata. - Sw.

- lanceolata. - Lamck.

- Lindeniana. - Rich. (nob.)

- callitrichoides. - Kunth.

BOEHMERIA littoralis. - Sw.

\section{PIPERACE E.}

PIPER aduncum. - Mill.

- umbellatum. - L.

- peltatum. - L

- verrucosum. - Sw.

- plantagineum. - Lam.

- articulatum. - Rich. (nob.)

- leptostachyum. - Rich. (nob.)

PIPEROMIA reflexa. - Miguel.

- nummulariæfolia. - Kunth.

- rotundifolia. - Kunth.

- acuminata. - Rich.

- lineatipila. - Rich. (nob.)

\section{CUPULIFERA.}

QUERCUS Cubana. - $\mathbf{R}$.

\section{JUGLANDACE E.}

JUGLANS cinerea. - L.

MYRICACEA

MYRICA Carolinensis, - Mill.

SALICACEAE.

SALIX Humboldtiana. - Wild.
CONIFER $A$.

PINUS occidentalis. - Sw.

CYCADACEM.

SAMIA integrifolia. - Wild.

ORCHIDACE $/$.

PLLUROTHALLIS ? pachyrachis, - Rich. (u.)

- Valenzuelana. - Rich. (nob.)

EPIDENDRUM lacerum. - L

- Sagræanum. - Rich. (nob.)

- fulcatum. - Lindl.

- hircinum - Rich. (nob.)

- ionosmum. - Lindl.

- oxypetalum. - Lindl.

- affine. - Rich. (nob.)

- ochrantum, - Rich. (nob.)

- nematocaulon. - Rich. (nob.)

- boothitanum. - Lindl.

- pyriforme. - Lindl.

- Phoniceum. - Lindl.

- Duboisianum, - Brong. (ns)

- oblongatum. - Rich. (nob.)

- plicatum. - Lindl.

- cochleatum. - L.

- amphistomum. - Rich. (nob.)

- rigidum. - Jacq.

- nocturnum. - Jacq.

BLETIA patula. - Hook.

- Havanensis, - Lindl.

- tenera. - Rich. (nob.)

L.ELIA Lindenii. - Lind!.

ANGRACUM Lindenii. - Lindl.

BRASSIA Lawrenceana. - Lindl.

- caudata. - Lindl.

ONGIDIUM Guibertianum. - Rich. (nob.)

- intermedium, - Knowles.

- altissimum. - Sw.

- pulchellum. - Hook.

- variegatum. - Sw.

- lemonianum. - Lindi.

JONOPIS pulchella. - Kunth. POLYSTACHYA luteola. - Hook.

?- membranacea. - Rich. (n.) RHYNCHADENIA Gubensis. - Rich. (nob.)

GHIESBREGHTIA calantoides, - Rich.

HABENARIA tricuspis, - Rich. (nob.)

- macroceras, - Spreng.

- bicornis. - Lindl.

- replicata. - Rich. (nob.)

VANILLA aromatica. - $\mathbf{S} w$.

PONTHIEVA petiolata, - LindI.

- lancifolia. - Rich. (nob.) 
44

SPIRANTHES tortilis. - Rich.

- orchioides. - Rich. (nob.)

- speciosa. - Rich. (nob.)

PHYSURUS Sagræanus. - Rich. (nob.)

\section{ZINGIBERACE $A$.}

ZINGIBER officinale. - Roscoe. RENEALMIA racemosa. - Rich. (nob.)

$$
\text { - amøna. - Rich. (nob.) }
$$

- occidentalis. - Rich. (nob.)

COSTUS spiccatus. $-\mathrm{S} w$.

\section{CANNACEE.}

THALIA geniculata. - Plum. MARANTA arundinacea. - Wild. CANNA indica. - Roscoe.

- glauca. - Roscoe.

MUSACE $R$.

MUSA paradisiaca. - L.

- sapientium. - L.

BALANOPHORACE $\boldsymbol{E}$.

HELOSIS Jamaicensis. - Rich.

AMARYLLIDACE $/$ E.

AMARYLLIS carnea. - Rom, et Sch.

CRINUM erubescens. - Ait.

PANCRATIUM Caribæum. - L.

AGAVE Americana. - L.

- spiccata. - Cavan.

FOURCROYA Cubeusis. - Haw

ALSTROEMERIA salsilla. - $\mathbf{L}$.

\section{BROVIELLAE $/$.}

PITCAIRNIA pendulifora. - Rich. (nob.) BROMELIA pinguin. - L.

$$
\text { - karatas. - L. }
$$

ANANASSA sativa. - Lind. GUZMANIA tricolor. - Ruiz et Pavon. TILLANDSIA usneoides. - $\mathbf{L}$.

$$
\begin{array}{ll}
\text { - } & \text { recurvata. - L. } \\
\text { - } & \text { breviscapa. - Rich. (nob.) } \\
\text { - } & \text { bulbosa. - Hook. } \\
\text { - } & \text { pulchella. - Hook. } \\
\text { - } & \text { tenuifolia. - L. } \\
\text { - } & \text { polystachya. - L. } \\
\text { - } & \text { fasciculata. - Sw. } \\
\text { - } & \text { Valenzuelana. - Rich. (nob.) } \\
\text { - } \quad \text { Balbisiana. - Schultes. } \\
\text { - } \quad \text { canescens. - Sw. } \\
\text { - } \quad \text { aloifolia. - Hook. }
\end{array}
$$

DIOSCOREACEA

RAJANIA mucronata. - Wild.

- cordata. $-\mathrm{L}$
INTRODUCCION.

RAJANIA hastata. - L.

DIOSCOREA alata. - L.

- bulbifera. - L.

SMILACACEE.

SMILAX Havanensis. - Rich. (nob.)

- syphilitica? - Wild.

- triplicinervia. - Wild

- pseudochina. - L.

DIANELLA Cubensis. — Rich. (nob.)

PONTEDERIACE $\boldsymbol{A}$.

HETERANTHERA limosa - Vahl. EICHORNIA azurea. - Kunth.

- cordifolia. - Rich. (nob.)

COMMEL YNACE $\boldsymbol{A}$.

coMuELYNA Cayennensis. - Rich$$
\text { - angustifolia. - Mich. }
$$

TRADESCANTIA discolor. - Smith.

PALMTE.

OREODOXA oleracea. - Mart. regia. - Kunth.

COPERNICIA hospita. - Mart. ? maritima. - Mart.

THRINAX multiflora. - Mart.

- yuraguana. - Rich. (nob.)

SABAL umbraculifera. - Mart.

- palmeto. - Lodd.

cocos nucifera. - L.

- crispa. - Kunth.

\section{ARACE $E$.}

ANTHURIUM crassinervium - Schott

$$
\text { - palmatum. - Kunth. }
$$

- cordifolium. - Kunth.

XANTHOSOMA sagittifolium. - Schott ANDROMYCIA Cubensis, - Rich. (nob. PISTI occidentalis. - Blume.

\section{TYPHACE E.}

TYPHA angustifolia. - L.

\section{CYPERACE/E.}

CYPERUS humilis. - Kunth.

- compressus. - L.

- viscosus. - Ait.

- vegetus. - Wild.

- Surinamensis. - Rottb.

-. filiculmis. - Rich. (nob.)

- auriculatus. - L.

- rotundus. - L.

- ligularis. - L. 


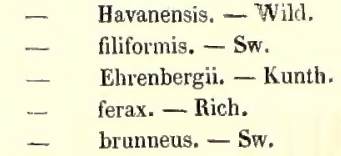

MARISCUS filiformis. - Spreng. KILLINGIA pumila. - Michaux.

- cruciformis. - Schrad.

ELEOCHARIS capilacea, - Kunth.

- capitata. - R. Brown.

- interstincta. - R. Browa.

SCIRPUS lacustris. - $\mathrm{L}$.

FUIRENA squarrosa. - Michaux.

- simplex. - Vahl.

FIMBISTYLIS laxa. - Vahl.

$$
\begin{aligned}
& \text { - } \quad \text { conferta. - Rich. (nob.) } \\
& \text { - } \quad \text { spadicea. - Vahl } \\
& \text { - } \quad \text { stans. - Rich. }
\end{aligned}
$$

DICHROMENA puberula. - Vahl.

$$
\begin{aligned}
& \text { - } \quad \text { setacea. - Kunth. } \\
& \text { - } \quad \text { Cubensis. - Pæp. }
\end{aligned}
$$

RHYNCHOSPORA cephalantha. - Rich. (n.)

$$
\text { - Cubensis. - Rich. (nob.) }
$$

CLADIUM mariscus, - R. Brown.

SCLERIA filoformis. - Swartz.

$$
\text { - scindens, - Nees. }
$$

- oligantha? - Michx.

ORlZA sativa. - I

PHARUS scaber. - Kunth.

- glaber. - Kunth.

ZEA mays. - L.

GOIX lachryma. - L.

PASPALUM conjugratum. - Berg

-. inflatum. - Rich. (nob.)

- foliosum. - Kunth.

- alterniflorum. - Rich. (nob.)

- Lindenianum. - Rich. (nob.)

- virgatum. - $\mathbf{L}$.

STENOTAFRUM Americanum. - Schrank.

OLYRA latifolia. - L.

- pauciflora. -- Sw.

PANicuM paspaloides. - Pers.

- colonum. - L.

- postratum. - Lanarck.

- pilosum. - Sw.

- distichum. - Lamarck.

-_ sanguinale. - L.

- fuscum. - Sw.

- distantiflorum. - Rich. (nob.)

- Valenzuelanum. - Rich. (nob.)

- pubescens. - Lamarck.

- minutiflorum. - Rich. (nob.) botavica.
- virgatum. - L.

- hirsutum. - Sw.

- obtusiflorum. - Rich. (nob.)

- trichoides. - Sw.

- myurus. - Lamarck.

- saccharoides. - Rich. (nob.)

- glutinosum. - Sw.

- ruscifolium. - Kunth.

OPLISMENUS undulatifolius. -Rom. et Sch.

- hirtellus. - Ræm. et Sch.

- loliaceus. - Beauv.

- crus galli. - Kunth.

SETARIA glauca, - P. Beauv.

- flava. - Kunth.

- Inacrostachya. - Kunth.

CENCHRUS echinatus. - L.

ANTHEPHORA elegans. - Schreb.

PIPTATHERUM setosum. - Rich. (nob.)

STREPTACHNE Gubensis. -- Rich. (nob.)

SPOROBOLUS Virginicus. - Kunth.

\section{- Indicus. - R. Brown}

- Domingensis. - Kunth.

POLYPOGON Cubensis. - Rich. (nob.)

CYNODON dactylon. - Pers.

CHLORIS ciliata. - Sw.

- radiata. - Sw

- cruciata. - Sw.

- Sagræana. - Rich. (nob.)

DACTYLOCTENIUM Egyptiacum. - Wild.

EUSTACHYS petræa. - Desvx.

LEPTOCHLOA filiformis. - Rœm. et Sch.

ELEUSINE Indica. - Getn.

EUTRIANA juncifolia. - Kunth.

POA pilosa - L.

- ciliaris. - L.

FESTUGA polystachya. - Michx.

$$
\text { -_ laxiflora. - Rich. (nob.) }
$$

MANISURIS granularis. - Sw.

ANDROPOGON scoparius. - Michx.

$$
\begin{array}{ll}
\text { - } & \text { ischæmum. - L. } \\
\text { - } & \text { bicornis. - L. } \\
\text { - } & \text { macrurus. - Michx. } \\
\text { - } & \text { Schænanthus. - L. } \\
\text { - } & \text { Halepensis. - Sibth. }
\end{array}
$$

SACHARUM officinarum. - L.

\section{ALISMACE $/$ E.}

LIMNOCHARIS Plumierii. - Rich. SAGITTARIA sagittifolia. - L.

$$
\text { - lanceolata. - L. }
$$

\section{NAIADACE $F$.}

PAT INOGETON Jucens, - $\mathbf{L}$. 


\section{CRIPT0GAIIIA.}

\section{ALG $\mathbf{E}$. PHYCE 2 .}

STYLARIA cuneata, - Ag. DIATOMA tenue. - Ag. DIDULPHIA Australis. - Montag. (nob.) CHLOROCOCGUM murorum? - Grev. MICROCOLEUS maritimus. - Bory, SCYTONEMA? rubrum. - Montag. (nob.)

$$
\text { - byssoideum. - Ag. }
$$

CONFERVA fascicularis. - Mert.

- riparia. - Dillw.

- brachyclados. - Nontag. (nob.)

- implexa. - Dillw.

- linum. - Roth.

- ægagropila. - L.

BRYOPSIS ramulosa, - Montag. (nob.)

CAULERPA fastigiata. - Montag. (nob.) ENTEROMORPHA clathrata. - Grev.

ULVA lactuca. - L.

ANADYOMENE stellata. - Ag.

CALLITHAMNION repens. - Lyngb. GERAMIUM clavulatum. - Ag.

$$
\text { var, tenellum. - Lyngb. }
$$

- diaphanum. - Roth.

- filamentosum. - Ag.

- rubrum. - Ag.

POSYSIPHONIA secunda. - Montag.

$$
\text { - Habanensis. - Mont. (nob.) }
$$

RHODOMELA calamistrata. -Montag. (nob.) CHONDRIA intricata. - Montag.

$$
\text { - thyrsoidea. - Mart. }
$$

$$
\text { - muscoides. }-\Lambda \mathrm{g} \text {. }
$$

SPHOEROCOCCUS multipartitus. - Ag.

$$
\begin{array}{ll}
- & \text { rigidus. }-\mathrm{Ag} . \\
- & \text { radicans. }- \text { Bory. } \\
- & \text { corneus. }-\mathrm{Ag} . \\
- & \text { corallopis. - Mont. (nob.) } \\
- & \text { acicularis. - Ag. } \\
- & \text { spinellus. }-\mathrm{Ag} . \\
-\quad & \text { purpuracens. }-\mathrm{Ag} . \\
- & \text { musciformis. }-\mathrm{Ag} .
\end{array}
$$

THAMNAPHORA triangularis. - Ag.

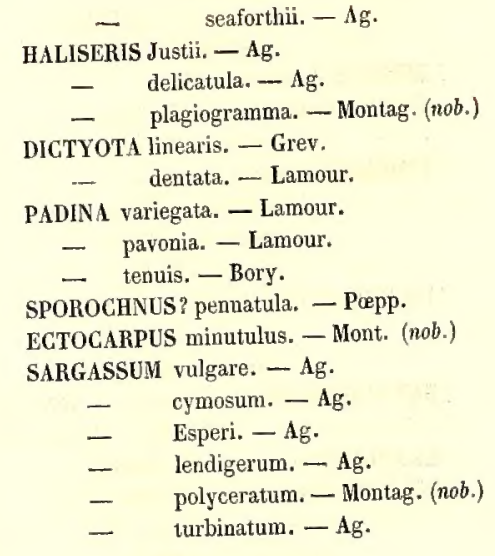

\section{BYSSACEE.}

COENOGONIUM Linkii. - Ehrenb. COLEMA chloromelum. - Ach.

LEPTOGIUM tremelloides. - Montag. (nob.)

- azureum. - Montag.

- marginellum. - Montag.

\section{LICHENES.}

STRIGULA Feei. - Montag.

- nitida. - Montag. (nob.)

- complanata. - Montag.

- rotula. - Montag. (nob.)

- nemathora. - Montag.

VERRUGARIA epidermidis. - Fr.

$$
\begin{array}{ll}
\text { - } & \text { pusilla. - Ach. } \\
\text { - } & \text { variolosa. - Montag. } \\
\text { - } & \text { tropica. - Ach. } \\
\text { - } & \text { tetraceræ. - Ach. } \\
\text { - } & \text { Catervaria. - Fée. }
\end{array}
$$

PORODOTHION Acharii. - Montag. TRYPETHELIUM anacardii. - Fée.

- porosum. - Ach.

PERTUSARIA desquamescens. - Montag.

- entophlæa. - Montag. (nob.)

- Americana. - Montagne. 
CHIODECTON lacteum. - Fée.

$$
\text { - Feei. - Meissner. }
$$

THELOTREMA Aubertianum. - Mont. (nob.

- olivaceum. -- Montag. (nob.)

- babianum. - Ach.

CONIOGARPON cinnabarinum. - DC

$$
\text { - Antillarum. - Fée. }
$$

FISSURINA nitida. - Montag.

$$
\text { - incrustans. - Fée. }
$$

USTALIA Caribæa. | Montag.

LECANACTIS punctiformis.-Eschw.

GRAPHIS Virginea, - Montag.

- Afzelii. - Ach.

- Leprevostii. - Montag

OPEGRAHA scripta.-Ach.

$$
\begin{aligned}
& \text { - inæqualis. - Fée. } \\
& \text { - Comma. - Ach. } \\
& \text { - } \quad \text { prosodea. - Ach. } \\
& \text { - } \quad \text { leptocarpa. - Montag. } \\
& \text { - } \quad \text { intricata. - Montag. } \\
& \text { - } \\
& \text { filicina. - Montag. (nob.) }
\end{aligned}
$$

GLYPHIS parvulosa. - Ach.

PIXINE sorediata. - Fr.

LECIDEA parasema. - Ach.

$$
\text { - parmelioides. - Hook. }
$$

BIATORA vestita, - Montag. (nob.)

- vernalis, - Fr.

- pusilla. - Montag. (nob.)

CLADONIA squamosa. - Flærke.

- coniocrea. - Herka.

- rangiferina. - Hoffin.

PARMELIA Valenzueliana. - Montag. (nob.)

- rufusca. - Fr.

- atra. - Ach. Meth.

- punicea. - Ach.

- varia. - Fr.

- gyrosa. - Montag.

- parvifolia. - Montag.

- corallina. - Montag. (nob.)

- gossypina. - Montag.

- pannosa.- Ach.

- picta. - Ach

- applanata. - Fée.

- Domingensis. - Ach.

- obsessa. - Ach.

- sulfurata. - N. et Flw.

- perlata. - Ach.

- parietina. - Duf.

STICTA quercizans. - Delise.

RAMALINA rigida. - Acharius.

EVERNIA flavicans. - $\mathrm{F}$ :

- furcellata? - $\mathrm{Fr}$

\section{FUVGI.}

\section{CONIOMYCETES.}

PUCCINIA graminis. - Pers.

$$
\text { - plagiopus, - Montag, (nob.) }
$$

TORULA orthoclada. - Montag. (nob.)

PERIOLA sphœriæformis.-Montag. (nob.)

\section{HYPHOMYCETES.}

FUSISPORIUM cylindricum. - Montag. (nob.)

$$
\text { - carneum. - Montag. (nob.) }
$$

DeMatuU gramineum. - Pers.

HELMINTHOSPORIUM dorycarpum.- Mont. (nob.)

ZIGOSPORIUM oscheoides. - Montag. (nob.) ASPERGILLUS candidus. - Link.

EUROTIUM herbariorum. - Link.

MUCOR croceus. - Montag. (nob.)

STILBUM cinnabarinum. - Montag, (nob.)

ISARIA gigantea. - Montag. (nob.)

\section{GASTEROMYCETES.}

STEMONITIS fusca. - Roth.

$$
\text { - typhoides. - DC. }
$$

DIDYMIUU crustaceum. - Fries.

$$
\text { - polymorphum. - Montag. (nob.) }
$$

ATHALIUM septicum. - Fries.

LYCOGALA epidendrum. - Fries.

TULOSTOMA exasperatum. - Montag. (nob.) HIPPOPERDON crucibulum. - Mont. (nob.) NIDULARIA intermedia. - Montag. (nob.)

\section{PYRENOMYGETES.}

GRAPHIOLA Phœnicis, - Poiteau. MICROPELTIS applanata. - Montag. (nob.) MELIOLA amphitricha. - Montag. (nob.) STIGMEA submaculans. - Montag. (nob.) DOTHIDEA corallina. - Montag. (nob.) DIPLODIA atra. - Montag.

-- anomala. - Montag. (nob.) SPHÆRIA pityrodes. - Montag. (nob.) HYPOCREA perpusilla. - Montag. (nob.)

$$
\text { - citrina. - Montag. Pers. }
$$

HYPOXY LON bomba. - Montag. (nob.)

$$
\begin{array}{ll}
\text { - } & \text { ustulatum. - Bull. } \\
\text { - } & \text { concreticum. - Grev. } \\
\text { - } & \text { Gonopus. - Montag. Fries. } \\
\text { - } & \text { Sagræanum. - Mont. (nob.) } \\
\text { - } & \text { Bacillum. - Montag. (nob.) } \\
\text { homatostroma. - Montag. } & \text { (nob.) } \\
\text { - } & \text { polyspermum. - Mont. (nob.) }
\end{array}
$$


HYPOXYLON OEdipus. - Montag.

$$
\begin{array}{ll}
- & \text { Cubense. - Montag. (nob.) } \\
- & \text { allantodium.-Montag. Berk. } \\
- & \text { scruposum. - Montag. Fries } \\
- & \text { dichotomum. - Mont. (nob.) } \\
- & \text { polymorphum.-Mont. Pers. }
\end{array}
$$

\section{DYSCOMYCETES.}

STICTIS thelotrema. - Montag. (nob.) LEPTOSTROMA ochidearum. - Mont. (nob.) RHYTISMA gyrosum. - Montag. (nob.) - maculans. - Montag. (nob.)

PHACIDIUM? tetraceræ. - Rudolphi. HYSTERIUM rufulum. - Spreng. PEZIZA leucorrhodina. - Montag. (nob.)

- anomala. - Pers.

\section{HYMENOMYCETES.}

EXIDIA fusco-succinea. - Montag. (nob.)

$$
\text { - polytricha. - Montag. (nob.) }
$$

HYPOCHNUS holoxanthus. - Montag. (nob.)

- ?albo-cinctus. - Montag. (nob.)

- nigro-cinctus. - Ehrenb.

- rubro-cinctus. - Ehrenb

GUEPINIA spathularia. - Fries. CORTICUM incarnatum. - Fries.

- Auberianum. - Montag. (nob.)

AURICULARIA lobata. - Fries.

STEREUM papyrinum. - Montag. (nob.)

TELEPHORA aurantiaca. - Pers.

FAvoLUS Brasiliensis. - Fries.

- cuculatus. -. Montag. (nob.)

HEXAGONIA polygramma. - Montag. (nob.) DEDALEA discolaor. - Fries.

- sanguinea. - Klotzsch.

- repanda. - Pers.

GLOEOPORUS conchoides. - Montag. (nob.) POLYPORUS vulgaris. - Fries.

- $\quad$ labellum. - Montag. (nob.)

- sector. - Ehrenb.

- pinsitus. - Fries.

- byrsinus. - Montag. (nob.)

- Lundii. - Fries.

- versicolor. - Fries.

- myrrhinus, - Kickx.

- occidentalis. - Klotzsch.

- velutinus. - Fries.

- palido.cervinus. - Schwz?

- pruinatus. - Klotzsch.

Valenzuelianus. - Mont. (nob.)

Auberianus, - Montag. (nob.)

licnoides. - Montag. (nob.)

senex. - Nees. Montag.
POLYPORUS nigricans. - Fries.

- Australis. - Fries.

- Gubensis. - Montag. (nob.

- labyrinthicus. - Fries.

- hydnoides. - Fries.

- adustus. - Fries.

- fumosus. - Fries.

- gilvns. - Fries.

- Sagræanus. - Montag. (nob.)

- sanguineus. - Meq.

- lucidus. - Fries.

- tricholoma. - Montag. (nob.)

pacbypus. - Montag. (nob.)

melanoporus. - Mont. (nob.)

- micromegas. - Montag. (nob.

- omalopilus. - Montag. (nob.)

SCHIZOPHYLLUM commune. - Fries.

LENTINUS eugrammus, - Montag. (1nob.)

- friabilis. - Fries.

- velutinus. - Fries.

- Lecomtei, - Fries.

- glabratus, - Montag. (nob.)

MARASMIUS hœmatocephalus. - Mont. (nob.) AGARICUS hyemalis. - Osbeck.

ERINEUM sepultum. - Kunze̊.

- calabœ. - Kunze.

\section{MUSCINAE.}

\section{HEPATICA}

PLAGIOCHILA distinctifolia. - Lindg

- Javanica. - Nees. Mont

- $\quad$ bypnoides, - Lingd.

- tenuis. - Lindg.

- adianthoides. - Lingd.

JUNGERMANNIA rhizantha.-Montag. (nob.) LOPHOGOLEA connata. - N. ab E.

RADULA pallens. - N. ab E.

FRULLANIA glomerata. - N. et M., L. et L

- aeolotis. - Montag. Nees.

- Kunzei. - Montag. L. et L

- diffusa, - N. ab E. Sw.

PHRAGMICOMA transversalis.-N. ab E. Sw.

$$
\text { - Sagraana. - Montag. (nob.) }
$$

LEJEUNIA serpyllifolia. - Libert.

- adnata. -- Kunze.

- angusta, - L. et L.

- læte-virens. - N. et M

- phyllobola. - N. et M.

- cancellata. - N. et M.

- myriocarpa, - N. et M 


\section{INTRODUCCION.}

LEJEUNIA radicosa. - N. ab E. Litt.

- cardiocarpa. - Montag. (nob.)

- unidentata, - L. et L.

- serrulata. - Mont. (nob.)

- Cubensis. - Montag. (nob.)

- Auberiana. - Montag. (nob.)

METZGERIA furcata, - N, ab E

MARCHANTIA papillata. - Raddi.

- chenopoda. - Linn.

FIMBRARIA Cubanensis, - Lehm. Herb.

CIATHODIUM cavernarum. - Kunze.

\section{MUSCI.}

GYMNOS'TOMUN harbula. - Schwægr. tortula. - Schwagr.

octoblephaRtM albidum. - Hedw. TOLTULA agraria. - $\mathrm{S}$ w.

- latifolia. - Montag.

SYRRHOPODON incompletus. - Schwægr. prolifer. - Schwægr.
BRYUMl nutans. - Sclorels.

coronatum. - Schwæegr.

FUNARIA hygrometrica, - Hedw.

FISSIDENS palmatus. - Hedw.

- exilis. - Hedw.

- bryoides. - Hedw.

NECKERA Domingensis. - Spreng.

- undulata - Hediw.

- disticha. - Hedw.

- polytrichoides. - Schwægr.

LESKIA pungens. - Sw.

- cæspitosa, - Hedw.

HOOKERLA depressa - Hoot et Grev.

ISOTHEGIUM tetragonum. - Brid.

- tenerum. - Brid.

HYPNUM gratum. - P. de Beauv.

- liliputianum. - Montag. (nob.)

- planum. - Brid.

- tamariscinum. - Hedw.

- Montagnei. - Schimp. (nob.)

El precedente epitome de la Flora cubana, presta materia para hacer algunas reflexiones sobre la riqueza vegetal y el aspecto de la regetacion de aquel rico suelo.

El número total de especies descritas en la presente obra asciende á 1,5044 , correspondientes á 125 familias y 752 géneros. - La clase de las FANEROGAMAS comprende 114 familias, 626 géneros y 1,248 especies. - En el grupo natural de las plantas Drcorruenones, hay 94 familias, 527 géneros y 1,018 especies, 'y en el de las Mosocotruenodes, 20 familias, 99 géneros y 230 especies. Desde luego, puede notarse el predominio de las plantas arboreas y arborescentes sobre las herbaceas, lo que da á la vegetacion cubana, el aspecto grandioso é imponente que distingue y caracteriza la flora de las regiones intertropicales.

La escasez relativa de plantas herbaceas, puede atribuirse al mismo predominio de la vegetacion arborea, que cubriendo, con su densa sombra, la superficie del terreno, impide el crecimiento de aquellas, y tambien á la influencia vigorosa del calor y de la luz, favorables á la transformacion leñosa del tejido celular. Esta se. gunda causa produce igualmente la grande abundancia de gomas, de resinas y de jugos lechosos, ricas secreciones que acompañan, con mas frecuencia, la vegetacion vigorosa de las regiones cálidas.

En la clase CRIPTOGAMICA, hallamos 11 familias distribuidas desigualmente en los tres órdenes de ALGAS, HONGOS y MUZGOS, comprendiendo 126 géneros y 306 especies diversas.

Si del análisis numérico de las plantas cubanas pasamos á cousiderar las familias en particular y su composicion en géneros y especies, podemos llamar la atencion hácia las que mejor caracterizan la vegetacion las las Legumosas, las Compuestas, las Conduceas, las Rubuceas, las Solanaceas, las Convolvulace is, las Verbevaceas, las Amarantaceas, las Eufolbiaceds y las Onoubeas. - En la mayor parte de estas familias, y con muy pocas esecpeiones, vemos dominar los géneros proporcionalmente mas que las especies. Esta observacion es aun mas gencral y positiva cuando se examina la promesicion de las familias poco numerosas en especies, en las cuales es lo mas frecuente hallar géneros muy pobres en aquellas y muy pocos que presenten un número algo considerable. En este áltimo caso se hallan

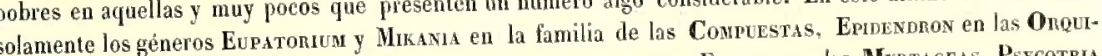
peas, y en menor escala, los Acacia y Cassia en las Legumivosas, Eugenia en las Mrrataceas, Psycotria

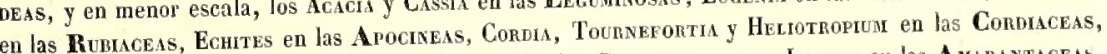
Son las Convolvulaceas, Iresine en las Amarantaceas, Solanum en las Solaneas, Com as Croton y Acaliphi en las Euformaceas, Tillandia en las Ris Gramineas. Casi todos los demas géneros de las otras familias, contienen pocas Botanica. 
y muchos una sola. Desconocemos la causa de esta particularidad, que parece dar suma preponderancia á los géneros en la vegetacion cubana; lo cual nos hace sospechar que, en lo sucesivo, se mostrarán mas ricos en especies á los exploradores que recorran aquella interesan lísima Isla.

La indicacion que venimos de hacer, atribuyendo la eseasez de especies en muclios géneros cubanos, á la

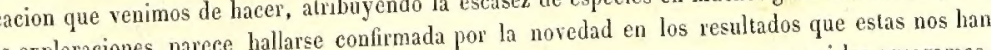
. De las 1,554 especies descritas en esta obra, 450 lo son por primera vez; y si les agregamos, ror parte de las 120 que envíamos de la Habana á De Candolle, que pudo mencionar en su Prodromus. cuando le publicaba, y ademas todas las nuevas especies que halló M. Lindlay y algunas descritas recientemente por MM. Ad. de Jussieu, Adolp. Brongniart, Decaisne, Moquin-Tendon, Benthan y otros, podemos asegurar, sin temor de equivocarnos, que de las especies cubanas de la presente Flora, 600 son enteramente nuevas.

Las familias que resultan mas enriquecidas con estas adquisiciones, son : las Avoviceas, las Flacovr-

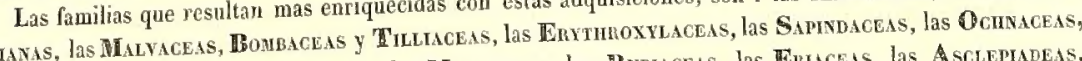

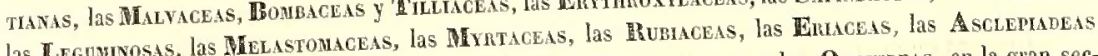
las Bigronuceas, las Verbenaceas, las Lauraceas, las Euforbiceas y las Oneurdens, en la gran secFA FroGamaS. Entre las CRIPTOGAMAS, todas sus once familias en general. E cios eseaso éneros; y estos tan reducidos en especies, que contamos mas de 400 géneros con una sola. Aunque en algunos la escasez en el número de las especies cubanas corres. ponda á la natural del mismo género, en olros no creemos que sea esta la causa de hallarse tan pobremente representados.

Tuesá en parte, son análogas á las de la misma ciencia sobre las leyes de distribucion de las plantas en las diversas regiones del globo, así como sobre la variabilidad numérica ó ciqueza relativa de las familias vegetales. Estas reflexiones tienen mas bien por objeto llamar la atencionde los botánicos que hayan de seguir nuestras exploraciones en la Isla de Cuba, hácia estos interesantes problemas de la geografia vegetal, que no el resolverlos. Otro tanto decimos de diversos puntos que hemos traado en la presente introduccion, verdadero resúmen de nuestro plan de estudio de la vegetacion cubana. Indicamos antes uno de los caractéres de su fisonomía 6 aspecto general, que era el predominio de las recies arbóreas y arborescentes sobre las herbáceas. - Otro carácter distiutivo de la vegetacion cubana especies ar resulta, del gran numero de fla bejucos y de curujeyes, con que respectivamente

ricos y generales como los de arboles y yu contadas las familias y los géneros que presentan plantas trepadoras, y las En Europa son escasas y muy contadas las famico a Isla de Cuba, lo mismo que en toda la rica zona parásitas fanerogamicas son extro familias y géneros, y les curujeyes intertropical, sucede lo contrano. Los bejucos se encingulares, cubre las constituyen una riquísima y hermosa familia, cuya extraordnaria variedad de especies singulares, chb cimas de los árboles y tapiza las quebraduras de las rocas. Hállanse en el primer caso, las Rancxculaceas y Defreaceas, con los Ciematis y Tetracera; los Triopteris, Banisterias y Stigmapiyllos, en las Milpighias; las Serjania en las Sapindaceas; los Cissus y Vites en las Ampelideas; las Crotalaria, Desmodery, Rinincosia, Abrus, Phaseolus, Dolichos, Vigna, Mucuna, Gullandina en las Leguminosas todas las Pasifloras, Cucurbifaceas y muchas Compuestas, particularmente Eupatorios y Mikanias; las Jacaranda y varias Bignonia en la familia de este nombre; las Tournefortia en las Condiaceas; varios Soraxur todas las cuarenta especies de Convolvulaceas cubanas; la Cinmisoa en las Amanantaceas; varias Tragia y Croton en las Euforiaceas; la Vanilla en las Orouneas; las Rajania y Dioscorea en la familia asi denominada; las Smucess y otras muchas que se elevan á grande altura, entretegiendo sus tallos por entre las masas densas de la vegetacion cubana.

En cuanto á las plantas parásitas, el número de las Orquideas descritas, y que se hallan en variedad infinita sobre las cimas'de los árboles, forman un conjunto de vegetacion aerea que extiende indefinidamente los limites naturales de la superficial del suelo. Generalmente provistas de singulares córolas, que aparecen mezcladas con las de los árboles y de las enredaderas arborescentes, contribuyen á la belleza floral de aquellas feraces regiones, donde el reino vegetal encuentra, en la fertilidad del terseno, el calor y la humedad de la atmósfera, tres condiciones eminentes para su desarrollo. 
Despues de haber dado esta idea general del aspecto de la vegetacion cubana, $y$ de la novedad y riqueza que la caracterizan, pasaremos á examinar estas mismas cualidades, en los diversos gruposó familias naturales que la constituyen, lo cual nos proporcionará la ocasion de indicar las causas de varios cambios y modificaciones introducidos por nuestros sabios colaboradores Richard y M. Montagne, y tambien de hacer algunas alusiones á la utilidad respectiva de las especies que componen dichas familias.

La familia de las Raxunculacess, sumamente escasa en la Isla de Cuba, ofrece especies de adorno para losjardines en sus cuatro especies de Clematis, de las cuales una es nueva, la C. palida, denominada así á causa del matiz que domina en todas sus partes. Tambien entre las pocas DiLcenraceas de la Isla, se hallan dos especies nuevas, á saber : la Divila Sagreana y la D. ciliata.

La familia de las Anonacess, ademas de los frutas delicadas y refrigerantes que ofrece, como el Anon, la Chirimoya, el Mamon y la Guanábana, comprende varios árboles de maderas de construccion, de los cuales algunos carecian hasta ahora de denominaciones botánicas. Estas nuevas plantas han permitido 2 M. Richard curiquecer unos géneros y rectificar otros, recientemente constituidos por el mismo. Notanse, en efecto, una nueva Avova, denominada bullata, que es el árbol vulgarmente llamado Laurel de cuabal; dos Xrkorias, la Cubensis, que es la Guacima-baria, de madera útil, y la obtusifolia, llamada Guavico por los naturales y Guimbá por los negros. Habíamos enviado ramas de este árbol, en herbario, á M. De Candolle, que su hijo se apresuró á publicar en su Memoria sobre las Anonaceas, bajo el nombre de Hanzelıa abtusicolia. Mejor estudiada por M. Richard, pasa naturalmente al género Xropra. Tambien comprendió una nueva especie, denominada neglecta, en el género Uvaria, que antes habia el constituido, con varias antiguas Uyarus y Unonas y los génetos Asumina de Adanson y Porcelia de Ruziz y Pavon. La nueva Uvaria neglecta, es la Yaya, árbol muy comun en la Isla de Cuba, y cuya madera se emplea en distintos usos. El nuevo género Oxanora se halla formado de Uvarias de Swartz y de Guettardas de Dunal, y en el aparecen dos nuevas denominaciones; la una, Oxundna virgata, es un árbol cubano que lleva tambien el nombre de $Y_{a y a}$ y deserito como Guatrena por Dunal y como Uvaria por Swartz; la otra, Oxinora laurifolia, perteneciento antes á los citados dos géneros.

Las familias de las Menspermaceas y de las Nrufeaceas, solo ofrecen una especie cada una, que las represente en la presente Flora. Pero debemos advertir, que de la segunda familia hay ciertamente mas especies en la Isla de Cuha, pues recordamos haber cogido y desecado otras Ninfeaceas, que sin duda han sido destruidas por los insectos en nuestro herbario. El Crssampezos carapeba de la primera familia, Ileva en la Isla de Cuba el nombre de Pareira brava, y tal vez pueda remplazar la raiz de la especie asi nombrada en las farmacopeas.

Solo dos Papaveruceas indígenas hallamos en la Isla de Cuba, la Angenone Mexicana y la Bocconia frutescens; la primera muy empleada por sus propiedades medicinales, que le han merecido el nombre de Cardo-Santo. La familia de las Crucranas solo cuenta dos especies en la presente Flora, pero estamos ciertos de la existencia de un Srnapis (juncea?) que vegeta abundantemente. M. Richard creyó conveniento reunir en uמa sola, las cuatro especies de Canice que llevan los nombres de Cubensis, Kunth., Americana, L., aqualis, DC., y maritima, Scop., bajo esta última denominacion. De consiguiente, el Cakite maritima, Rich., el Lepiduar Virginicum, L., y el Srmapis (juneea?) pareen ser los únicos representantes cubanos de las Cruciferas que hemos hallado en la Isla.

De la poco mas abundante familia de las C.ranidas, hallamos en las cercanías de la Habano dos especies que resultan ser nuevas; la Cueome Cubensis, y el Cappanis emarginata, que ha sido figurado en esta Flora.

La falia de las Fucourtrasas contiene, en la Isla de Cuba, varios árboles útiles del género Lsta, que

La familia de las Facourtravas contiene, en la il nombre de ellos, Guaguaci. El exámen de las numerosas muesproducen una resina medicinal que lleva el nombre draido, ha permitido á M. Richard la formacion de dos especies tras, que de diversas localidades hemos traido, ha permitido a M. Tichard la foria En la misma familia, nuevas que ha descrito y figurado con los nombres de Latra longifolia y L. crenala. Ln la misma ramia, M. Richard formó el nuevo género Zuecinia, muy parecido al precedente, con una sola especie lasta ahora, la Z. latioides, llamada así por la mencionada semejanza. La constitucion de este género lia sugerido á su autor varias observaciones que extractaremos luego, al hablar de las SAHYdeas.

Las Viocarias solo se hallan representadas hasta ahora, en la Isla de Cuba, por una especie, y otra, al parecer nueva, la Dnosera ineisa, caracteriza la existencia de las procenaceas. Entre las cinco PolygaLAs descritas, una es tambien nueva (P. peduncularis); y en la numerosa familia de las Malvaceas, que 
y ocho especies cubanas, se hallan diez y ocho nuevas, á saber: las PAyonu linearis é incermixta, los Mavaviscus Sagraanus y pulvinatus, los Hibiscus costatus, Cubensis, criptocarpus y truncatus, que era un Hisiscus de Swatt, los Abuticos iriquetrum, lignosum, confertifolium, hir um y trichotum, la GAYA affinis, las SIDA lanceolata, obtusa é involucrata. En las Bombacess aparecen dos Hestapifolia y el furfuracea, y una PAchira, la emarginata, que es un árbo magnífico Ilamado Ceibon de arroyo en la Vuelta de Abajo.

Las dos familias de las Malvicens y de las Boubaceas reunen plantas utilisimas para la industria, por textiles que los tallos de varias procuran, la lana vegetal que rodea las semilla de otras, y por las las hojas, las flores y las raices de muchas otras.

áltima propiedad, la Guacima de la Isla de Cuba, perteneciente al género Participa, en alto grado, de esta utto la diversidad de sus hojas, hizo sospechar á M. Richard que sean Guazuna, cuya especie tomentosa, por la diva diversas especies, las formas ulmélia y lomentosa de

Las Tulucens fueron enriquecidas con dos Triumpheta, la hispida y la grossulariafolia, y con un nuevo odedicado un médico distinguido frances que dejó nombre en la Habana. Su única especie hasta ahora, la B. greviafolia, ha sido figurada, y es la Majagua macho, uno de los árboles mas Cotra planla nueva para la ciencia, aunque de antigno apresacion (Guacima baria), y un arbusto de poca utilidad, la Procki tomentosa.

- Isla, resultan set nuevas dos, la Ternstroema

Entre las tres solas Tersstioemhcess que hallamos en la isla, resulan ser a obovalis, arbusto sin nombre de la Vuelta de Abajo, y la LAPLACEA Cungana, que es el Alephlla, especie nueva comarca. Entre las Autantuceas, recibimos del interior de la de un género que hasta ahora no se habia hallado en el nuevo mundo, y que por lo mismo hizo dudar a M. Richard que fuese indigena.

a cestras herborizaciones. El y tambien es nueva la única Hippocratea (integrifola quc hemos género Erythroxyblun ofrece tres nuevas especies: el E. spinicens, el E. alaternifolium y el E. affine, todas procedentes de la Vuelta de Abajo.

Las plantas que hemos traido, pertenecientes á la familia de las Malpiguras, fueron confiadas á M. Ad. de Jussieu, que entónces formaba una Monografia. Esto le proporcionó enriquecerla con cinco especies nuevas, á saber : los Stygmaphyzon Sagrœanum, reticulatum y diversifolium (este último ya descrito por Kunth como una Bunisteria); la Spachea parviflora y la Byrsonima Cubensis.

La familiaide las Sapridaceas habia ya ofrecido á De Candolle varias especies nucvas, en las muestras que le enviamos, á las cuales M. Richard pudo añadir las que despues recogimos. La familia resulı pues enriquecida en la Isla de Cuba, con el Cardospennum ferrugineum, la Serjania Ossana, la Schmideua (a S. macrocarpa, las Cupania multijuga, triquetra, juglandifolia, macrophilla y oppositifolia.

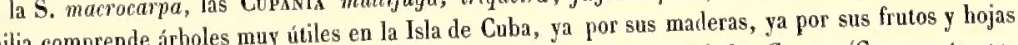
El Palo de caja (Schuretu comminia, Sw.), las Guaras (Cupania tomenpara el alimento de los a losa y macrophilla), el Macurige (C. Oppositifolia),

este caso ; ademas del Mamoncillo (Mera fasilia de las Meliaceas,

Mas interesante aun, por sus árboles de maderas de conctruceion, e labo de pues comprende al Cedro y la Caoba, y, en segunda linea, el Famao (Guanea trichiloides, L), el Cabo de hacha (Tnichicia spondioides, Jacq.), y laCiguaraya (T. Havanensis, Jaeq.). Muy parecida á esta ultima, y llevando el mismo nombre vulgar, se halla en Cuba otra nueva Tuchilia, denominada minor por Richard, representada en una lámina de esta Flora.

A rperideas, muy escasas en la Isla, tienen alli una especie mas, el Cissus intermedia. Hay tambien á lo menos, del género Vitis, una mencionada en esta obra, y la otra perdida sin duda en nuestro herbario. Ambas llevan el nombre de Bejuco de parra ó Parra cimarrona. M. Belair ensayó inger. tar sobre ellas las vides europeas, y obtuvó felices resultados, que no sabemos se hayan continuado despues. Entre las Oxalideas hay tambien una especie nueva, la 0 . intermedia, que denominó así M. Richard, por deber colocarse entre las violacea y latifolia.

La familia de las Rutaceas, que comprende el utilísimo Guayaco ó Palo santo (Guaracum officinale, L.), 
y otra especie, el Guyacancillo (G. verlicale, Ort.), de semejantes usos, se ha enriquecido con cinco mas.

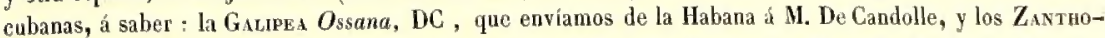
xycus coriacum, bombacifolium, dumosum y tadiosum, descritos los cuatro y figurados los dos primeros en esta obra. Las maderas de todos ellos son útiles, como las de otras dos especies cubanas, el Z. lanceolatum (Ayua macho ó amarilla) y Z. juglandifolium (Ayua hembra ó blanca).

Entre las Ochnaceas cubanas, halló M. Richard dos especies nuevas, la Gonphamialaternifolia' y la G. elliptica, ambas nuy vecinas de la G. cassinefolia, DC.

Las CElastrinas comprenden un nuevo género y tres especies tambien nuevas. Estas son : el Eleodendron attenuatum, el Celastrus parciflorus y el ILex mimulifora. El nuevo género Monteverdu, con su única eśpecie buxifolia, fué dedicado á un laborioso y entendido cubano, D. Manuel de Monteverde, vecino de l'uerto Príncipe, que nos envió muy útiles indicaciones sobre aquella comarca. El género Monteverdia debe colocarse entre las Eyonimus, Myginda y Celastrus, segun M. Richard, y por las razones que ha manifestado.

Entre las Rhameas se hallan dos árboles útiles cubanos, la Bijaguara, que antes era un Ceanothus, que M. Bronguiart reunió á los Colubrina con el nombre de C. ferruginea, y el Yayajabico, que pasó tambien á ser la C. reclinata, Brong.

Como introduccion á la familia de las Samydeas, M. Richard hace reflexiones importantes sobre el nuevo género Zuelania, que estableció en las Flacourtunas y que parece constituir una analogía entre las plantas de esta familia y las Casearias y las Samydas. Por estas razones, opina que debe formarse con todos estos géneros, una sola familia, que entónces comprenderia las Casearias, las Samydas, las Laetias y las Zuelanias, y su lugar en la série estaria, despues de las Capparidaceas y antes de las Malvaceas. - Entre las CASEaria, solo hemos traido una especie nueva, denominada alba por M. Richard.

La rica familia de las Terebintaceas presenta en la Isla de Cuba dos nuevas lcigas, una del todo desconocida hasta ahora, á saber : la Icica copal, que da la resina de este nombre, y la otra, constituida por la Hedwigia balsamiflora de Swartz, que Richard denomina I. Hedwigia. Nuestro amigo creyó oportuno reunir en el Icica de Aublet las Hedwigius de aquel autor. Como árboles tambien útiles en esta familia, deben mencionarse el Marañon (Avacardium accidentale, Jacq.), el Mango (Mangrera indica, L.), tan generalizado ya que puede considerarse como indigena, la Aguedita (Picramnia pentandra, Sw.), subcedanea de la quina, el Jobo (Spondias lutea, L.), el Ciruelo (S. purpurea, L.), el Almacigo (Burseri gummifera, Jacq.) y las Coabas (Awres maritima y sylvatica, Jacq.), cuya madera encendida alumbra exhalando un delicioso aroma. Con estas plantas útiles y agradables, de propiedades beneficiosas, se encuentra naturalmente asociada, en la misma familia, el peligroso Goaoa, Comocladia dentala, Jacq. cuyo contacto y hasta cuyas exhalaciones producen una hincliazon venenosa, pero su madera es excelente para diversos usos. Este conjunto de plantas constituye la familia de la Tencbintaceas, una de las mas útiles en la Isla de Cuba. Llegamos á la mas numerosa de las Iafuminosas, representada en la Isla de Cuba por å6 géneros y 115 especies. Vamos á indicar ligeramente las nuevas con que varios de aquellos se han enriquecido.

Las diversas muestras del árbol llamado en la Isla Balsamo del Perí, que hemos traido en nuestro berbario, permitieron á M. Richard compararlas con el ejemplar auténtico del Mirospermu Toluiferum cogido en las cercanias de Tolú por M. de Humboldt, y referir aquellas á la misma especie, dando ademas una descripcion completa y una lámina con todos los detalles. Pero debemos advertir que no tenemos una seguridad absoluta de que dicho árbol sea indigena de la Isla de Cuba, antes bien nos inclinamos á creer lo contrario, pues no se halla indicado en ninguna de las listas de especies indigenas que hemos reunido de diversas localidades. Nos fueron enviadas ramas de Arcos de Canasi, y tambien habia una alameda plantada de ellos en el Jardin botánico de la Habana, procedente de semillas enviadas de aquel punto, donde pudo muy bien haber sido introducido por M. Belair, lábil jardinero del Señor D. Juan Montalvo y O'Farrill.

En el género Centrosems, formado por Beutham, hay dos espeeies nuevas, el C. intermedium y el C. ferrugincum, ademas de la recientemente descrita por el mismo autor con el nombre de C. pascuorum, y que M. Martius halló por primera vez en el Brasil. El género Centrosera ha sido formado por Benthamá expensas

1. En nuestra ausencia, puso equivocadamente $\mathbf{X}$. Richard, como nombre vulgar de esta cspecie, orillas de Arroyo, que era la indicacion de los parages donde vereta; y asi fué traducido al castellano. Desgraciadamente, no ha sido esta sola la equivacacion indicacion de los parages donde vegeta; y as fue Paris, para desempeñar, varias veees, las funciones de Diputado á Córtes. Botanica. 
del antiguo Curronu de Linneo, por lo cual solo aparece en este la ternated, como especie cubana en la presente Flora. El género Galactia tiene una especie nueva, la G. parvifolia; en el género Lonchocarpus se ha eunido el pyxidarius de De Candolle al sericeus de Kunth, por no diferir en cosa alguna. Con este motivo diremos la causa del nombre pyxidarius, dado por De Candolle á las muestras que le envíamos de la les llegaron tambien otras de la Schunes. cominia, que lleva en la Isla de Cuba el nombre de Palo de Caja, cuya tarjeta pasó, sin duda, á alguna nuestra del Lonchocanpus, é indujó á De Candolle á Jenominarla pyxidarius. En caso de conservar este nombre especifico, deberia referirse á alguna de las nueras Schmoelas, que en la Vuelta de Abajo llevan el nombre de Palo de Caja. El Lonchocarpús pyxidarius, DC.

El género Zorvis, desmembracion del Heprsarum, tiene una especie nueva, la Z. Havanensis ; el PhaseoI.US vexillatus, D., pasa al género VigNa, con la misma denominacion específica. El género STEnoLobum, formado por Bentham, tambien con especies de Pfiseolus, tiene un representante en Cuha, el S. caruleum, cuya raiz comestible lleva el nombre de Jicama y merece ser cultivada, pues la creemos suscentible de aumento en su volúmen.

El antiguo y numereso género Douichos ha cedido varias especies para formar el Cinaviria y el Mucuna Entre las Enythrinas cubanas hechamos de menos la cristagalli, que se conoce en la Isla de Cuba con el nombre de Piñon real, y cuyas muestras se habran alterado y perdido en nuestro herbario, por lo carnoso de las flores, muy dificiles de conservar.

El género Swartzia se halla representado hasta ahora en Cuba por una sola especie, pero esta es nueva, la S. multijuga, que M. Richard ereyó oportuno representar en una lámina. Las AcAcL, extraidas de las antiguas Mrmosa, ofrecen siete nuevas especies cubanas, á saber : la pauciflora, la Valenzuelana, la Insularis, la propinqua, la litoralis, la lentiscifolia y la microcephala. Procedentes tambien de las Murosa son las INGa de Plumieri, que tienen dos especies mas en la Isla de Cuba; la I. hixtris y la I. ovobalis. El género Deswavthus, desmembrado tambien de las Mimosa, ofrece una nueva especie cubana, el D. comosus. Las Cesslpiria se hallan enriquecidas con una hermosa especie mas, la C. horrida, llamada asi por hallarse herizada de aguijones rectos y punzantes. El género Poeppigla, formado con una Cesativia del autor á quien va dedicado, se halla enriquecido con otra especie, la $\mathrm{P}$. excelsa, árbol hermoso y útil, el Abey hembra, cuya

El numeroso género Cassia, que hasta ahora cuenta ya diez y siele especies en la Isla de Cuba, comprende dos nuevas descritas por Richard y denominadas C. grissea, C. chrysopluylla. Del género Coparfena, envíamos de la Habana á M. Moricand de Ginebra, muestras de un magnífico árbol de construccion de la Isla de Cuba, llamado Quiebra hacha, á causa de la extaordinaria dureza de su madera, que fué inmediatamente descrito y figurado con el nombre de Copsmera hymenafolia. El género CrNomerra, que parecia ser exclusivo del antiguo continente, tiene ya un representante incontestable en el nuevo, en la $\mathrm{C}$. Cubensis, que es el árbol liamado Pico de gallo en la Vuelta de Abajo. Richard observa, con este motivo, que si la especie muy dudosa señalada por M. Vogel en la Isla de Haiti, es realmente una Crnometra, entónces serán ya dos las que se hallan en la América.

La série de Leguminosas cubanas termina por una especie de un nuevo género, dedicada á M. Belair, hábil horticultor frances residente muchos años en la Isla de Cuba, que le debe la introdnccion de muchas plantas de jardinería y de hortaliza, y de prácticas modernas de cultivo. El género Becarnia fué colocado por M. Richard al fin de la familia, porque ofrece un gran número de caractéres discordantes de las diversas tribus de Acacias, de Amariposadas, de Casalpinias, de Geofreas y de Casias. La descripcion y la lámina de la B. spinosa, tipo de este nuevo género, le dan á conocer debidamente.

Al mencionar las nuevas adquisiciones hechas en Cuba, en aumento de la familia de las Leguminosas, indicamos algunas de las plantas útiles á que se refieren. Otras eran ya conocidas en la ciencia, tales como el Añil, el Palo de Campeche, el Brasilete, entre las tintorias; el Granadillo (Brra ebenus, DC.), el Sabicú (Acacia formosa, Kunth), los Moruros (Acacia arborea y litoralis, Rich.), el Tengue (otra Acacia), la Yaba (Andira inermis, Kunth), como árboles de maderas de construccion; el Ptenocarpus gummifer, Bert., la Hrmenea courbaril, L., la Monniga pterigosperna, Gotu, ya generalizada, por sus resinas y aceites : las CAssia, como la fistula y otras, por sus virtudes medicinales: el Tamarindo, el Mani, las Frijoles, las Jíeamas, como comestibles, ete. 
La familia de las Prosacess es pohre en la Isla de Cuba, pero comprende dos árboles útiles : el Icaco (Chrysoralanus icaco, L.), por sus frutos para dulce, y el Cuciani (Cerasus occidentalis, Loisel), de madera sumamente dura, para la contruccion civil y marítima.

Entre las Combertaceas cubanas, halló M. Richard, en los caractéres de un árbol muy útil en la lsla de Cuba, el Chicharron, motivos bastantes para constituir un nuevo género intermedio entre los Terminama y Combretum, por lo cual denominó Chicharronia intermedia, la única especie que hasta ahora le constituye, representándola en una lámina. Una nueva Tenminalia, que llamó eriostachia, viene tambien á enriquecer csta escasa familia, representada ademas en la Isla de Cuba por la Yana (Conocarpus erecta, Kunth), por varias especies de Bucida, por el frondoso Almendro de la India (Termisala catappa, L.), introducido y muy generalizado, y por una Lagunaria y una Porveea.

Entre las Onagras solo sa halló una especie nueva, la Jussiza Sagreana, con la cual llegan ya á seis las species cubanas de este género. El Mangle, es el único representante de las PhHzophonas de Cuba, y entre las Litrarus hay may pocas especies indigenas. No sucede así con las Hecastorus, que ya tienen ocho nuevas que las representan alli, á parte de diez tambien cubanas, pero ya conocidas. Algunas de las primeras fueron hace años mencionadas por De Candolle en su Prodromus, y ahora pueden agregarse la Antriostema Cubense, la Clidemia Valenzuelana, el Calycogonium Cubense, la Conostegra acutidentata y la Miconia delicatula. Ademas de estas cinco especies de géneros conocidos, M. Richard halló en nuestro herbario, tres mas pertenecientes á dos géneros nuevos, á saber : el Panchyanthus, próximo al género Tetrazygia, y representado por la especie P. Cubense, y el Naudinia, inmediato al Diplochita, represen. tado por dos especies, la N. argyrophylla y la N. chrysophylla.

Macho mas rica que la familia precedente, parece ser en Cuba la de las Mrntaceas, representada por $\mathbf{2 3}$ especies, de las cuales son nuevas doce. Las numerosas muestras que hemos reunido de diversas localidades de la Isla, han facilitado á M. Richard su estudio, y el baber determinado órganos poco conocidos antes, comoel ovario, el fruto y la sèmilla de las Mouninas, que conserva definitivamente en las Mrruceas y no traslada á las Mecistomas, como habia hecho M. Endiicker. Halló en ellas las 12 indicadas especies nuevas que denomina : Mouniria Valenzuelana, Psidur guayabita, Eugenia brevipes, microplylla, rigidifolia, phyllivecfolia, heterophylla, farameoides, verrucosa, guayabillo, fermginea y Valcnzuelana. Esta última, aunque muy parecida á la E. pimenta, presenta caractéres mas bien del género Irrcci de De Candolle que no del Eugensa; pero M. Richard no ha juzgado conveniente alejar dos especies tan afines por su aspecto y aplicaciones. Como plantas útiles cubanas, pueden citarse en esta familia, ademas de las conocidas Guayabas (Psydun pyriferum y pomiferum), y el frutal Poma rosa (Eugenia jambos, L..), tres mas que son un arbusto de madera usual, Yaya (Mourina myrtilloides, Poir.), y dos Malaguetas ó Pimientas (Eugenia pimenta, DC., y E. Valenzuelana, Rich.).

La dificultad de conservar desecadas las flores y los frutos de las Pasionaras, hizo perder muchas muestras de nuestro herbario. De las diez que menciona M. Richard, solo una es nueva, la Pasiflora coriacea, semejante á la P. punctata de L. - Entre las Tunveraceas cubanas, halló tambien una especie nueva de género Priqueta de Aublet, la P. jonidioides, cuyo aspecto semeja al de la Tunnera cistoides de $\mathrm{L}$.

La familia de las Cucunbraceas, que ofrece en Cuba los curiosos Chajotes (Sechium edule, Sw.), ha suministrado un género nuevo, perfectamente caracterizado con una sola especie hasta ahora, que M. Richard ha representado en una lámina de esta obra con el nombre de Tricenatia bryonioides.

La Pontulaca microphylla es la única especie nueva, que ha proporicionado nuestro herbario cubano. En la siguiente familia de las PnYtolacess, M. Richard ha introducido reformas en el género Rivina, dejando en el algunas especies antiguas y constituyendo el nuevo género Truchostigua, con otra de ellas, la H. octandra, L., que denomina Trichostigma rivinoides. Ademas, halló una especie nueva del género Stegropenua, que denomina $\mathbf{S}$. Cubense, muy vecina de la $\mathrm{S}$. halimifolia de Bentham, pero euvas diferencias se explican en la frase especifica y en la lámina.

Hemos raido muy pocos Cactus de la Isla de Cuba, á eausa de la dificultad de conservarlos en herbario, y tambien porque, esperando siempre procurarnos una coleccion viva, descuidamos esta familia. Por esto no son mencionados mas que una Pereskia y una Ripsacis. Nada notable hemos traido tampoco de la familia de las Unbelladas, muy escasa en la Isla, donde solo encontramos tres Hydrocotrue y un ERyngium, ya conocidos en la ciencia. 
Un árbol de magnífico aspecto por la forma y color de sus hojas, la Yagruma macho (PAxax undulata, (ub.), y una Yos ánicos representantes cubanos, hasta el dia, de la familia de las

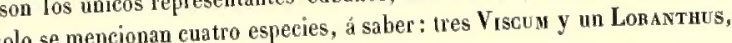
Analiaceas. De las Lorantace

de las principales que presta su fisonomía a la vegetacion cubana, y

La familia de las Rubracess es una de las principar quárboles que comprende. El número de muestras que merece una mencion particular por la uthidad de los asbolos quermitido á M. Richard constituir tres que hemos traido, procedentes de diversas localidades de la Isla, ban permitido a M. Richard constituir trapida-
nuevos géneros y tambien enriquecer los antiguos con nuevas especies cubanas. Vamos á enumerar rapida mente los unos y las otras.

El primer género formado es CAsasia, en memoria de un ilustre y memorable capitan general de la Isla de Cuba, D. Luis de las Casas. Denominó la especie calophylla, por su porte y la forma de sus hojas; pero careciendo los ejemplares de flores, hay que esperar la confirmacion de un estudio futuro. Mas fijamente caracterizado se halla el género Gonianthes, uno de los mas bellos de la familla, por el tamaño de sus flores. Las especies tienen el porte de la Portlanda grandifora, y hasta ahora se conocen solo dos, descritas bajo los nombres de G. Lindenianả y G. Sagræana.

- nos pareció, cuando la hallamos, ser la Campanulata, y que con este nombre la

De una Catesba que nos parecio, cuando la hallamos desde luego, formó M. Richard otro género nuevo, Echodendnum, mencionó DC., á quien se la enviamos desde laego, forno M. Tichard otro genero nuevo, Echones. que describió y figuró en la especie tipo E. campanulatum. Las nuevas especies y denominaciones introducidas esta familia son las siguientes; la Posopueria Havanensis, DC., transformada e nensis, Rich.; la Genipa pubescente, que habíamos remitido á De Candolle; la Gardenia Sagraana, muy próxio a G. randia, Sw.; dos CATESB 达, la longispina y la macrantha, esta figurada; tres RondeLETIA, la alaternoides, vecina de la R. levigata, Ait., que tambien se halla en Cuba, la R. Lindeniana, vecina de la precedente, la R. peduncularis, completamente diversa de las conocidas; ademas de la R. Berteriana que envíamos á aquel sabio, y las R. Americana y R. leptacantha, DC., que antes le habia sido remitida por nuestro predecesor. D. José de la Osa. En el género Gonzalea de Pers. dos especies nuevas, la G. brachyantha y la G. leptanta, ademas de la G. spicata, ya publicada por De Candolle en el Prodromus. Ea el género Huxus, se debe una nueva especie á M. Linden, que la cogió en Santiago de Cuba, y es la H. brevifolia, Rich. Unanueva Morinda, la ferruginea, seis Guettarda nuevas, á saber : la Havanensis, que con el Sr. La Osa envíamos de la Habana al profesor le Ginebra, y que este publicó entónces en el Prodromus; la ambigua, que tambien le remilimos entónces, y las $V$ alenzuelana, Lindeniana, vigida y calytrapa, descritas ahora por la vez primera. El Stenostonum dichotomum, DC., pasa á ser la Melanea dicholoma de Rich.; el género Chrone. de DC. que tenia solo una especie, cuenta ahora dos con la Cubana ó Cubensis, Rich. Mencionanse igualmente dos especies de Entrhalis, la angustifolia, DC., y la pentagona, DC., que en su tiempo enviamos á Ginebra. En el género Siderodendron, hay la nueva especie S. floribundum, y en el Psxchotria, bien trabajado por Richard, introdujo tres especies nuevas, á saber: las involucrata, obovalis y tubulosa. El género SPERMacoce se ha enriquecido tambien con dos especies cubanas nuevas, la $S$. tetraquetra y la $S$. microcephala: el género Richandonia, con la R. Cubensis, que parece ser la primera que se halla en las Anillas, pues todas las Richardsoniss viven sobre el continente americano. El género Mrtracarpum, Zuechar, que ya tenia una especie nueva cubana, el M. Sagroanum, que describió M. De Candolle, cuenta ahora tres mas : el M. linearifolium, el M. dioidioides y el M. crassifolium; en todo cuatro Mrtracarpum cubanos y nuevos.

La familia de las Rubuceas no figura en la Isla de Cuba tan solo por el número de las especies que allí vegetan y la novedad de muchas de ellas, sino tambien por la importancia económica de las plantas que la constituyen. En efecto, ademas del Cafe, se hallan varias Exostemas ó Quinas silvestres, las Psychotrias y las Coephelis, que poseen propiedades vómicas, y los árboles Yayajabico (Erithalis fruticosa, L.), la Vibona (E. pentagona, DC.), el Dagame (Calxcophy udu candidissimum, DC.) la Jagua (Genipa Americana, L.), y otros varios útiles por sus maderas ó por sus frutos y hojas comestibles por los animales.

Otralia, es la de las Synantheras, entre las cuales ha hallado M. Riehard varias especies nuevas, y precedentemente M. De Candolle babia consignado en su Prodromus otras que le enviamos. Antes de mencionarlas, daremos cuenta de los nuevos géneros de esta familia, establecidos en la presente Flora. 
El género Lachnorhiza, cuyo tipo es la especie piloselloiles, se aproxima á las Vennona. El género Temacantaus pertenece á la division de las Tagetinas, y hasta ahora solo posee una especie, el T. linearifolius. Por último, el género Pinillosia, aunque no ha sido formado por M. Richard, le consignamos entre los nuevos, porque fué M. De Candolle quien le constituyó con una planta remitida por el Señor la Osa, y que el profesor de Ginebra publicó bajo la denominacion de P. tetranthoides. Fué dedicado, como se consig. nú primero en el Prodromus y luego en la presente Flora, al Exmo. Señor D. Claudio Martinez de Pinillos, Conde de Villanueva, Superintendente general de la Hacienda pública en la Isla de Cuba, quien des* pues de haber protegido y segundado nuestras tareas en aquel país, recomendó eficazmente al Gobierno Supremo la publicacion del resultado de ellas en la presente obra.

11. De Candolle insertó en su Prodromus muchas Conpuestas nuevas que nos apresuramos en remitirle, porque nos las pedia con urgencia para el tomo que entónces redactaba. Todas ellas se hallan consignadas en la presente Flora y ademas las siguientes, nuevas tambien, que halló M. Richard en el herbario que de confiamos.

En el género Vennowia hay dos especies nuevas, la V. Vulenzuelana, que, segun el mismo Richard, pudiera bien no ser mas que una variedad de la Y. Sagreana, DC., y la V. gnaphalifolia; el Pectrs Roribunda, la Lonentea Cubensis, los Eupatonium heterophyllum, veticulatum, trichosanthum, mudiforum y Lindenianum: este último cogido en las cereanías de Santiago de Cuba por el distinguido botánico á quien va dedicado; la Mikania ranunculifolia, cogida en la isla de Pinos por el laborioso D. Elvecio Lanier, muchas veces citado en la presente Flora, por ser á él debidas todas las especies que comprende de dicha localidad; el Soldago Lindeniano, la Wedelia veronicefolia y la Melanantaera angustifolia.

Las modificaciones y variaciones introducidas por M. Richard en la clasificacion de las Conperstas cubanas, se reducen á la reunion de las das Pectis postrala de Cavanilles y costala de DC. bajo la primera denomiracion, por ser idénticas; á la reunion, tambien, por el mismo motivo de identidad, de las dos Viguiera helianthoides de Kunth y Sagraana de DC. bajo el primer nombre; á referir el Chrusanteluum Swartzii de DC. al C. procumbens de Rich. padre; á reunir, bajo la denomination Lebetrinia cancellata, Cass., la Drsodia porophylla, DC., y á reunir á la Leria leiocarpa, DC., la L. simuata del mismo.

La familia de las Syvantueras ofrece varias especies cubanas útiles como pasto de animales; un Eupatorso (E. aromatisans, DC.), llamado Trebol, que se emplea para aromatizar los cigarros, y la Fuaveru contram herba usada como vermiluga. Pero no se lan estudiado aun debidamente los Eupatonios y Minanias aromáticas que allí vegetan, y que probablemente están dotadas de propiedades muy cnérgieas, como la célebre Miкалis graco de Quito y de Nueva España.

En la escasa familia de las Lobelacens aparecen dos especies nuevas: el Siphocamphuds Cubensis, vecino del decumbens, DC., y la Lobelia salvicfolia. La familia de las Vaccinaceas se halla representada linicamente por una especie, y está nueva, del género Thrbaudia, la T. Cubensis, que M. Richard describió é bizo representar en una lámina de la presente Flora.

De las siete especies que en el dia forman en la Isla de Cuba la familia de las Encaceas, seis son nuevas, á saber : las Levcothoe myrsinefolia, affinis, glandulosa y latifolia; la CLethra Cubensis y la Cost.eA Cubensis. Esta última corresponde ademas á un nuevo género formado por M. Richard, que lo dedicó á su anigo el profesor Coste. Estas seis especies nuevas y la Crrilla Antillana, ya conocida, componen pues la tal familia en Cuba.

En las Mrrsinaceas nada apareció de nuevo despues de las tres especies cubanas que describió M. Alph. Candelle, la Mrrsine Cubana, la Ardisia Cubana y la Icacorea dentata.

Las Sapotaceas fueron enriquecidas con el género nuevo Diplocalyx, representado por la especie D. chrysophylloides, que si bien concuerda por la forma de las hojas con el Chrissophrenum glabrum, Jacq., no debe allarse en este género ni en ninguno de los otros de la familia. En el género Lucuma apareció la especic nueva L Valenzuelana, ademas de la L. nervosa, que habia constituido DC. en su Prodromus. Frutas Tas durisimas, hacen recomendables las pocas pero muy cultivadas espemuy agradables y árboles de maderas dun Culebra cies cubanas de esta familia. Tales son el Cainilo (Cing (Lucuma serpentaria, Kunth.), el Mamey colorado (L. mammosa, (Bumelis nigra, Sw.) y el Almendro silla Jocuma (Syderoxyllum pallidum, Spreng.), el Cucuyo o Jiqui (Bumela que completa con la anterior un vestre (Dipholss salisifolia). - Ea la siguiente familia de las Ebenaceas, que completa con la ato Botasica. 


\section{INTRODUCCION}

grupo bastante natural, solo se halla en el Sapote negro, especie nueva segun M. Richard, que la denomino A mente á la del A. obtusifolia, dada por Kunth.

Pasamos á la peligrosa fanilia de las Apocineas, que ha suministrado un árbol para constituir el nuevo y que la sido figurado con el nombre de $\mathbf{O}$. Galeottianum, y seis Echres nuevos, , el $V$ alenzuelana, el cinerea, el calicosa y el macrocarpa, si electivamente saber : el crassipes, el forruginea, el Falona pertenece al mismo género. La plauta mas notabe madera para la construccion, y el jugo lechoso que fluye Maboa (Camerana latifolia, Jacq.) por

de su tronco, de propiedades activísimas. especies nuevas; el Astephamus ovalifolius, la Metastelita linearifolium, tres Marsoenia, affin, angifora yatureicfolia y el Gonolonus Cubensis, sumamente parecido al Crnanchum racemosum, Jacq., que sirvio a M. Decaisne para formar la especie Jacquinia de su género Roulixia.

La familia de las Gentlanaceas, poco abundante en especies cubanas, solo se ha enriquecido con una cn el género Listantuus, denominada L. glandulosum por Ricliard. Entre las Bignoniaceas y en el género típico de las Bignonias, se hallan tres especies nuevas : la B. simplex, la B. lepidopleylla y la B. gnaphalantha. Las Condiaceas cuentan ya en Cuba con cuatro especies nuevas mas en el género Cordia, la C. Galeottiana, la C. angiacarpa, la C. parviflora y la C. Valenzuelana, y con dos mas en el género Ennetia, á saber: la E. caloplylla y la E. cassinefolia. Entre las especies cubanas de estos dos géneros, se Eutiles por sus maderas, como la Baria (C. gerascanthoides, Kunth.), el Ateja hemencuentran varios arboles utiles por Rolle negro (E. tinifolia, L.) y el Rable guayo (E. bourreria, L.).

bra (C. Valenzuelana, kich.), el Roulc negro (E. Lifín quallan

La familia de las Solaneas es otra de las caracterstion ofrecido pocas nuevas: el Solanom indecorum, el las especies de varios de sus géneros. Sin embargo, tque es vecino del C hirlum, Sw.

S. Sagraanum y el Cestrum ferrugineum, que vechos muchas

Tambien son características de la Fora cubana las Corwoulado nuevas la Puanutis calycosa, cuvo género muestras en nuestro herbario. Entre las que quedaron han resultado nuevas la Pathe cal formó Choisy con varios Convolyulus é Yponeas; el Colonyction megalocarpum, vecina del C. speciosum, Choisy, que era la Ipones bona-nox de L.; otra nueva especie, argenlifolia, que con al género IPousa; y el Convolvulus Valenzuelanus.

En la familia de las Venuevaceas, comenzaremos por mencionar el nuevo género Espades ${ }^{1}$ de la segunda tribu ViteE, aunque no perfectamente caracterizado para entrar en ella. Fué dedicado, por recomendacion nuestra, á la memoria de un dignísimo obispo de la Habana, el Exmo. Señor D. Juan de Espada y Landa. protector ilustrado de las ciencias y de las letras. Dicho género cuenta solo una especie hasta el dia, la E. amœna, y es el arbusto que lleva en la Isla el nombre de Rasca barriga, cuyas ramas de una resistencia y elasticidad notables, suelen emplearse para castigos inhumanos. Ademas de esta especie de un nuevo género

Ga dado motivo á las reflexiones siguientes, que la comunicado á la Socíedad ' El género EspadDE, formado por Richard, ha dado motivo a las retlexiones siguichtes,

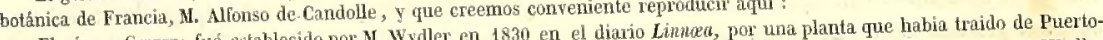

"El género Goetzes fué establecido por M. Wydler en 1830 en el dilo lono en mi herbario, donde las plantas de M. Wydler aco, y cuyas muestras eran probablemente raias o malas, pues no hallo algura lebiar ctar completas. Cuando er conservador de mi herbario, creyo reconoces una planta de la debiancs co mismo género que la de Puerto Rico. Esta presente una nervacion D. Ramon de la Sagra bajo el naina en las hojas tan particular, que habiento risto, por castaliad, la misma especie, con hojas y

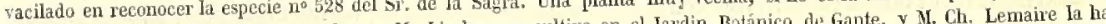
lores mas chicas, ha sido traida de Cuba por M. Linden : se cultiva en el Jardin Botanico de Gante, Moloreada (p. 77). nomlrado ApMesisstrus apiculatum, en el Vol. IV del Jaydinier fleuriste, donde se balla una lámina no coloreada (p. 77).

La besa no parece dudosa : hay solo que rerificar el andisis que ofrece

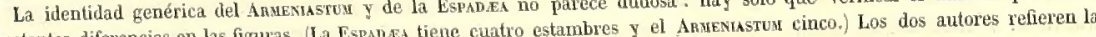
bastantes diferencias en las figuras. (La Espada tiene cuatro estambres y el Ariesta

planta á la familia de las Verbanaceds. El nombre dado por Richard es el mas antiguo, En cuanto al Goetzea primitivo de Wydlex, el de Puerto Rico figurado en la Linnata, no me atrevo á admitir su identidad con el género Espanda, por que los estambies son seis, los ovalos estan representados como colgantes y el estilo como mas corto que los estambres. No es una EBENACEA como creia M. Widler, y tampoco una especie de Espadzs de Cuba, á menos que no que los estambres. No es una Ebliacea como cria. W. Wydler. Lo mas prudente pues me parece considerarla como un génaya crrores graves en la descripeion y en la lámina de M. Wydler. Lo mas prudente pues me parce con de France. - Tom. III, 18 o, p. 348. - Séance du 13 juin. 
cuentan las Verbenaceas con siete mas nuevas é interesantes en la Isla de Cuba, á saber : la Lantana microcephala, vecina de la involucrata de L., las Cablicarpa fulva y cinerea; los Clenodendron tuberculatum y Lindenianum y los VITEx ilicifolia y avicennioides. Ademas de muchas especies herbaceas y subfiuticosas medicinales de los géncros Lippia, Verbena y Lantana, esta familia comprende rambien árboles útiles en la Isla de Cuba, como los son : el Roble amarillo (Cithanexroum caudatum, L.) y el Mangle blanco (Avicennia tomentosa, Jacq.).

Las Escrofuratus ofrecieron tres especies nuevas en el género Bunnfersu, y son la B. cestroides, la B. sinuala y la B. parvifolia, y ninguna en los demas. Las Lanadas solo han dado como nueva, la ScutecLama Cubensis, hallada por M. Linden en el monte Libano, cerca de Santiago de Cuba. Las Acantaceas se han anmentado con dos especies, el Colophanes Cubensis y la Rhytrglossa Sagreana. Las Prumlaceas, Centrularaceas, Plumbaginaceas, Plaviaginaceas y Nictaginaceas, puco numerosas en especies cubanas, no han sido aumentadas con nuestras herborizaciones; y las Amaranthaceas, mucho mas numerosas, les deben solo el Achrranthes hirtiflora y una especie dudosa de Inesine, la gossypiantha, que agregó Riclıard á las otras especies del mismo género, que hallaron los Señores Humboldt y Bompland.

Pasamos por alto las Salsolaceas y las Polygonaceas, que nada nuevo ofrecen hasta ahora en la Isla de Cuba, excepto la Coccoloba coriacea, que parece nueva, para mencionar las Launaceas que ofrecieron á M. Richard materia para adiciones importantes. Tal consideramos la formacion de una nueva tribu, consti tuida por el nuevo género SYMPrysodAPHNE. La única especie que hasta ahora le pertenece, el $\mathrm{S}$. Cubensis, se halla en nuestro herbario y tambien la lalló M. Linden en la provineia de Santiago de Cuba. Mencionaremos ademas la Phorbe Valenzuelana, la $\mathbf{P}$. hypoleuca, la Pensea silvestris, el Aydendnon? Cubense, la Nectandna cigua, la N. Boniato, la N.? longifolia, la N.? magnoliofolia, la Orlodaphne? obozata, la O. Lindeniana y la 0 .? alba; en todo doce especies nueva. Los árboles útiles de esta familia, cn la Isla de Cuba, son el frutal Aguacate (Pensea gratissima, Goetn.), la Cigua, ya cilada, y los Boniatos (Nectandra, Oreodaphis) como maderas mas ó menos útiles.

Lamilia sumanente corta de las Dapuracess, pues solo comprende tres especies cubanas, ha procurado dos nuevas : la Lageta Valenzuelana, muy próxima á la L. lintearia, Lám., y la Hageasseria Cuba. na. Las LaGetta son notables por el tejido relicular de su albura ó capas subcorticales, empleadas en Cuba para hacer cuerdas blancas de suma resistencia.

Se lan perdido tambien, nor la dificultad de conservar las flores y los frutos, varias Aristolociras de nuestro herbario. De las tres que se han conservado, dos resultaron nuevas : la Anistolochis tigrina y la A. passiflorafolia.

Debemos mencionar la familia de las Luronbaceas como característica tambien de la regetacion cubana, pues comprende 28 géneros con 67 especies. Aunque el jugo lechoso de muchas de ellas, sea un obstáculo para su conservacion en herbario, el nuestro y varias uuestras comunicadas por M. Lindley han proporcionado formar un nuevo género y 25 especies tambien nuevas, que enumeraremos rápidameute.

Eénero Bovasu parece vecino del Sarathrostachys de Klolsch. Fué dedicado, por indicacion nuesra, í $D$. Sebastian Bonani, amigo laboriosisimo que nos segundó por el mayor zelo en nuestras tarcas esta. dísticas en la Isla de Cuba, y que hallándose útilmente empleado despues en la Administracion pública, donde dió repetidas pruebas de su idoneidad, falleció víctima del colera morbo. La única especie que constituye este nuevo género, lleva el nombre de B. Cubana. Las otras con que se ha enriquecido la familia que nos acupa, fueron, en el género Eupionna, la Lindeniana, la trachyphylla, la dumosa y la pedunculosa; la Sricingia laurifolia y la variedad microphylla de la eglandulosa; las Acacrpha setosa, membranacea, glechomefolia y pygmaa; las ADELIA microphylla y pedunculosa; los Croton nummularicefolium, vaccinioides, hippophaleoides, Lindenianum, ellipticum y fuloum; la Capenonia neveosa; los Payleanteus micranthus, pruinosus, laurifolius y pubigerus, y la Tricena Cubona. Esta familia es rica en especies útiles á la medicina, á la construccion civil y la economía doméstica. Conocidas son las propiedades de los aceites le Ricino y Je Jatropha curcas, denominada ahora Curcas Indica. Las semillas de otras especies de Cnoton y de J Gora $\mathrm{N}_{\text {aninot }}$ edulis, ofrece dos curiosisimas variedades, indénticas en lo exterior para los botánicos, pero muy diferentes en las propiedades de las raices, pues las de la una (Yuca dulce) son inocentes y agradables, sirviendo de alimento harinoso, y las de la otra (Yuca agria) contienen un jugo venenoso, que es preciso se- 
parar por medio de grandes lavaduras, y utilizar así la pulpa rallada para el pan de Casabe, que es la fariña Dos bellos árboles, introducidos en la Isla de Cuba y muy generalizados

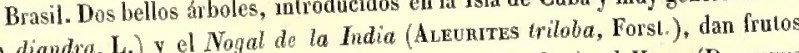
ahora, el Avellano (Omphalea diandra L.) y el Yaiti (Excæacarua lucida, Sw.), el Hueso (Dnxpetes aceitosos que pueden utilizarse. Otros arboles, como el Yaic (Bxonstruccion; por viltimo, las semillas de la alba, Poir.) y el Maco (D. glauca, Vahl.) dan madera pebemos añadir que este árbol, que descubrimos entre Stiungia sebifera, suministran un sebo vegetal, pero debor los que forman la alameda de la Habana, no creemos que sea indigena. En este conjunto Mancinella, L.), de aunque provistos de jugos nocivos, se encuentra tambien el Manzanilho (Hhome funesta reputacion.

Is la de Cuba mucho mas rica de lo que aparece en la presentc Flora donde está representada por 8 géneros comprensivos de 20 especies, entre las cuales resultaron nuevas el Celts parvifolia, el Ficus Jacquiniefolia y las Urtica cuneata y Lindeniana. Las plantas de esta familia son aplicables las unas por las fibras textiles de sus tallos, como los Jagneyes (Ficus populnea y Wild.) y el Chiehicastre (Untica baccifera, L.), otras por la materia colorante de sus troncos, como el Fustete (Broussonetia tinctoria, Kunth). Oira especie, que vegeta en los jardines de la Isla, pero que no es indigena, sino de la China, para la fabricacion del papel (B. papyrifera). Debemos mencionar tambien. entre los árboles útiles introducidos, el llamado del Ule de Méjico, descrito por Cervantes y poco estudiado aun por los botánicos. Vegeta con suma rapidez, se multiplica fácilmente de semilla, y produce, por las incision del tronco un jugo lechoso que es un verdadero caoutchoue ó goma elástica.

Despues de la familia de las Piperaceas, que nada de notable ofrece hasta ahora en la Isla de Cuba, mas que tres especies nuevas (los Piper articulatum y leptostachium y la Peperomia limeatipila), nos hallamos con una nueva especie de Encina (Quencus Cubana), que bien pudiera ser una de las variedades del diversifolia de Wild, que vegeta en el vecino continente de Nueva España. Es el único representante cubano de la familia de las Cupuliferas, tan comunes en Europa y en la América septentrional. El fruto de esta especie sirve en la Vuelta de Abajo lo mismo que las bellotas europeas, para el alimento de los cerdos. 作 chere ques fué remitido de la Vuelta de Abajo y que dudamos sea indigeno, pues Michaux le reconoció en la América del Norte, de donde pudo ser traido á la Isla de Cuba. Sin embargo, el Señor Valenzuela no nos hizo observacion alguna al remitirnos las ramas en herbario.

La familia de las Mrricaceas tampoco se halla representada mas que por una especie, la Mrrica Carolinensis, Mill., idéntica á la hallada en los Estados Unidos, de donde tal vez pudo haber sido introducida. En general dudamos conceder carta de ualuraleza cubana á estas especies solitarias en las familias, que se hallan asociadas con otras en el continente vecino á la Isla de Cuba. Esta reflexion se refiere á los tres representantes que venimos de cilar, de tres familias que no son intertropicales. Otro tanto podemos decir de la única quan el Libano, cerca de Santiago de Cuba.

La familia de las Conifenas tampoco tiene en la Isla de Cuba mas que un representante, el Prnus occidentalis, que ademas de la Vuelta de Abajo, vegeta abundantemente en la islita de Pinos, que le debe su nombre desde la época del descubrimiento por Cristobal Colon.

Pasando rápidamente las Cicadaceas, que no creemos indigenas, llegamos á la rica y hermosa familia de las Onguidens, representada en la presente Flora por 50 especies, que indudablemente serán aumentadas en las futuras exploraciones que se hagan en los bosques cubanos. Las copas de los árboles se hallan cubiertas de estas lindas plantas, y por lo tanto creemos que, examinándolas con detencion, se hallarán muchas mas especies que las de nuestro herbario, $y$ las que pudo estudiar nuestro sabio colaborador en el Jardin de Faculaad le Medicina que dirigia. Entre ellas halló varias plantas nuevas, con una de las cuales formó el nuevo género Ruynchadena, que solo liene aun una especie, la R. Cubana, y cuyo lugar en la ciencia sè halla entre los géneros Ornithidium y Ornithorynchus; y ademas 17 especies nuevas en los géneros ya conocidos, á saber: los Perurothalds? pachyrackis y Valenzuelana, que con duda refirió á este género; los Epilendeum Sagraanum, hircinum, affine, ochranthum, nematocaulon, Duboisianum, oblongatum, amphistamum; la Bietia tenera, el Oncidium Guibertianum, la Polystachia? membranacea, las Habenaria tricuspis y replicata, la Ponthievra lancifolia y el Physurus Sagraanus. A esta lista de especies nuevas cubanas, deben agregarse cuando menos diez y seis otras halladas por M. Linden y publicadas poco tiempo antes de 
haber sido comprendidas por M. Richard en la presente obra. Ademas, creyó este conveniente trasladar al género Spiranthes varias especies del Stenonhynchus, que aparecen asi con nuevas denominaciones. Come especie útil, solo podemos cilar hasia ahora la Vamilla, de la cual no se hace uso alguno en la Isla de Cuba

La familia de las Zingueracess ha suministrado á M. Richard una nueva especie cubana en el herbario que le confiamos, á saber: la Renealma amona, habiendo ademas transladado á este género dos antiguas dupinias, la racemosa y la occidentalis. Este grupo presenta plantas medicinales de propiedades muy importantes, como son el Gengibre, el Cojate (R. occidentalis) y la Cañela Santa (Costus spicatus, Sw.).

La familia de las Cannaceas está representada en la Isla de Cuba por tres géneros, Thata, Manantia y Canna, que no han sido enriquecidos por nuestras herborizaciones. Siguen las utilísimas y alimenticias Musaceas con su género típico bien conocido. Vienen luego las Amaruldorceas, donde están los Agave y Fourcnoy , aplicables para la cordelería y los tejidos, y la Alstroemenia comestible, muy poco apreciada en las Antillas.

Otra familia, muy aline á la precedente, y que ligurará con ella en la bistoria de las artes textiles, es la de las Bromeliaceas; comprende las Pitcairina, las Bronelia, las Ananassa y las Tulcandsta, todas úliles por la notable firmeza y resistencia de las fibras de sus hejas. El último de estos géneros ha sido enriquecido con dos especies nuevas, á saber : las Tillanosia breviscapa y Valenzuelana, ademas de otras recientemente halladas en Cuba y descritas por M. Hooker.

La familia de las Sucacess es recomendable por las virtudes medicinales de la raices de las especies del género tipo; pues ademas de la Zarzaparilla, hay otras muy usadas, como la syphititica, la pseudo-china y otras.

En las Pontederuceas, muy escasas en la Isla, se ha hallado una nueva especie, la Eichoniara cordifolia, y las Commelinaceas, nada ofrecieron en los dos géneros Commeryay y Tradescanthia, que no fuese conocido.

Nuestro herbario presenta un gran vacio que lienar con las diversas especies de palmas cubanas, cuyos nombres vulgares reunimos, pero sin haber podido conseguir que de las mas nos enviasen espatas floridas. Por esto, solo se mencionan 10 especies, cuando indudablemente hay mas en la Isla de Cuba. En general son árboles utilisimos por sus hojas y sus frutos, y la Palma real silvestre, que es delgada y se eleva mucho en el interior de los bosques, ofrece una madera durísima que puede usarse en la ebanistería, por el jaspeado negro de las fibras leñosas.

En la familia de las Anacess, ha formado M. Richard un nuevo género con una especie hasia ahora, la Avorovycia Cubensis, que se aproxima al género Pebtanona de Rafinesque. En la misma familia se halla

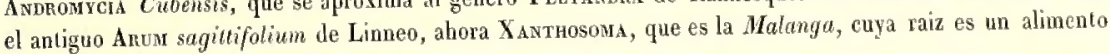
farinaceo muy estimado por los negros.

La familia de las Traceas no ha presentado mas que la especie comun, T. angustifolia, L.; pero en la siguiente de las Cyperaceas, se encuentran nuevas especies; tales son el Cypenus filiculneus, el Fimbistyus; conferta, las Rhyncosposa cephalantha y Cubensis. No obstante haber reunido 36 especies cubanas, no creemos suficientemente bien representada esta familia en nuestra Flora.

La siguiente de las Grumess será tambien aumentada considerablemente en lo sucesivo, y merece ser de nuevo estudiada en la parte económica del uso que hacen los animales y el efecto que su alimento les produce. La dificultad de obtener datos exactos procede de la confusion de las denominaciones vulgares, pues es sumamente general el nombre de grama y de yerba, que indistintamente aplican los naturales á especies de géneros muy lejanos. Debe ser muy rica esta familia en la Isla de Cuba, puesto que ya hallamos en ella representantes de todas las tribus de Gramineas, y algunos géneros con un número bastante notable de especies. El total de las de la familia asciende á 70, en 28 géneros distintos; y el de las especies nuevas á 13 . á saber : los Paspalum inflatum, alterniflorum, Lindenianum; los Panicum distantiflorum, Valenzuelanum, minutiflorum, oblusiflonum, saccharoides; el Piptatherdar setosum, el Streptachan Cubensis, el Polypogon Cubensis, la Crucons Sagreana y la Festuca laxifora. La última Graminea de la Flora cubana es la Caña de azúcar, que bien merece carta de naturaleza, aunque no sea indigena ninguna de las variedades que alli se cultivan.

Terminaremos las Fanerógamas por dos pepueñas familias : las Alisuaceas y las Namdaceas, ambas escasamente representadas hasta ahora por plantas cubanas, que no dejarán de existir y que serán la conquista de nuestros continuadores.

Botanica. 
Dada esta rápida idea de la vegetacion de plantas vascurares, vamos á presentar una revision igualmente sucinta de las plantas celurares.

Como ya indicamos, el estudio y la determinacion de las especies criptogámicas que hemos traido de la Isla de Cuba, fueron confiados al laborioso y concienzudo Mr. C. Montagne, quien confirmó, en el interesante trabajo que hizo, las esperanzas que justamente inspiraban otros muchos con los cuales habia ya ilustrado su nombre. Felizmente para nuestra obra, y aunque en perjuicio de otras secciones que fueron publicadas mas tarde, pudimos conceder á nuestro sabio amigo, cierta latitud para exponer sus reflexiones y describir las especies, que no nos fué posible extender mas tarde al distinguido y malogrado Richard, para la seccion de las plantas fanerógamas. Gracias á este privilegio de las circunstancias, le fué dado á M. Montagne enriquecex el volúmen de la Criptogamía, con seis apéndices notables y utilisimos sobre cada uno de los órdenes y grandes secciones de ella, correspondientes á las Frceas, las Brsaceas y los Liovenes, los Hongos, las Iepaticas y los Muzgos.

Al lacer tal concesion de espacio á M. Montagne, Hevabamos la mira de procurar á los Institutos y Bibliótecas cientificas de España, una nueva y selecta doctrina sobre esta parte de la botánica, que no sabemos exista scmejante en obra alguna publicada en lengua castellana. Con igual motivo autorizamos á nuestro digno colaborador, para que, en la representacion de las especies, presentase los detalles anatómicos suficientes para dar a la juventud española una idea exacla de la organizacion y de las funciones de tan interesantes vegetales, que por su extremada pequeñez y blandura, no pueden ser vistos en las plantas vivas. La cómara lúcida, perfeccionada y aplicada al microscopio acromático de C. Chevalier, fué el grande auxiliar de M. Montagne para figurar tan imperceptibles cuanto ruriosos detalles; y con el ha podido aumentar, por ejemplo, 180 veces el tallito del Cenanrum clavulatum y hacer tres secciones en un espesor que apenas llega á medio prouto.

Las doctrinas que ha emitido sobre la organizacion, el desarrollo y la procreacion de las diversas familias de Criptógamas, revelan al lector toda la serie de misterios y de prodigios de la vida vegetal en esos curiosos seres; desde los inciertos y ambiguos de algunas Algas llamadas Zoospermas y Diatomaceas, análogos óidén ticos á los de los animales infusorios, hasta los evidentes y regulares, por sexos separados, como en las Hepaticas y los Muzjos.

Entre las reflexiones á que se ha entregado M. Montagne sobre las Criptógamas en general y las de la Isla de Cuba en particular, no podia menos de aludir á la mision de las mas imperfectas de esas plantas en el órden universal y admirable de las creaciones vitales ú orgánicas, formando como los embriones ó primeras manifestaciones de la vida, que parecen no piden á la naturaleza mas que un poco de humedad para desarrollarse. Tal es esa multitud de Algas que tapizan los lugares humedos, ya bajo el ciclo helado del polo, como el Hematococeus nivalis, Ag., ya en la temperatura ardiente de las aguas minerales á 40 grados cenlígrados, como la Oscrlearia Moutgeolli, Bory. Esas imperceptibles cuanto innumerables formas orgánicas, fueron probablemente los primeros labitantes del globo en la époea de la aparieion de la vida sohre su superficic, y cuyos restos amontonados por los siglos, la procuraron la costra terrea adecuada para la vegetacion sucesiva de las demas especies vegetales.

Tampoco podia olvidar M. Montagne el hacer alusion á los usos de muchas Criptógamas, ya para el alimento, ya para la medicina, ya para las artes tinctorias. Pero al mencionar las propiedades útiles de unas, no pado ocultar las dañosas de otras, y particularmente sus efectos desastrosos, como parásitas casi invisibles que ya atacan y deterioran el organismo animal, como la Muscardina del guano de la seda, ó ya se ceban en las mas ricas cosechas, como el carbon del trigo, el oidium de la vil y tantas otras plagas de la época presente. Bajo este punto de vista, adquiere sumo interés el estudio, antes descuidado, de las plantas criptógamas.

Pasando ahora á hacer una revision de las especies que reunimos en la Isla de Cuba, y que ya dijimos as. ciendan ả 306 , distribuidas en 126 géneros, comenzaremos por las ALGAS sumeng Das ó pHyceas.

Comprende esta familia 57 especies, de las cuales 12 son enteramente nuevas. Vamos á indicarlas rápidamente. La Broulphia Australis, en ese curioso órden de las Draromacens que M. Ebrenberg presenta como animales infusioros con caparacho siliceo; el Scrtonema rubrum, de género dudoso; la Confenva brachyclados, la Bropśs ramulosa, vecina de la Ballisiana, la Cuulenpa fastigiata; las Posysiphonia secunda y Habanensis, la Rhonomela calamistrala, el Sphenococcus corallopsis, muy parecido á una Gigartina, Ag.; 
el Haciseris plagiogramma, el Ectocarpus minulilus, cuyogénero es dudoso, y el Sargassun polyceratum.

M. Montagne propone subdividir en dos el género Rhodovica, dando el nombre de Bostrychia al nuevo, cuyos earactéres presentan de acuerdo con M. Duby.

La familia de las Brssacens comprende tres géneros, con un total de solas cinco especies, de las cuales tres fueron incorporadas por M. Montagne al nuevo género Leptogrum de Fries. La familia de los Licuenes comprende 69 especies distribuidas en 22 géneros poco ricos, exceptuando el Parmest, que tiene 17 espe. cies. Las especies que M. Montogne halló nuevas, en la coleccion cubana, fueron 9, á saber : las Striguxa nitida y rotula, la Pentusarua entophloca, las Thelotrear Aubertianum y oliraccum, la Opegrapha fliciana, las Biatora vestita y pusilla, y la Parmela Valenzueliana.

Los HONGOS, distribuidos en seis familias naturales, comprenden 116 especies distribuidas en 53 géneros. En la primera familia, Covionxceres, hay tres plantas nuevas, una en cada género de los tres que la representan hasta ahora en la Isla de Cuba, y son la Puccinia plagiopus, la Tonula orthoclada, vecina de la herbarum, $y$ la Pencoca sphariaformis.

La familia de los Hrpiomrenes, que solo comprende diez especies, ofrece siete nuevas cubanas, á saber : los Fusisponum cylindricum y carneum, los Hetanshosponum dorycarpum, Zygosponum oscheoides, Mucon croceus, STLbux cimabaritum y la lshna gigantea. Casi todas estas plantas son tan extremadamente chicas, que es preciso aumentarlas 800 y mas veces para percibir sus órganos, describirlos y representarlos con exacLitud, cual se hallan en las preciosas láminas de la presente Flora. En algunas, como en ol Asporgillus candidus, Link., M. Montagne ha llevado el aumento lrası 1,200 diámetros, para ver de descubrir ciertos órganos indicados por los autores. El Stı́nи cinnabarium necesitó el aumento de 780 diámetros para ver su estructura. La IsAnis gigantea, en fin, es una produccion singular que M. Montagne no se atreve á asegurar ser realmente una Isaru, pues pudiera ser tambien una CLavaria.

De las nueve esprecies que ofiece en la Isla de Cuba la familia de las Gistenosrcetes, cuatro son debidas á M. Montagne, por haberlas descubierto en el herbario que le confiamos. Son el Dinxuum polymorphum, el Turostoma exasperatum, que el autor sospecha pueda formar el lipo de un nuevo género, el Hipporerdon crucibulum, especie de un nuevo género, distinto de todos los otros Lycoperdon, que con tres de este forman hasta ahora el grupo genérico que describe; por último, la Niducaria intermedia, que parece colocarse entre las N. plicata, Fries, y N. stricta, Bull.

La familia de los Pronomycenes cuenta 24 especies en la Isla de Cuba, 14 de ellas nuevamente descritas por nuestro sabio colaborador, y casi todas las demas estudiadas de nuevo. Entre las primeras se hallan el Micropertis applanaia, la Meliora Amphitricta, la Sigmea submaculans, la Dothidea corallina, la Diproda anomala, muy parecida a una Sphara; la SPHeria pityrodes, la Hypocrea perpusilla, los Hypoxyon bomba, Sagraanum, bacilhm, hemalostroma, polyspermum, Cubense y dichotomum.

Las Drscomretes solo cuentan ocho especies en la Isla, y de ellas einco son nuevas. El Stretis thelo. threma, la Leptostroma orchidearm, los Rhyтsma gyrosum y maculans, y la Prziza leucomhiodina, que fué preciso aumentar $\mathbf{8 0 0}$ veces para percibir sus tecas y esporideas. Las cúpulas son tan chicas que no exce. den de un cuarto de milimetro, aun estanclo liumedecidas.

La última familia del óden de los Hongos, los Hemexomceres, es la mas numerosa de todas en la Isla de Cuba, puesto que comprende 61 especies distribuidas en 17 géneros de los cuales el Poryporus tiene 32 especies; en contraposicion otros nueve solo están representados por una sola. M. Montagne halló en nuestro lierbario 25 especies nuevas, á saber : las Exious fusco-succinea y polytricha, los Hrpocnus holoxanchus y albo-cinctus, esta última dudosa, porque puliera ser un thalus esteril de un liquen; el Conticum Auberianum, el STereum papyrium, muy parecido al membranaceum, Fries, de la Isla de Borbon; el Fuyorus cucu. latus, vecino del Europeus, y que une este género eon el Potyporus; la Hexaronia polygramma, cl Glozoponus conchioides, que semeja á la Tneliphona hirsuta de Pers.; los Polyponus flabellum, byrsinus, Valenzue. liamu, Auberianus, lycnoides, senex, Cubensis, Sagreanus, tricholoma, pachypus, melanoporus, micromegas, y omalopitus; los Lentinus eugrammus y glabratus y el Marasmes hamatocephalus. - Me será permitido hacer aquí una pausa, para consignar la expresion de mi reconocimiento á M. Montagne, por haber unido mi nombre, en el género Poryponus, á los de mis buenos, antiguos y laboriosísimos amigos Valenzuela y Auber, que tanto me han ayudado en mis penosas investigaciones sobre las plantas cubanas.

Al llegar al órden de los MUZGOS, sentimos con nuestro digno colaborador, que nuestro herbario sea 
tan escaso en especies, pues solo contamos 59, de las cuales 32 Hepaticas y 27 Muzgos propiamente tales. En la primera, encontró M. Montagoe 11 especies nuevas : la Jungenmana thizantha, la Phragmcoms Sagraana, las Lejeunia lata-virens, phyllobola, cancellata, myriocarpa, radicosa, cardiocarpa, serrulata, Cubensis y Auberiana; algunas de estas últimas fueron determinadas por nuestro amigo en union de M. Nees, Eutre los Muzgos propiamente tales, halló solamente dos especies nuevas, ambas en el géncro Hypurr, a saber : el liliputianum, denominado así á causa de su tamaño microscópico, y que se halla figurado en esta Flora, y el Montagnei, dedicado á nuestro colaborador por M. Belanger, que le halló por la vez primera en la Isla de Java.

De la revision que venimos de hacer resultan ser nuevas 92 criptógamas de las 306 descritas en la presente abra, las cuales, unidas á las 450 especies nuevas de Fanerógamas que hemos citado, componen un total de 542 especies agregadas á los archivos de la botánica.

Pero no es solo el número de las especies ya antes descritas, ya nuevamente halladas, lo que hace mas importante el conjunto vegetal de la Flora Cubana, sino la variadad de aplicaciones ya como alimento del hombre y de los animales, ya en la medicina, ya en la industria; pues dificilmente se encontrará otra comarca en el globo, cuya vegetacion ofrezca un número proporcionalmente tan considerable, como en la Isla de Cuba.

En el precedente análisis procuramos dar una ligera idea de esta particularidad preciosa, indicando, muy de paso, las especies útiles que mas particularmente se distinguen en eada familia; pero bien se puede conocer que tan rápidas menciones, no son de modo alguno suficientes para el fin que debe proponerse el viagero que al reunir las plantas de una region tan venturosa, ha tenido sumo cuidabo de recoger cuantas noticias ha podido sobre las aplicaciones y usos. De este acopio de datos, unidos y relacionados con los catálogos de las denominaciones vulgares, podiamos entresacar un interesante tratado de Prantas usuales DE Los Cubsnos, el cual comprenderá, ademas de las denominaciones que diversas veces publicamos, la noticia detallada de las propiedades y usos.

De estos dimostambien, una muy sucinta idea en las mencionadas listas; pero requerian mas ámplias explieaciones sobre las cuales hemos reunido muchos materiales. En la scceion de plantas medicinales, en la de maderas, y en la de fibras textiles, creemos que nuestras notas, siendo publicadas, llamarian la atencion sobre la riqueza cubana, y prestarian motivo para organizar empresas para explotaciones valiosas. Despues de haber mencionado la correspondencia que establecimos y los resultados que nos ha procurado, experimentamos una verdadera pena de dejarlos ineditos. Esto será fácil de creer cuando nos atrevemos á expresar el deseo de completar la grande obra que hace tantos años emprendimos, sin que la fátiga de tamaña tarea y las contrariedades y los disgustos que nos ha ocasionado, nos arredren en al propósito. En efecto, la exposicion metódica de los usos de las plantas cubanas, nos parece que seria un complemento utilisimo de la presente Flora, y una obra que podrian consultar por separado, las personas extrañas á la ciencia. Ella completaria el cuadro de la riqueza vegetal cubana, presentándole bajo el punto de vista de su utilidad económica, industrial, agricola y medicinal. 

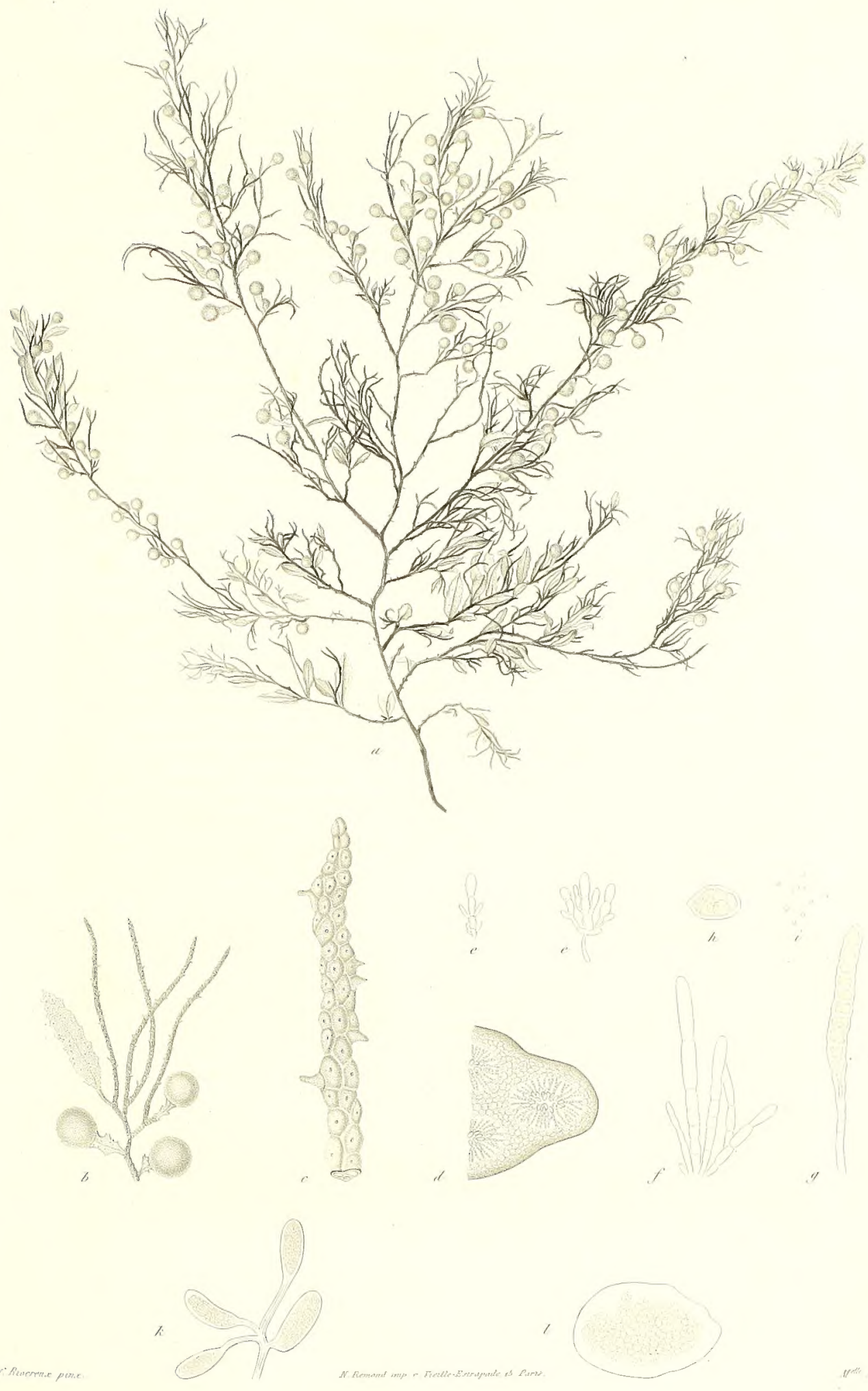

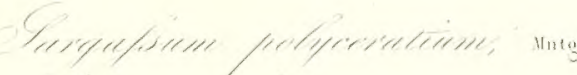




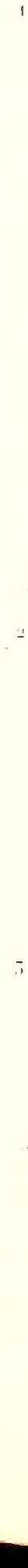




$$
\begin{gathered}
b^{-6} \\
0
\end{gathered}
$$



iptolugamit.

l'lisceil.

'Y.4, III

1.
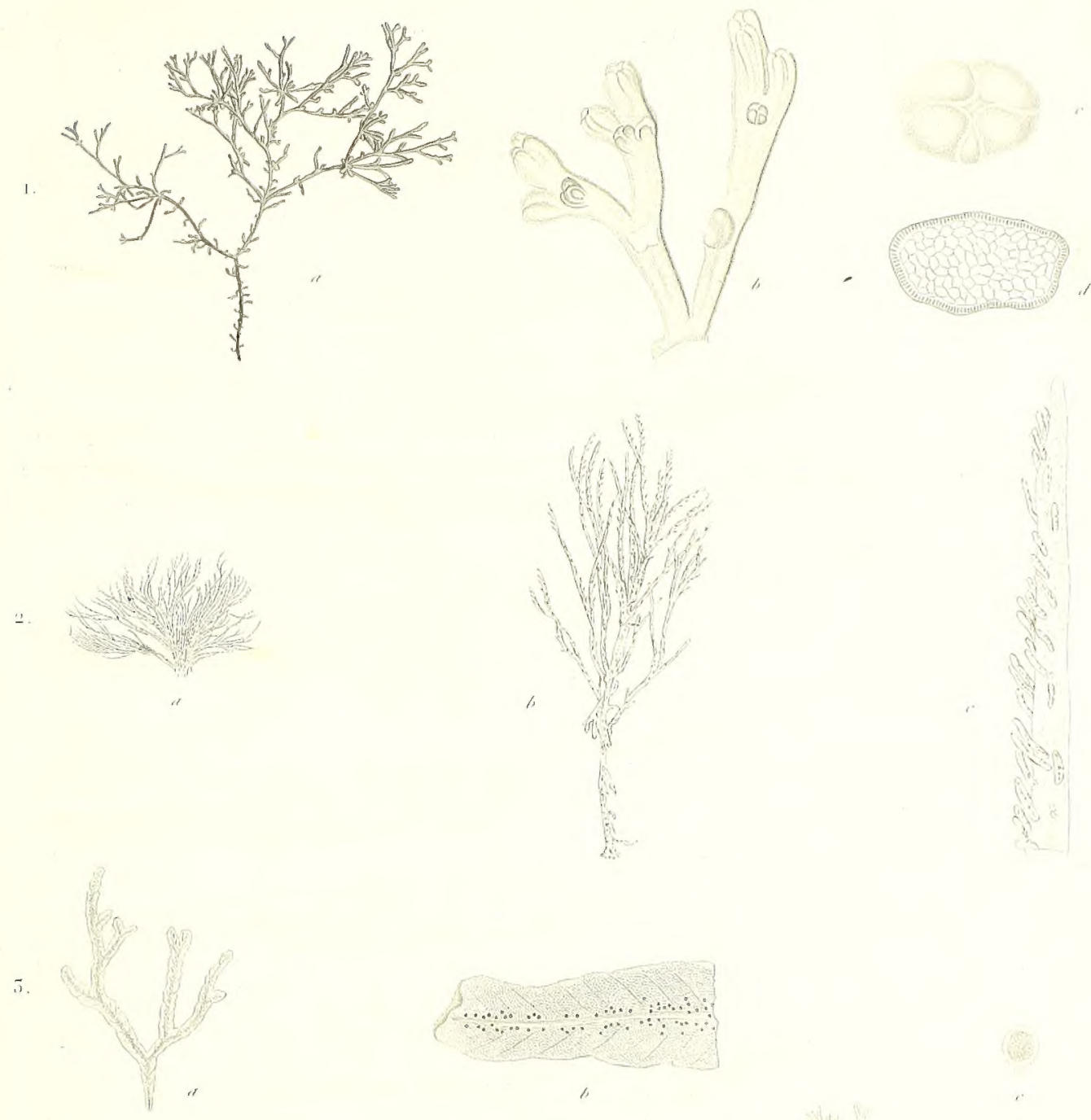

4.
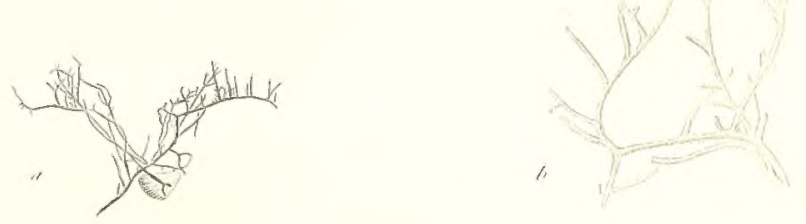

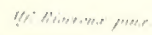

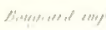

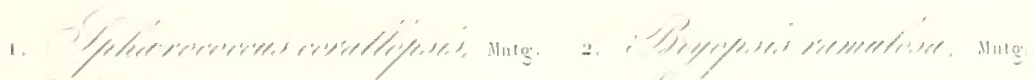

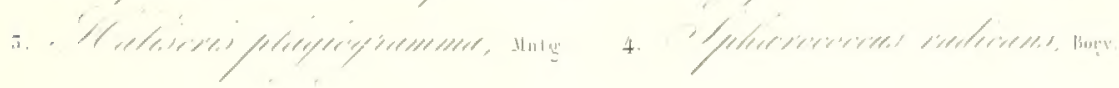




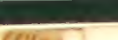
. 

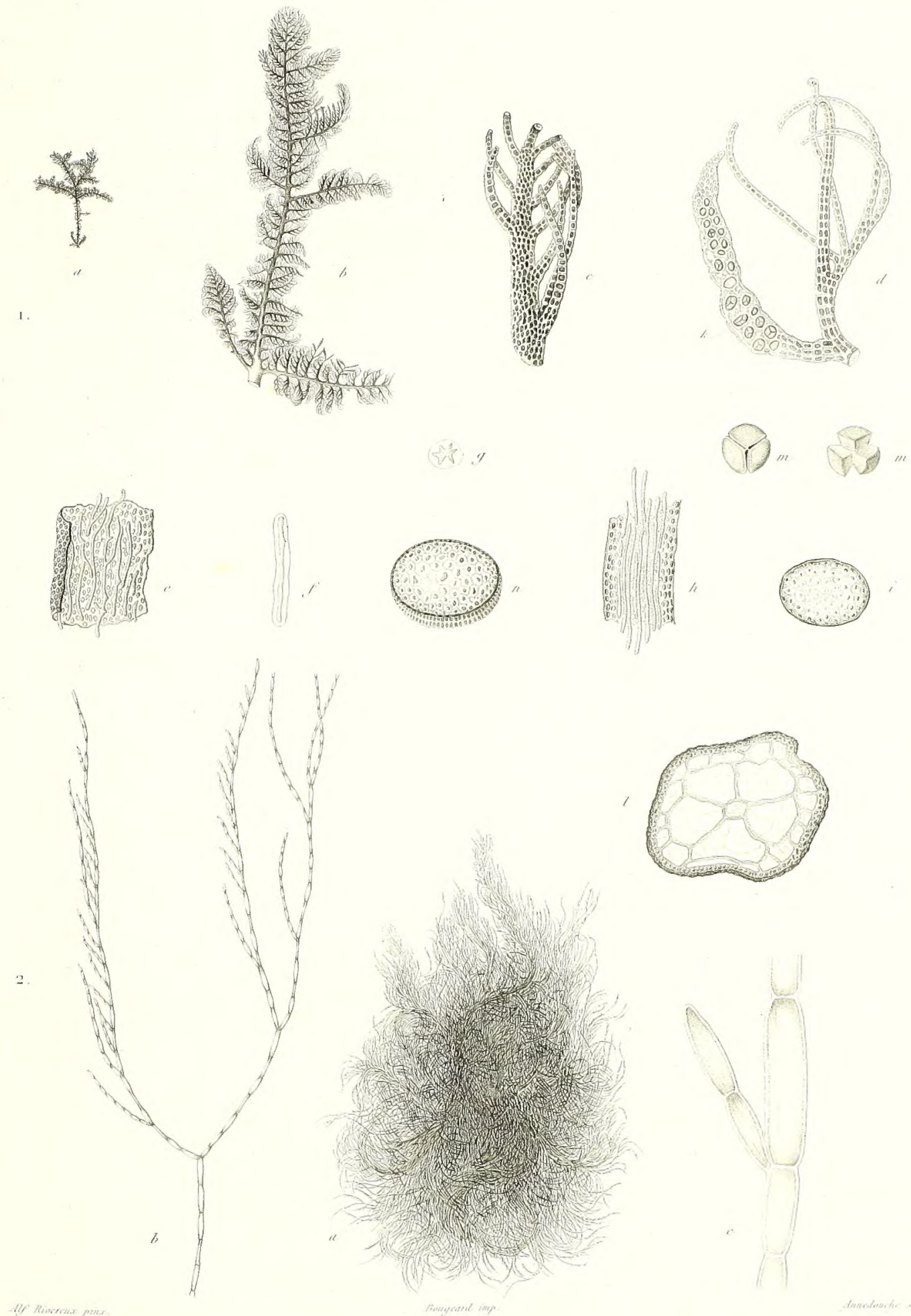

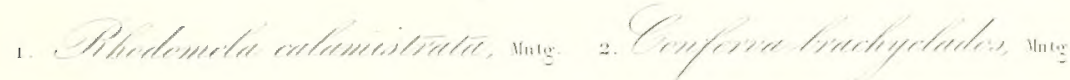




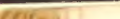




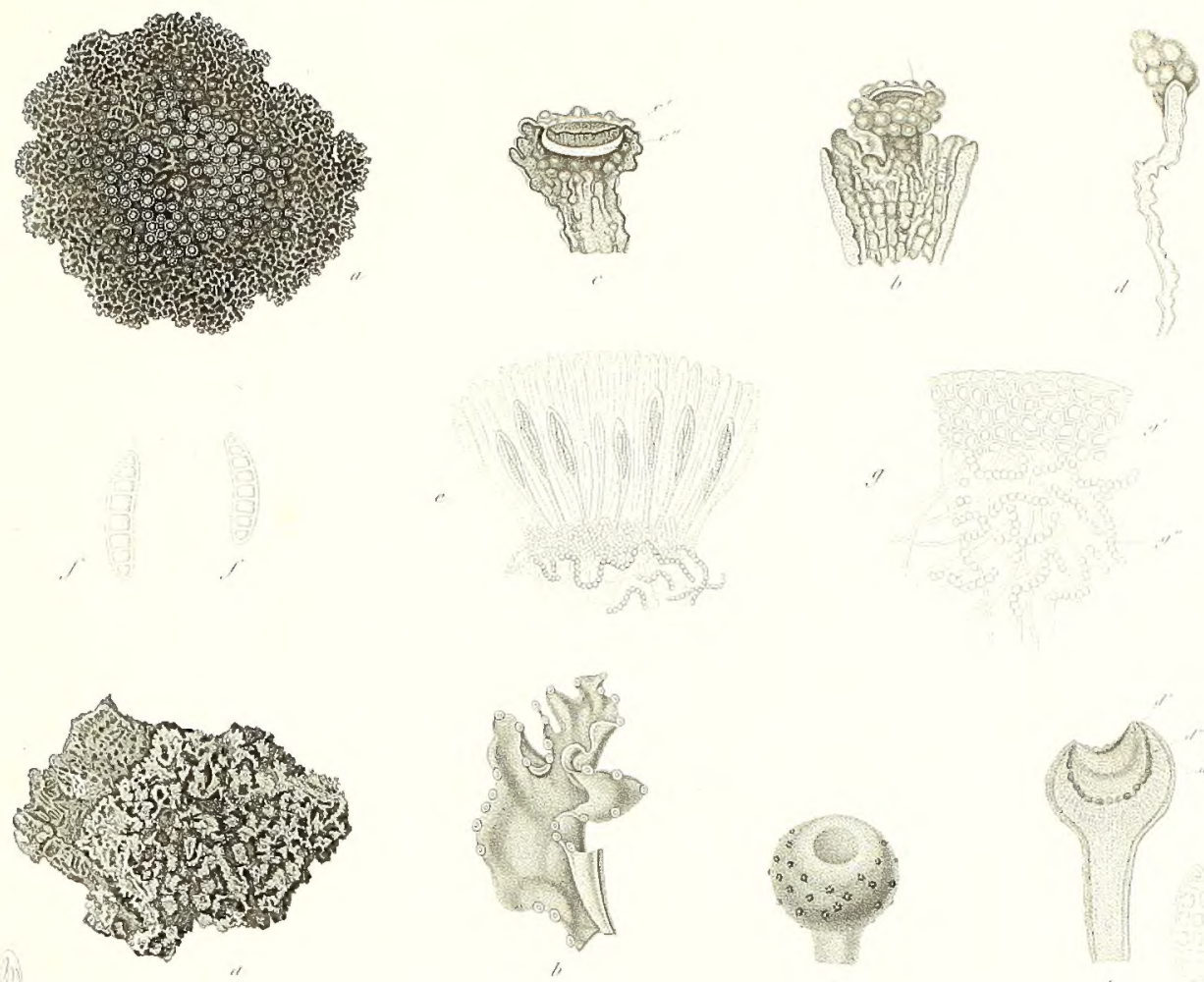

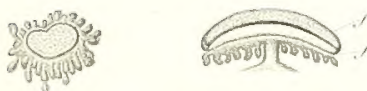
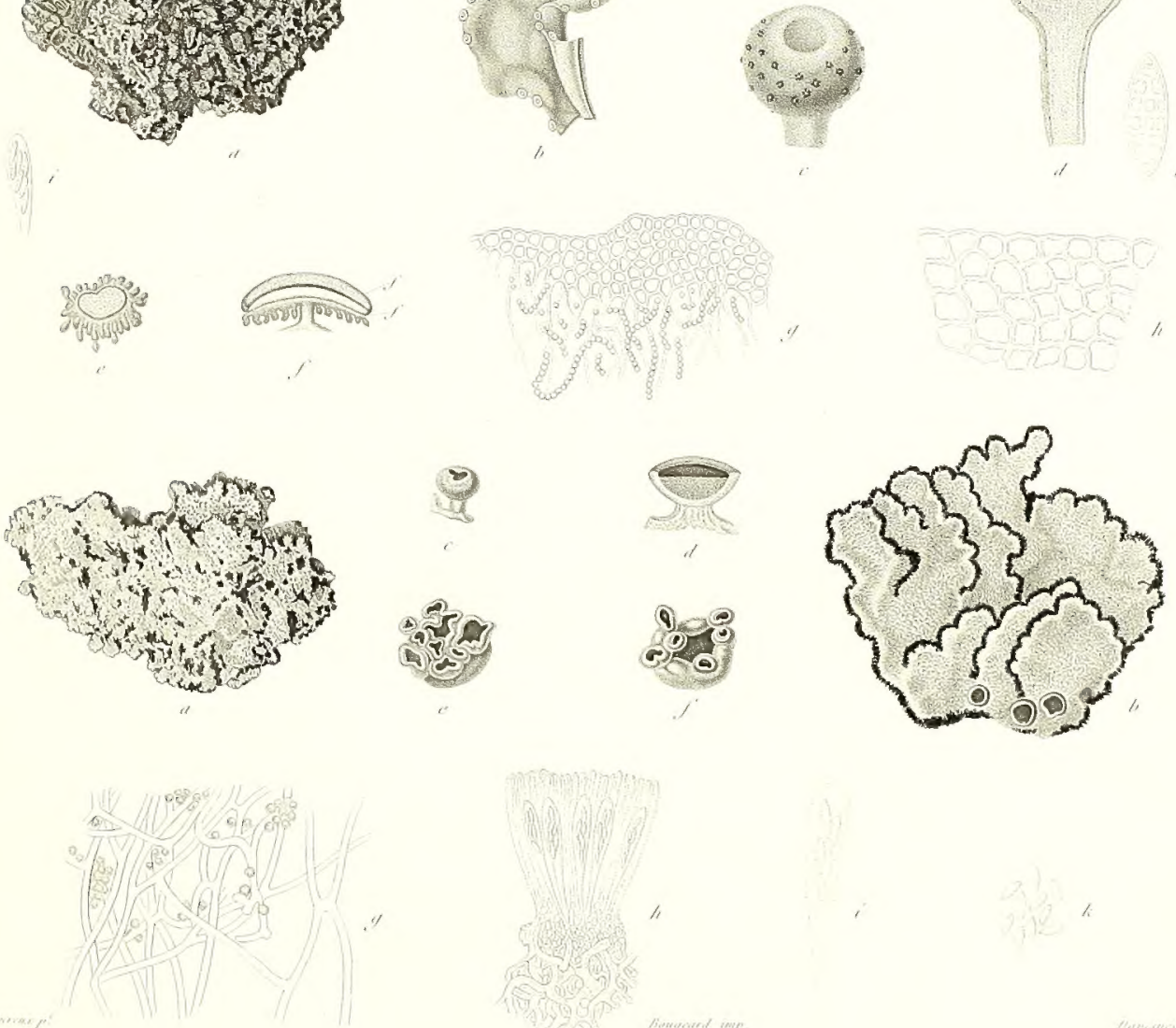

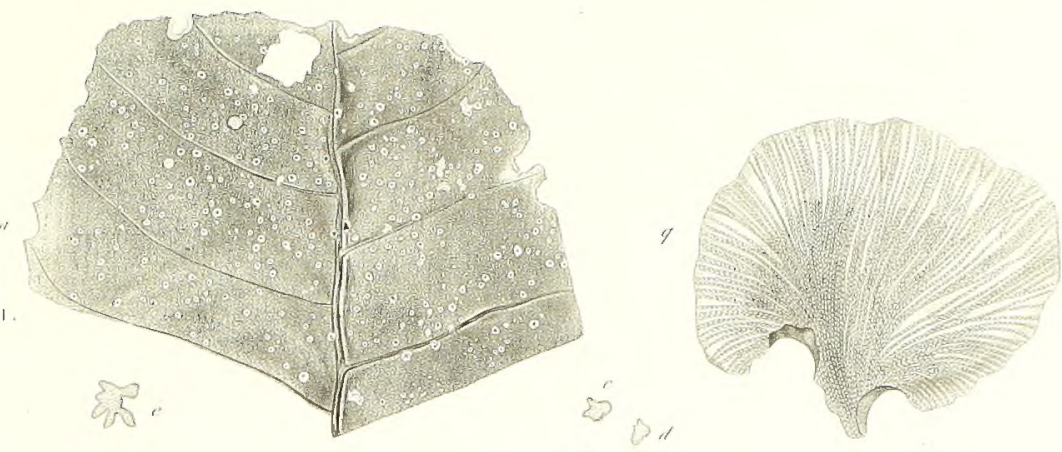

0 होis
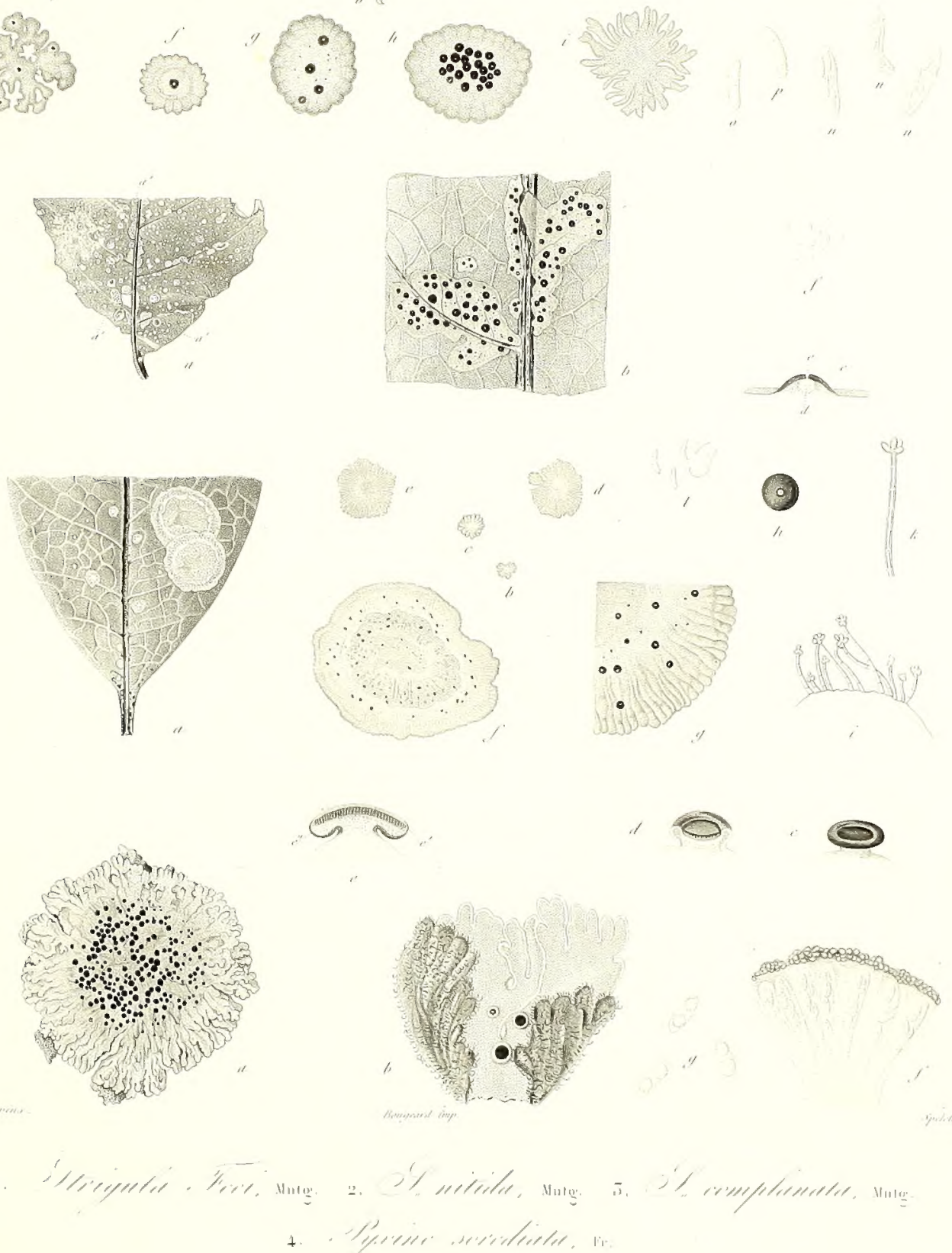


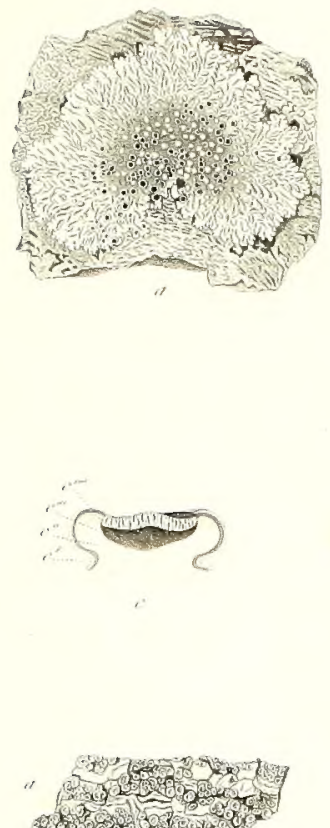

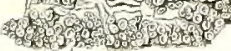
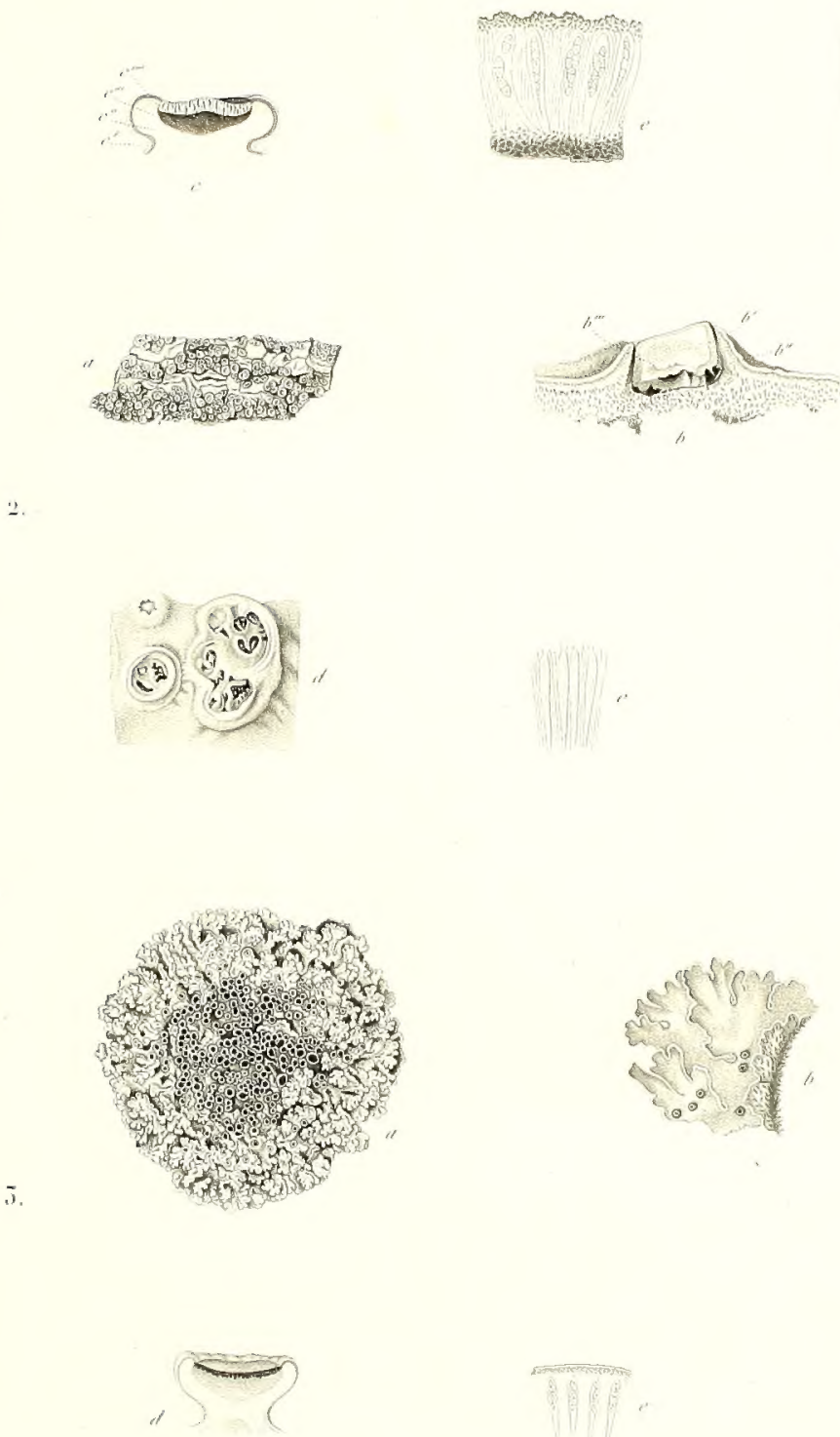

cont

$$
(2,5)(969)
$$

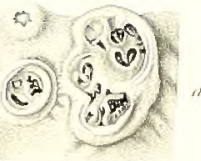

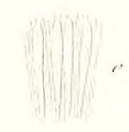
00
(4)

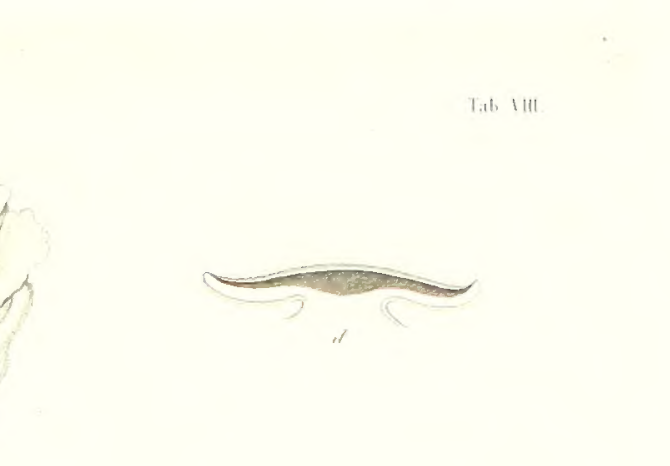




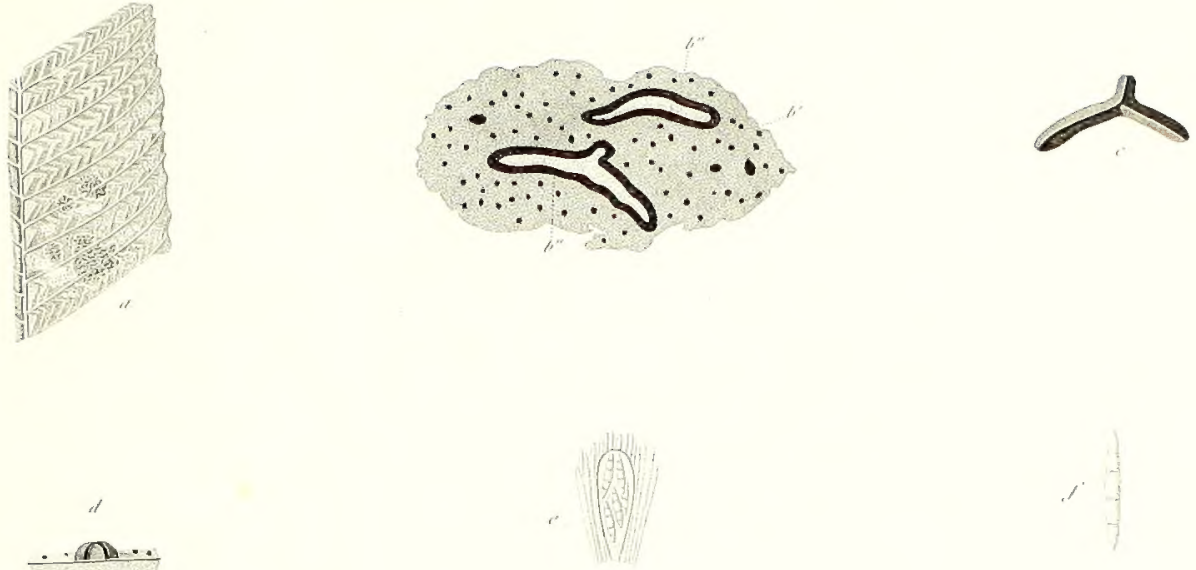

. $1 \mathrm{a}$.

Enimatis
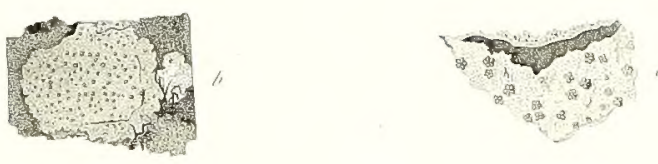

\section{सिएक}

Silo

$\varsubsetneqq$
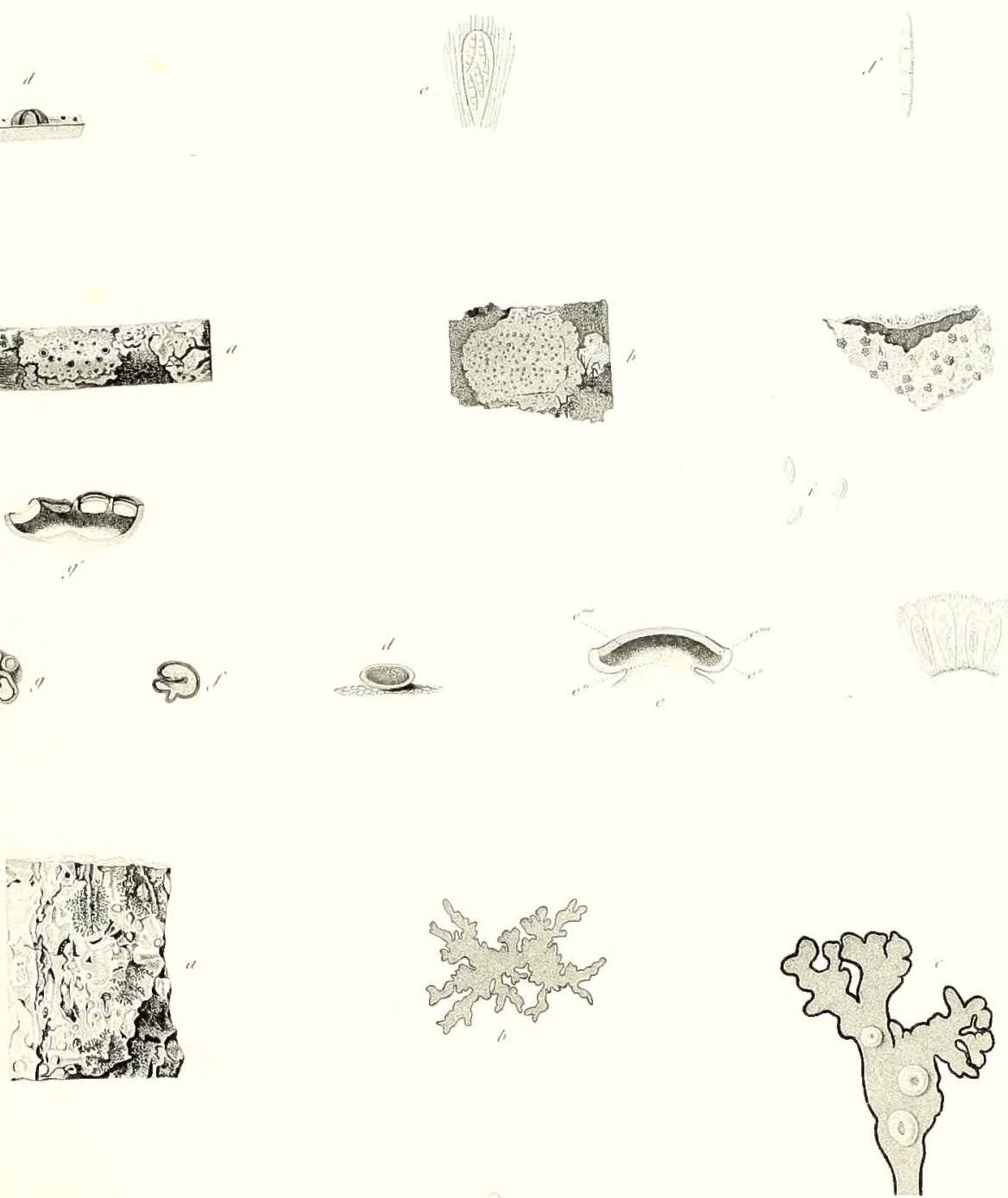

जा ? 


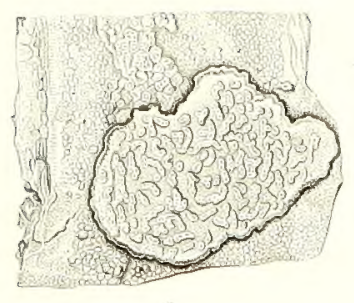

$$
\frac{10010}{x+1}
$$

$$
\text { और }
$$
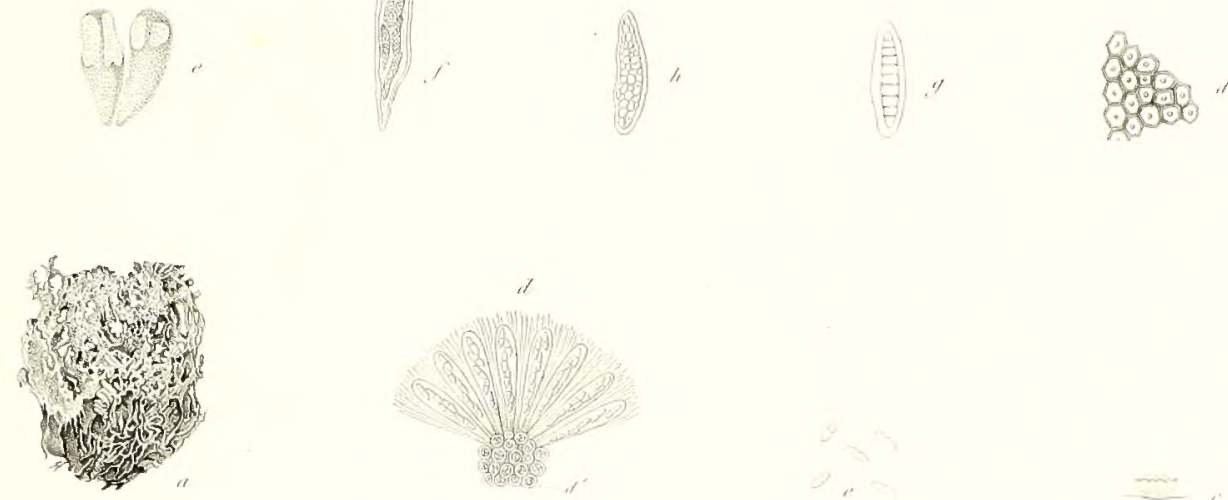

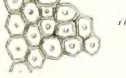

(B)

(2)

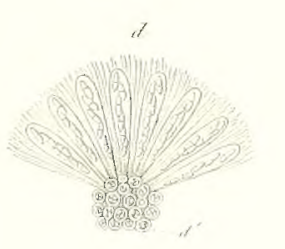

- vits-3.

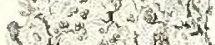

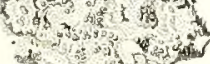
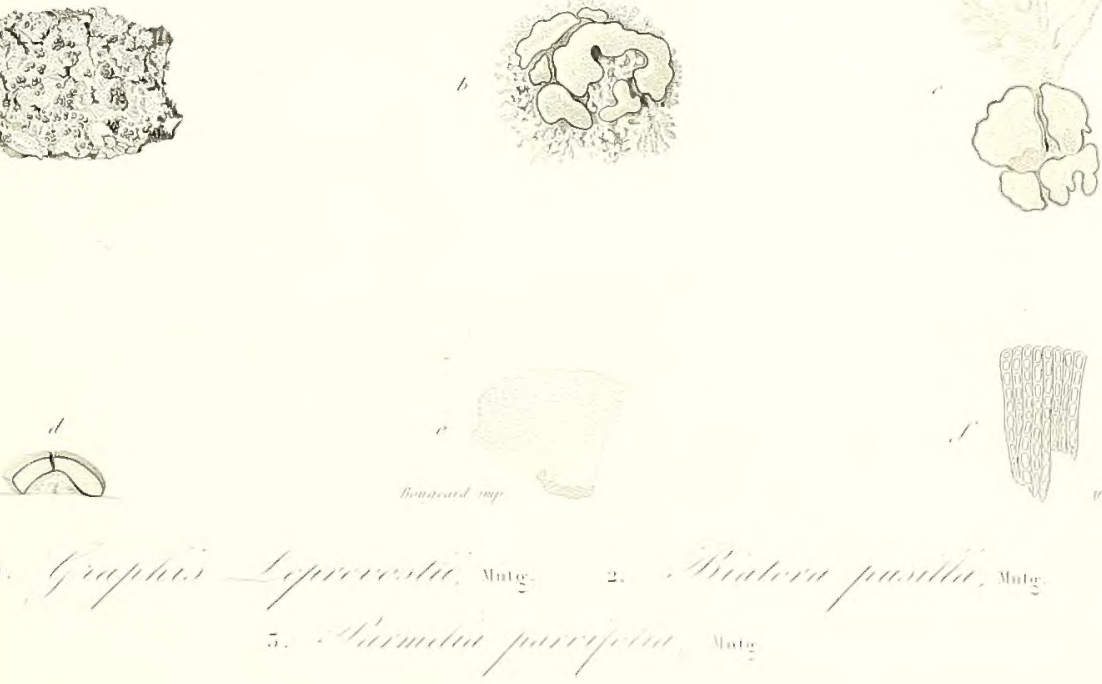

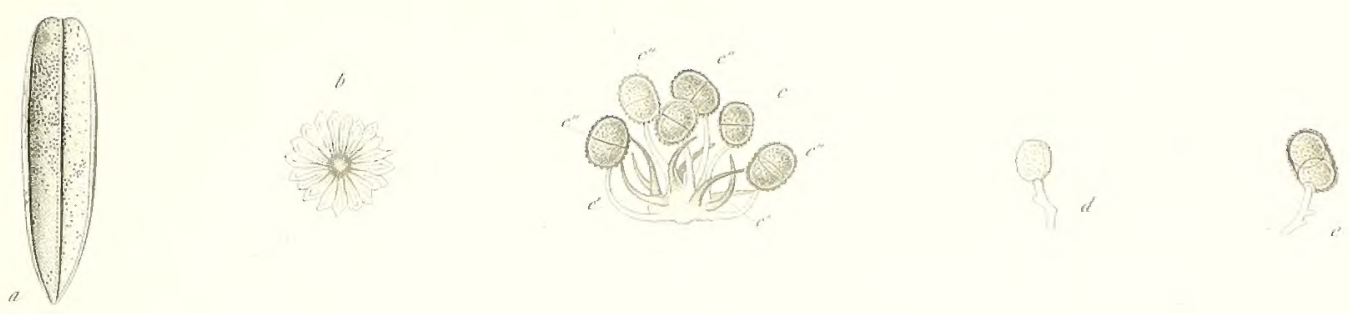

9
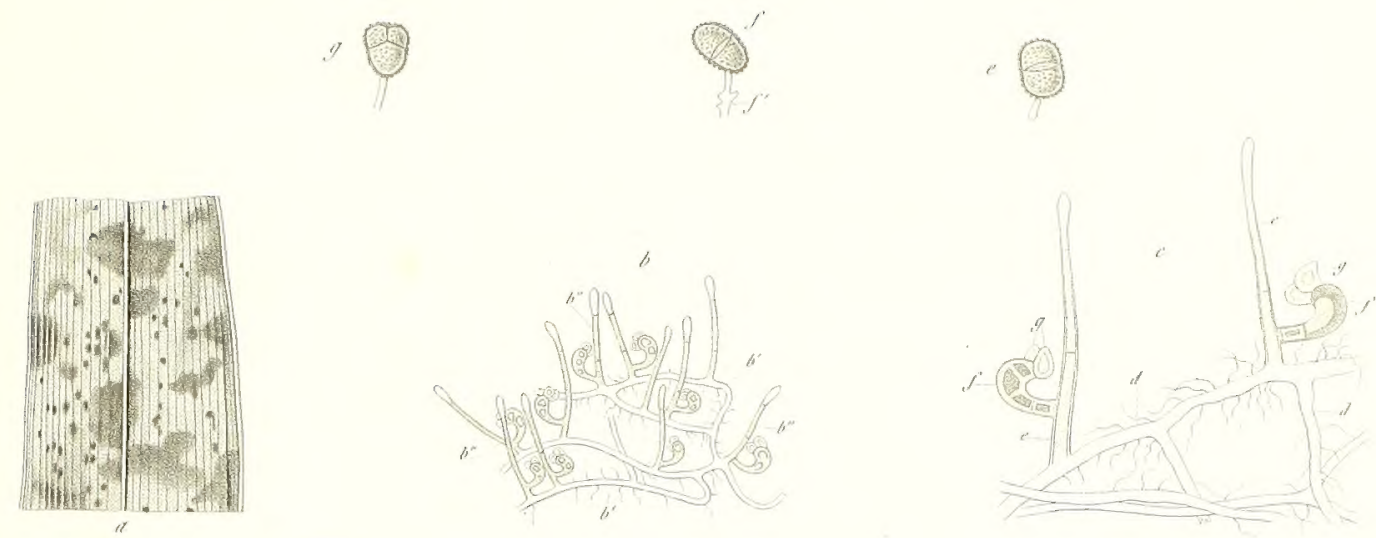
98
00

\section{1}

\section{$99929 \%$}
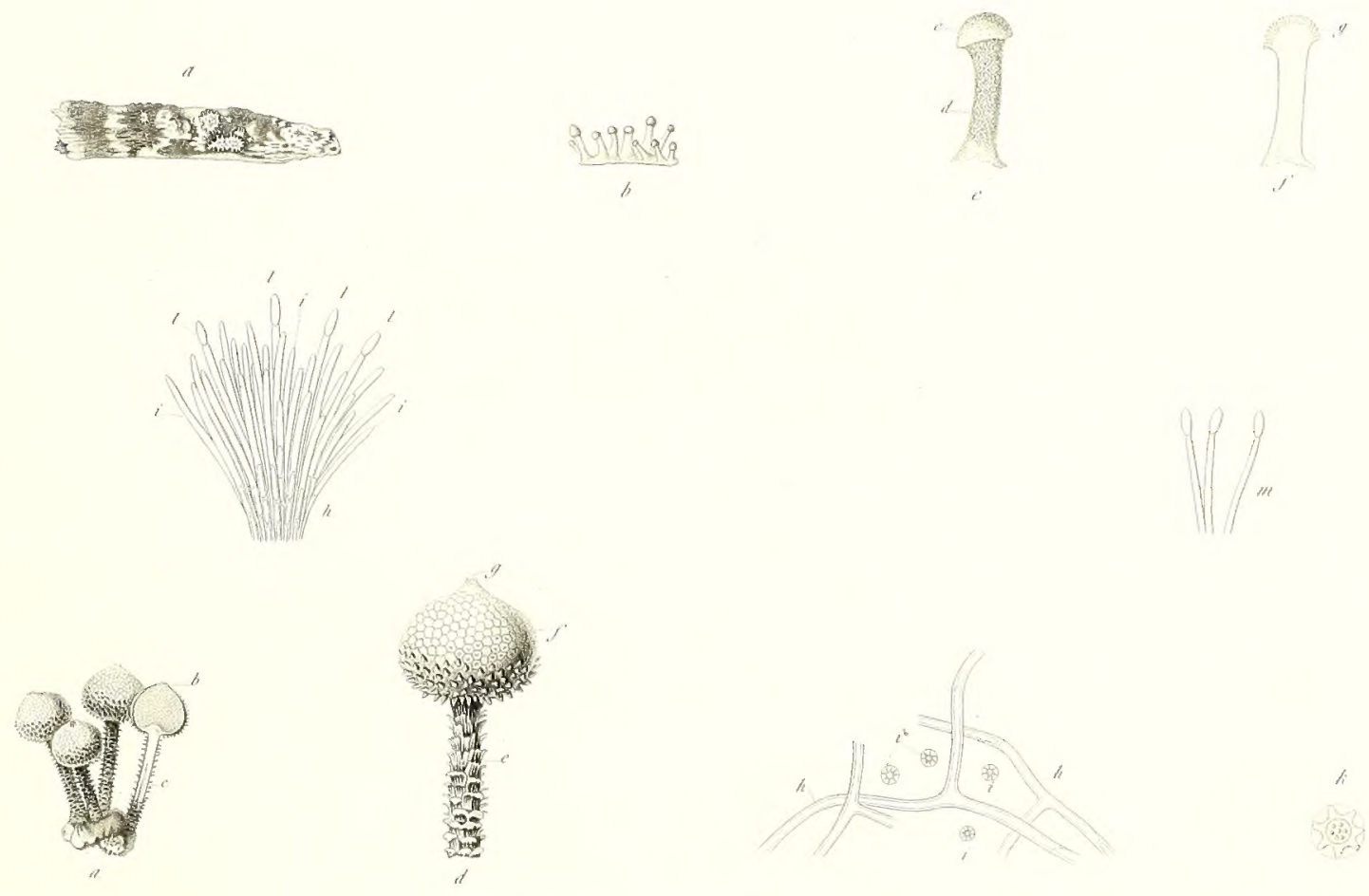

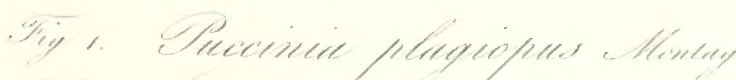

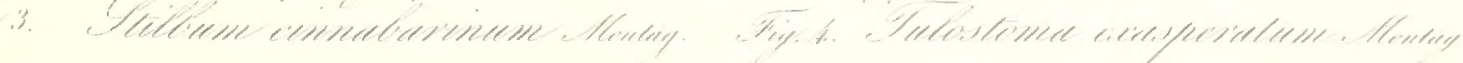



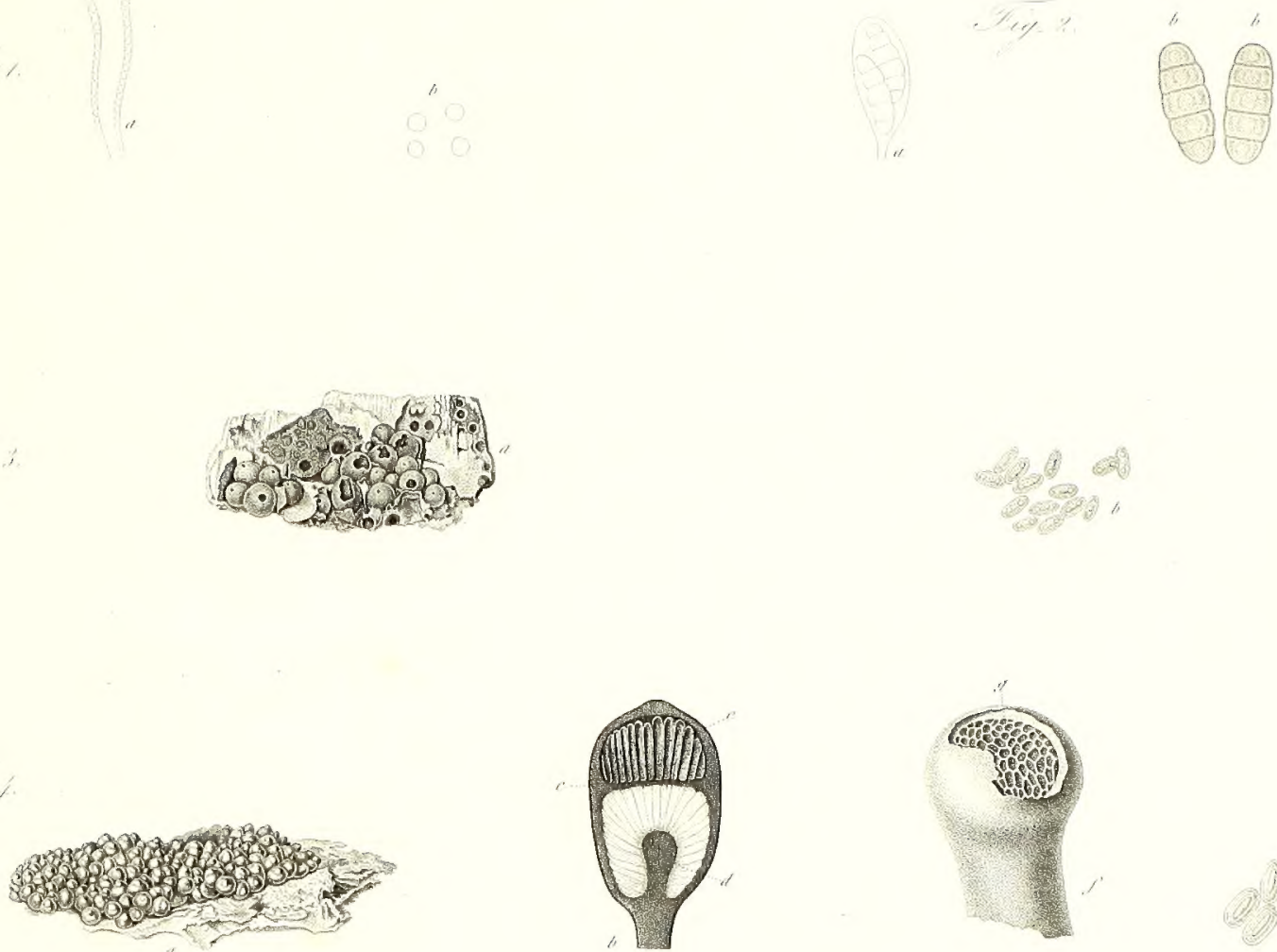

$(2,0)^{4}$
9
9
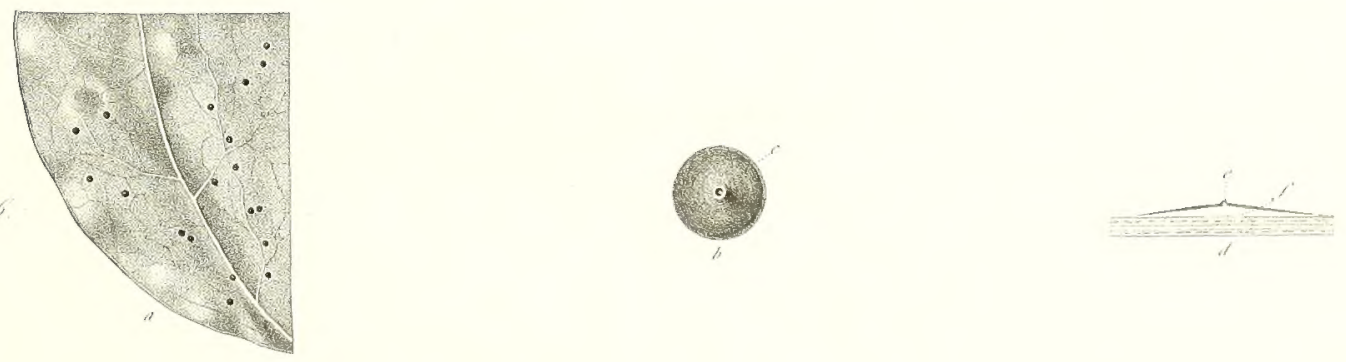
lingei
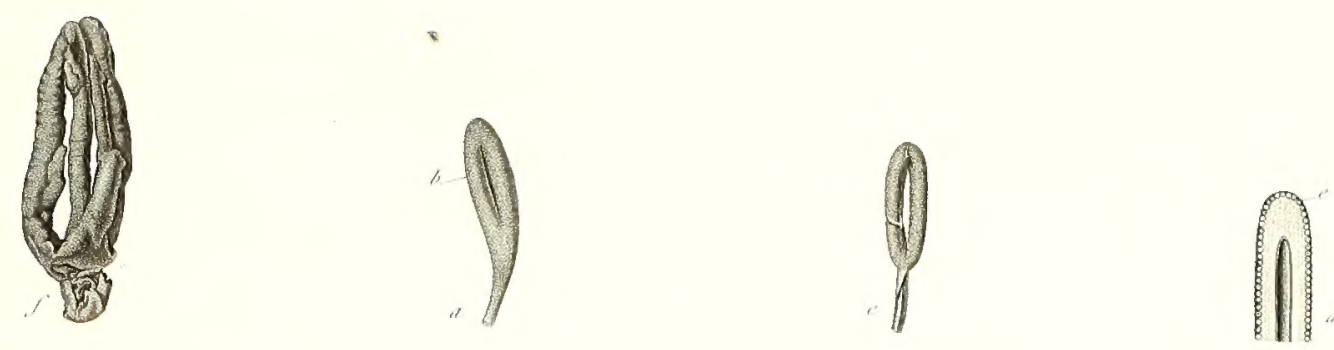

(6)
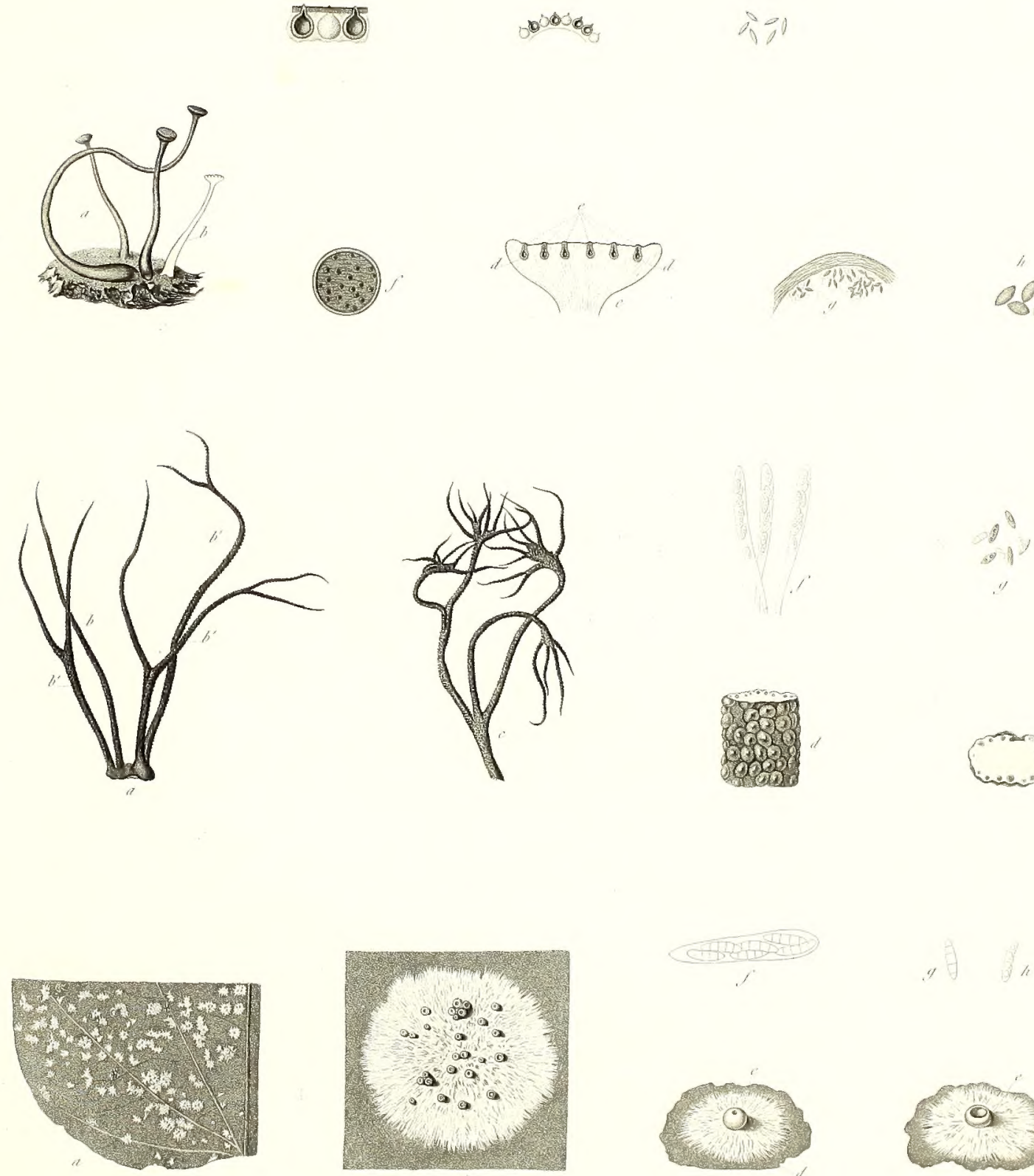

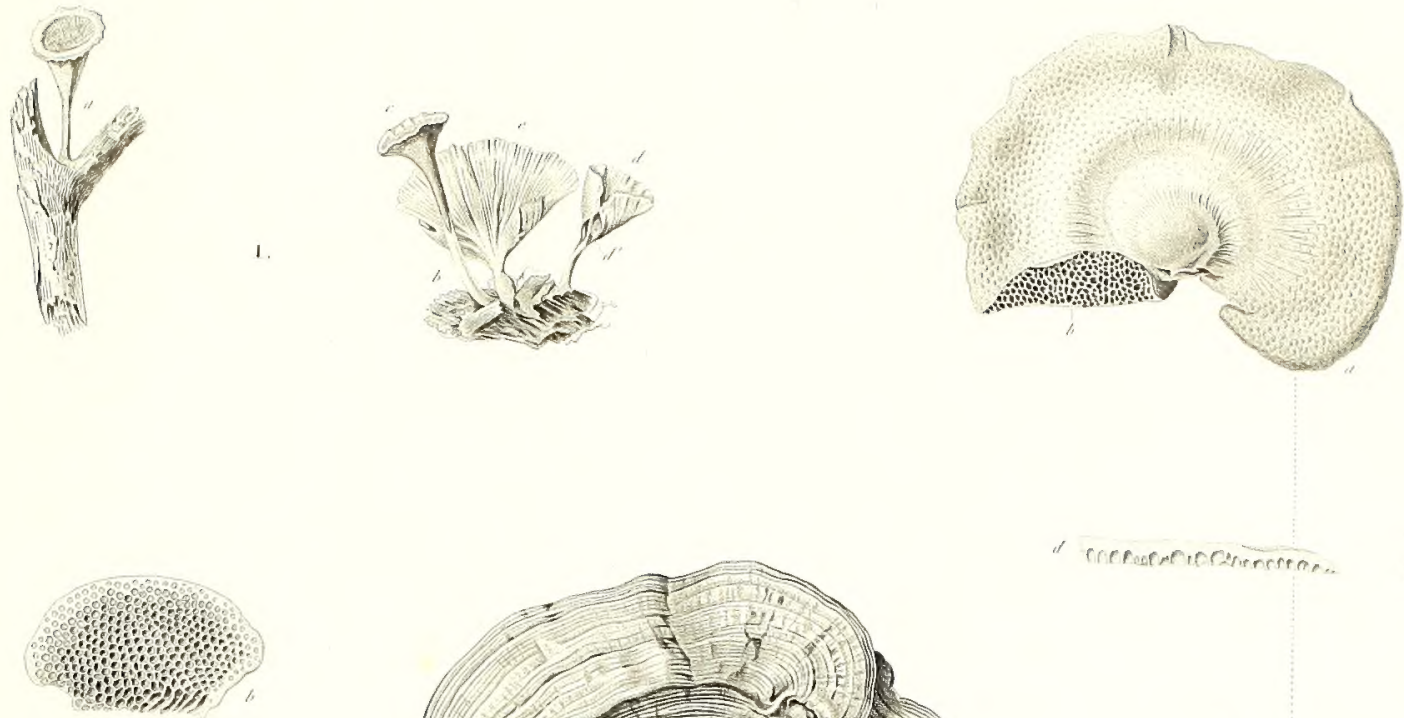

5

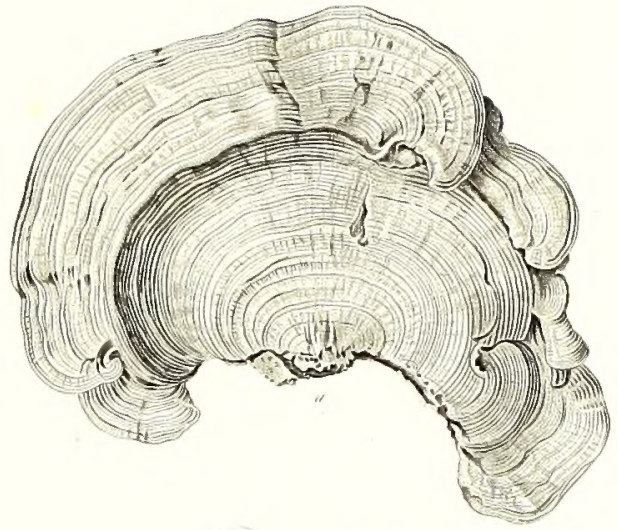

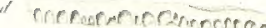
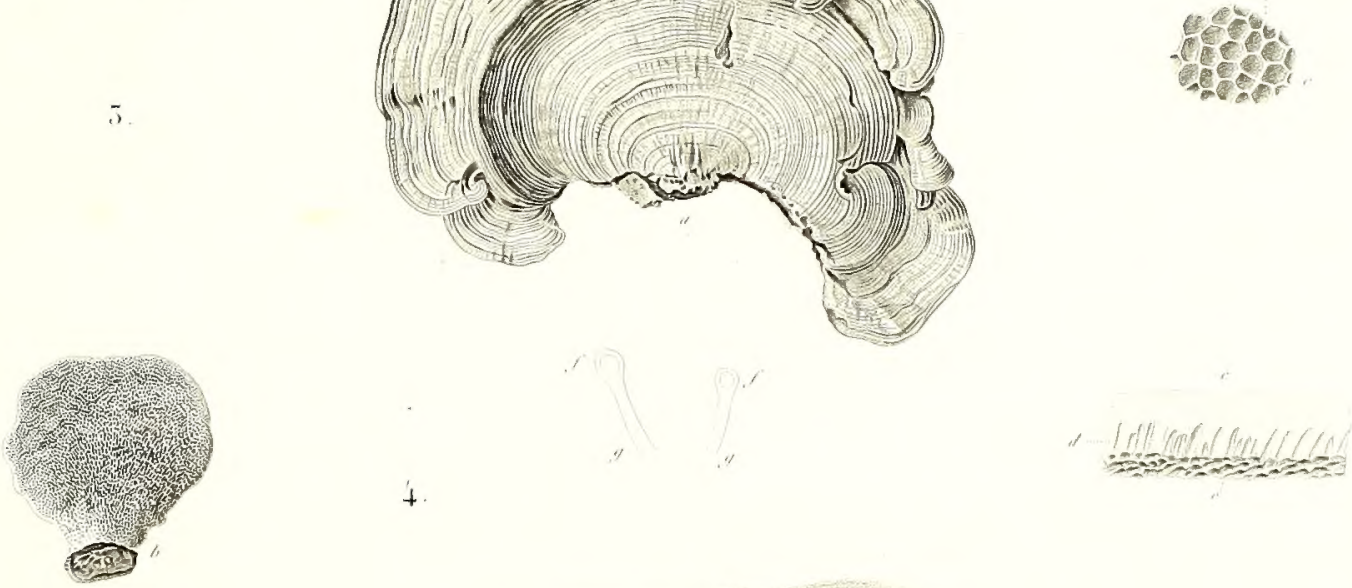

$+$

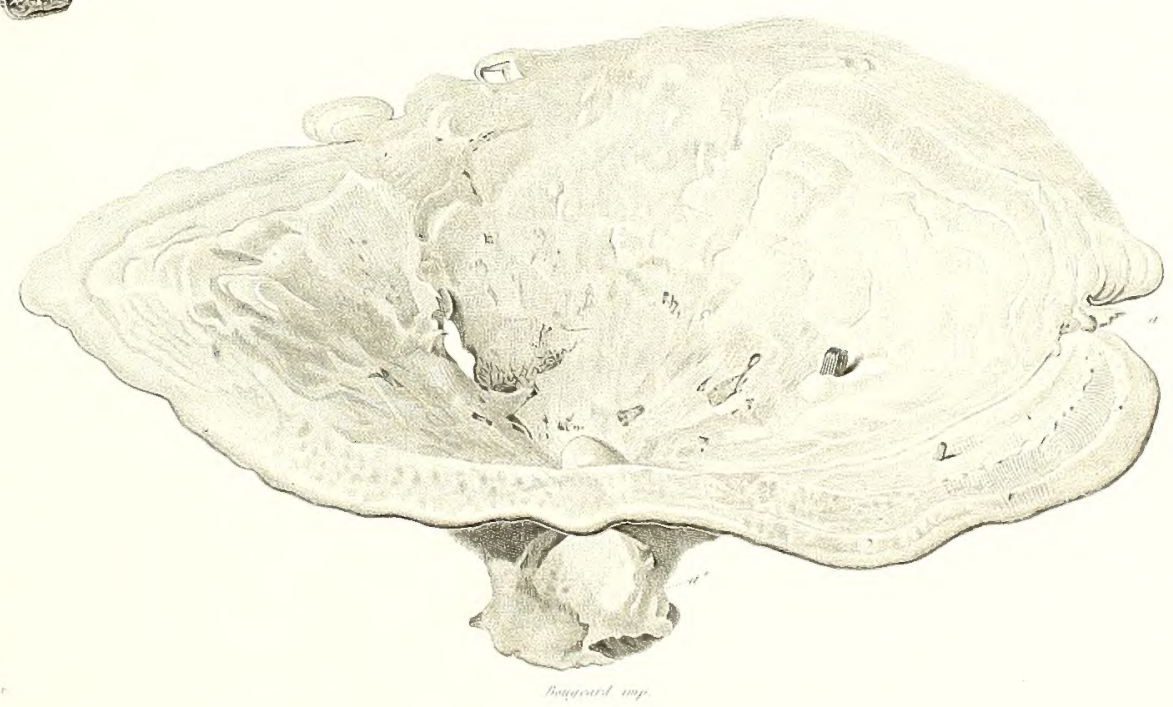

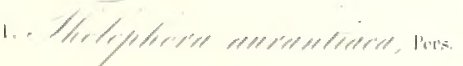

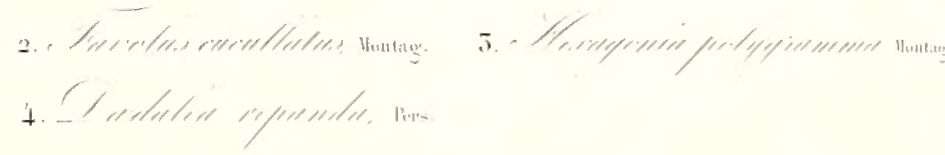



$\operatorname{limg} \operatorname{lig}^{\circ}$

Tab. 11.
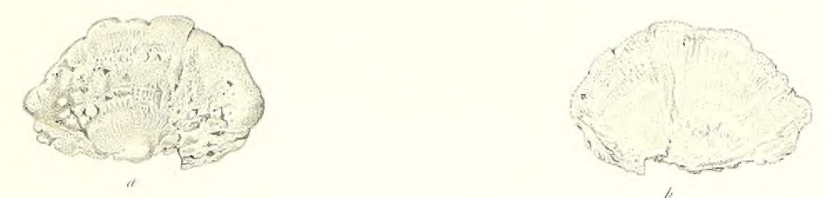

$\therefore$
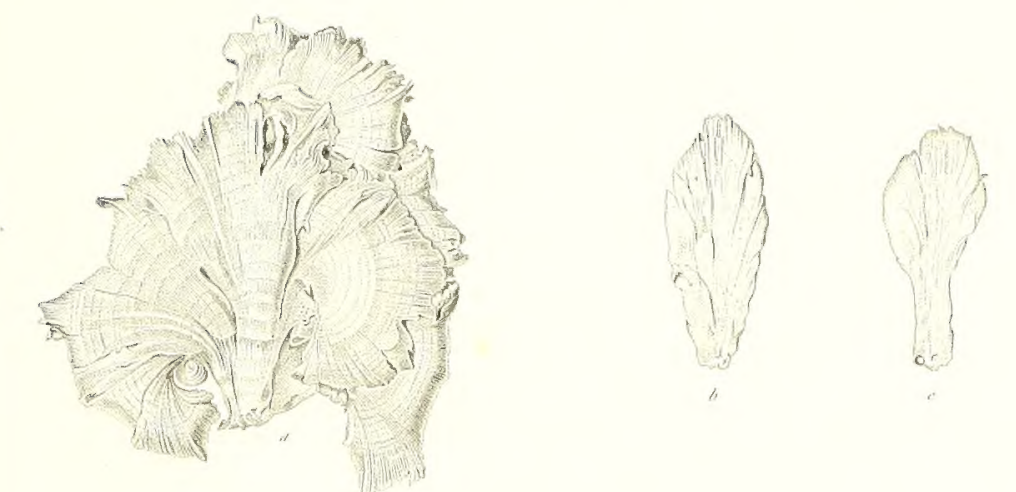

renconomere

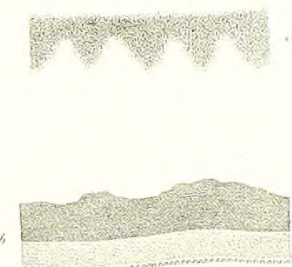

4
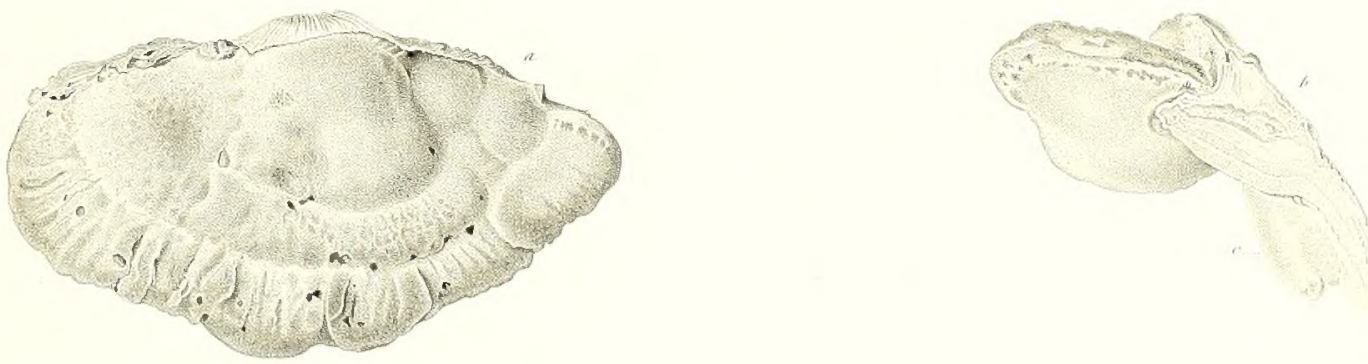

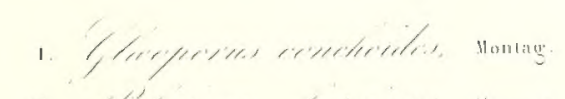

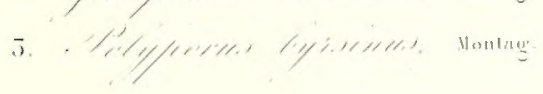

(). (0) 

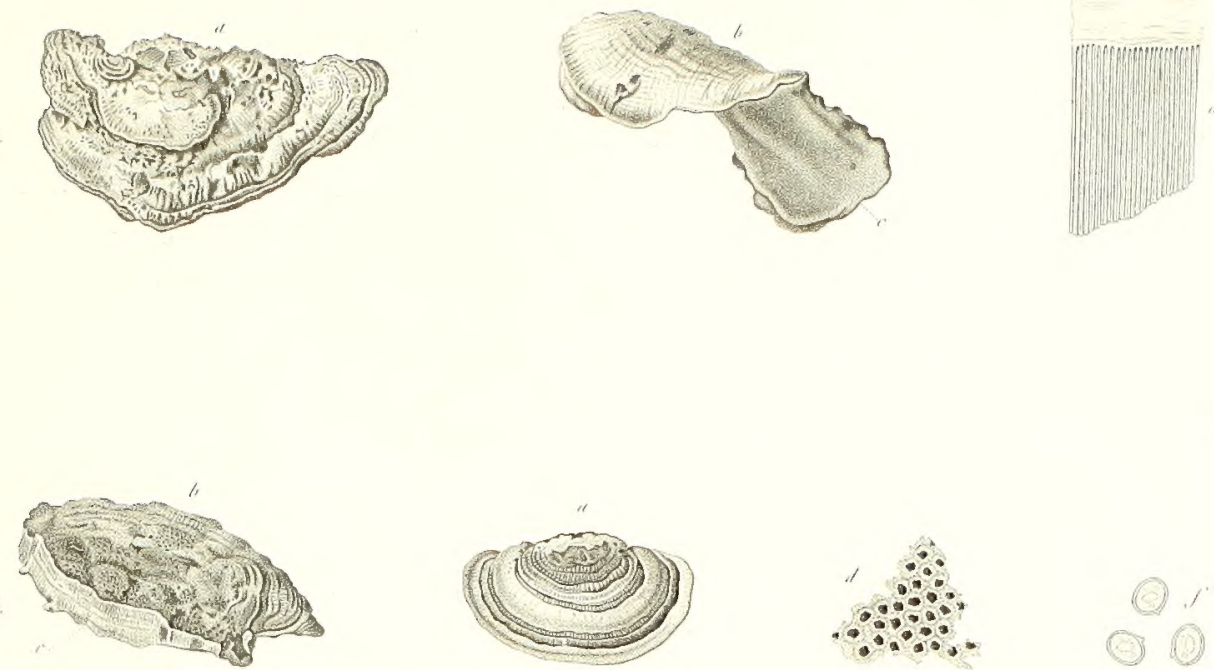

$\because \because \because \because \cdots$
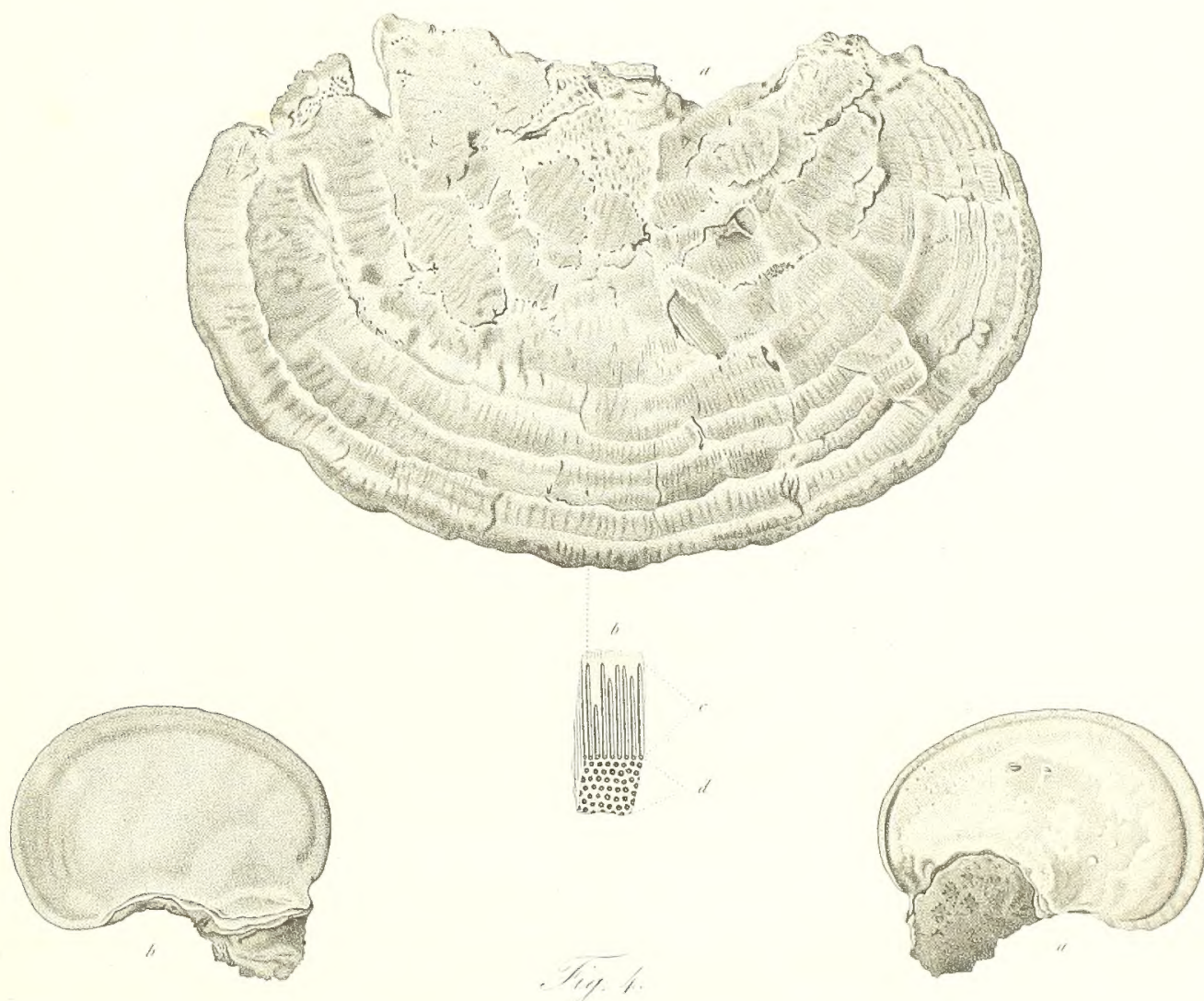

- broflenconaros

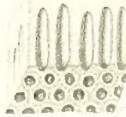




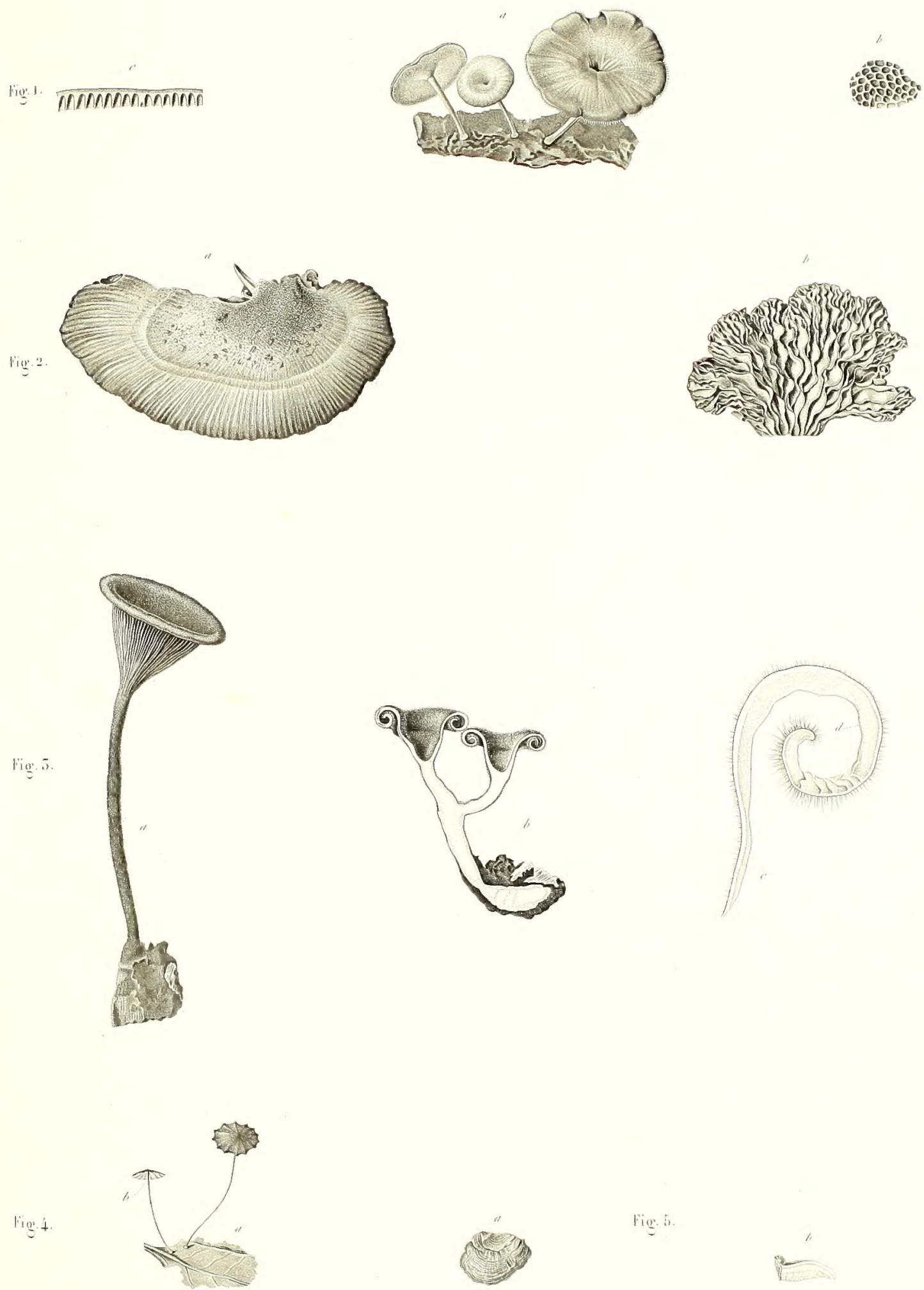

Fig.

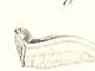

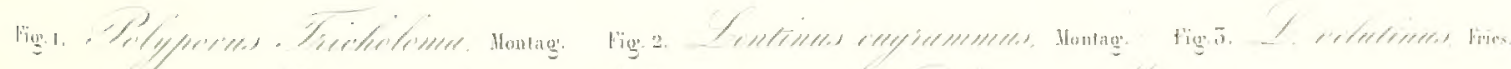

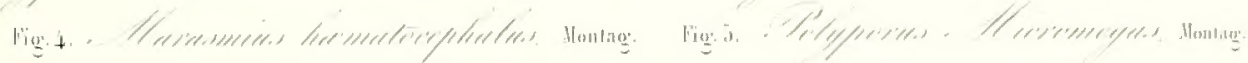




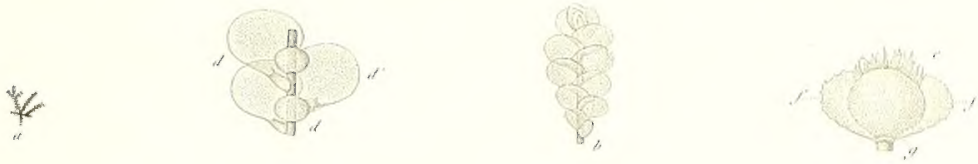

1.
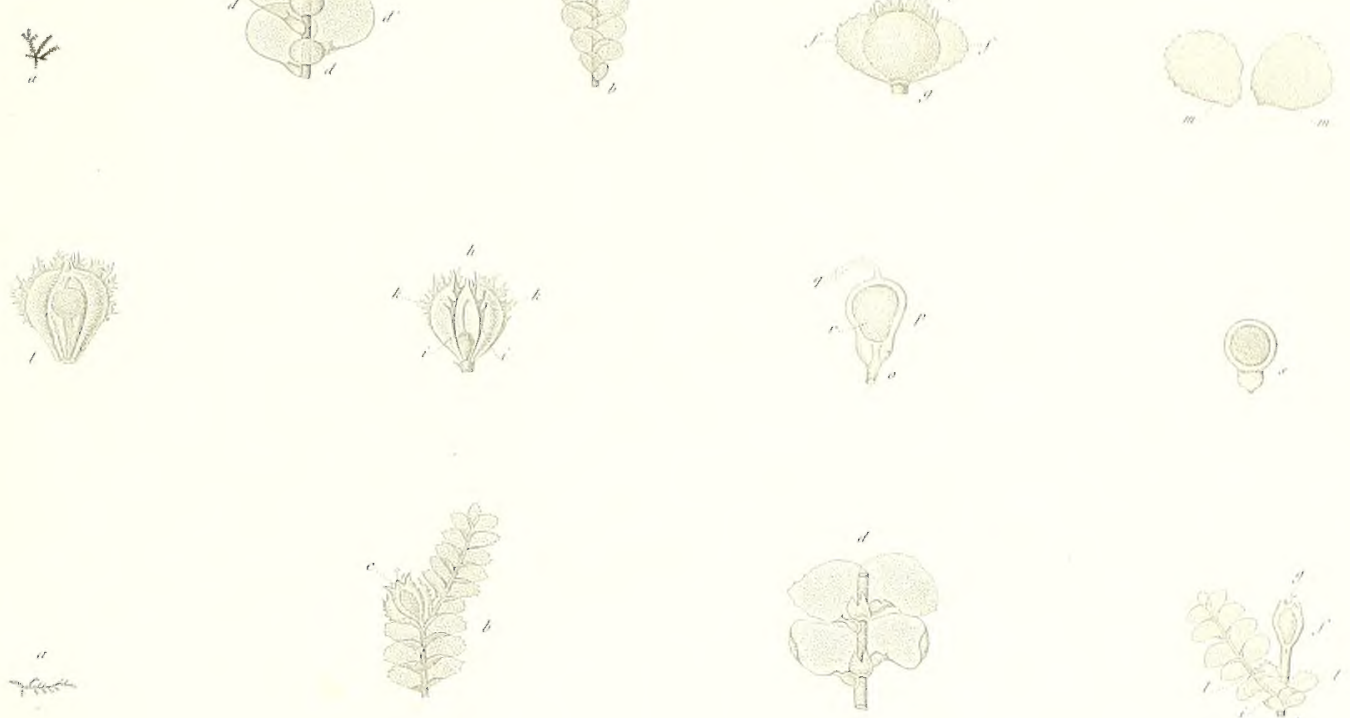

2.
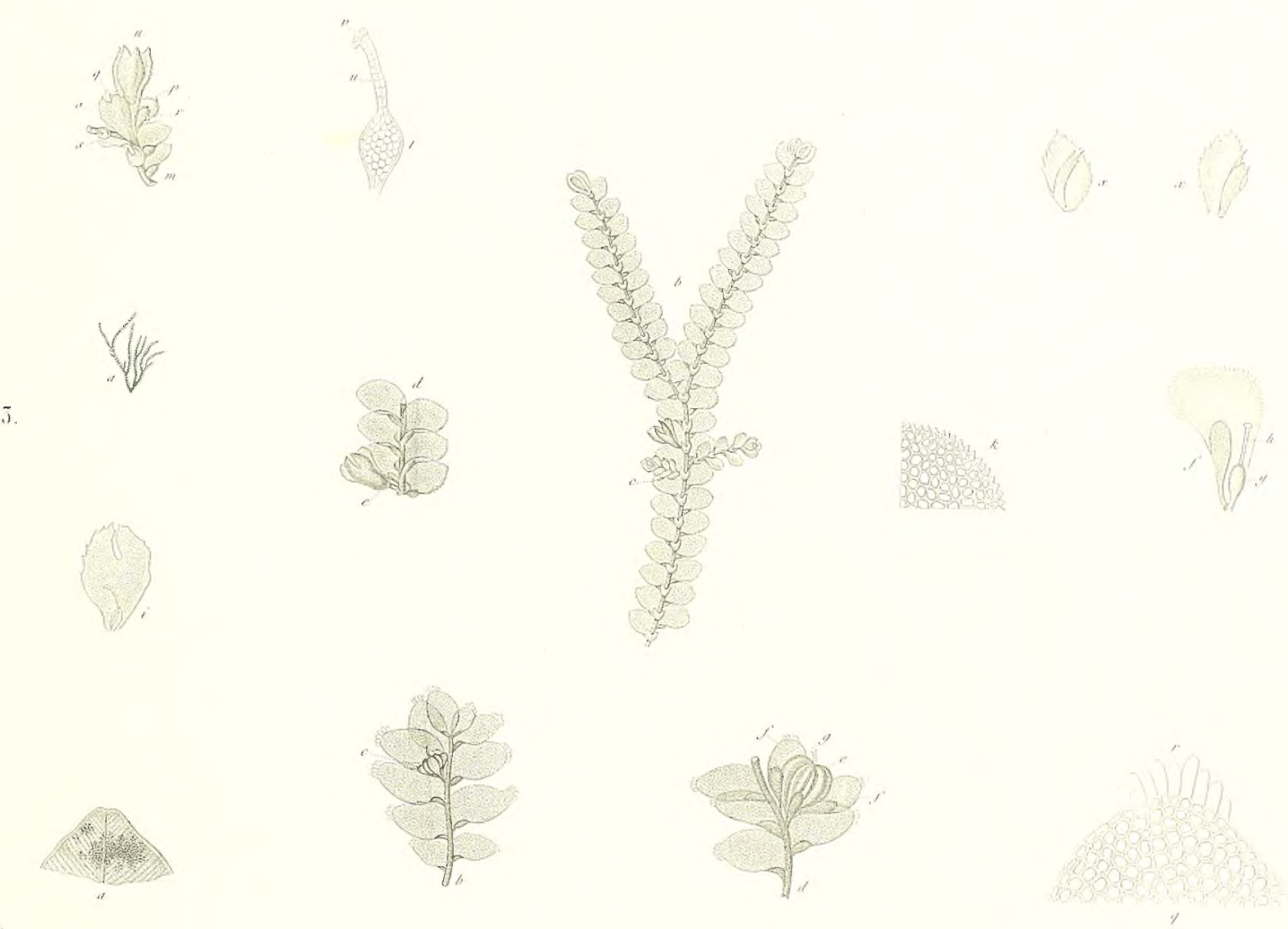



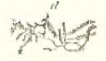
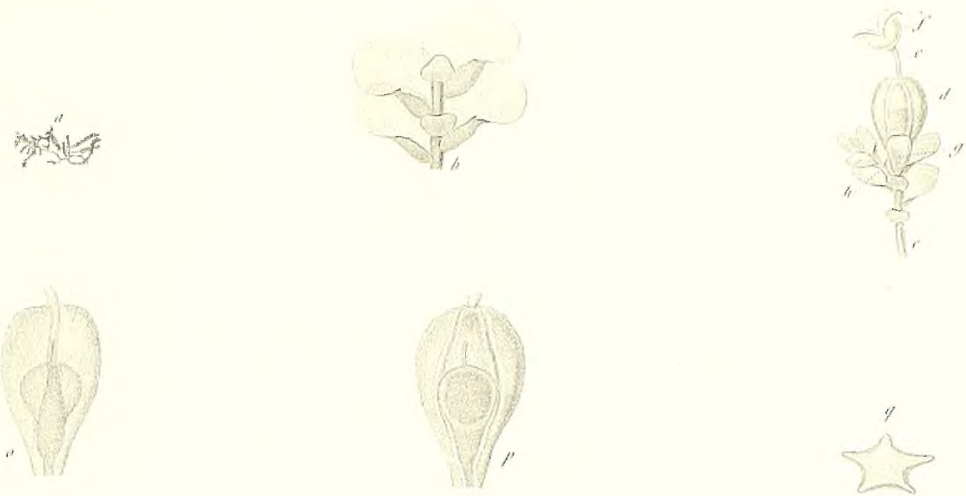

soto
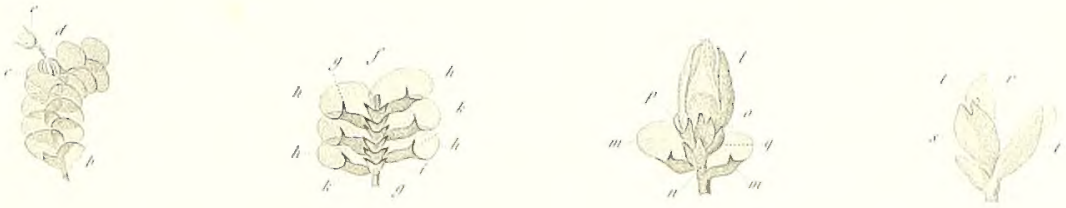

1

5
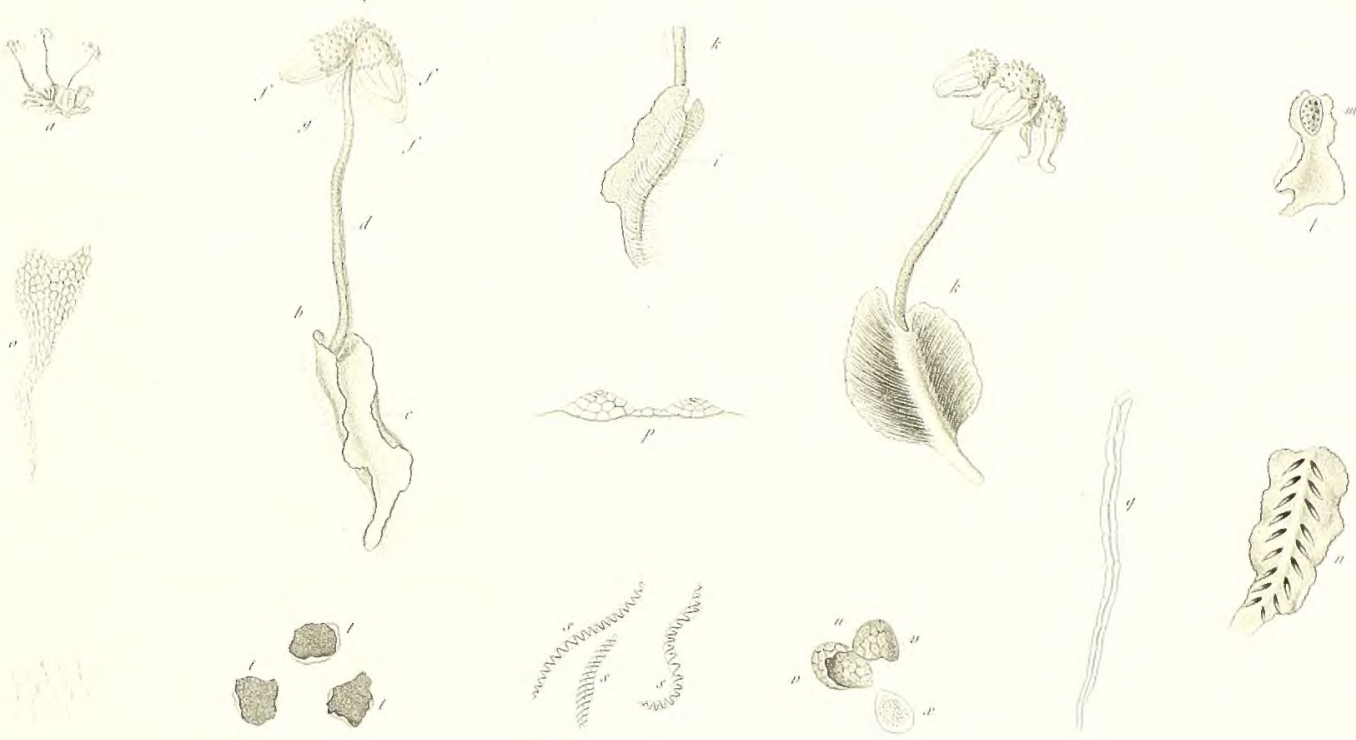

"cos"
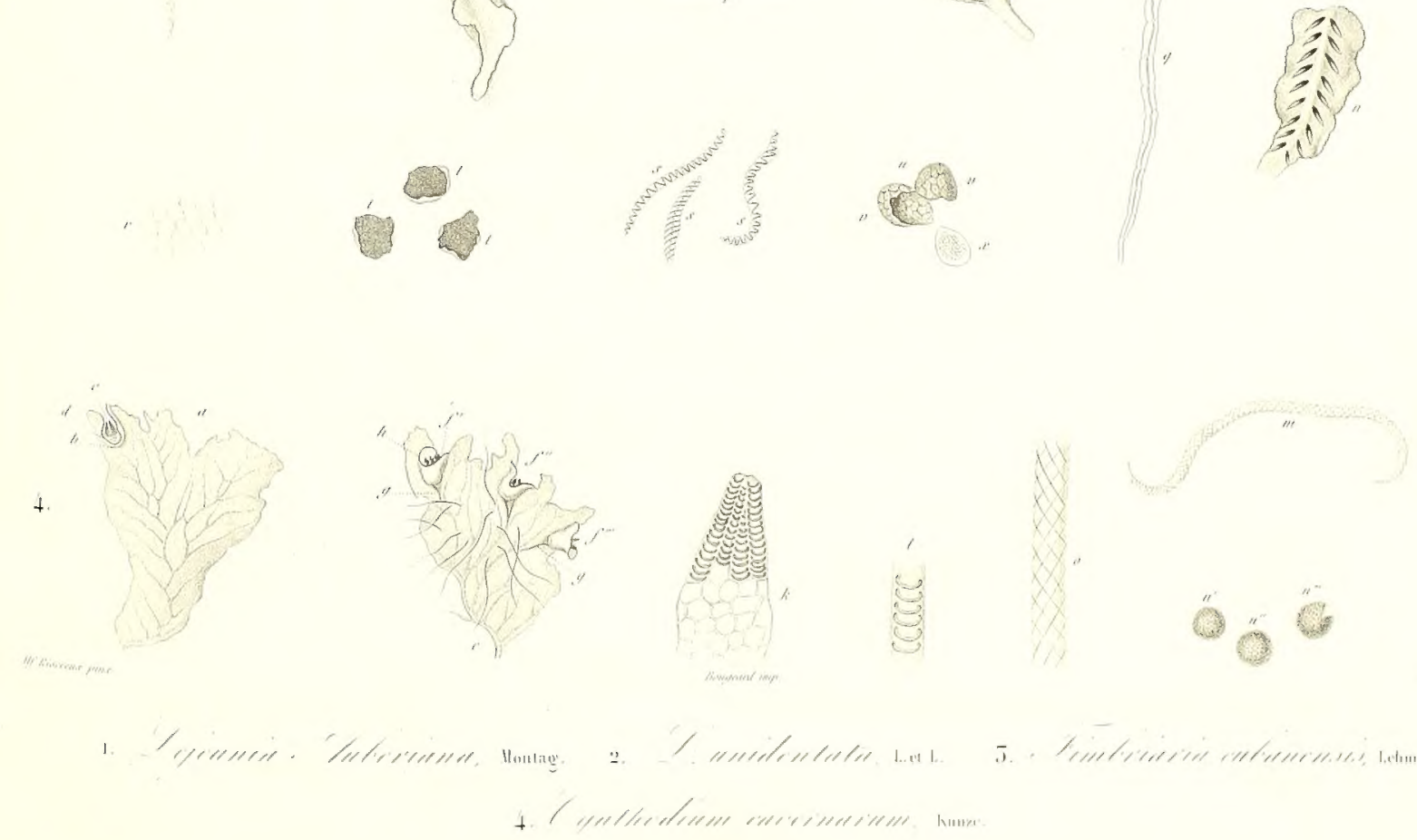


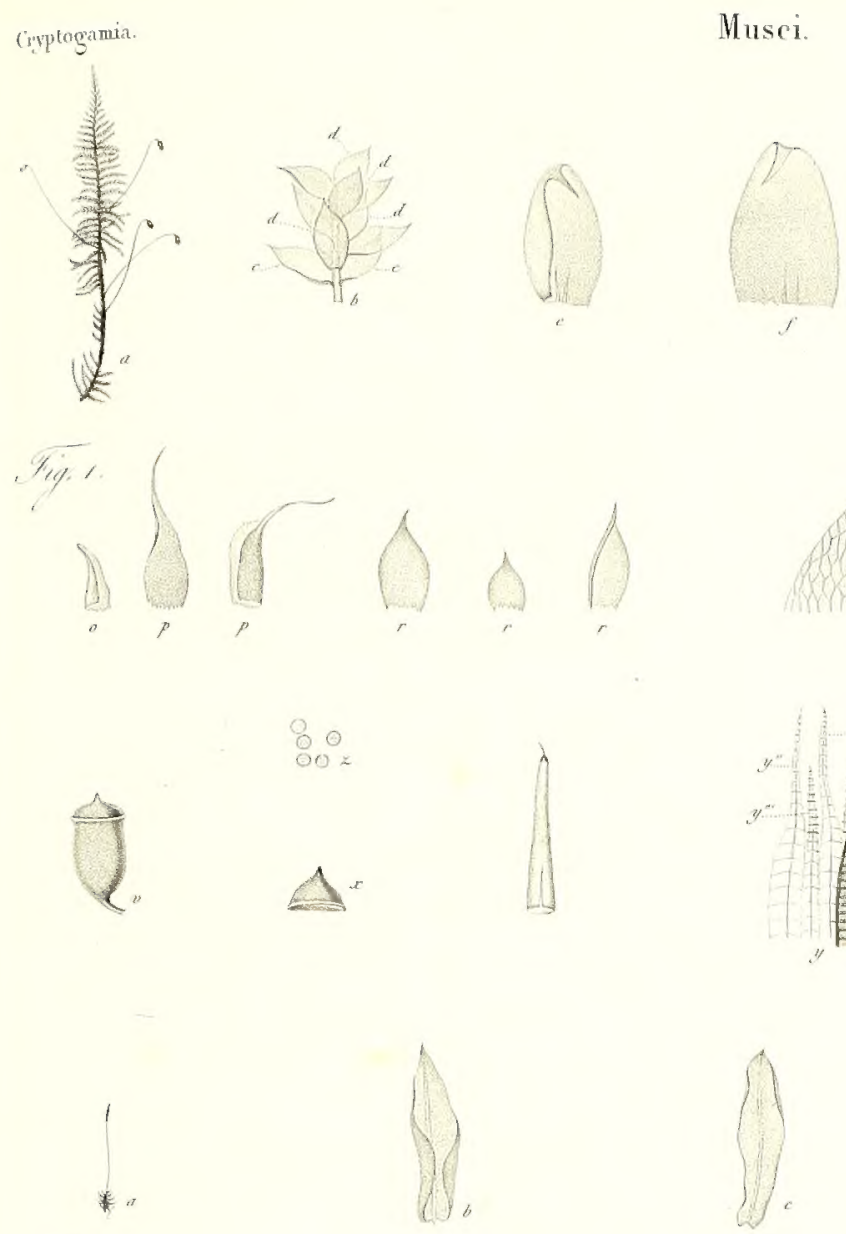

Hip. 2
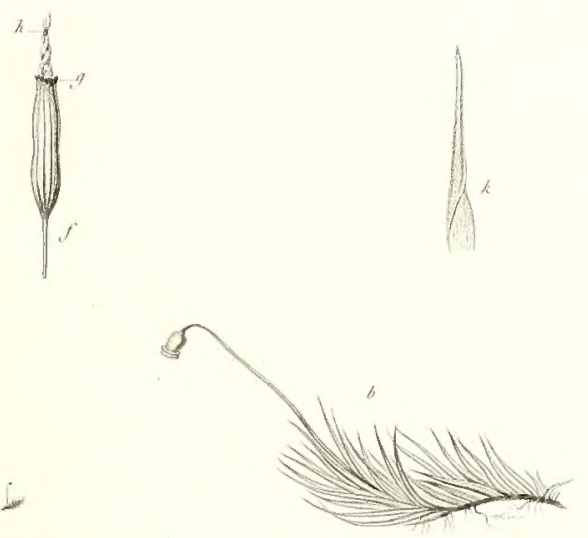

Tig. 3

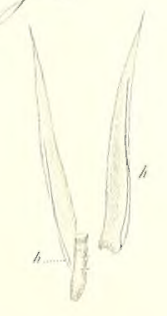

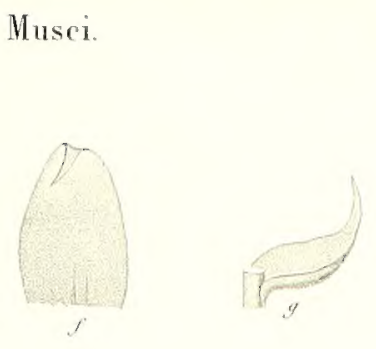
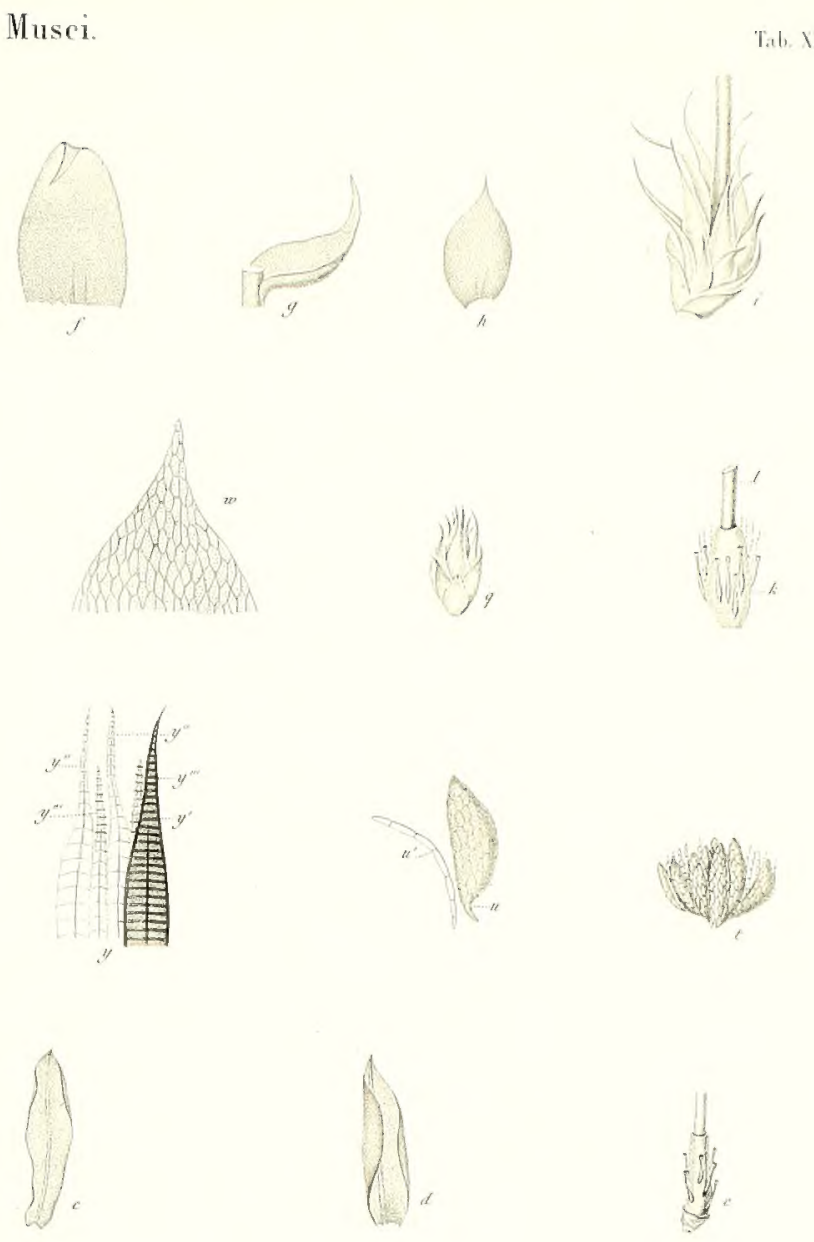

1. $x$

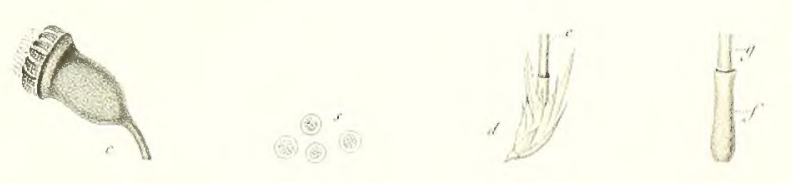

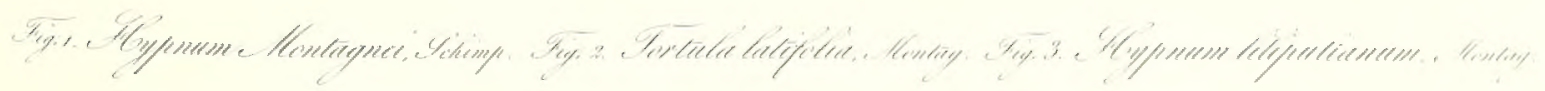





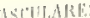

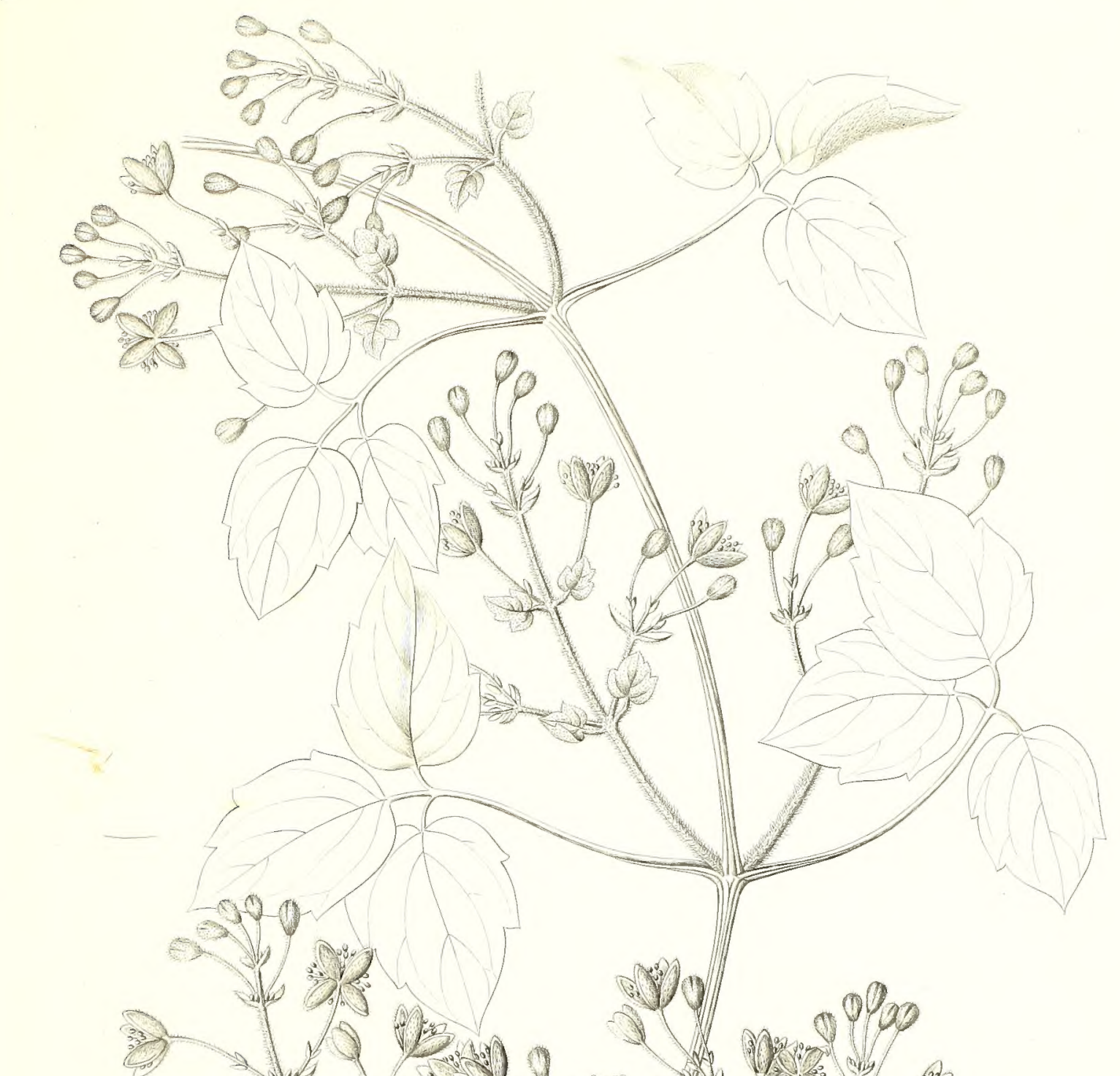





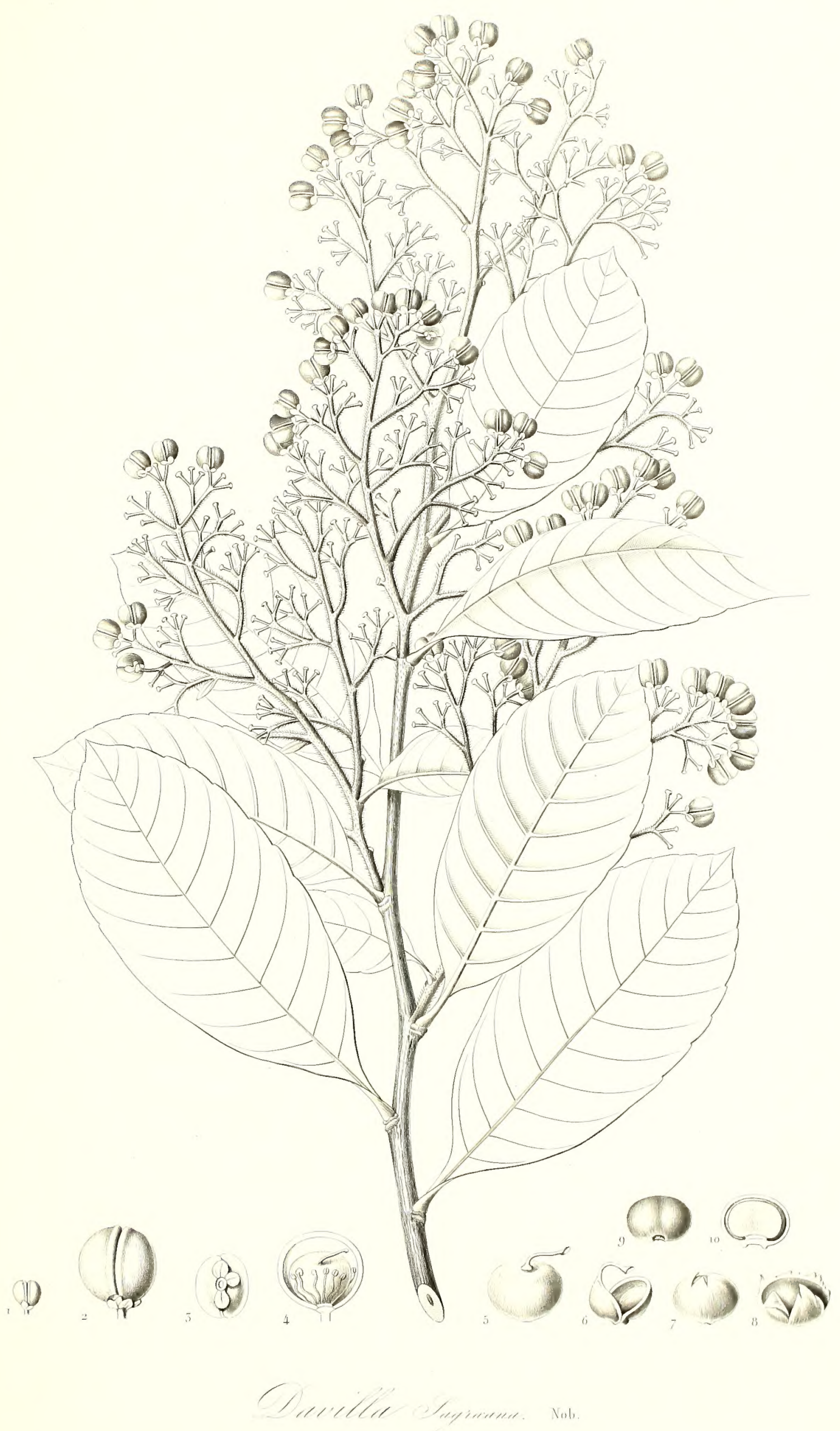





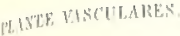

I.1. 3

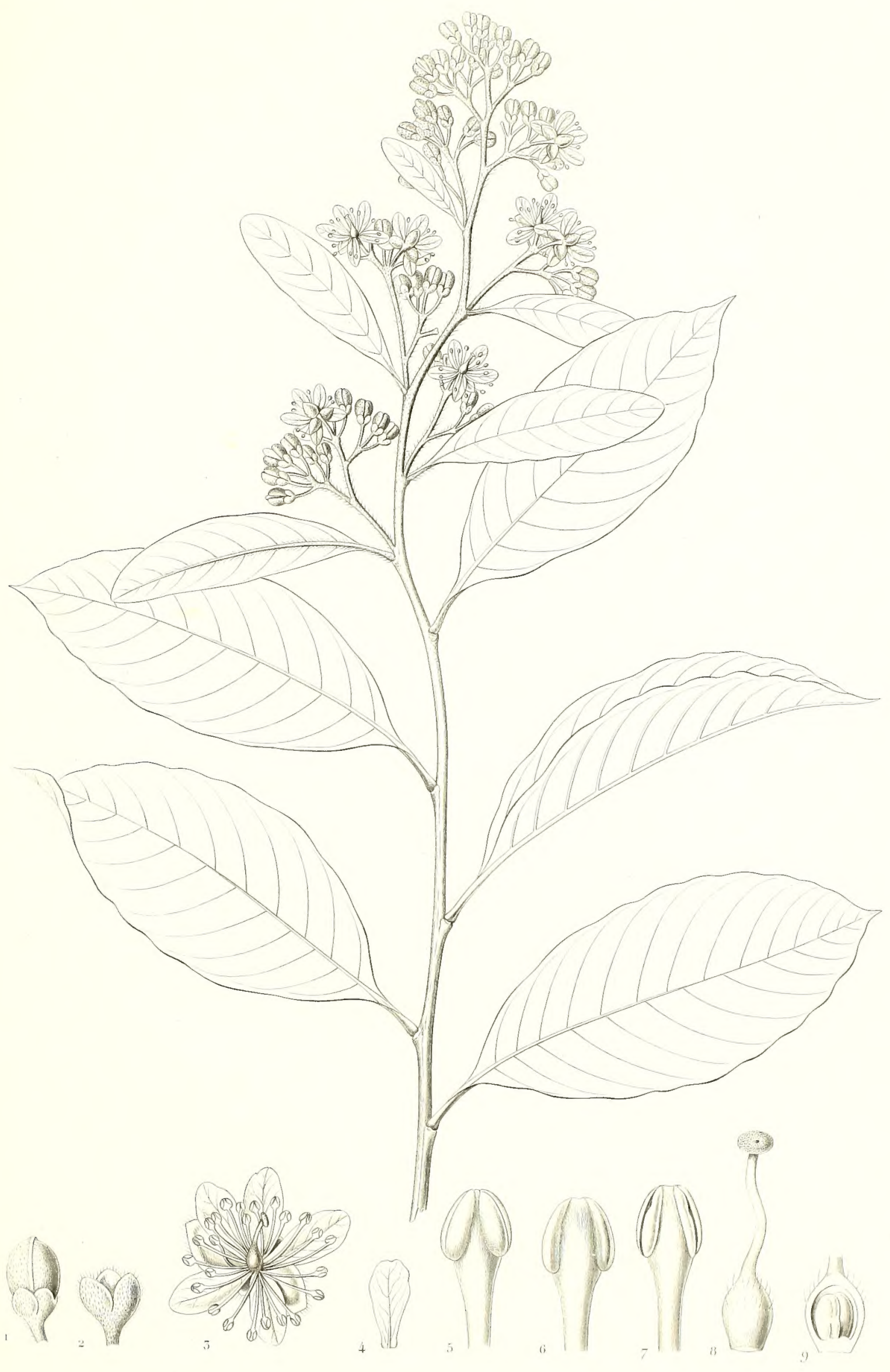

Gerville miriser. xob. 



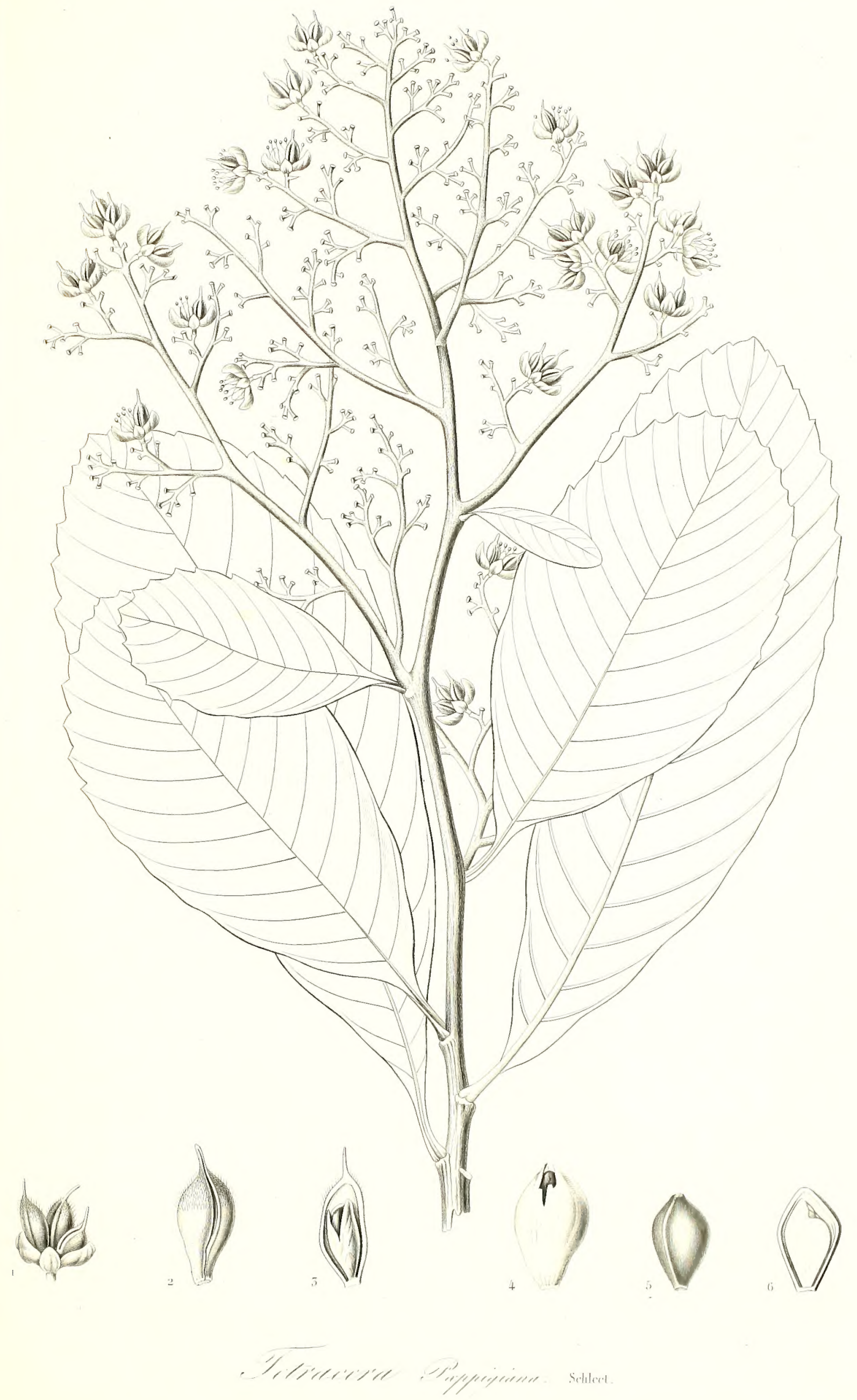





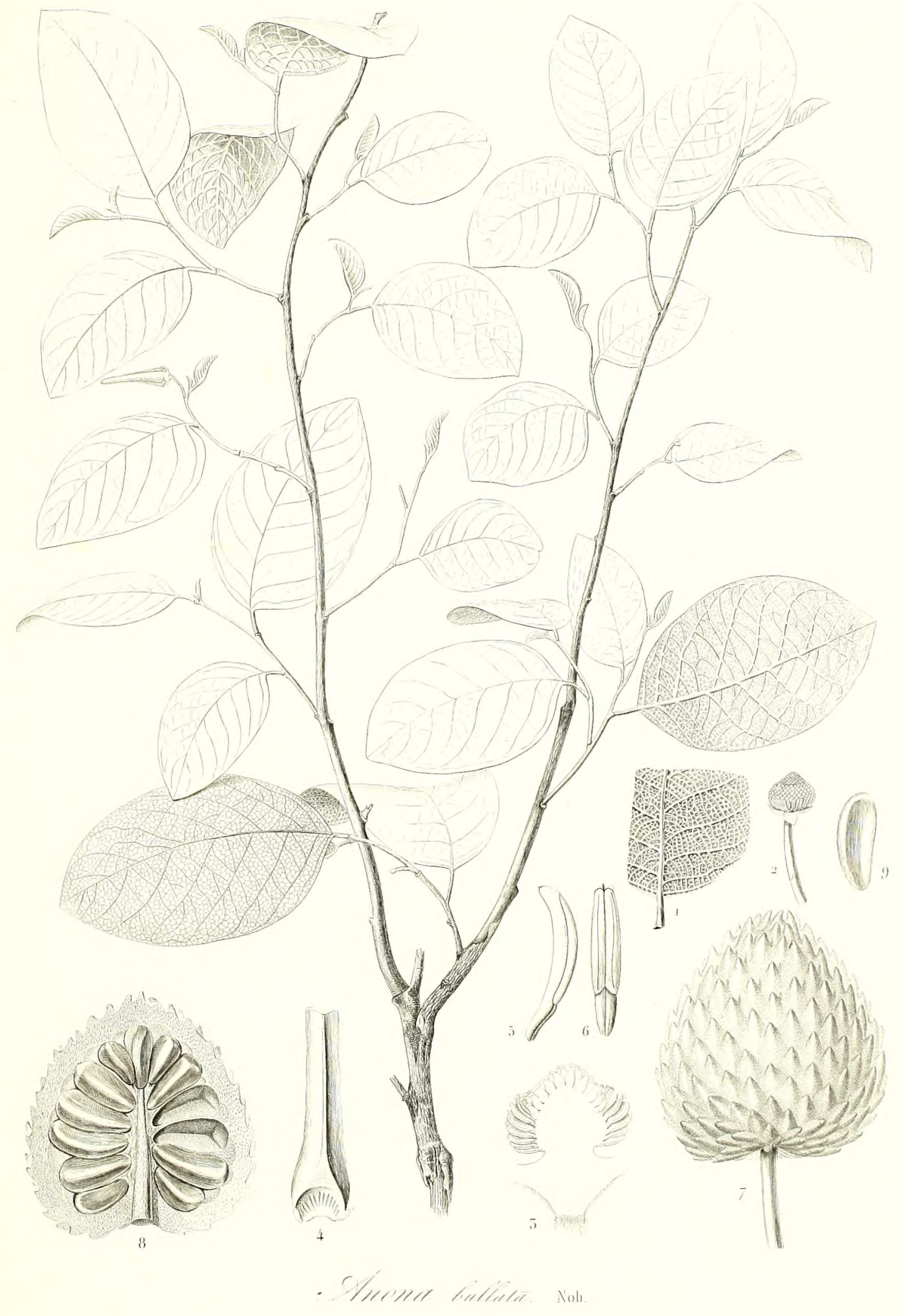





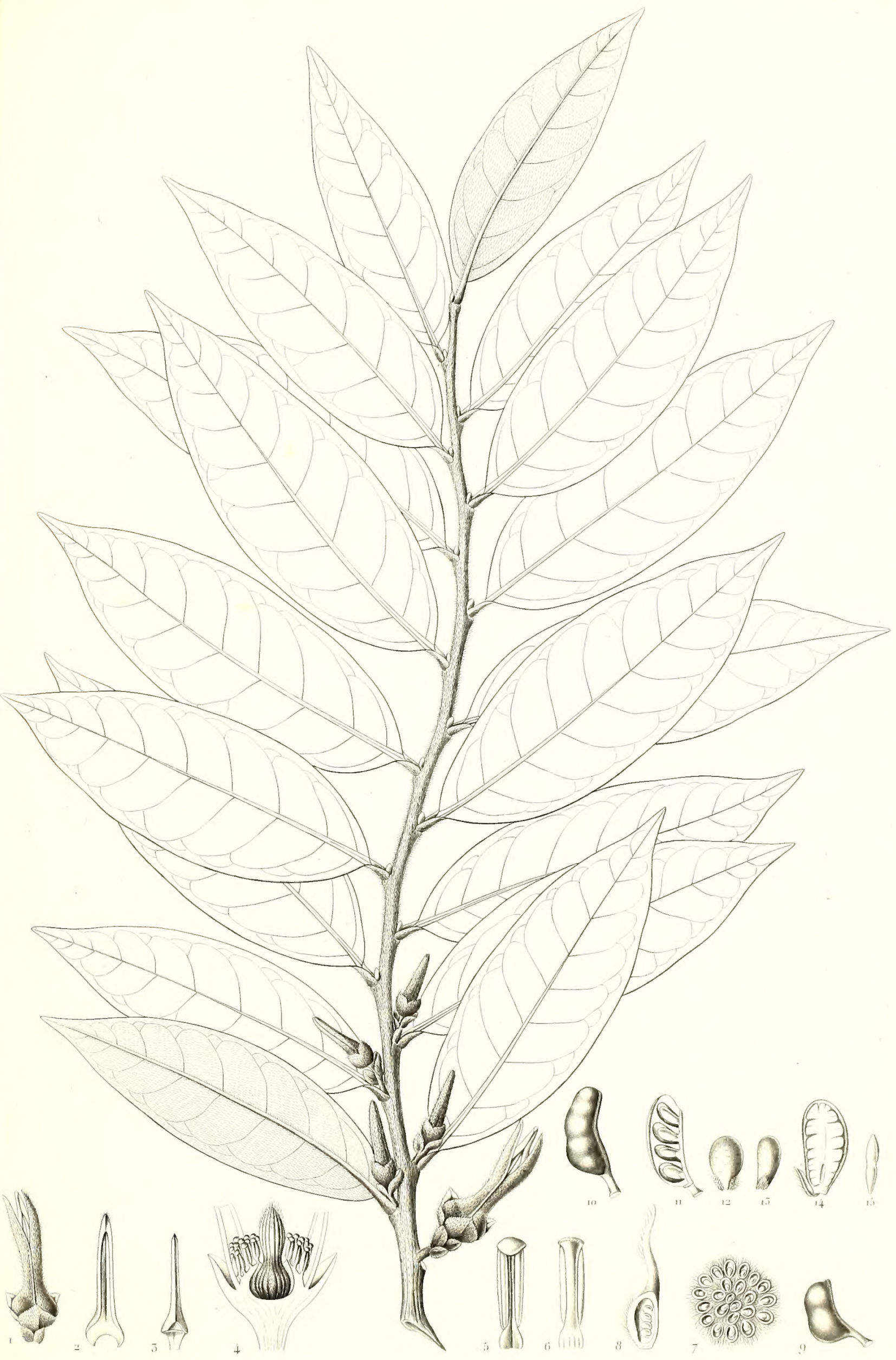







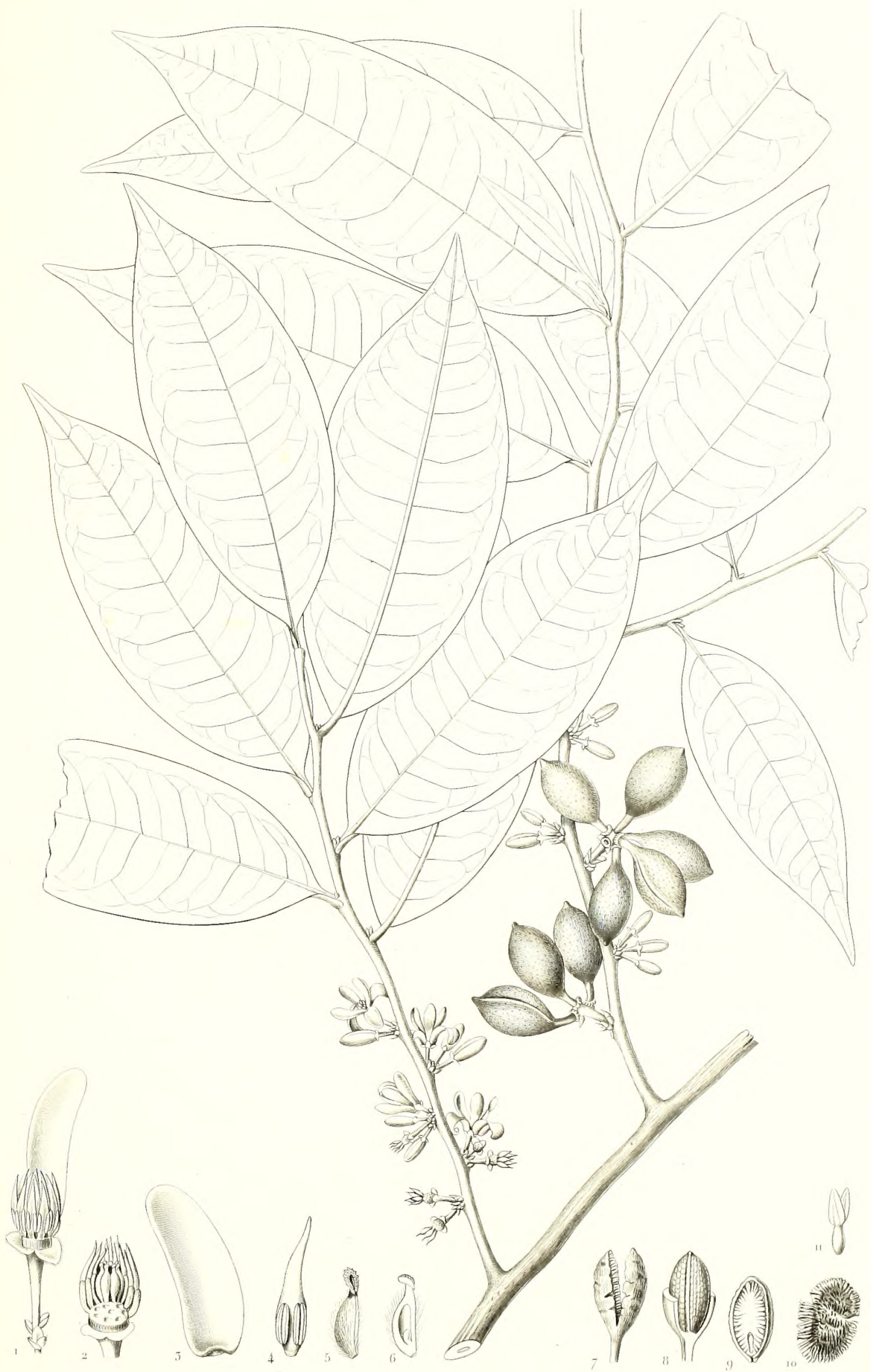



PIATER VASCLARES

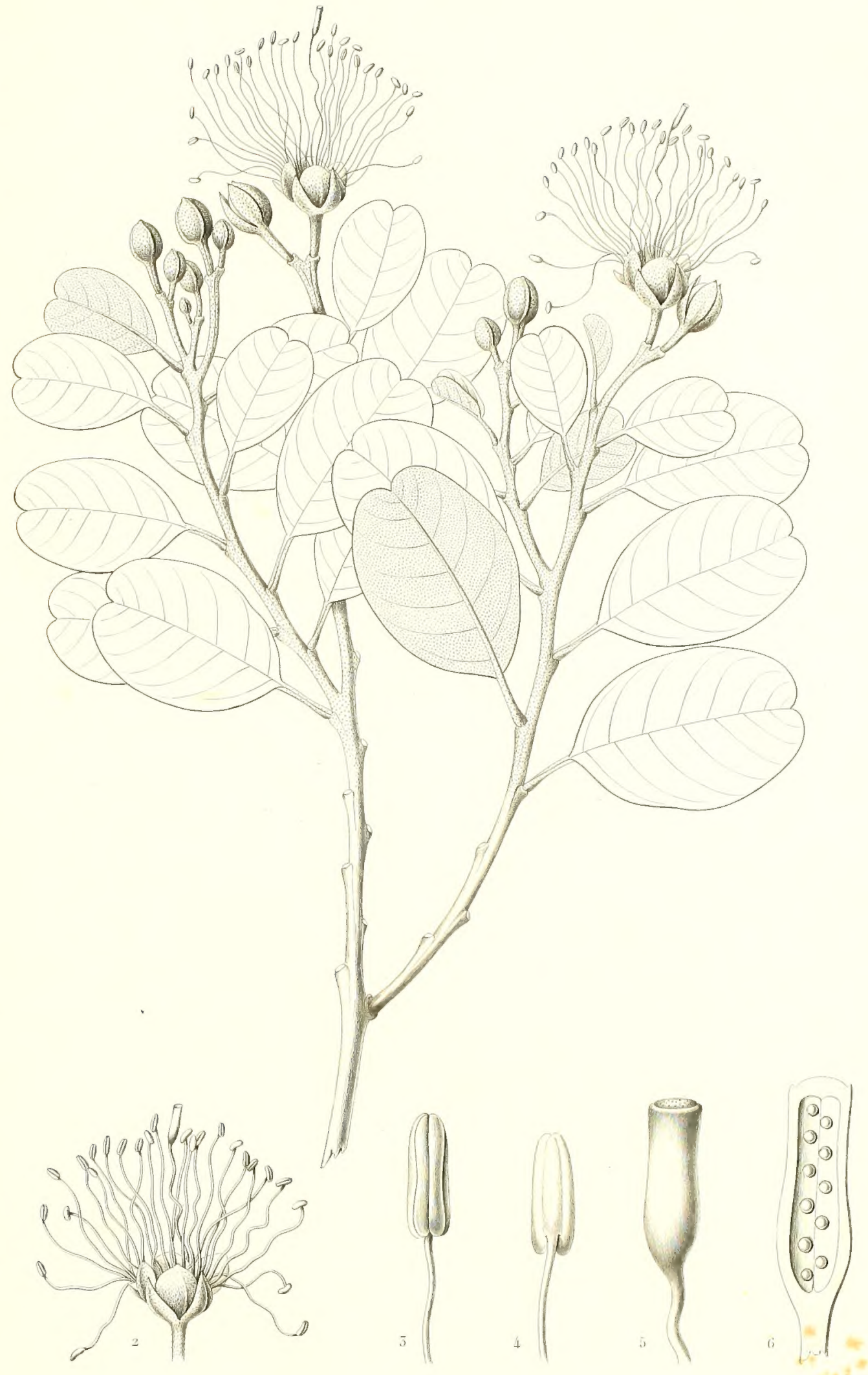



PHATE MSCULARES

Tili, its

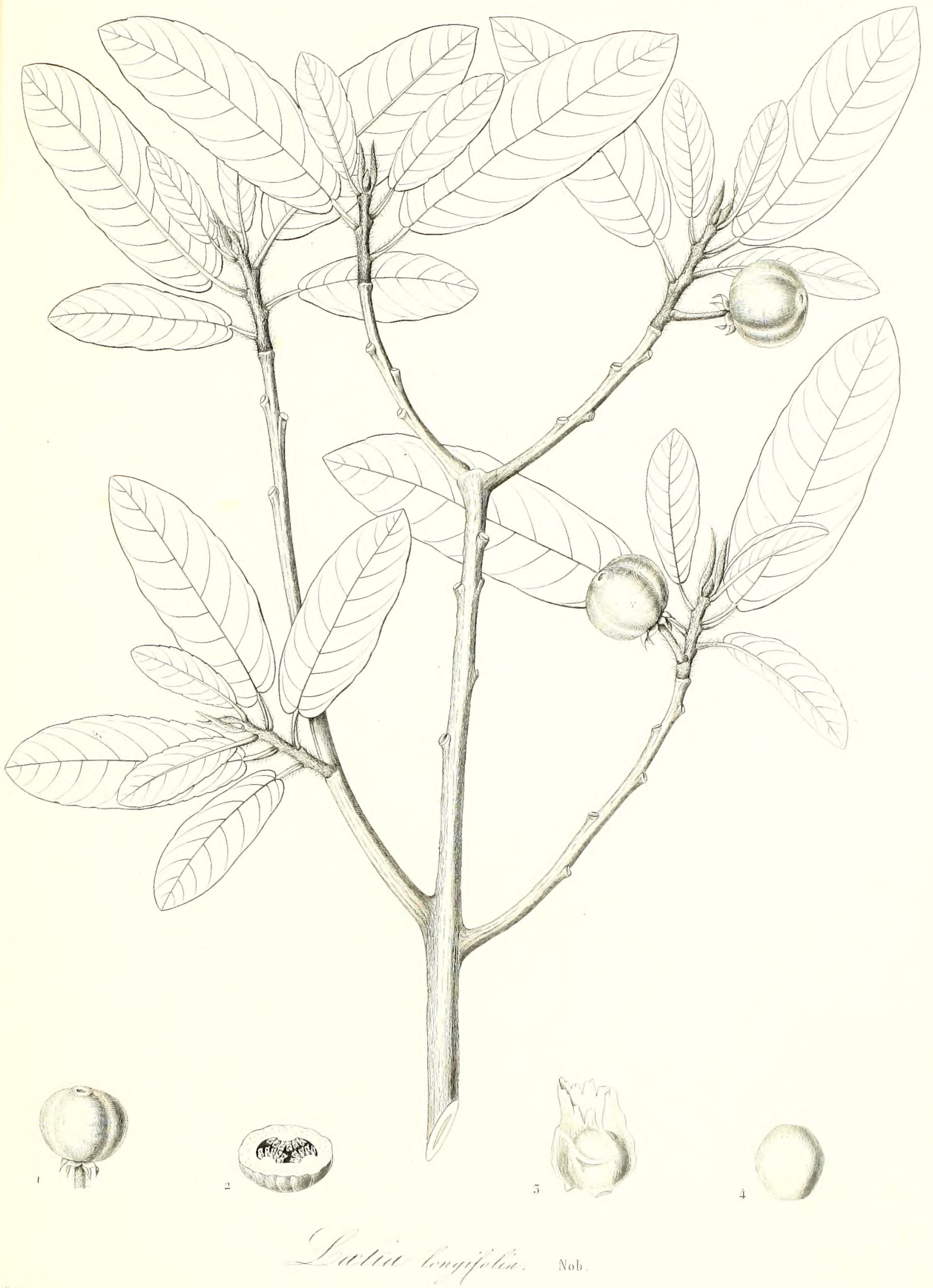




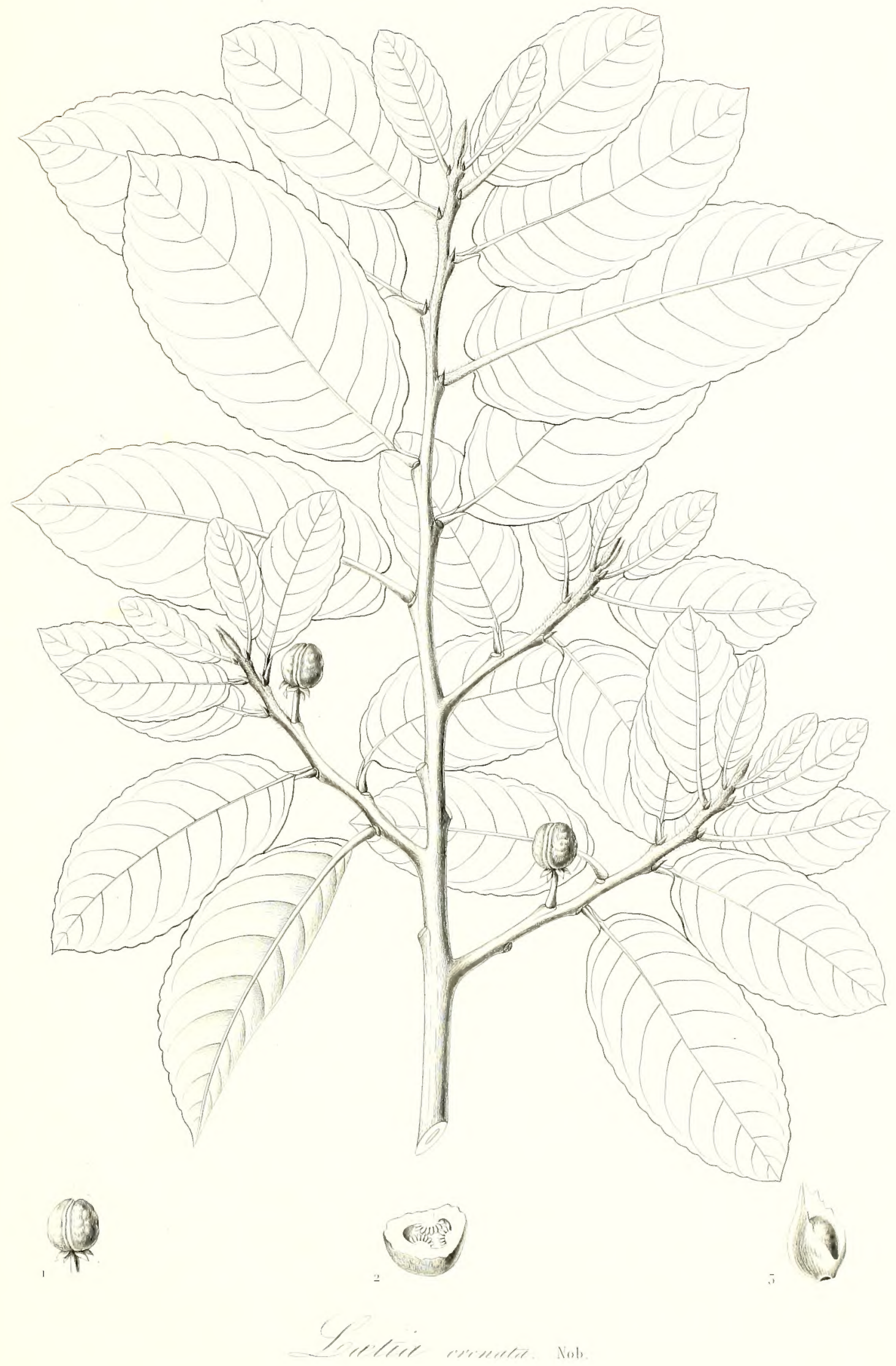



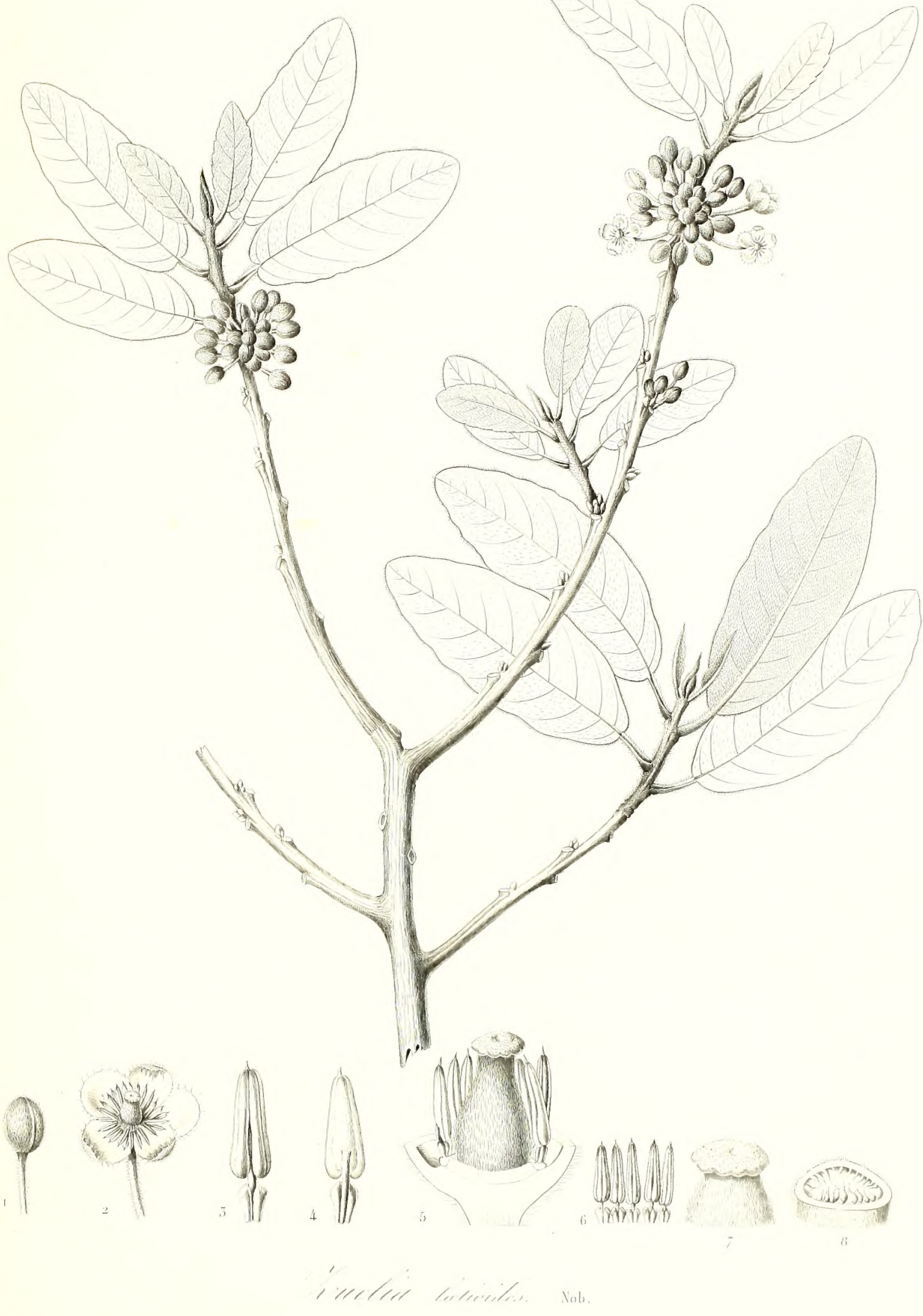



PTANTE VASCTHABKS.
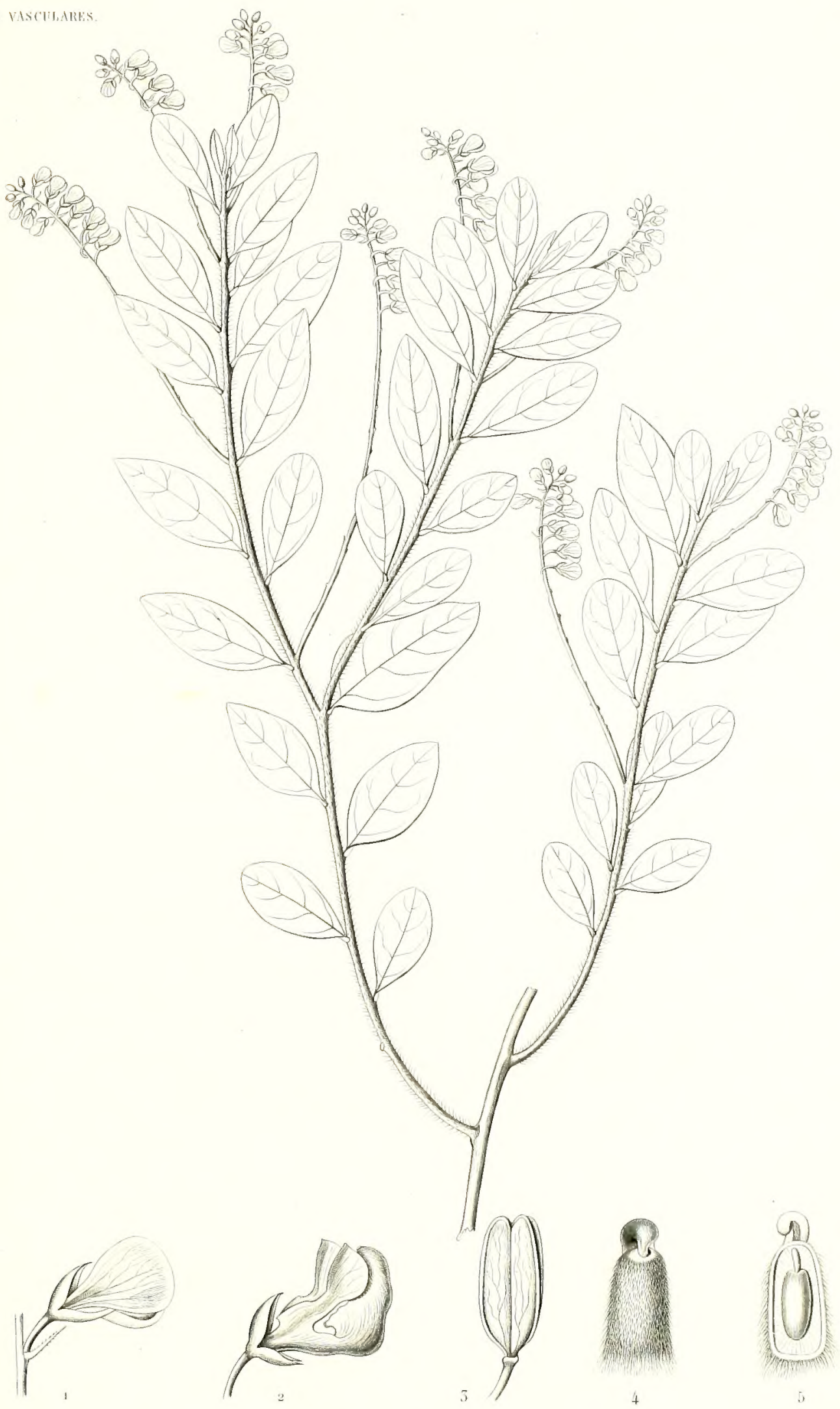

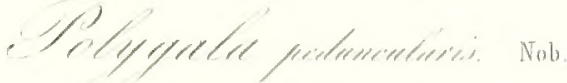




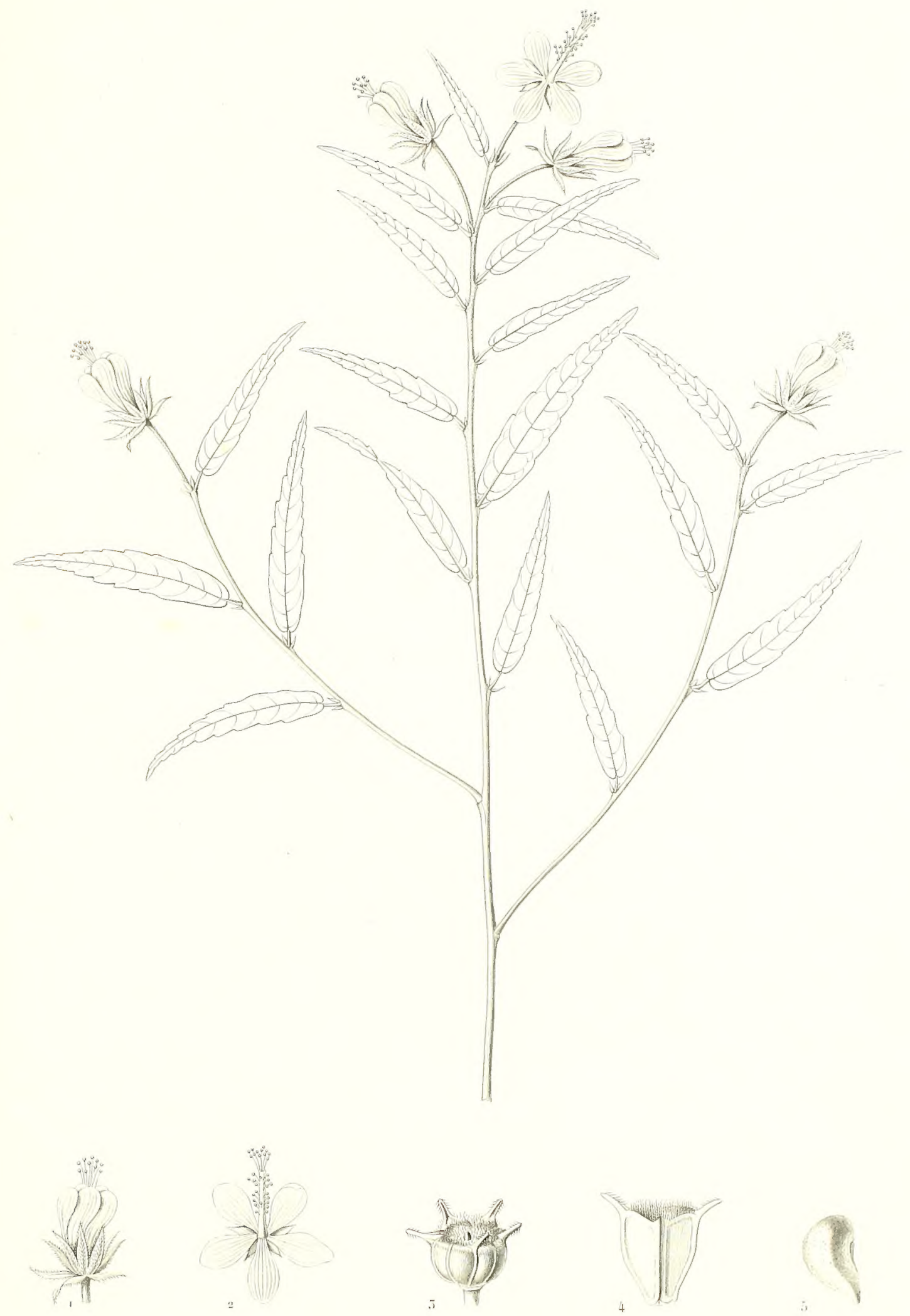

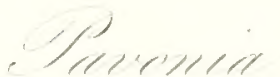





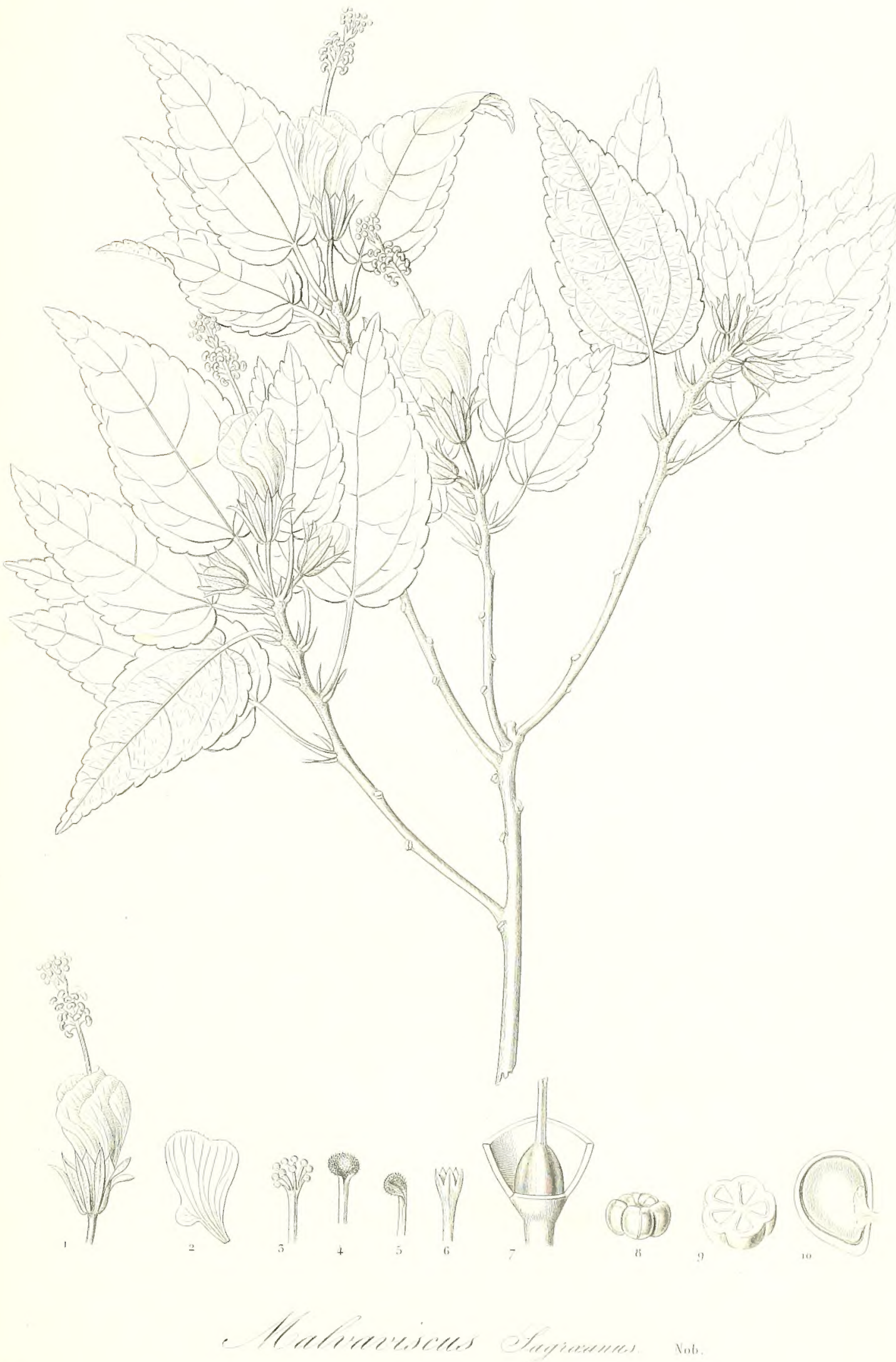





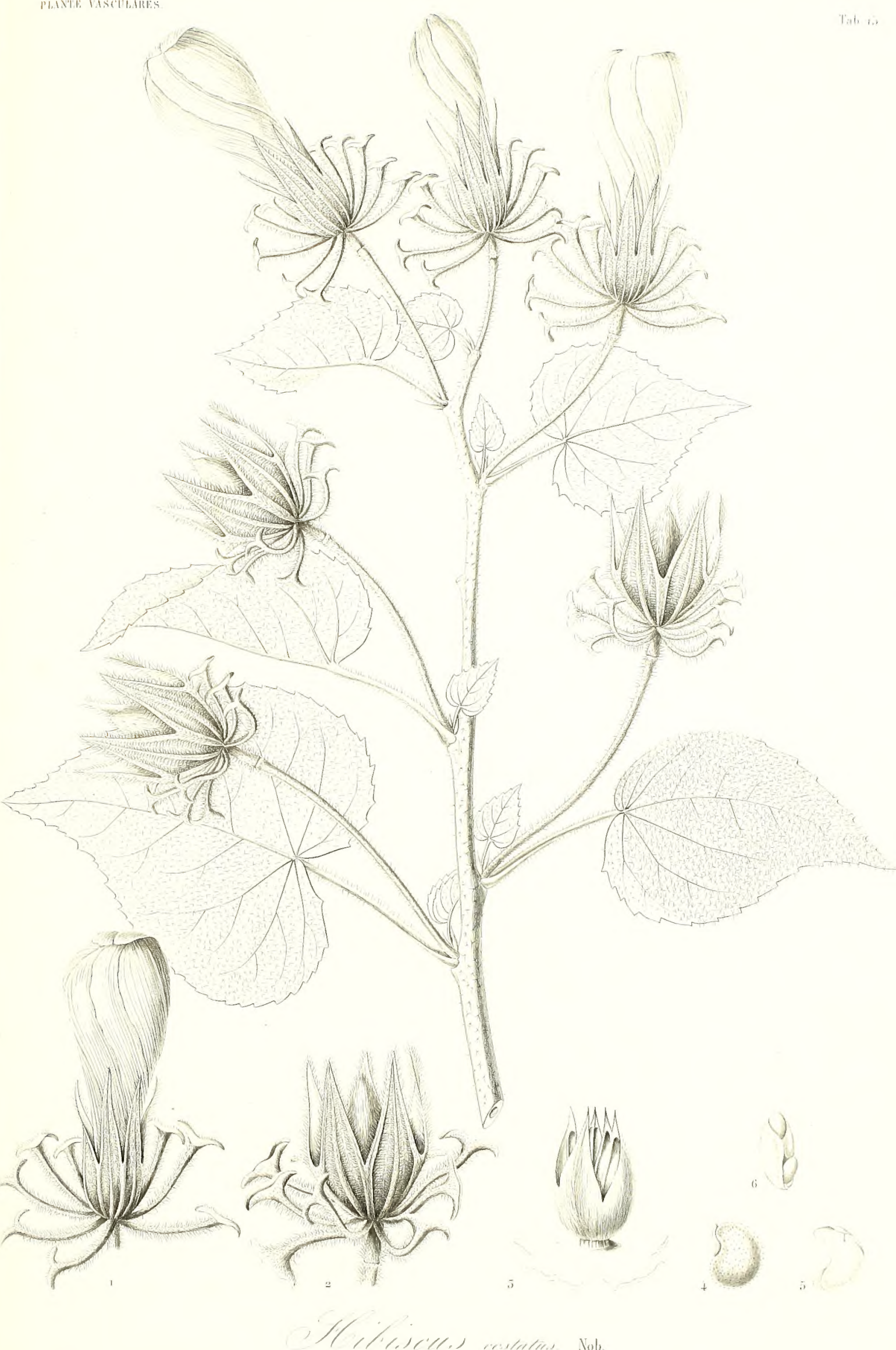





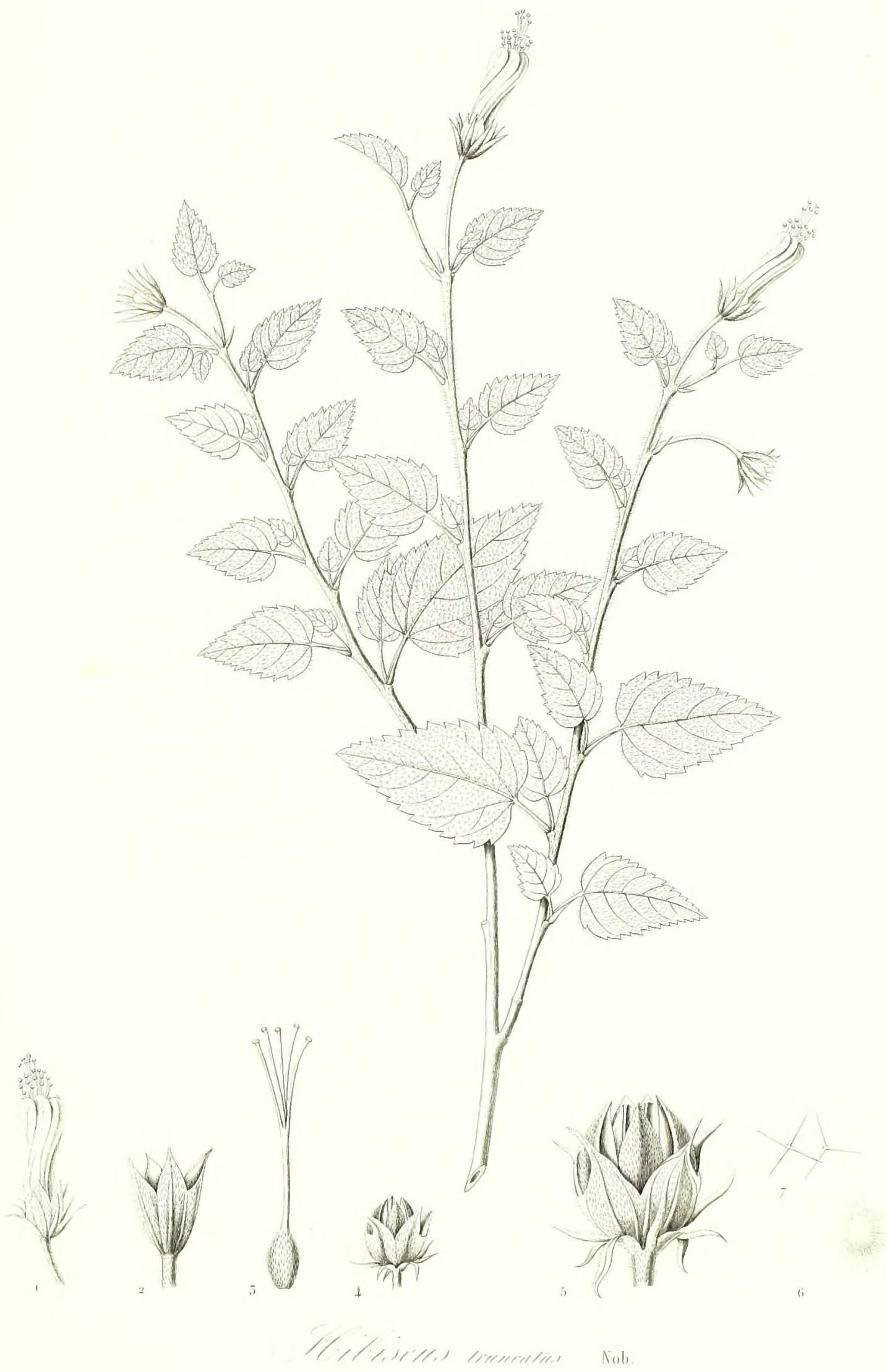





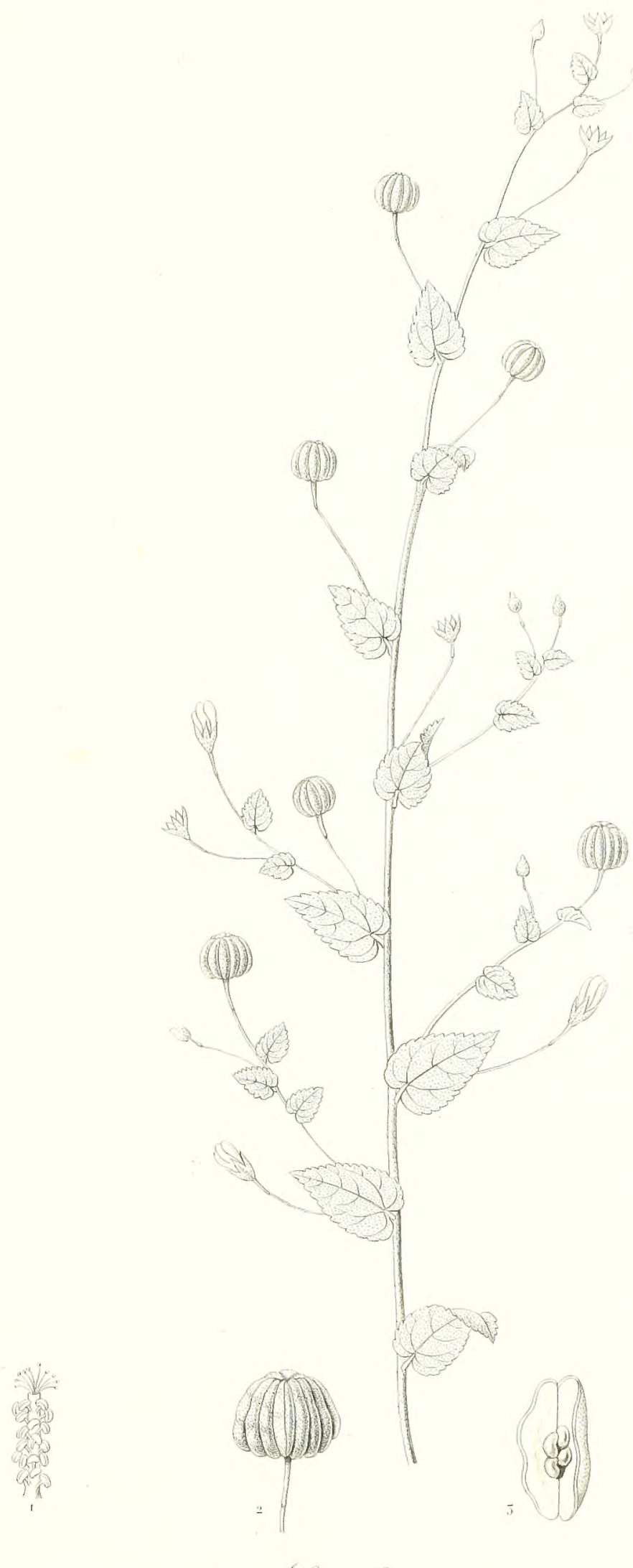

T.1. . -

- Preitilone sucrestums. 



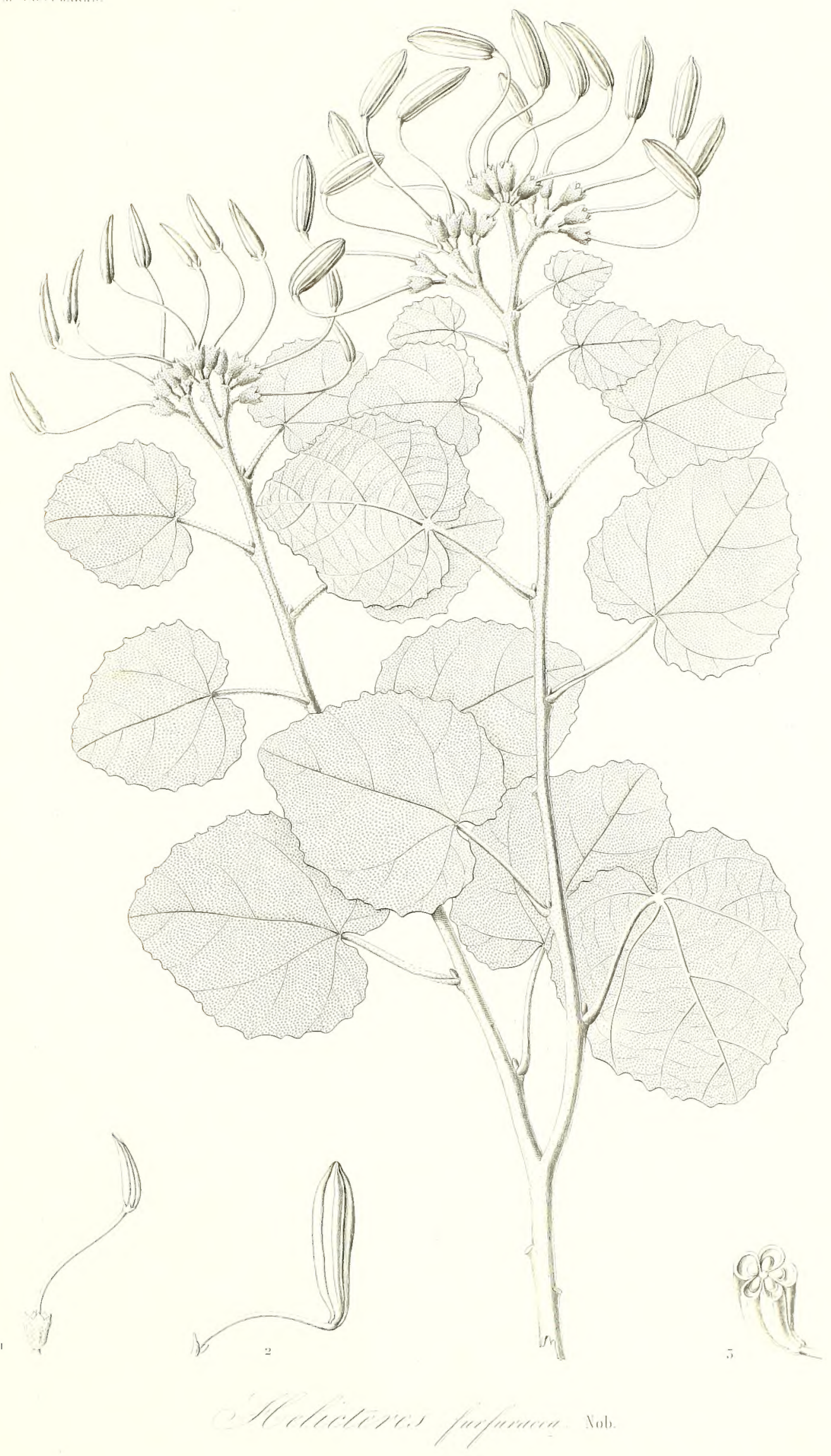





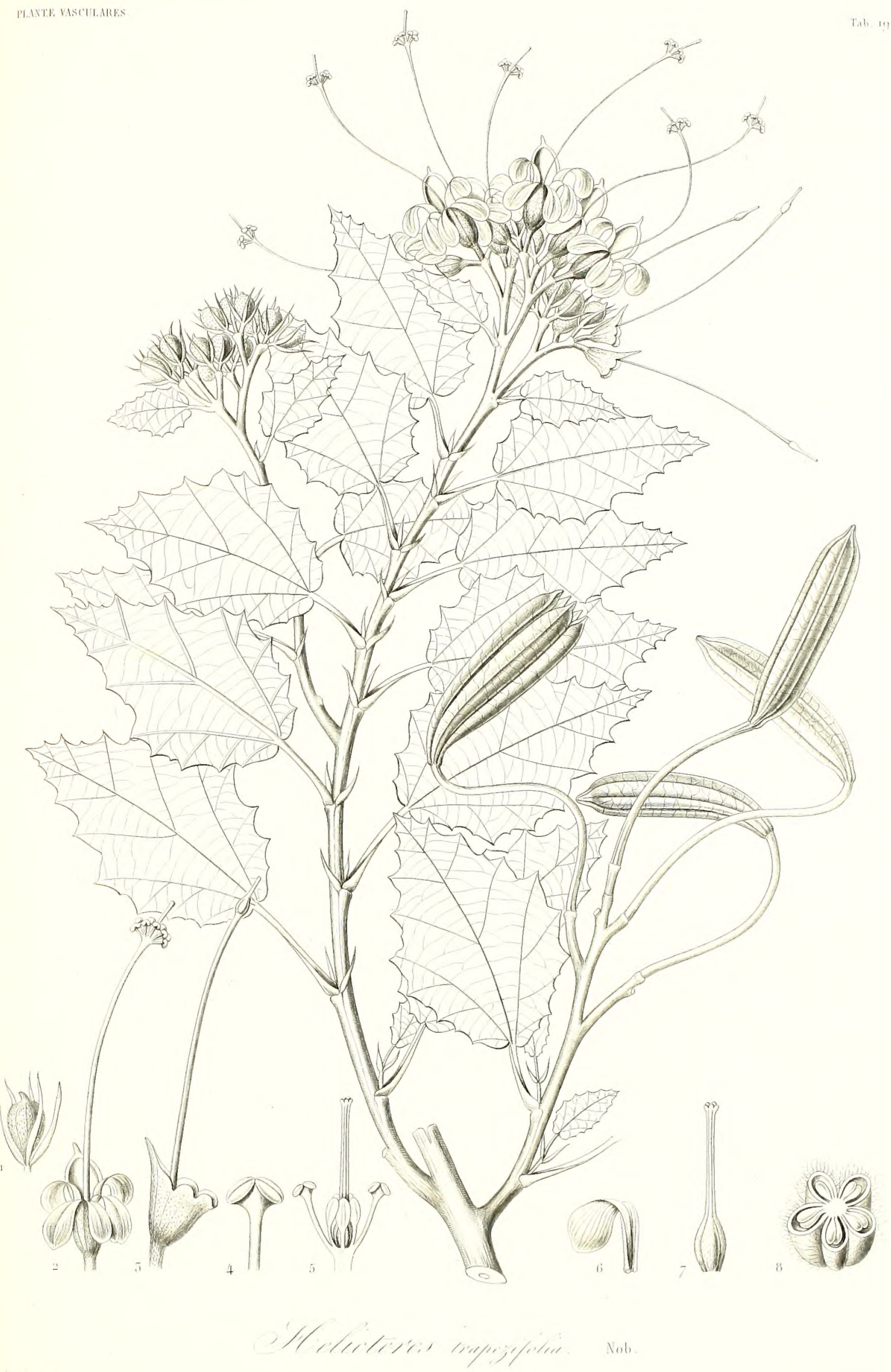





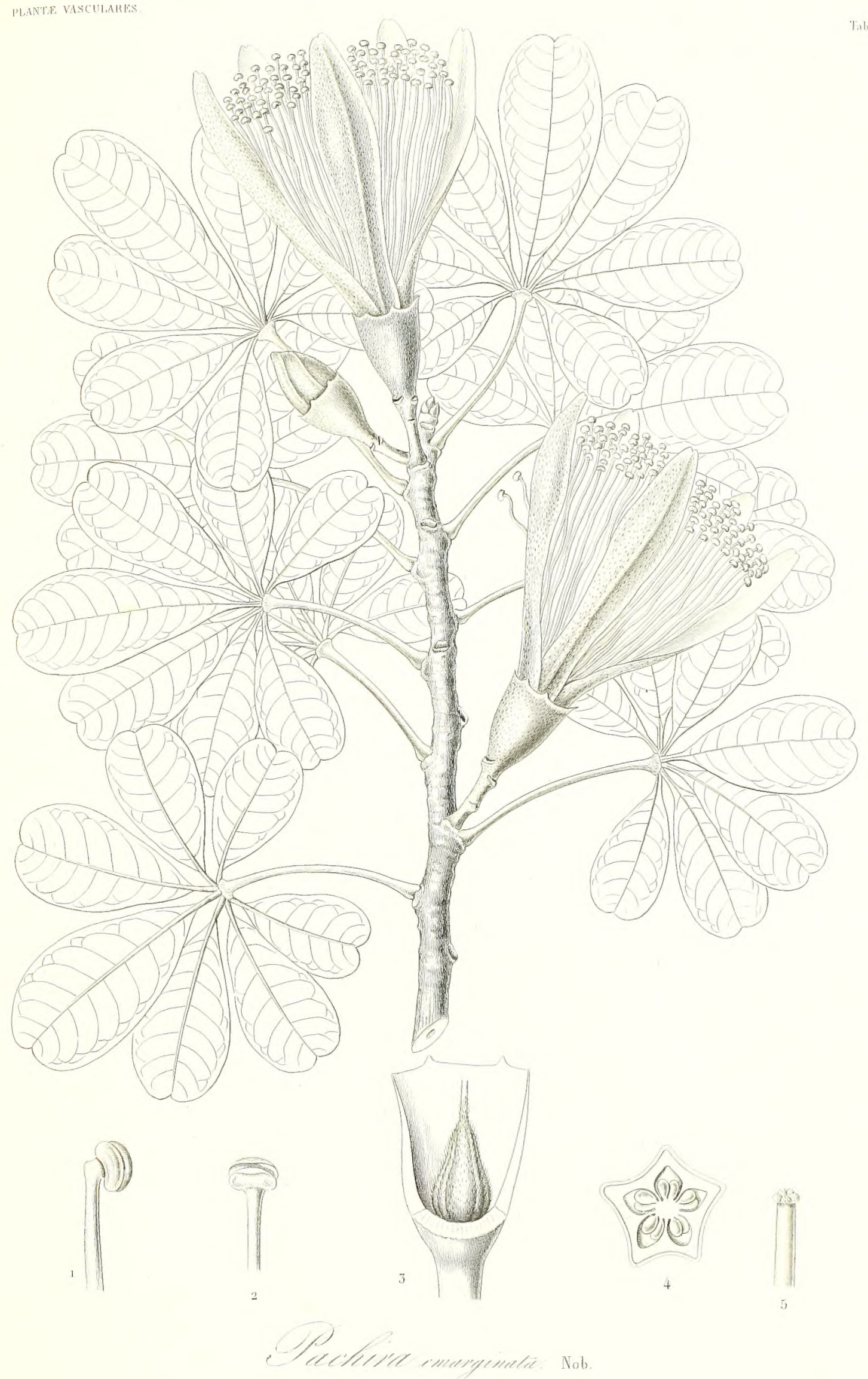




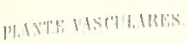

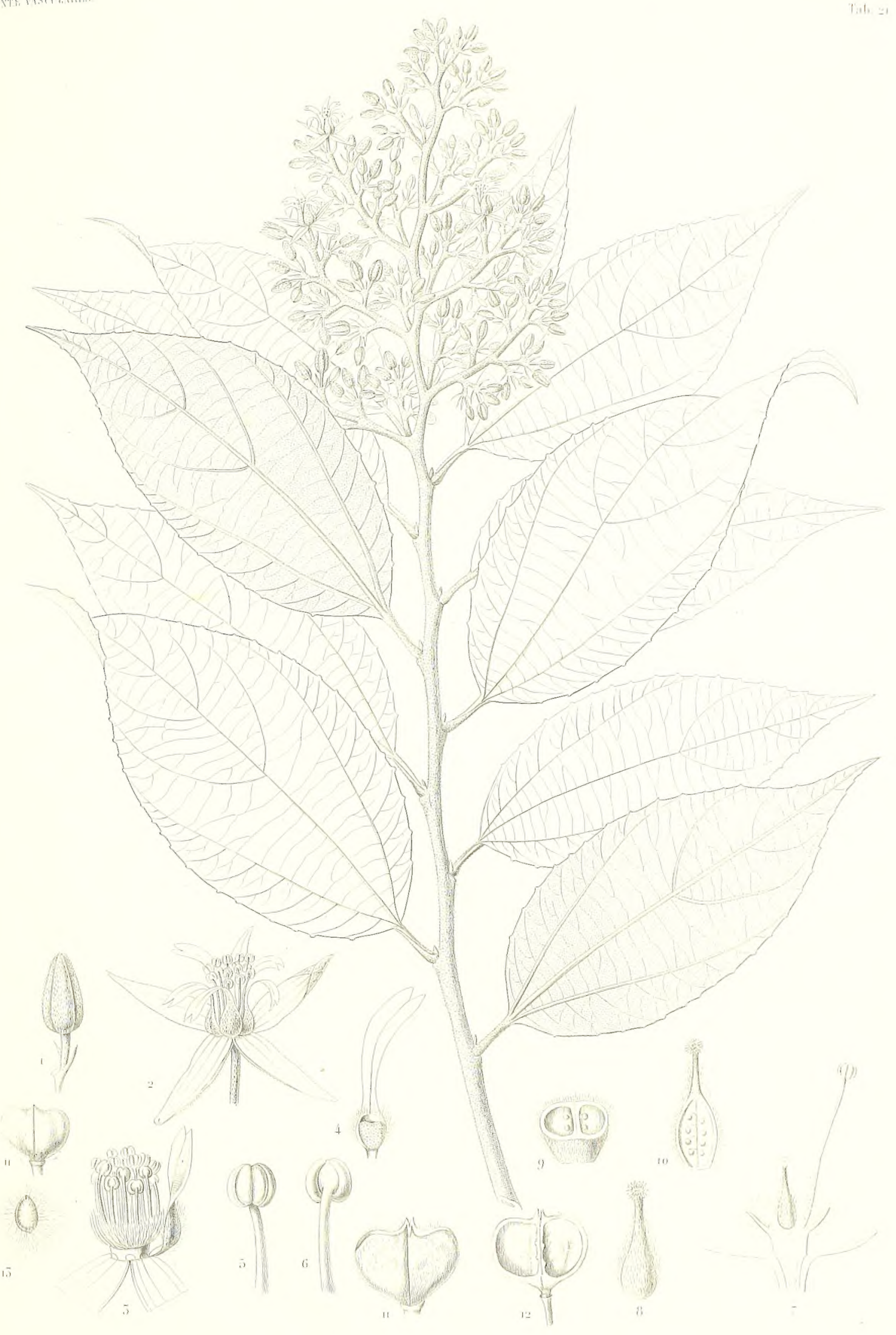

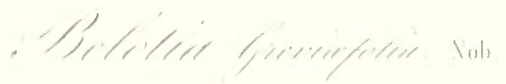




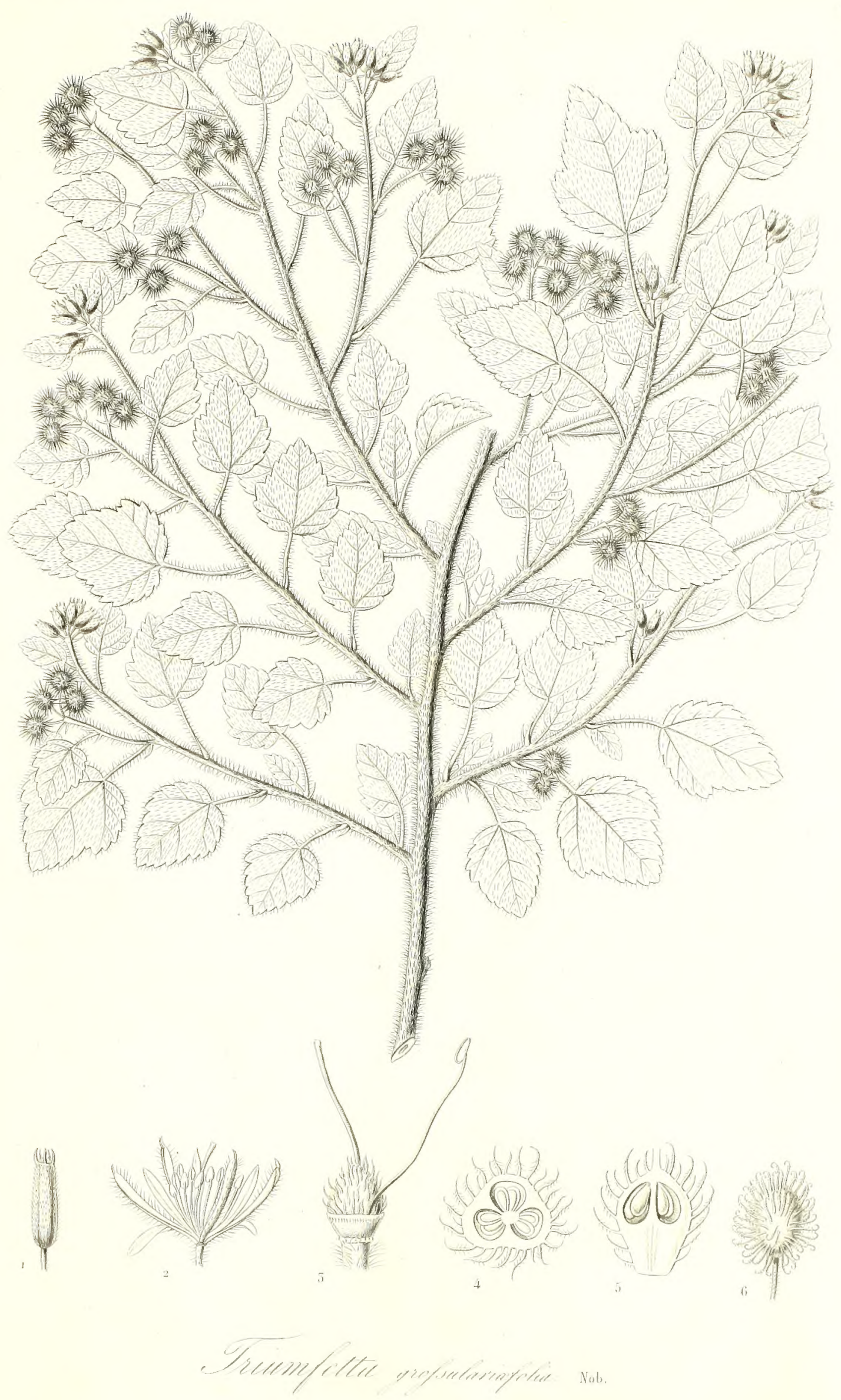






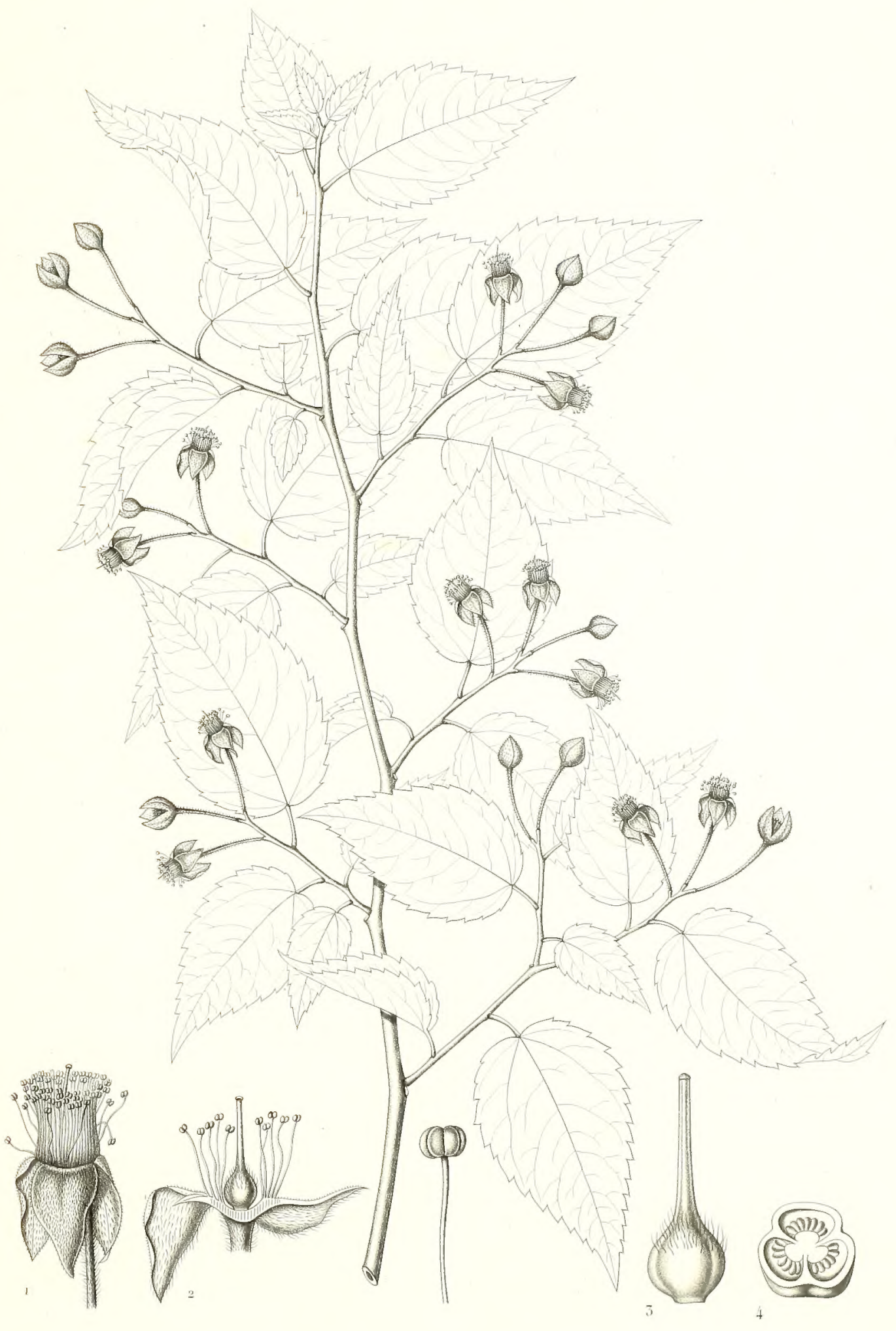



PLWTE VASCTIATSS,

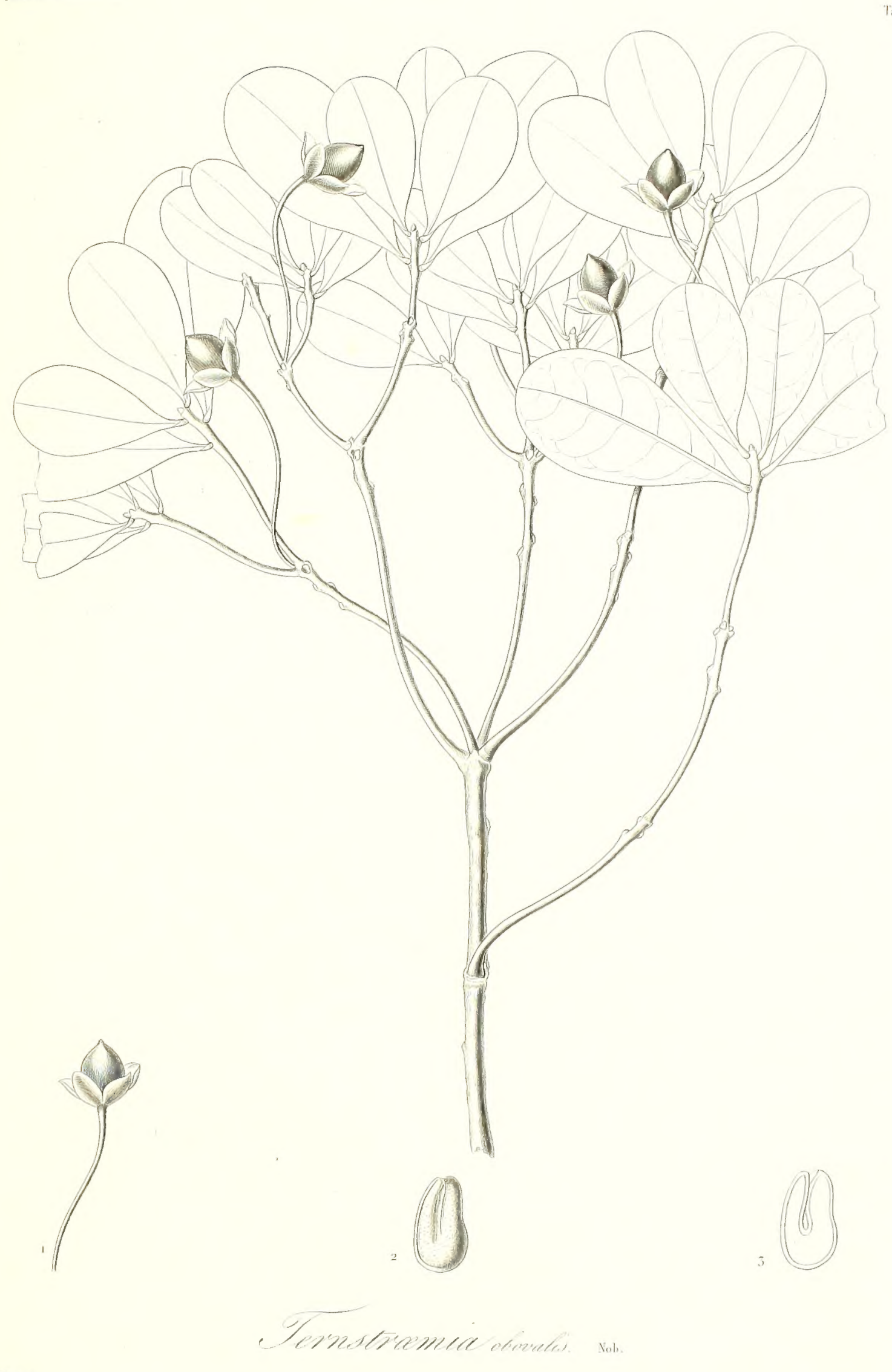





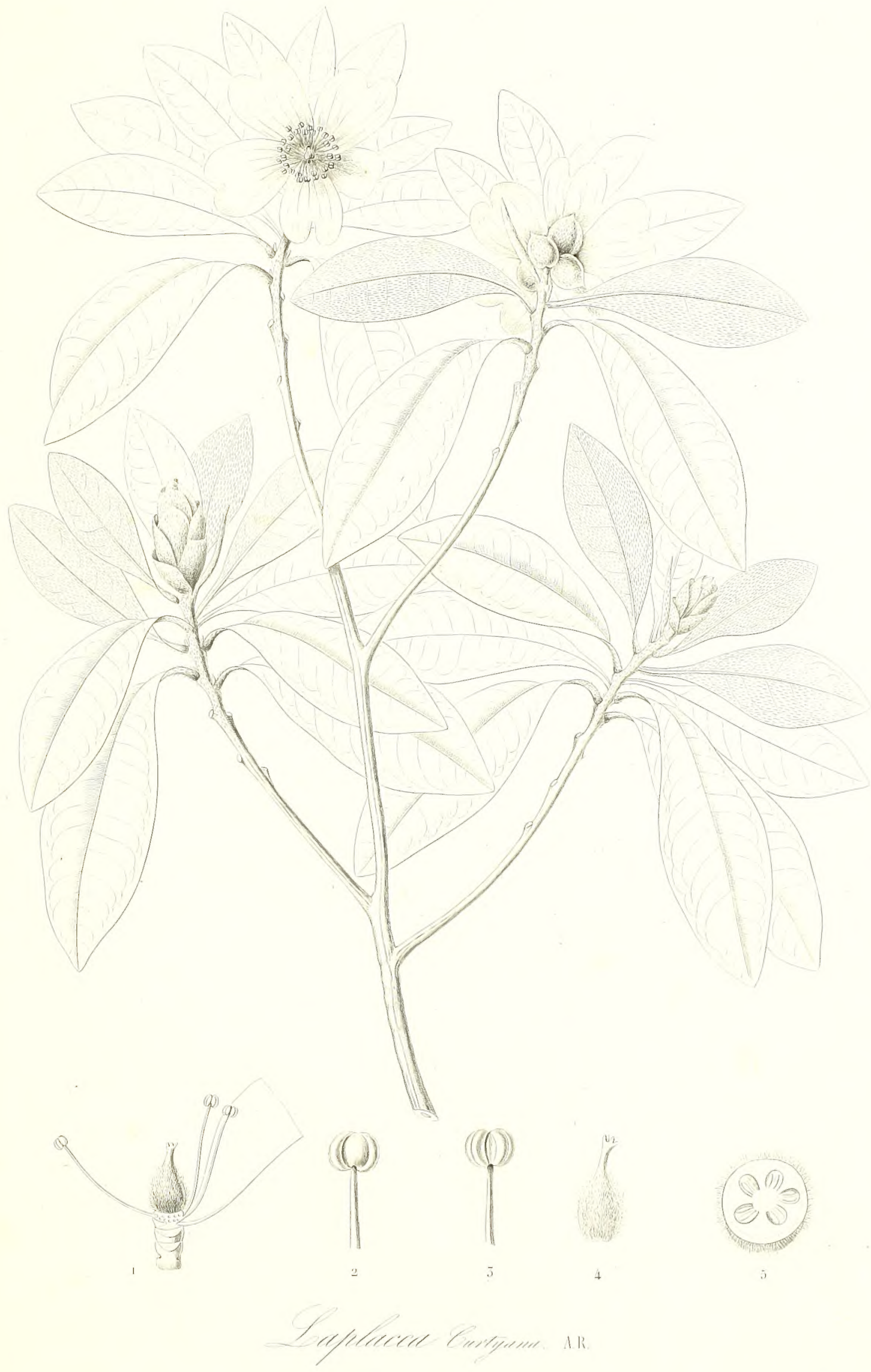





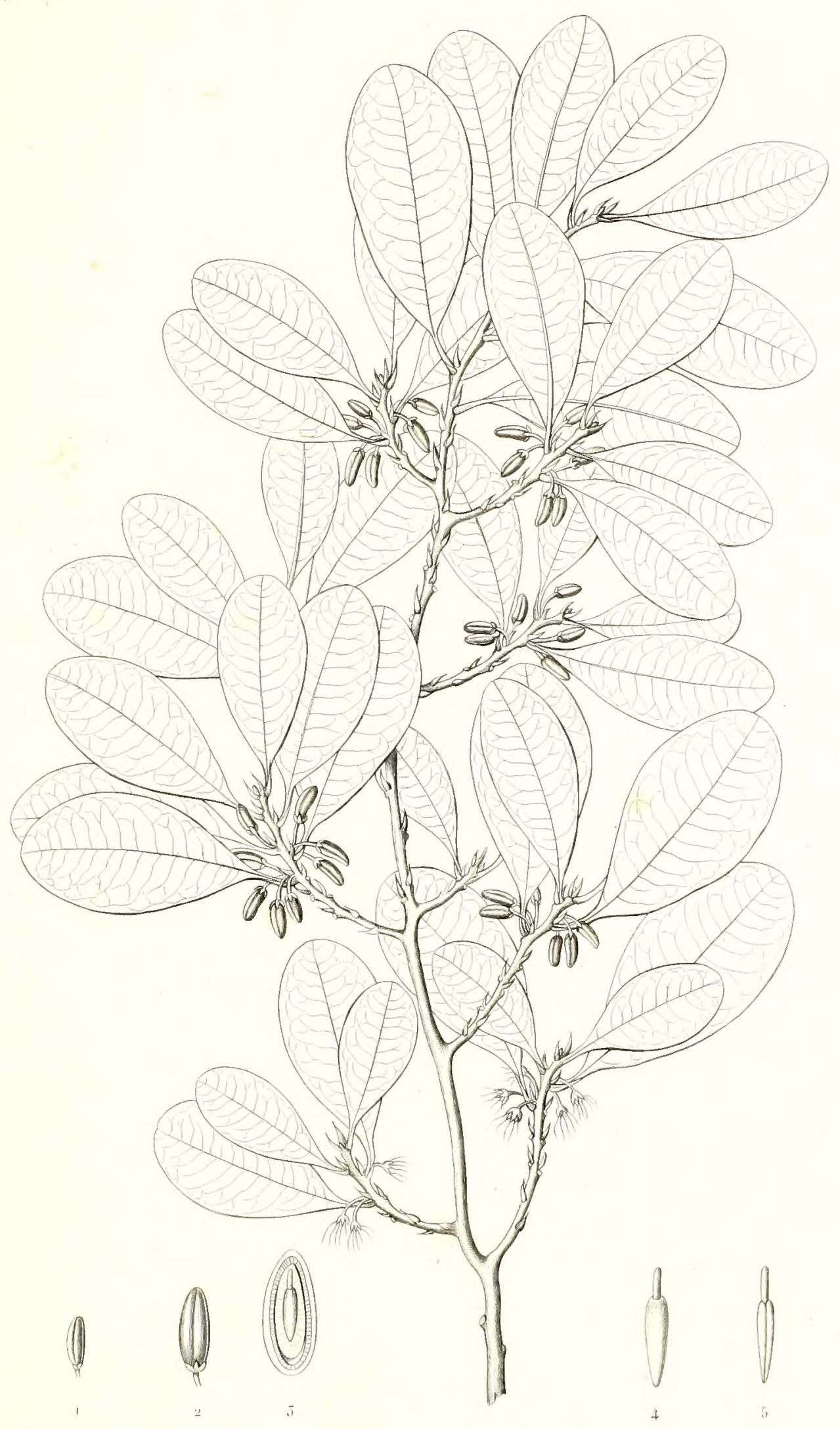

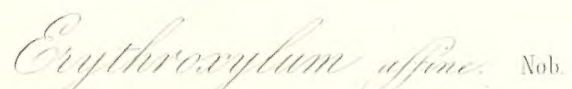





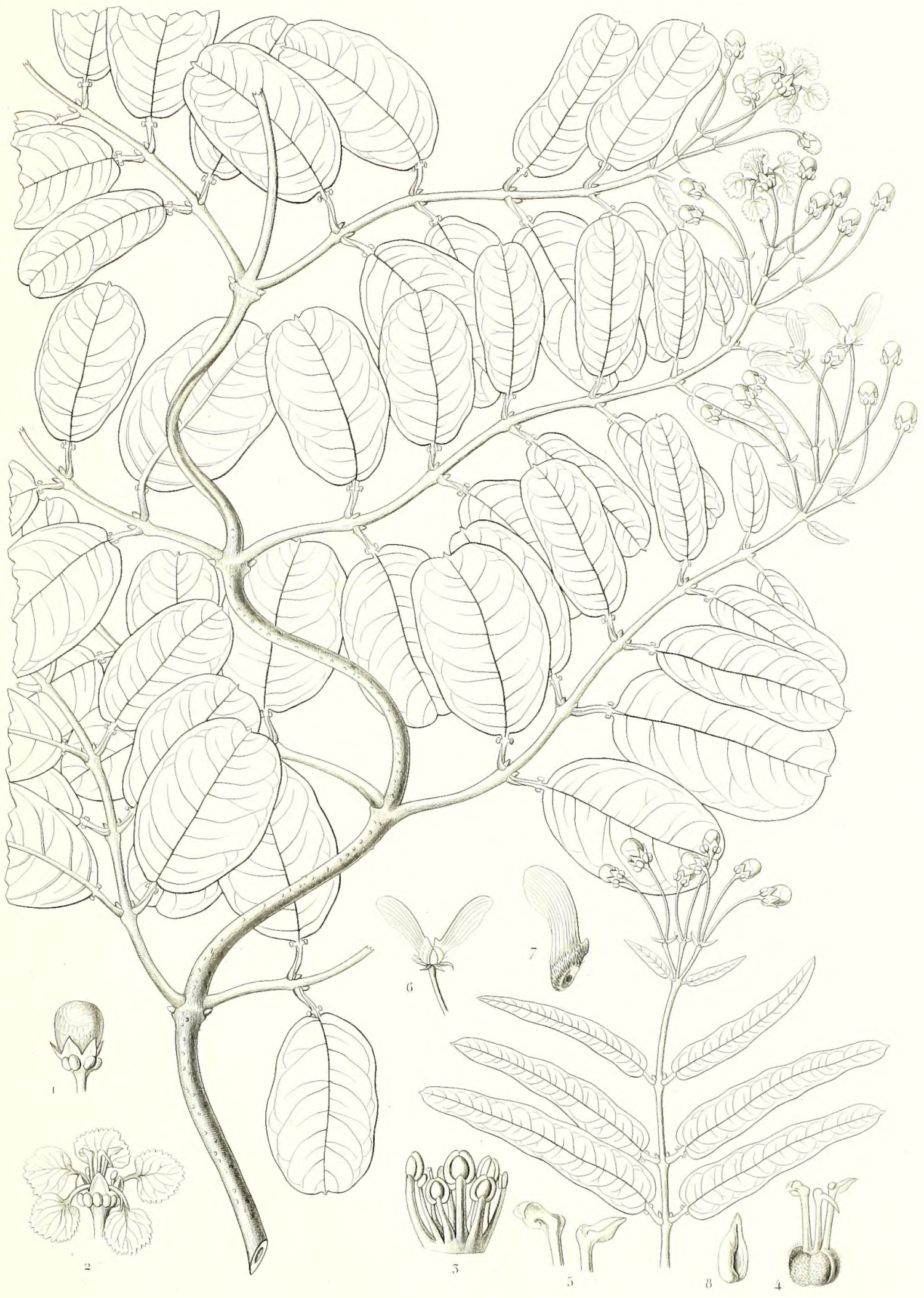

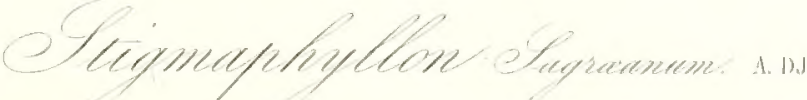





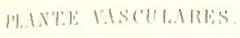

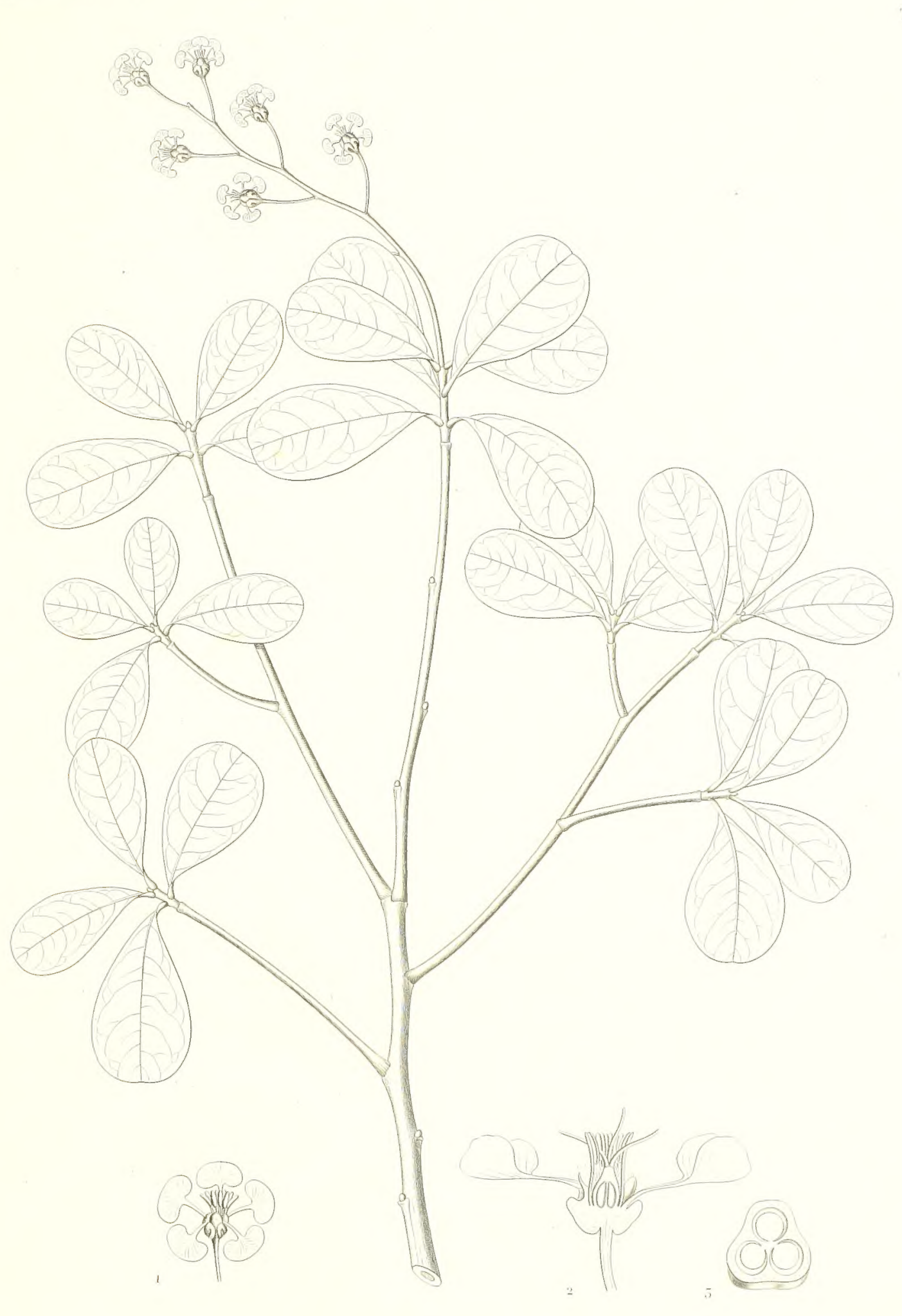

Tal. $28^{\text {hite }}$ 

HSTE MSctuath th

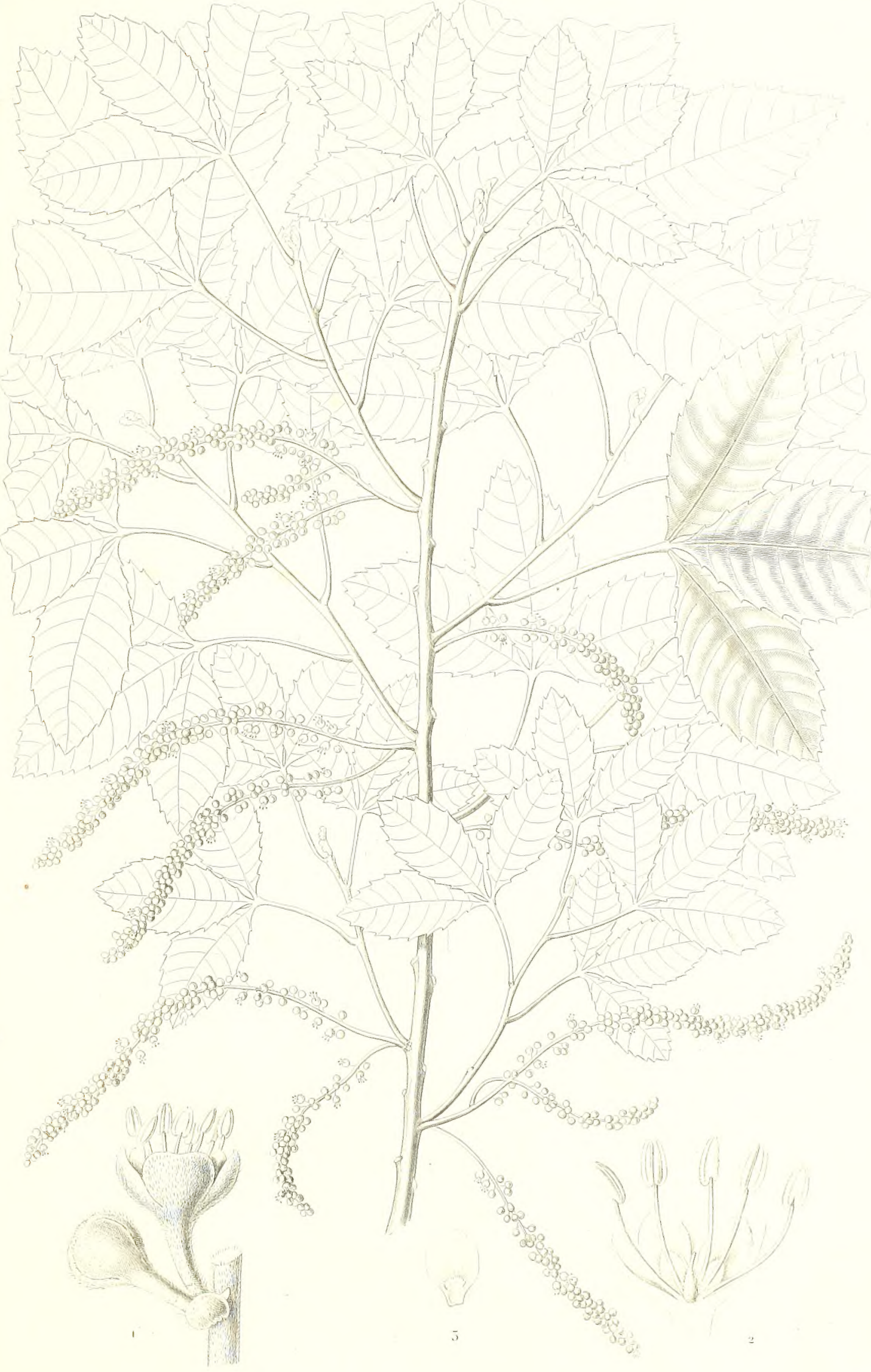





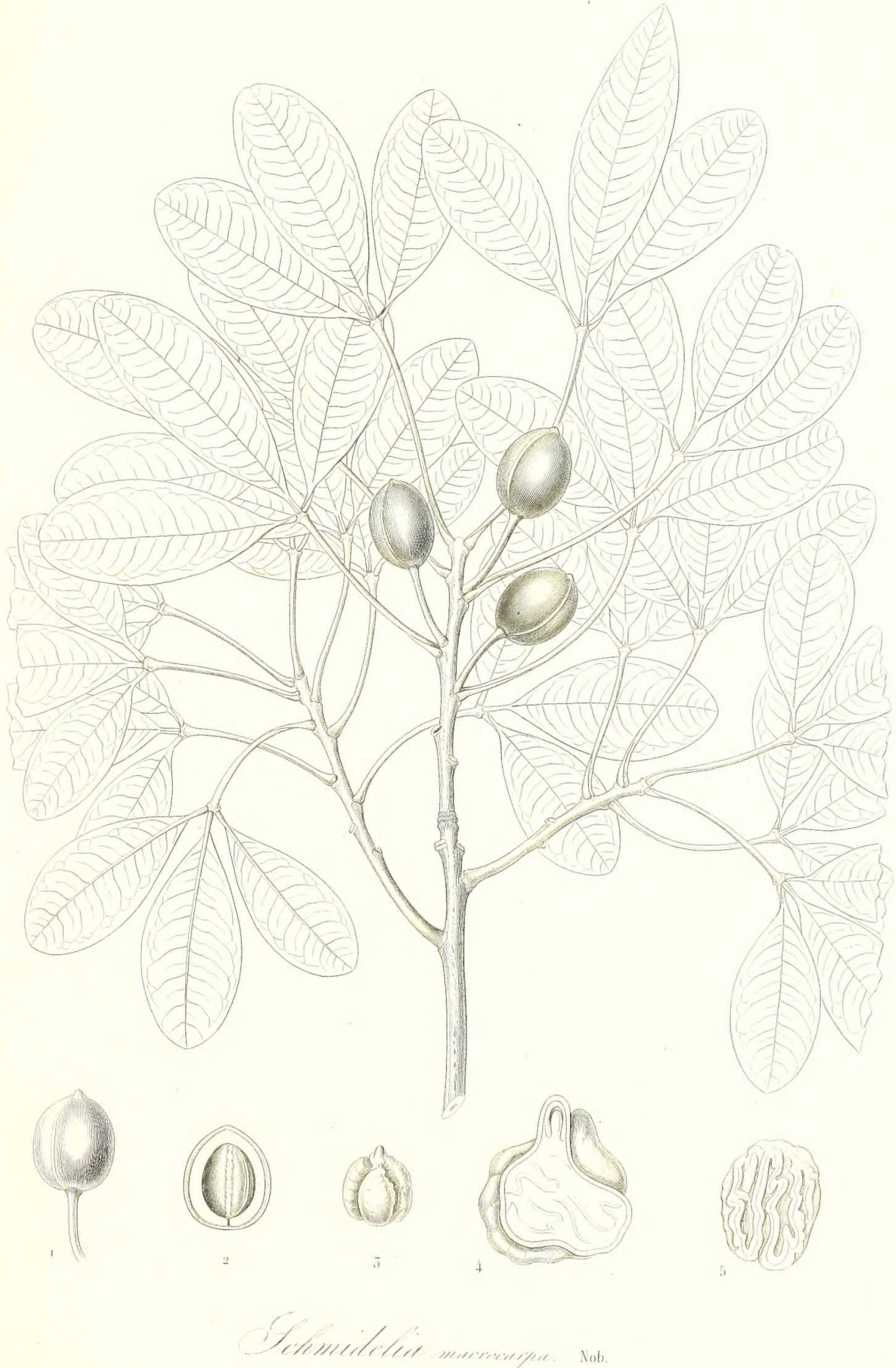





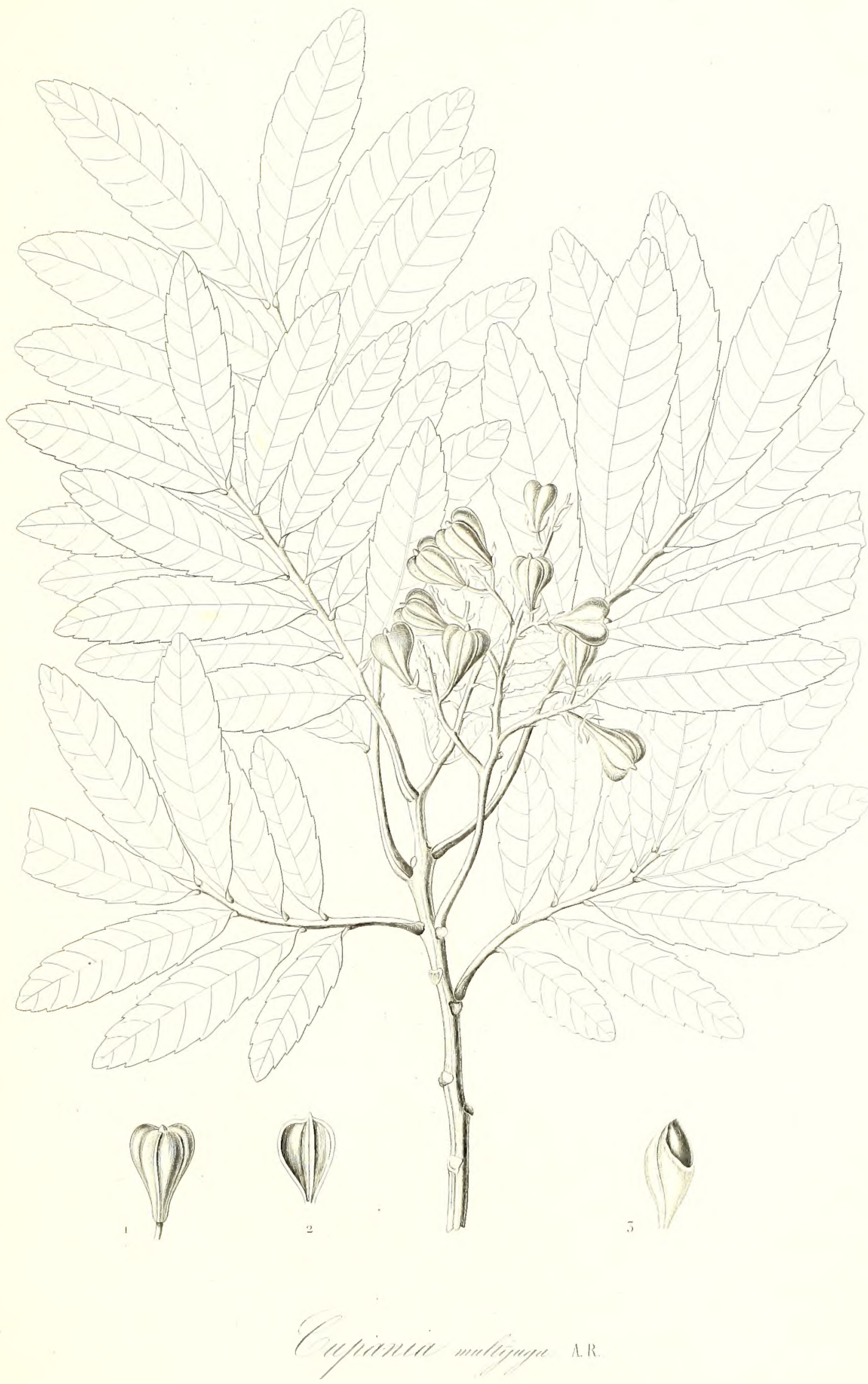


$\checkmark$ 

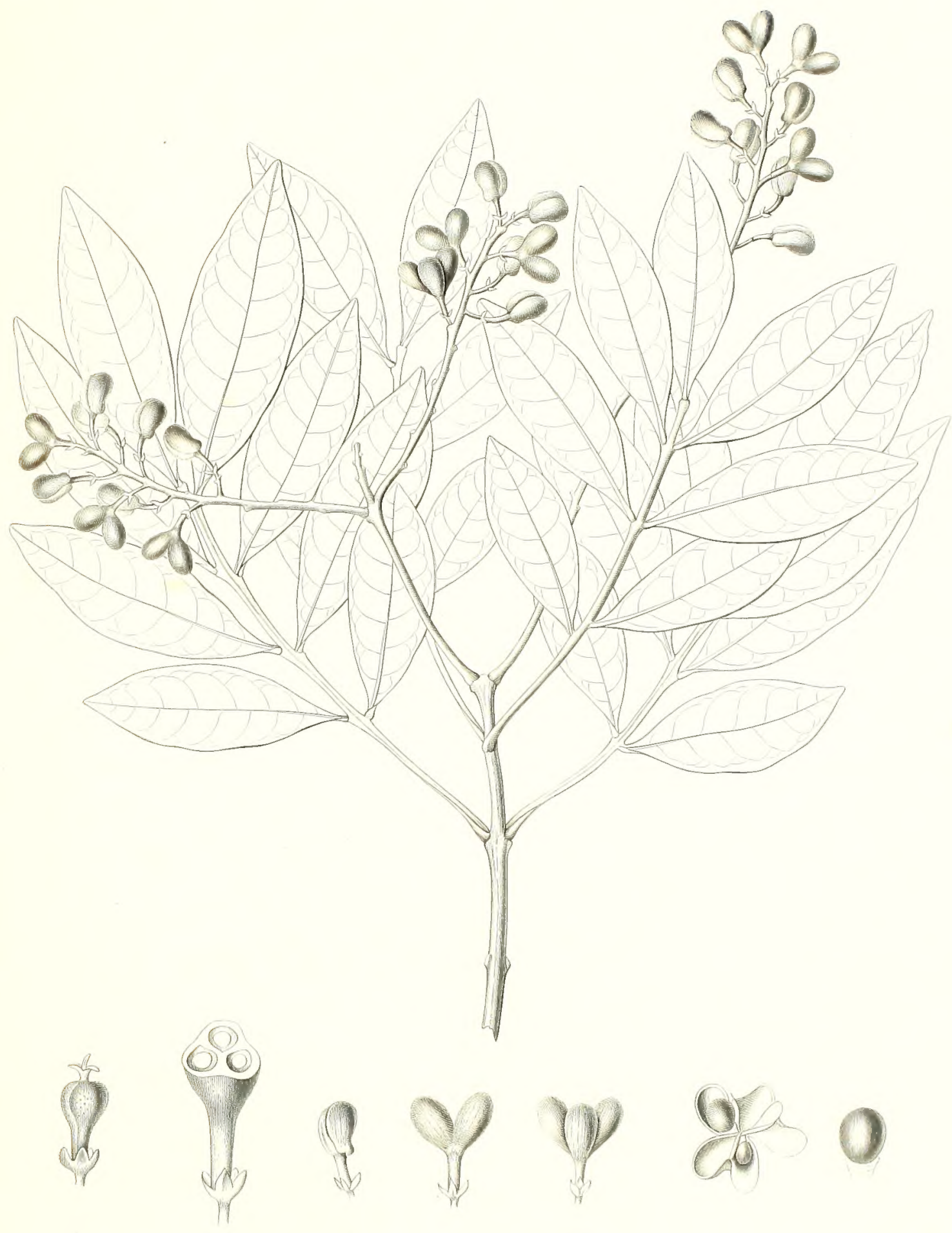


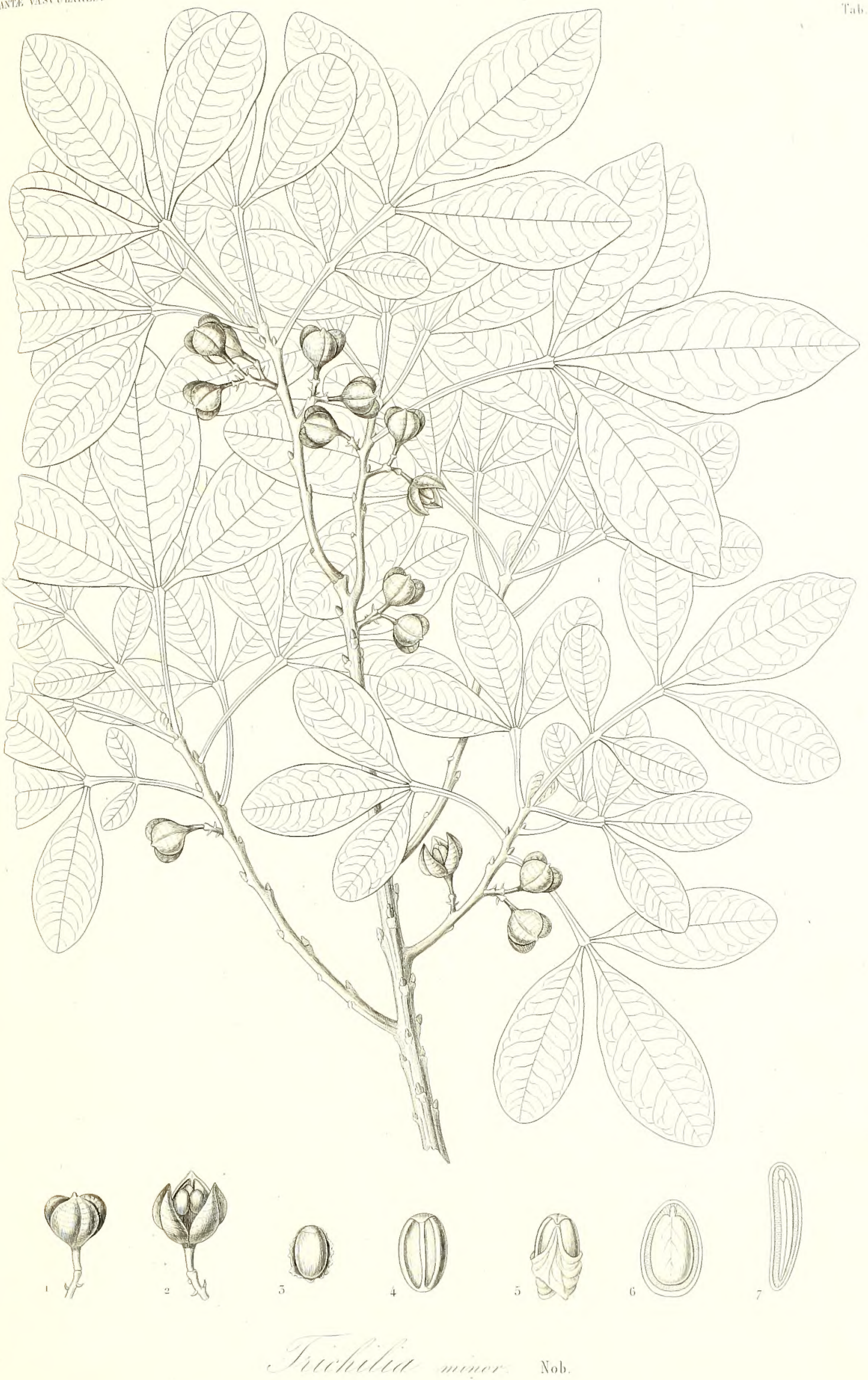




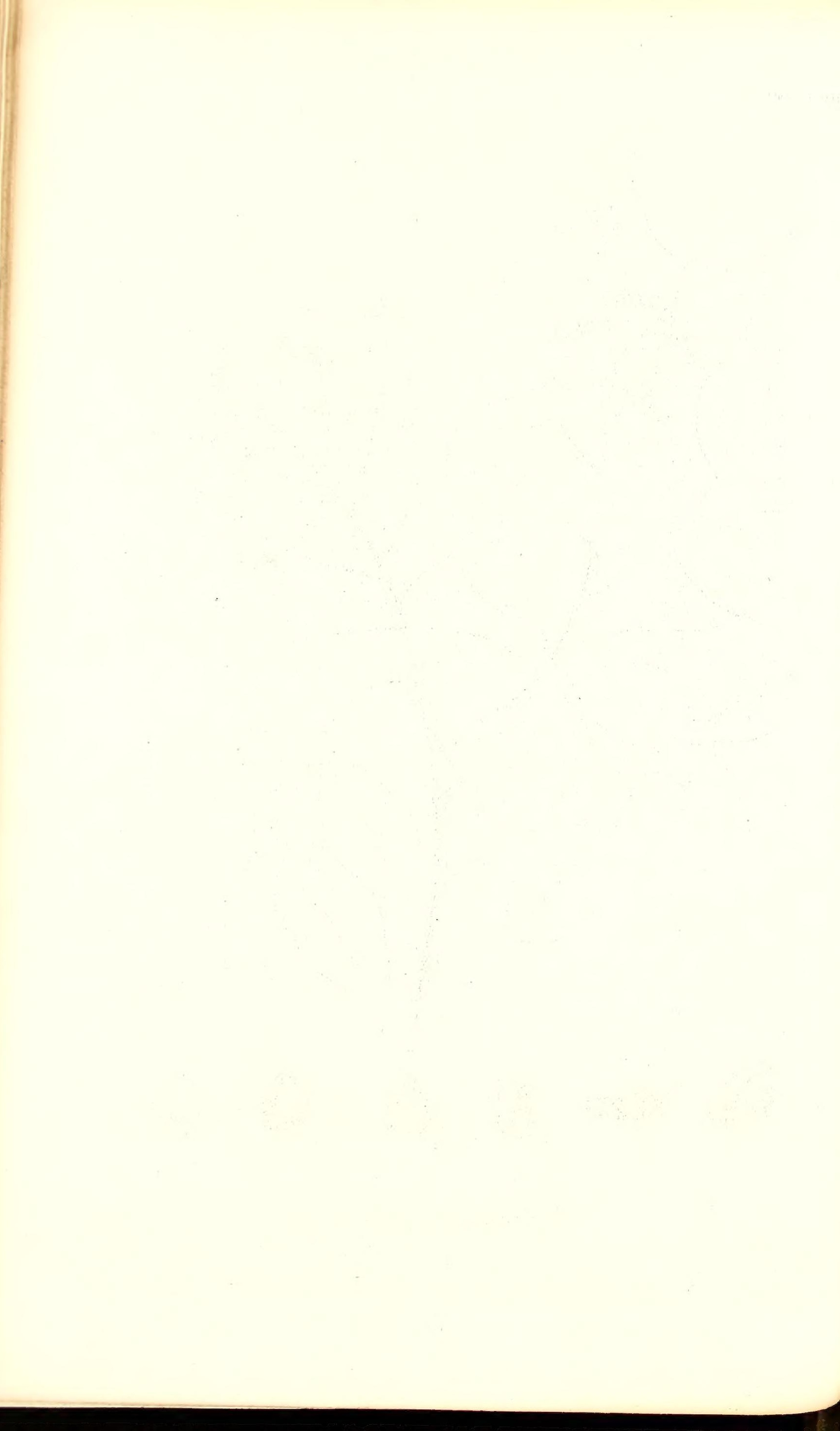


JJASTE MATHAARLS.

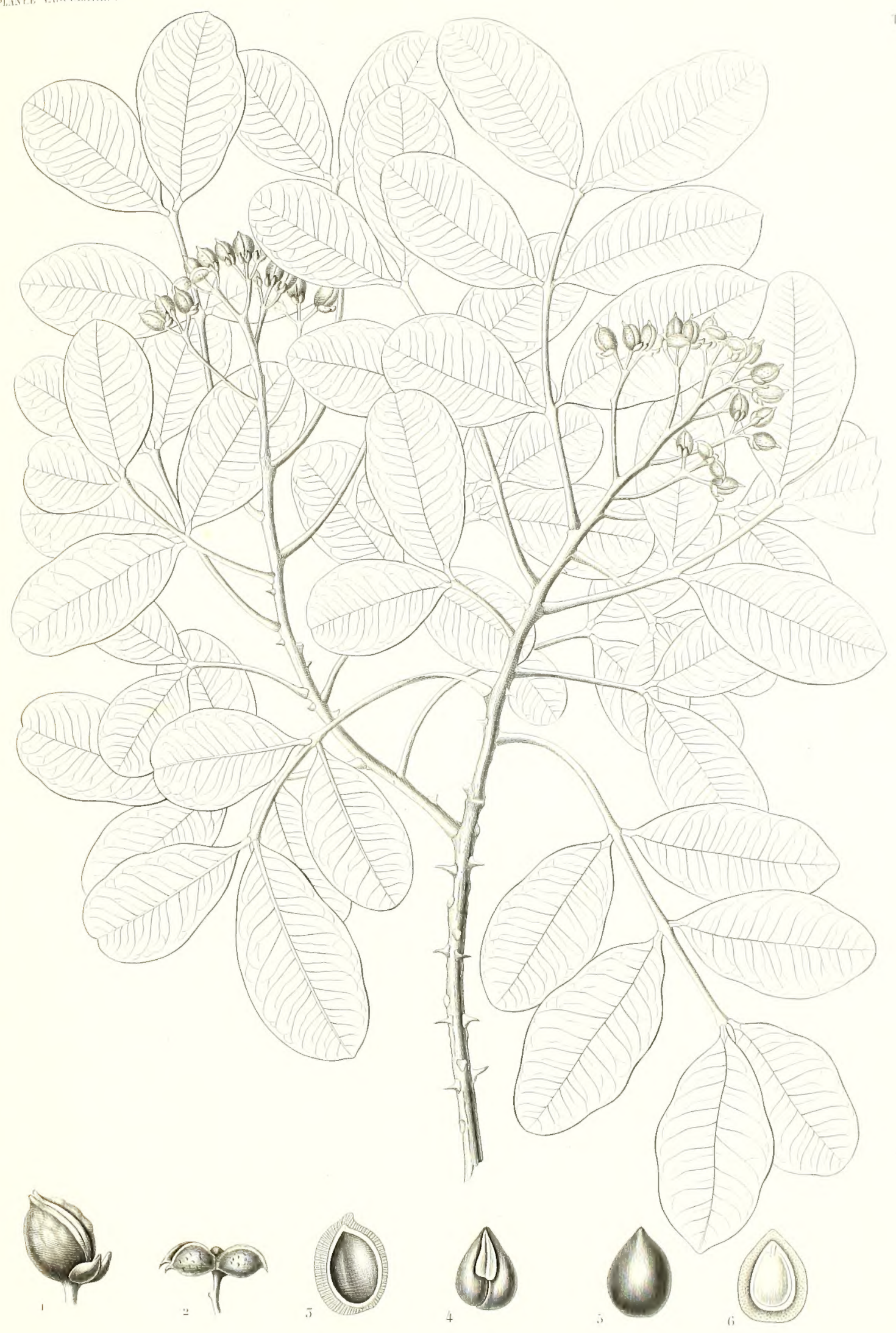

1.1. if 



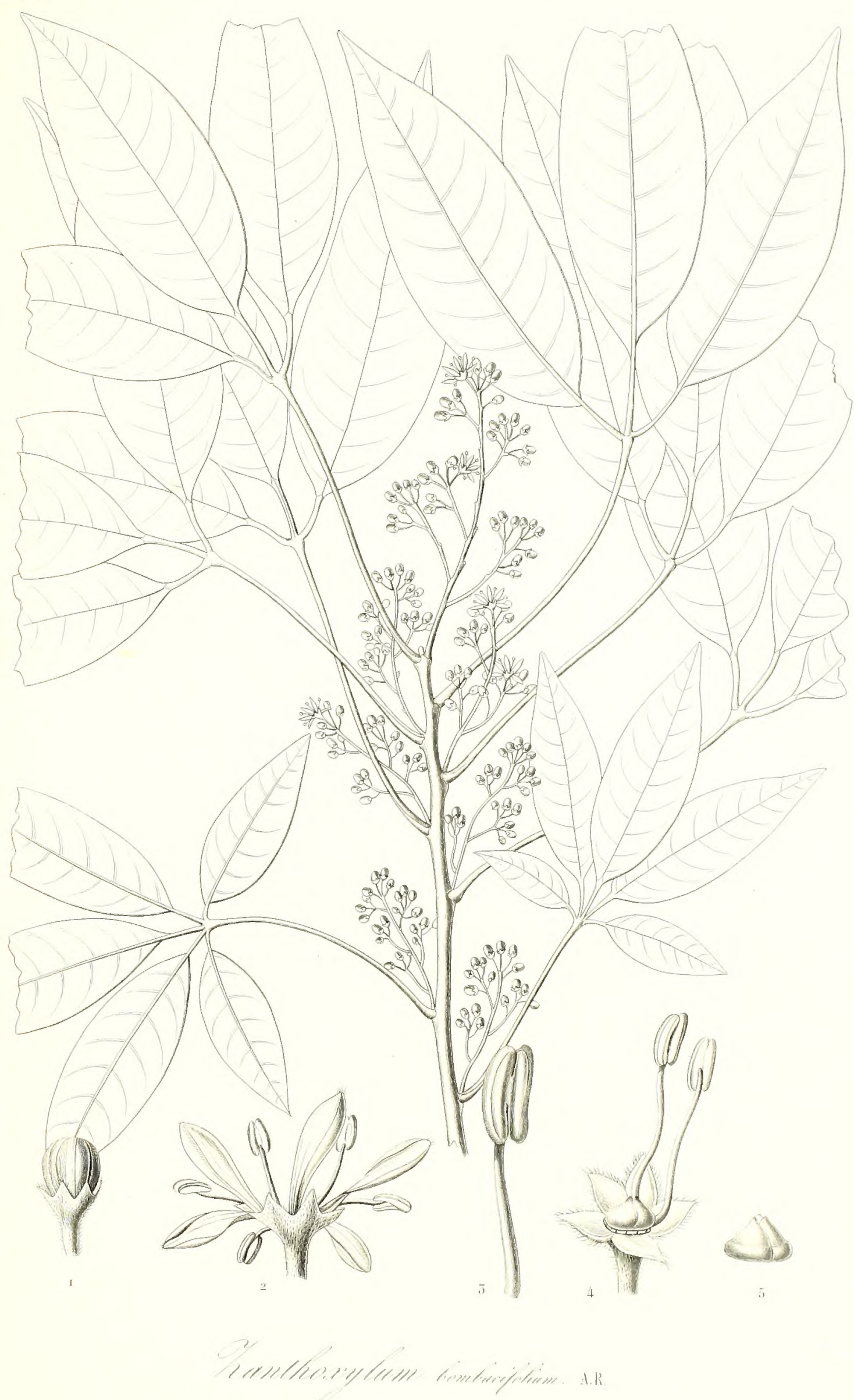




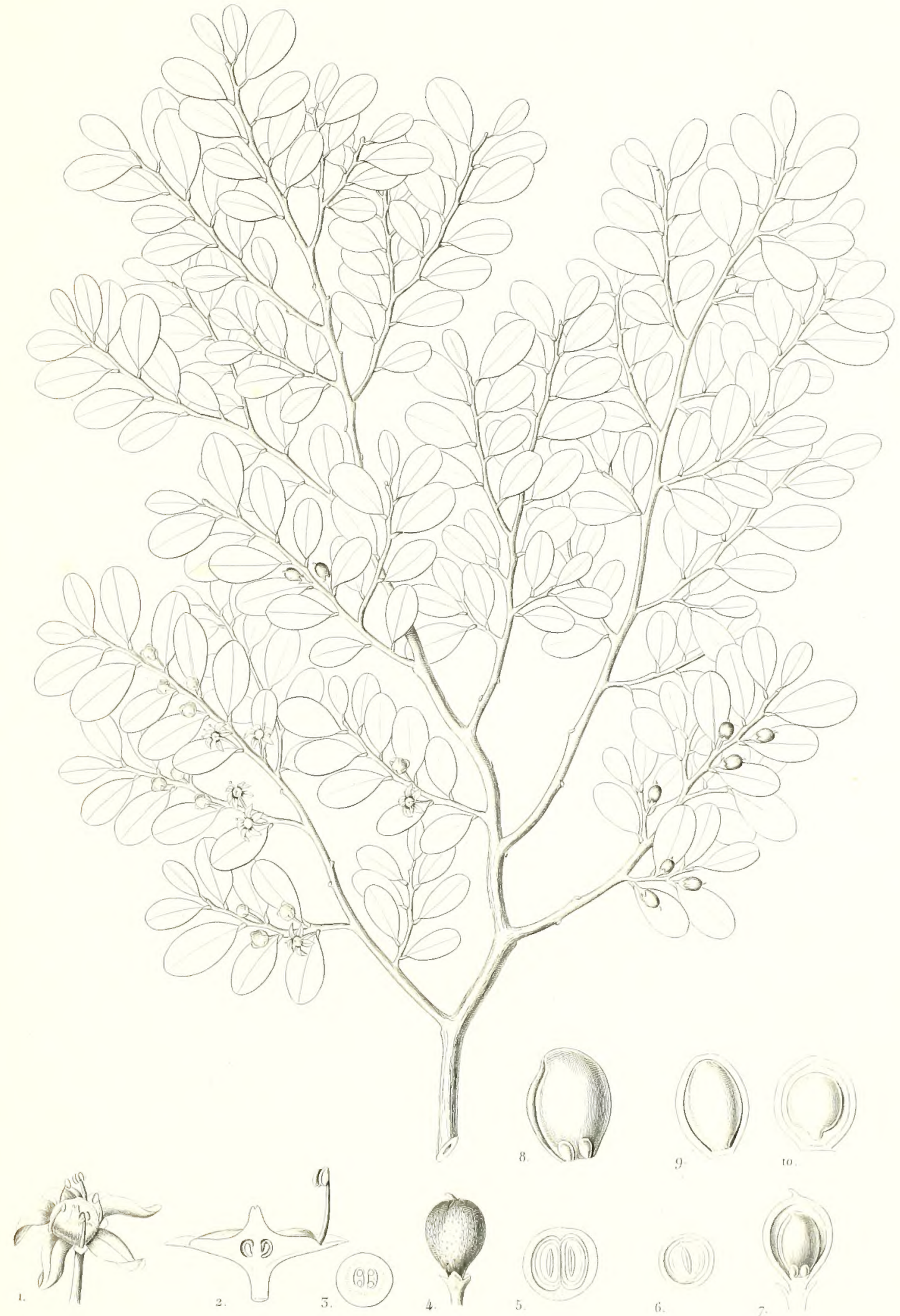

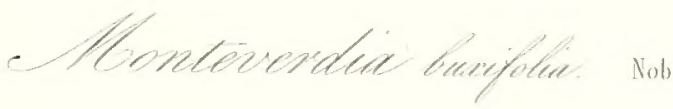




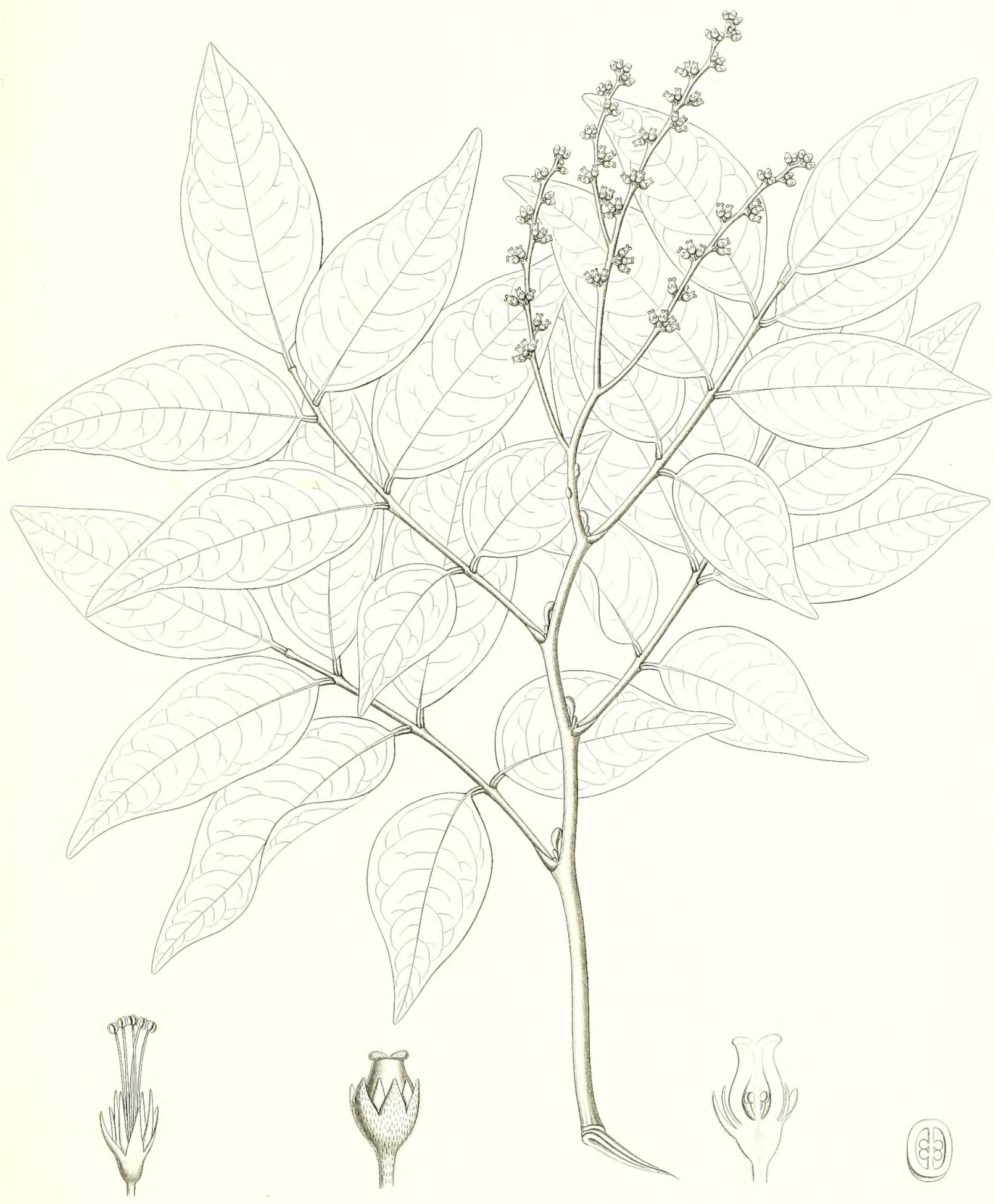





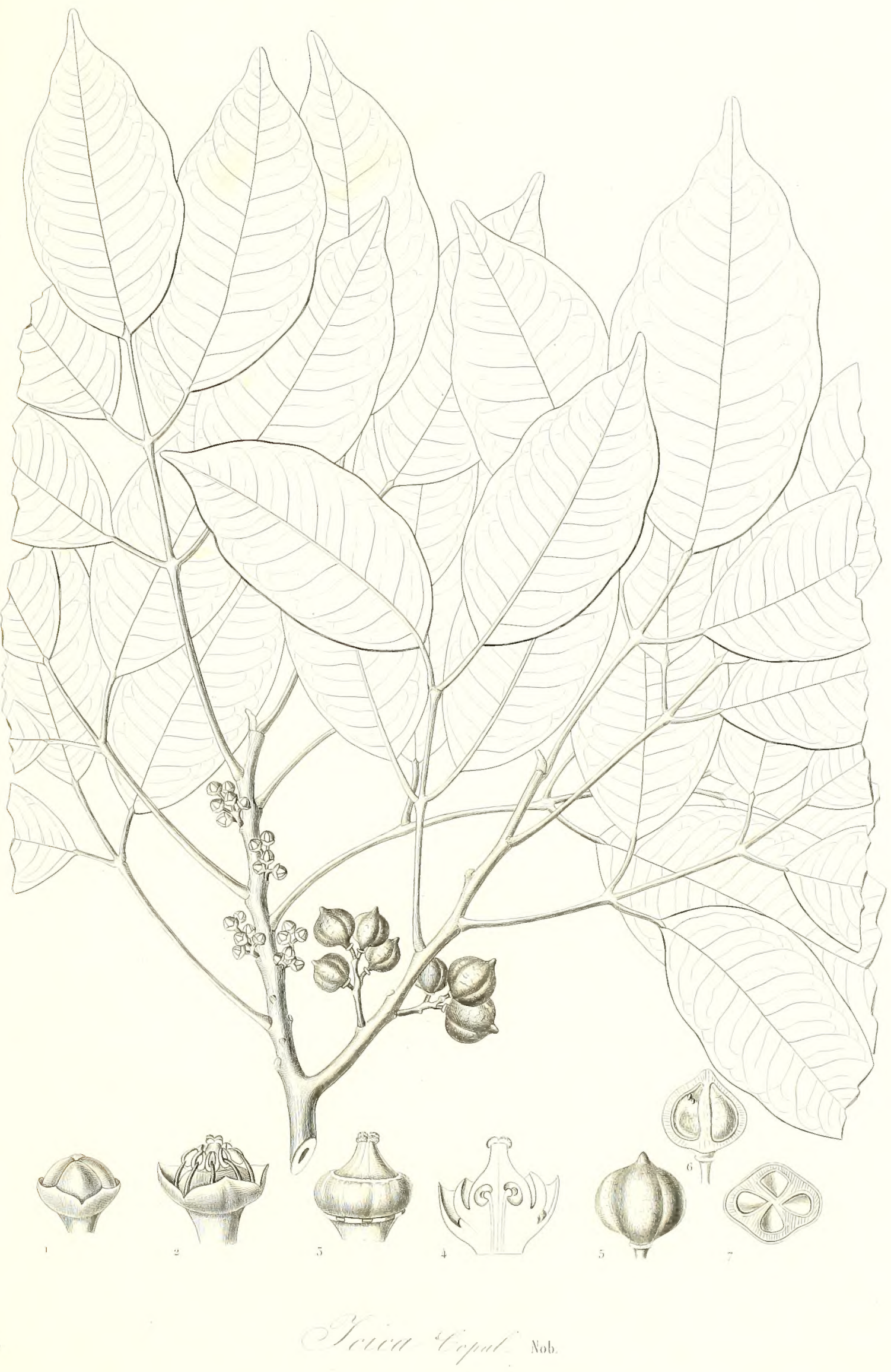





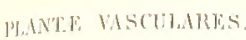
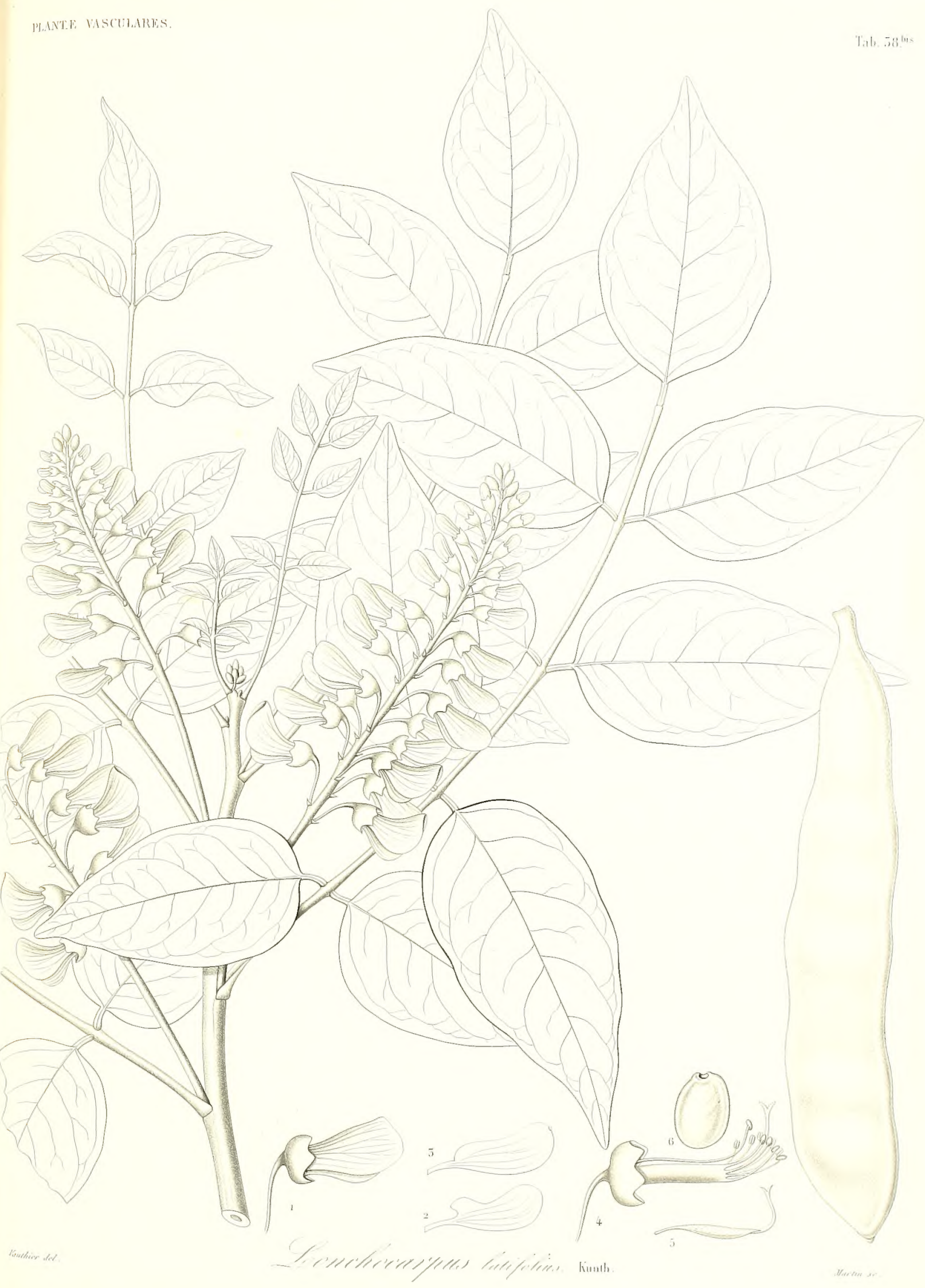



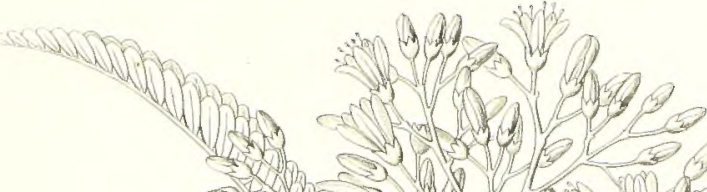

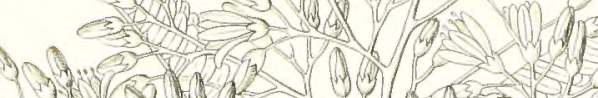

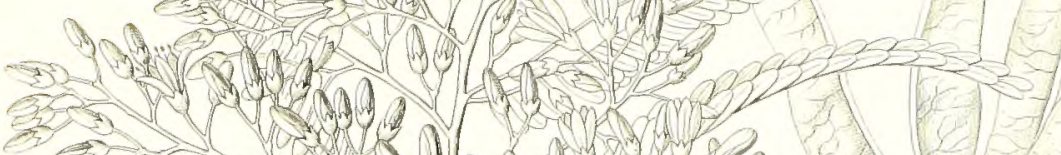
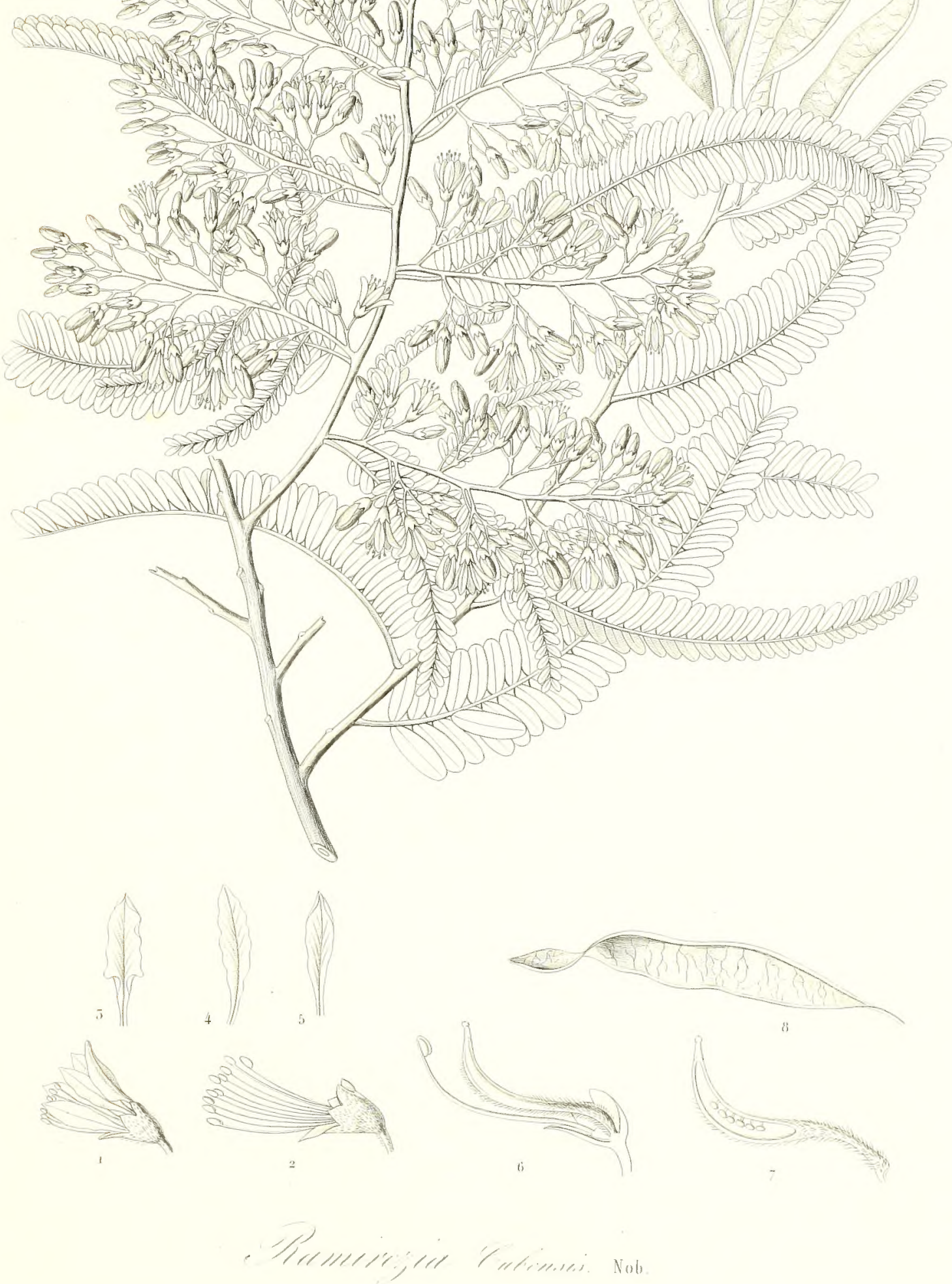


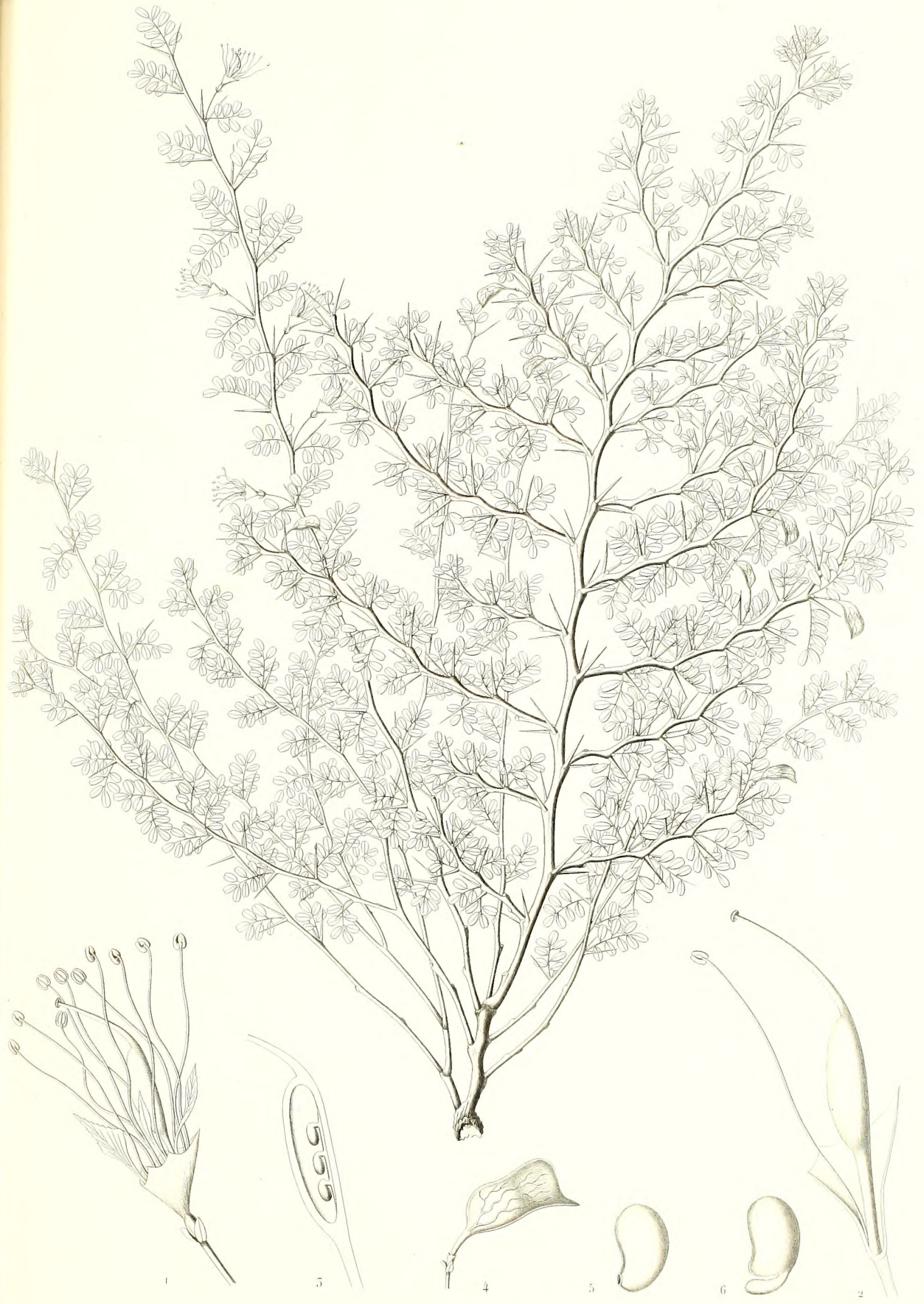

H WNE YASCILARES.

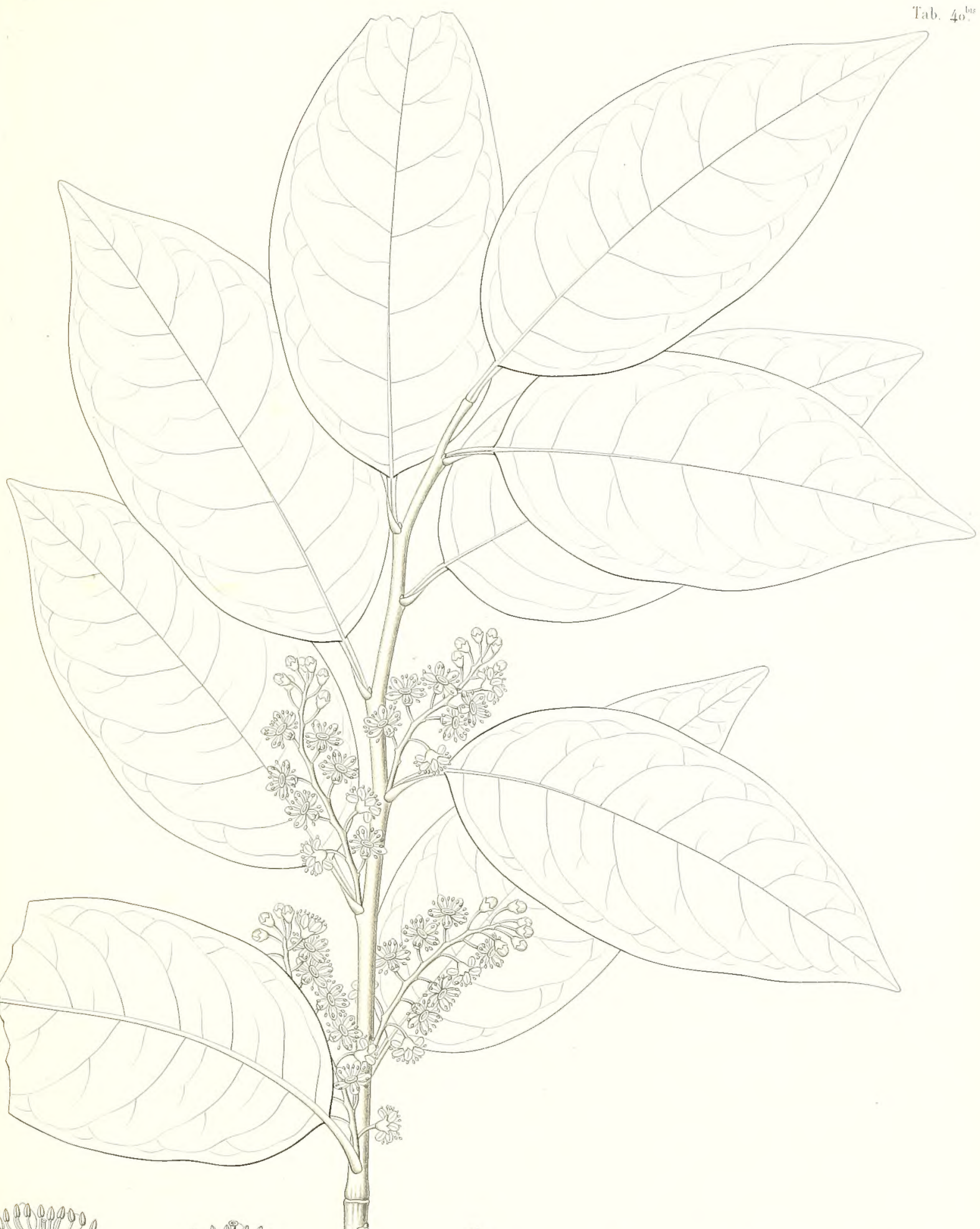

orogogogon smpros $\pi$

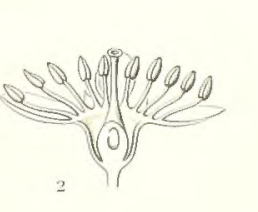

3
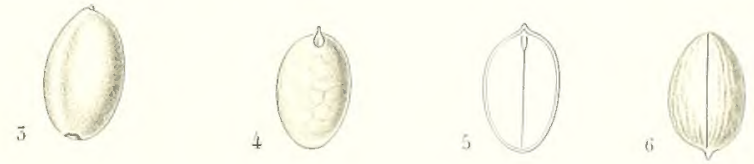

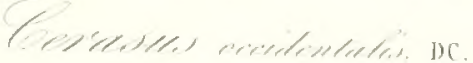





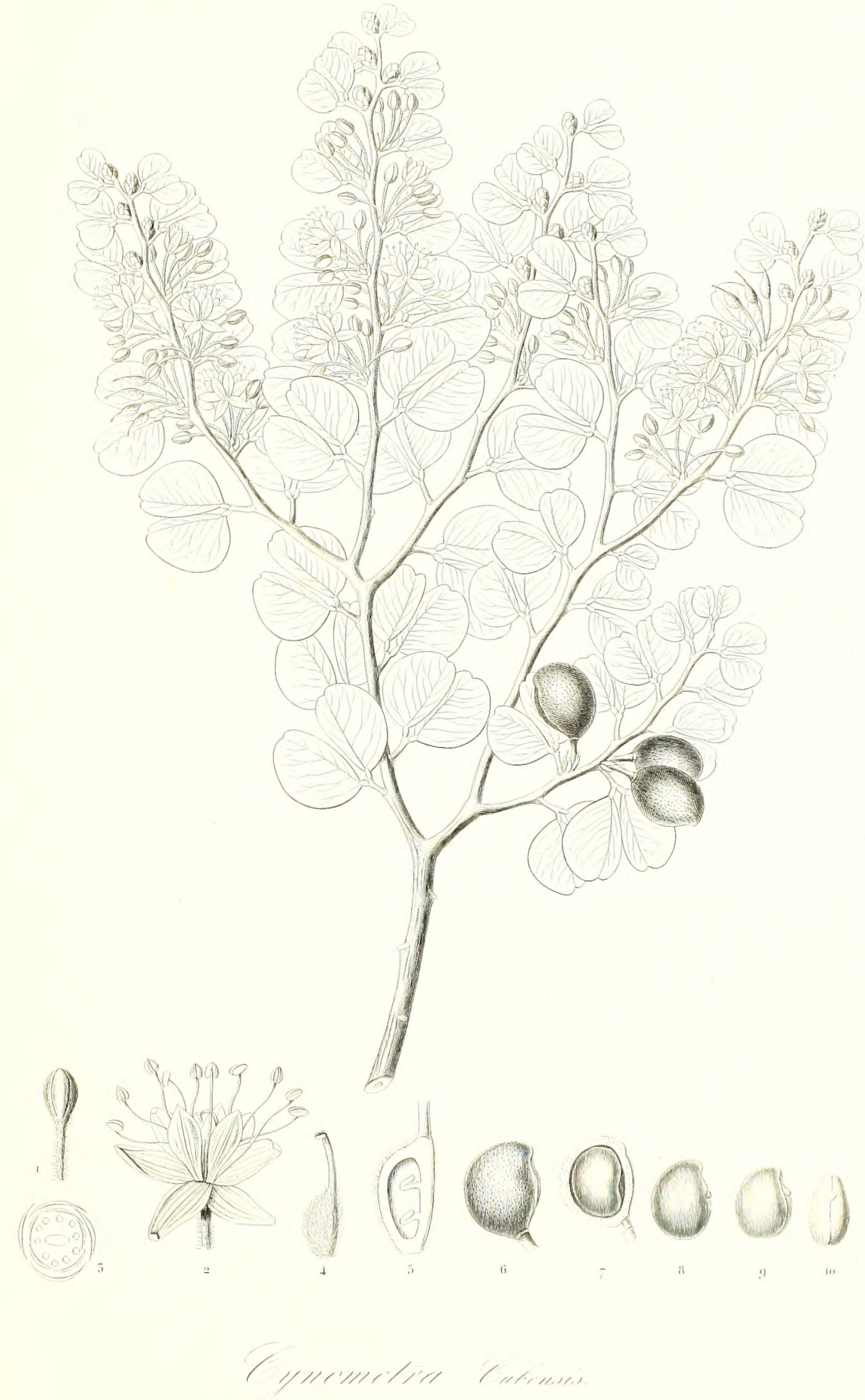



Pill 4-3
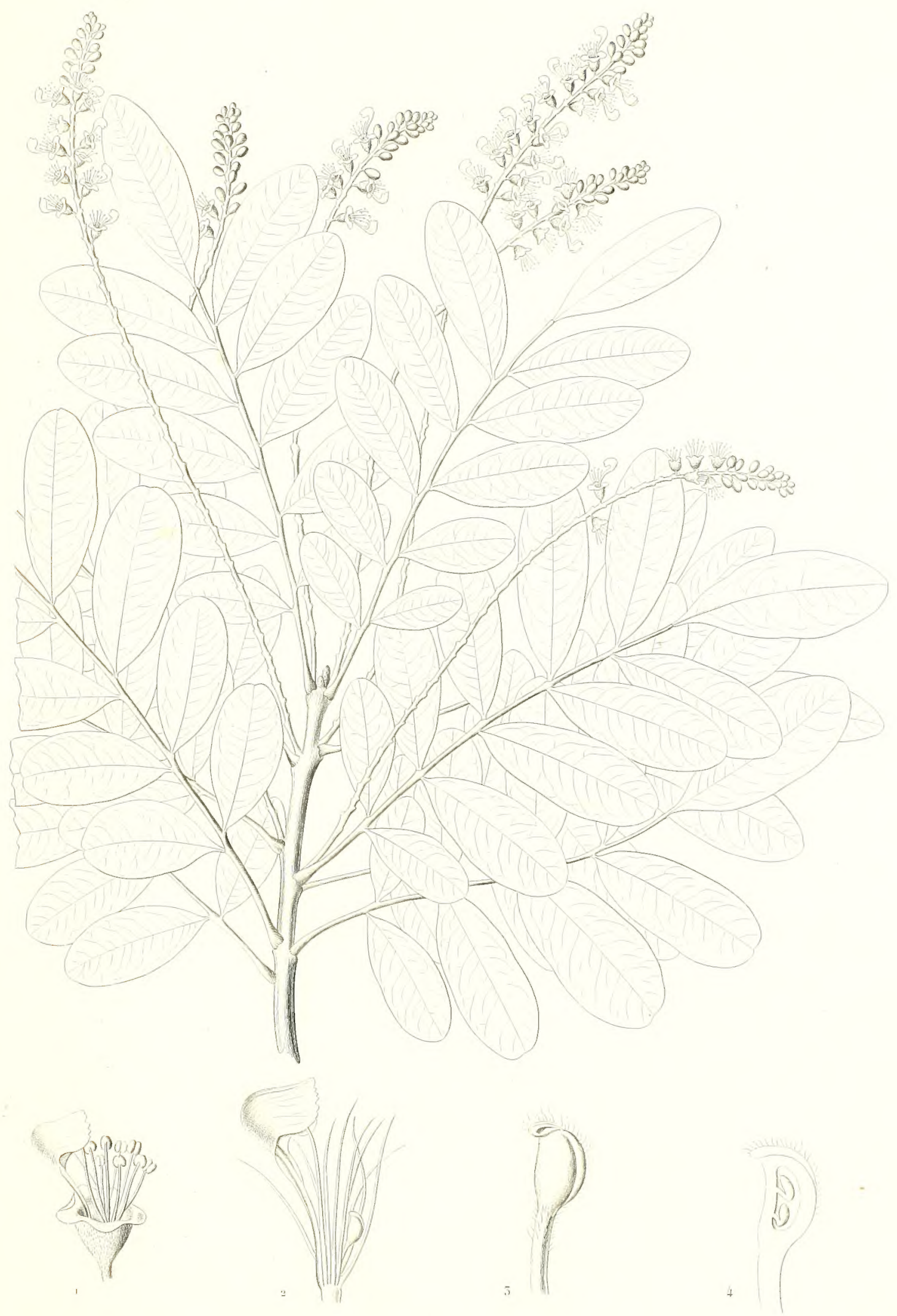

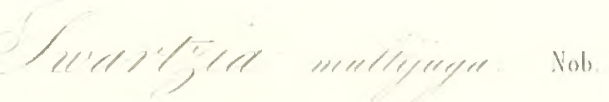





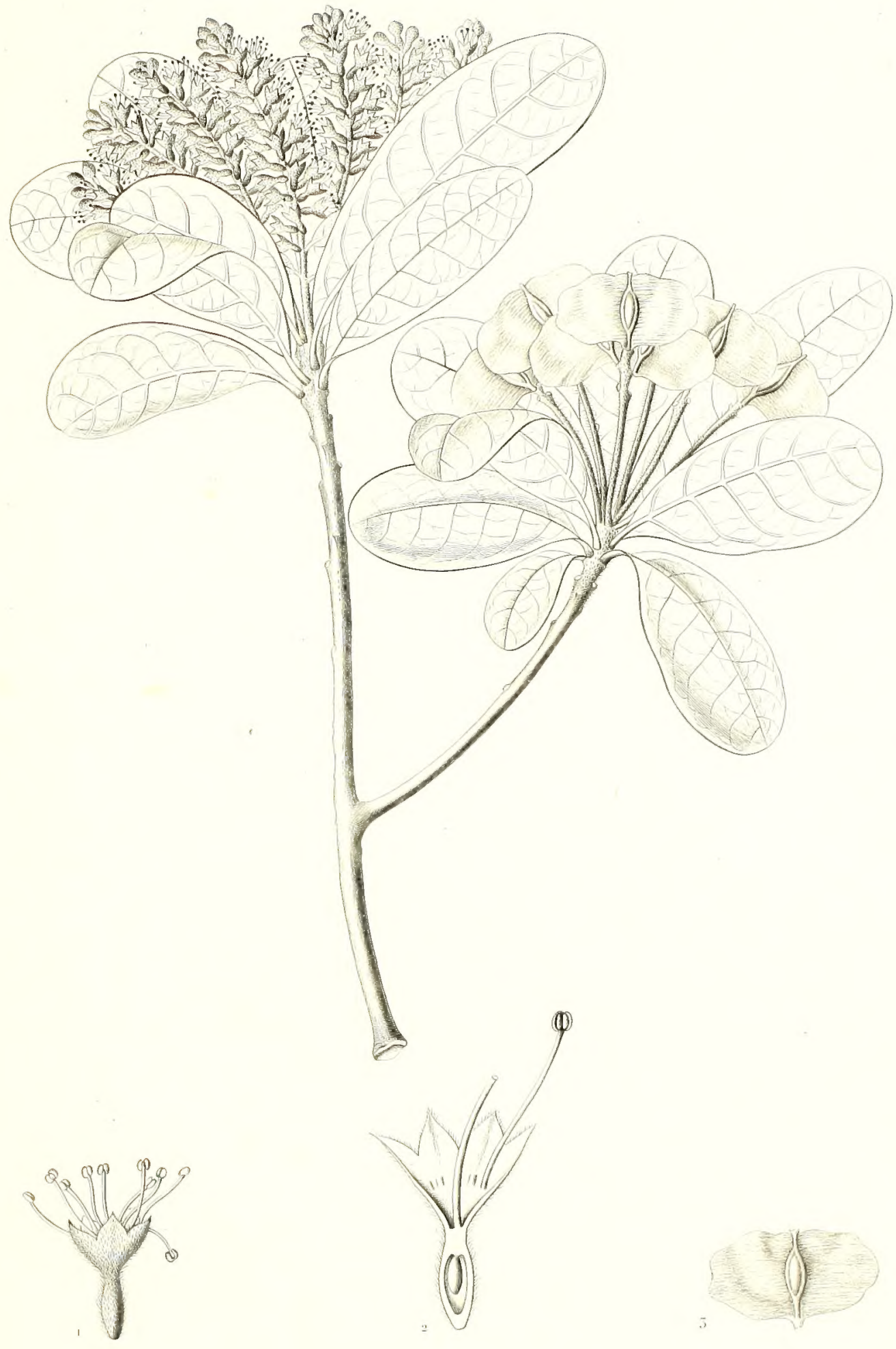



I'al +4

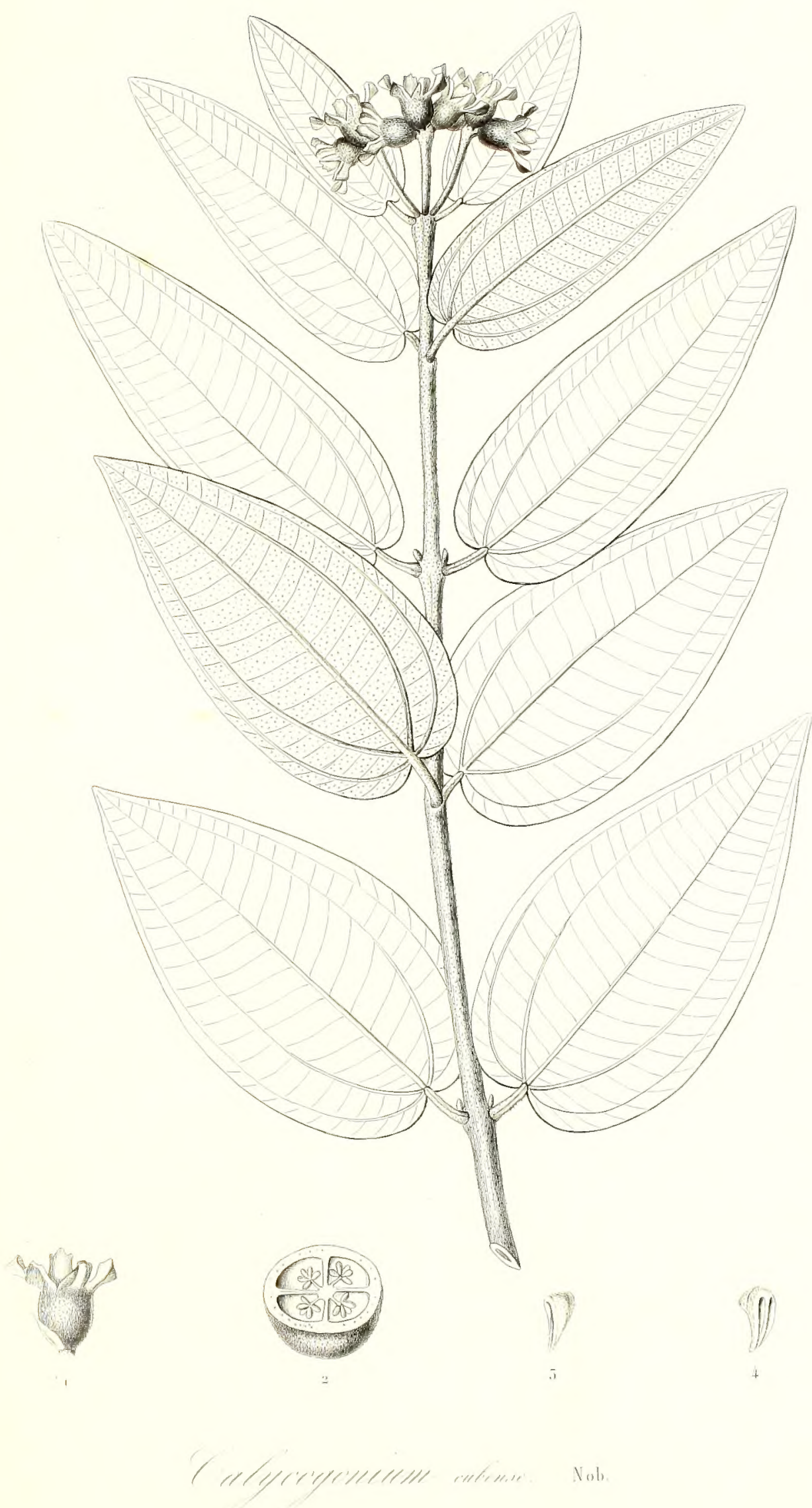





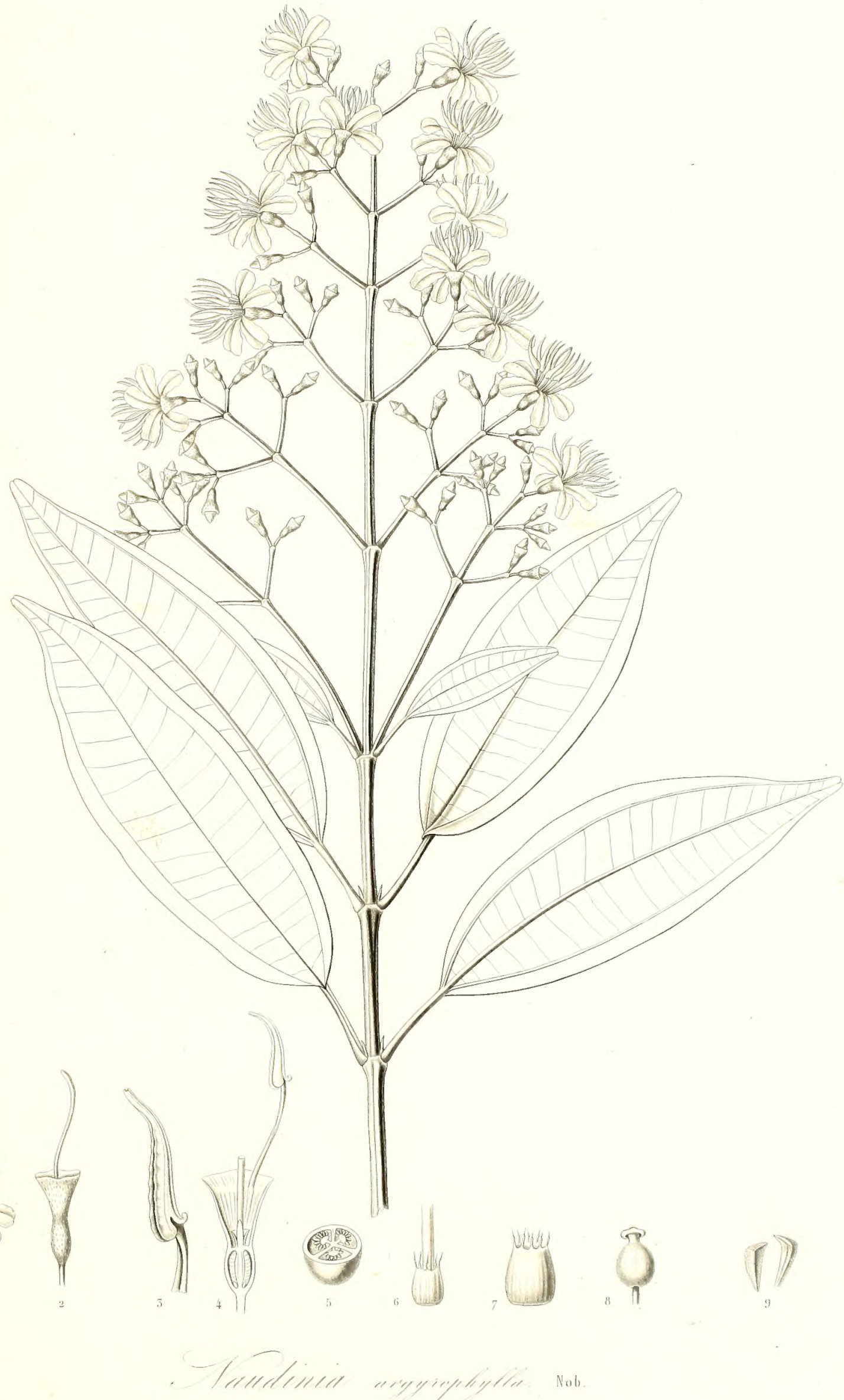





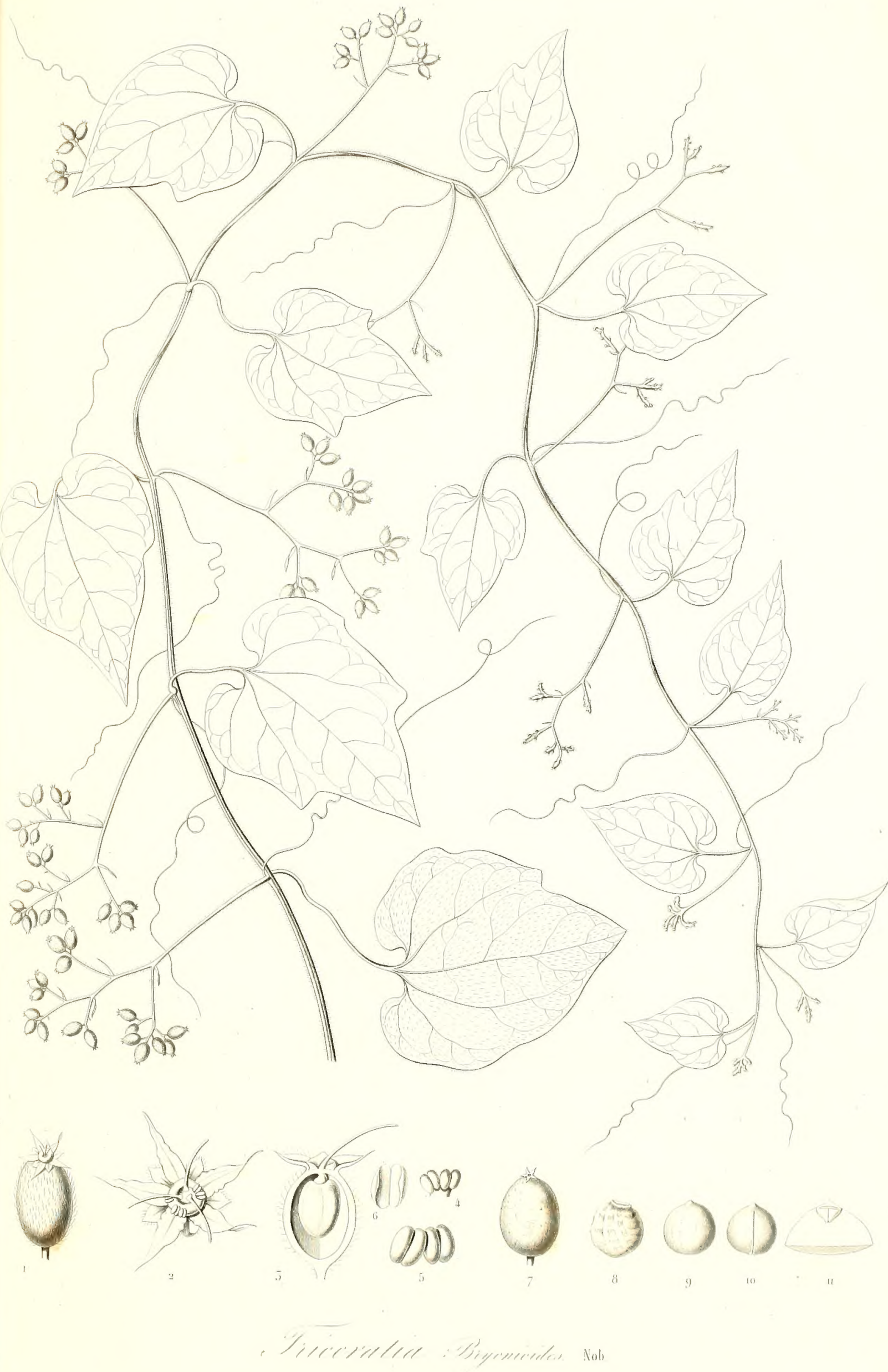




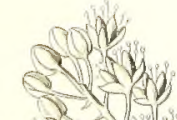

at N

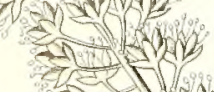

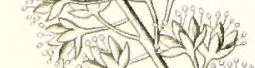
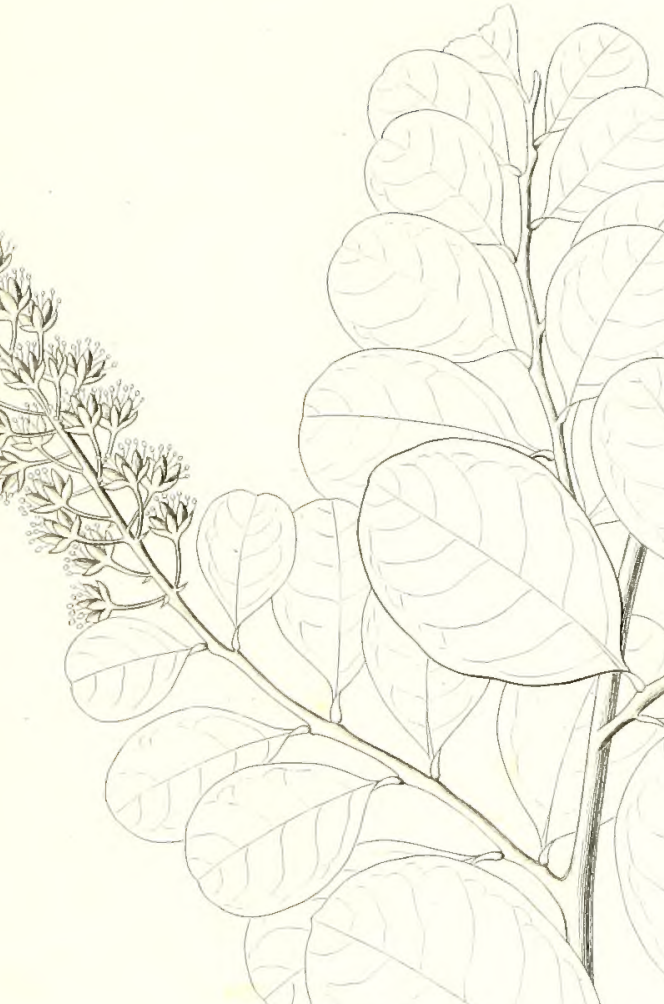


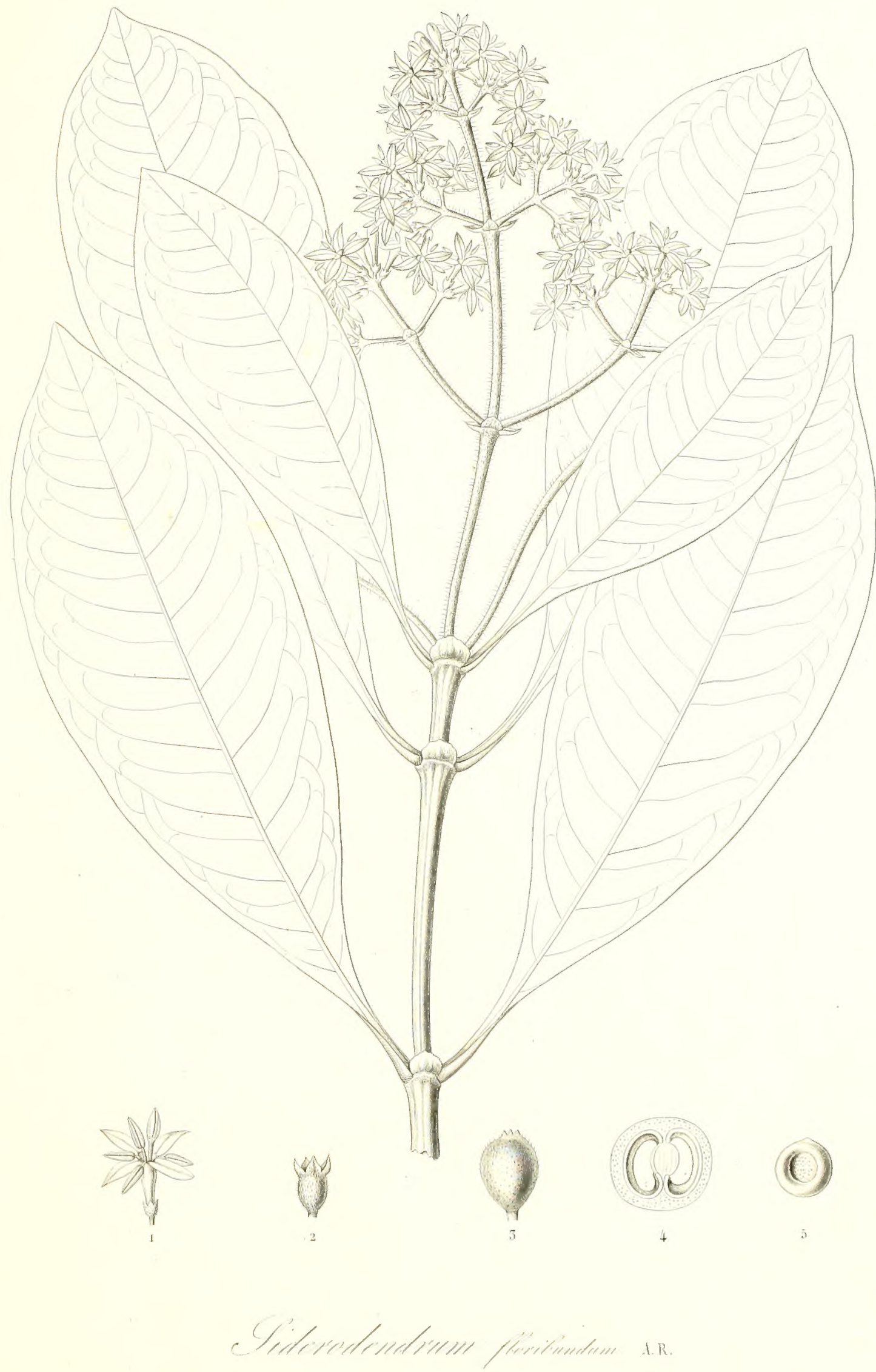




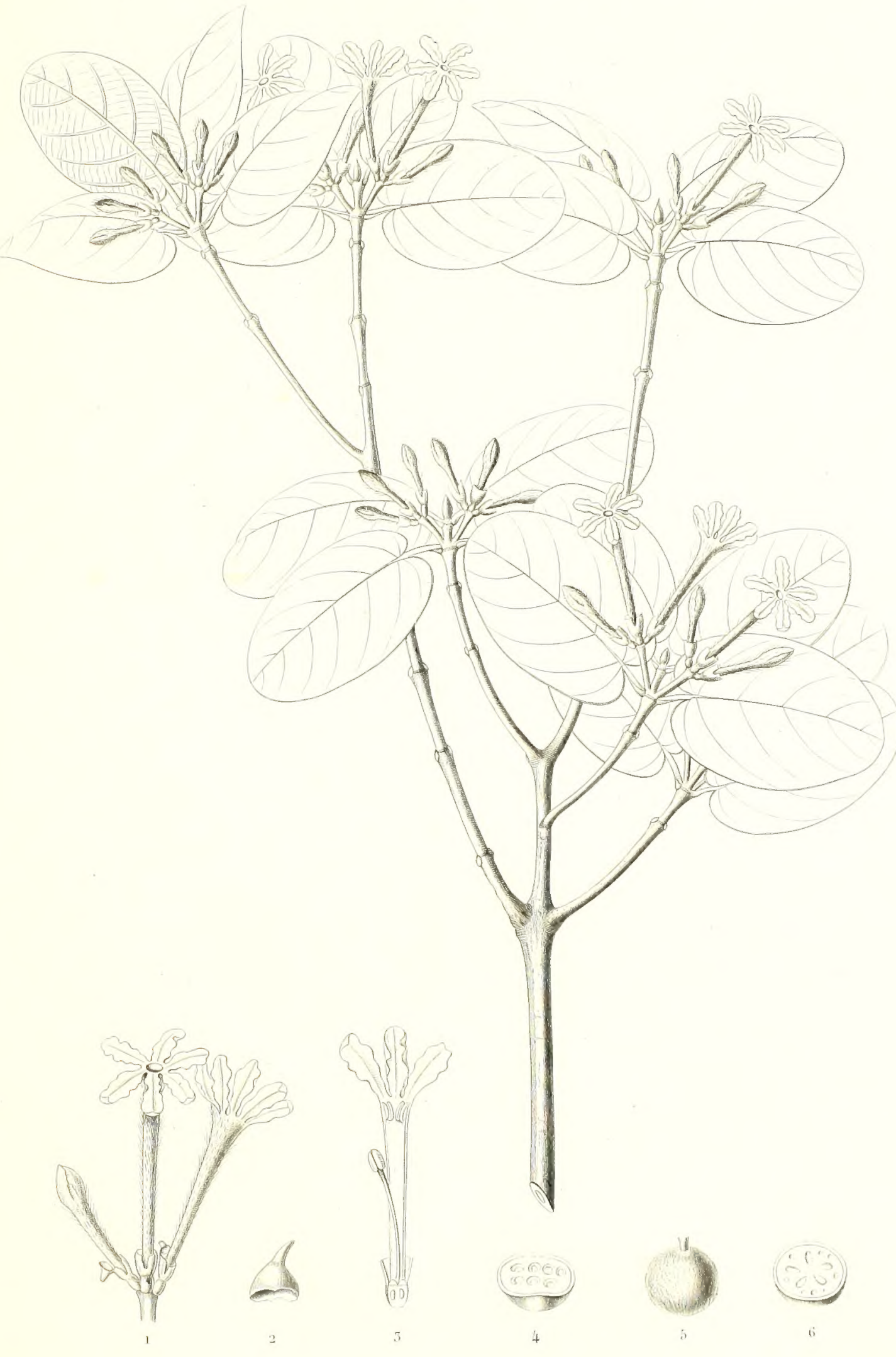

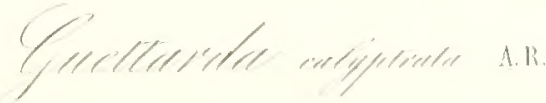





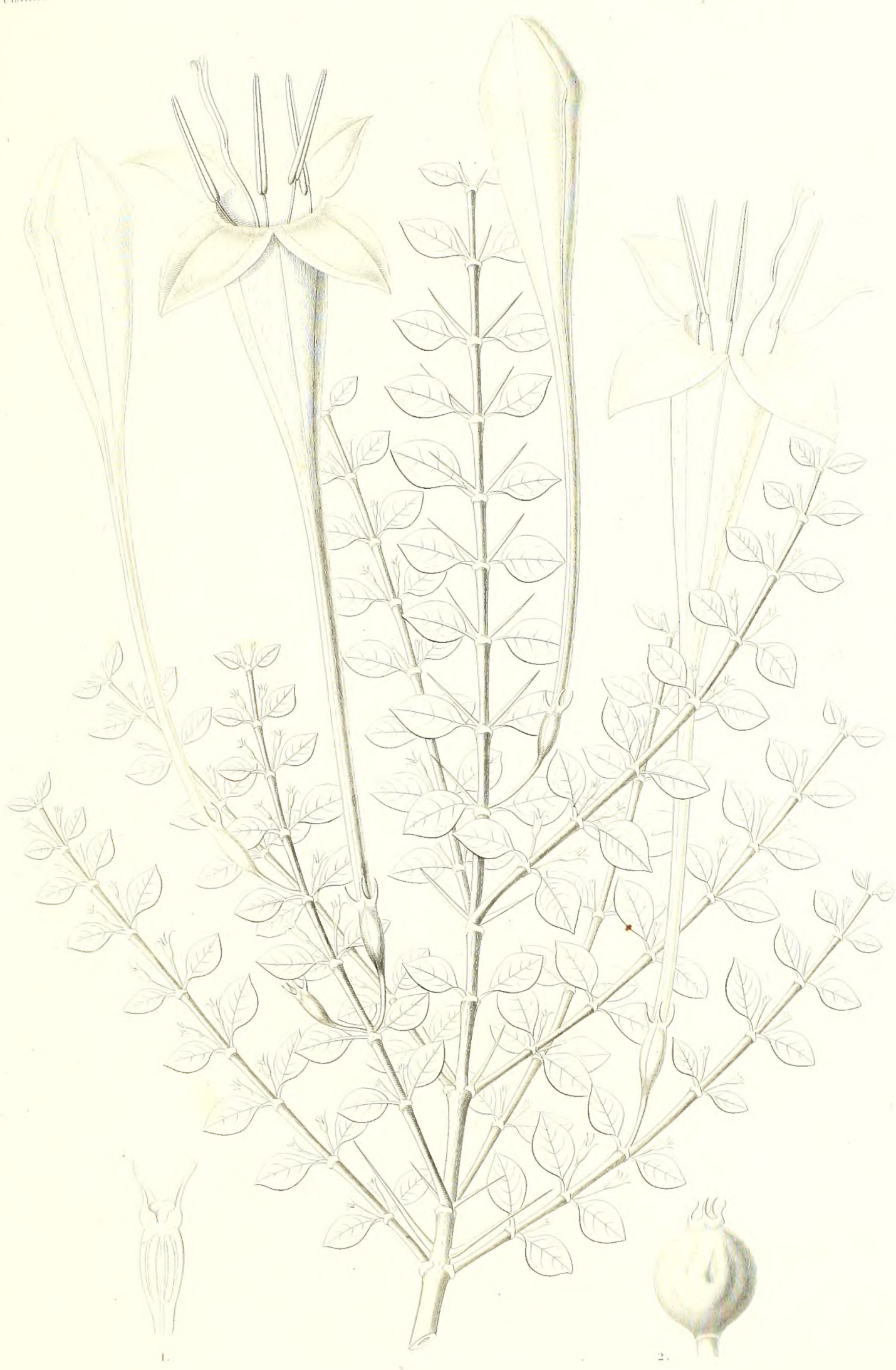




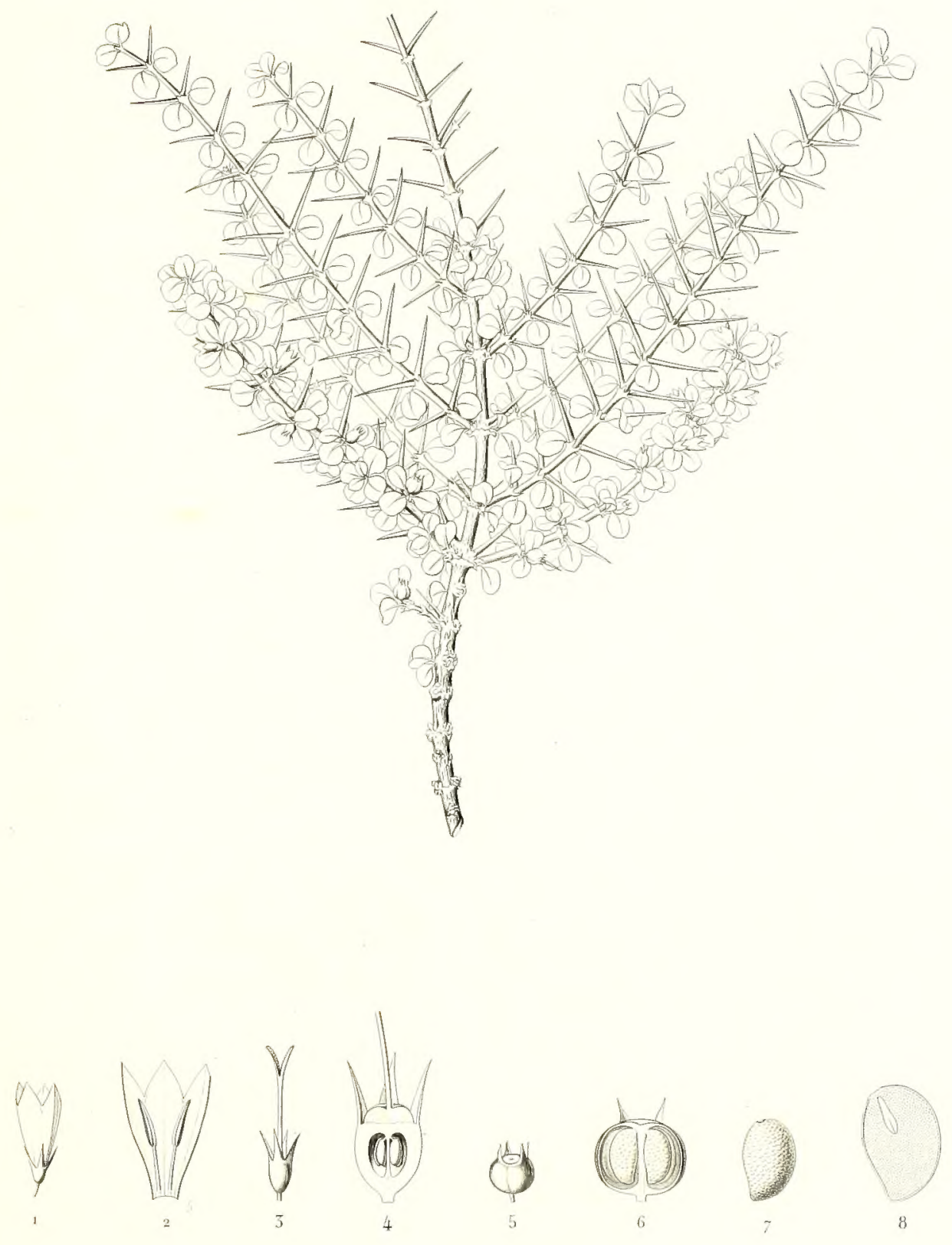

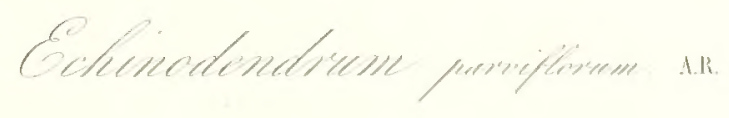




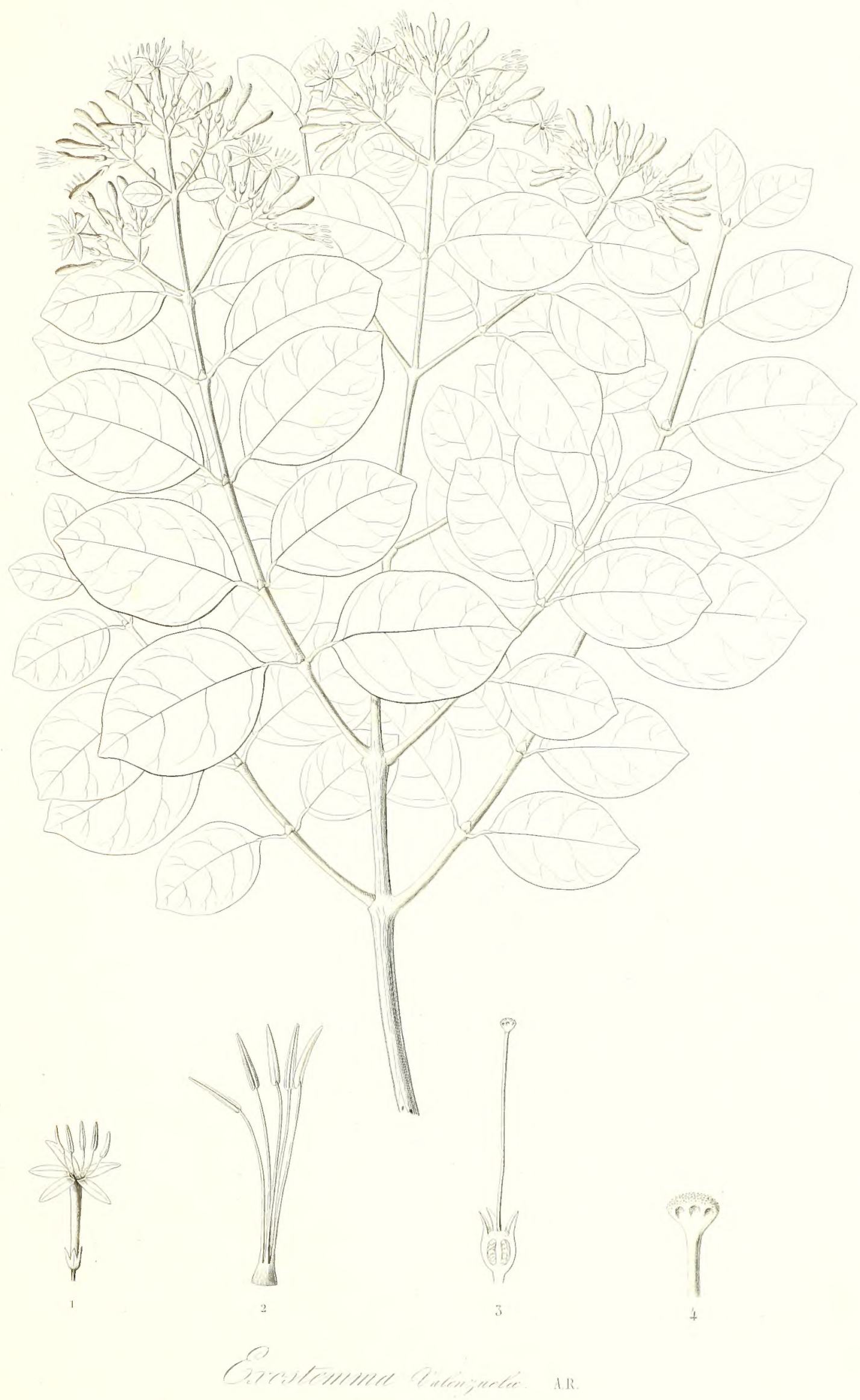





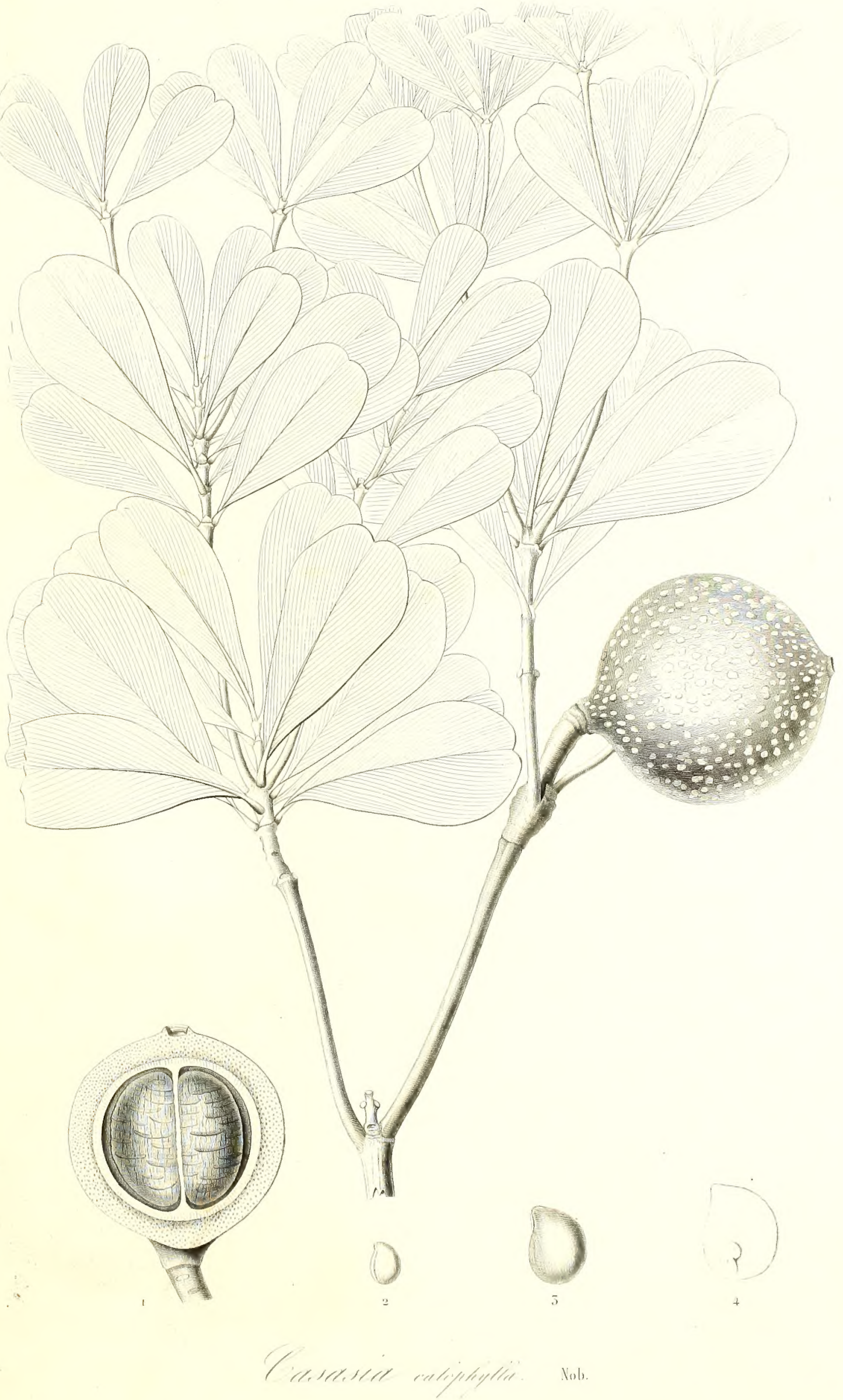


PHANTE VASTULARES,

Tab 49 as

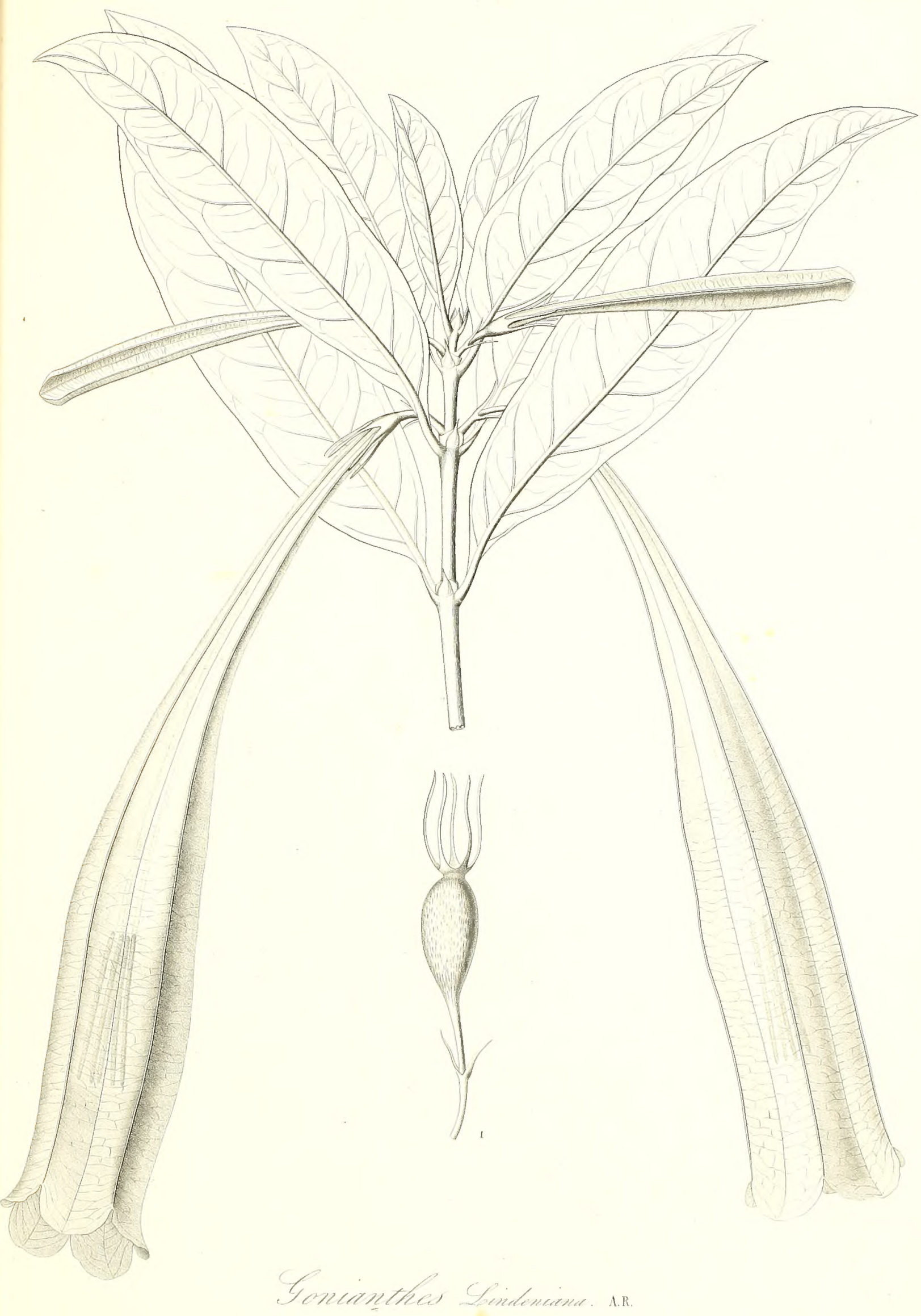

Goveluse del.

Guryand 


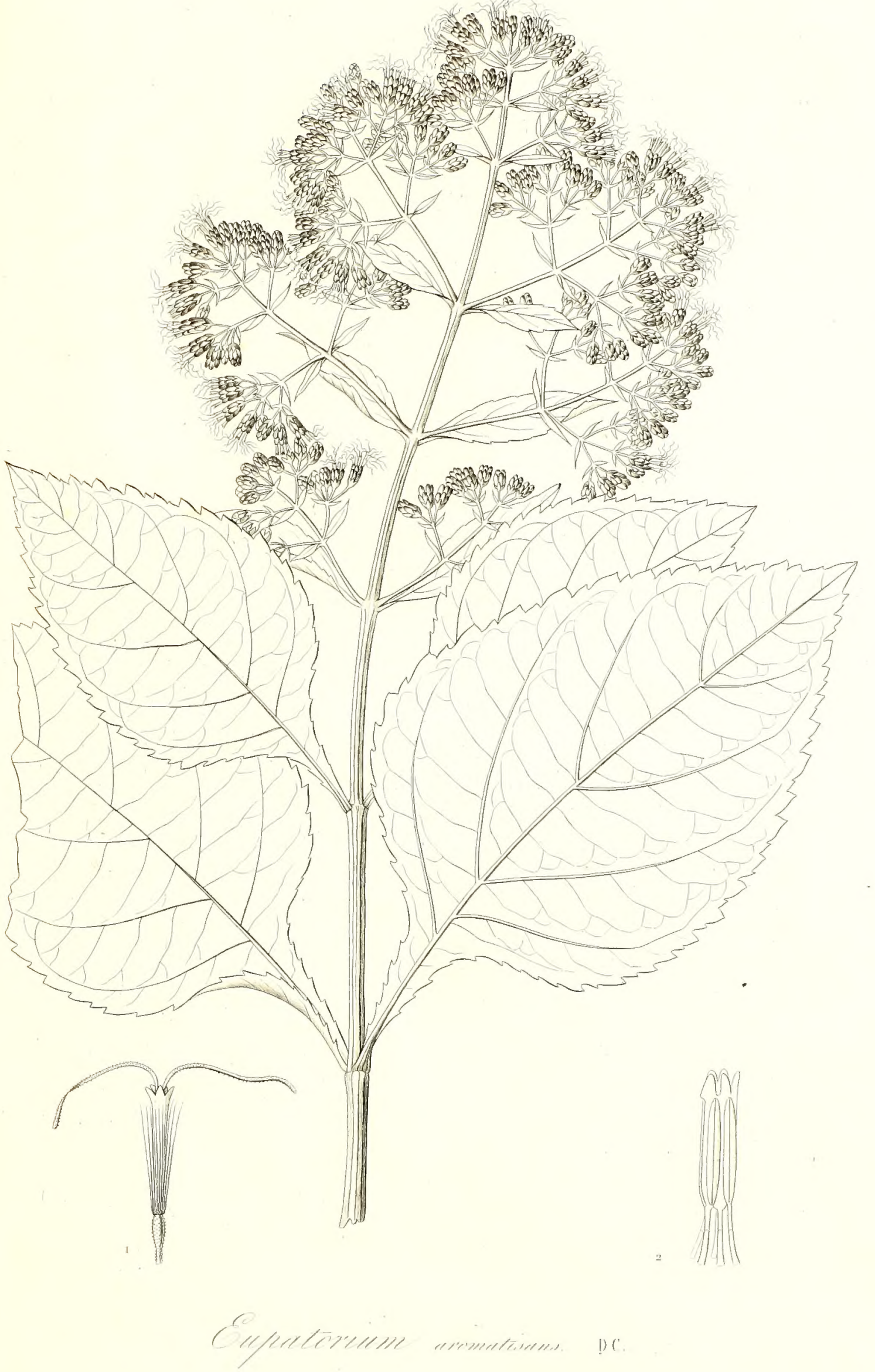




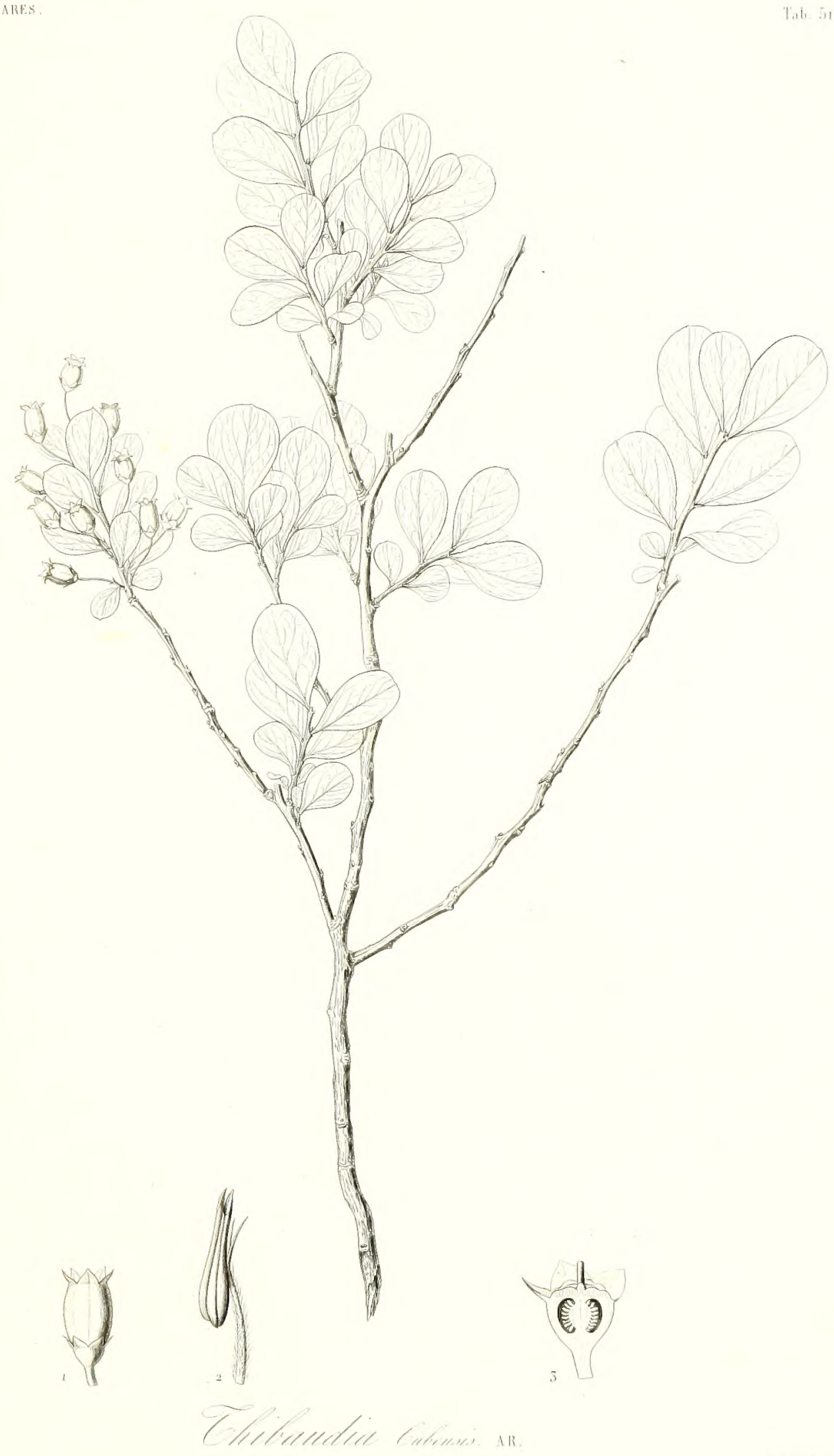





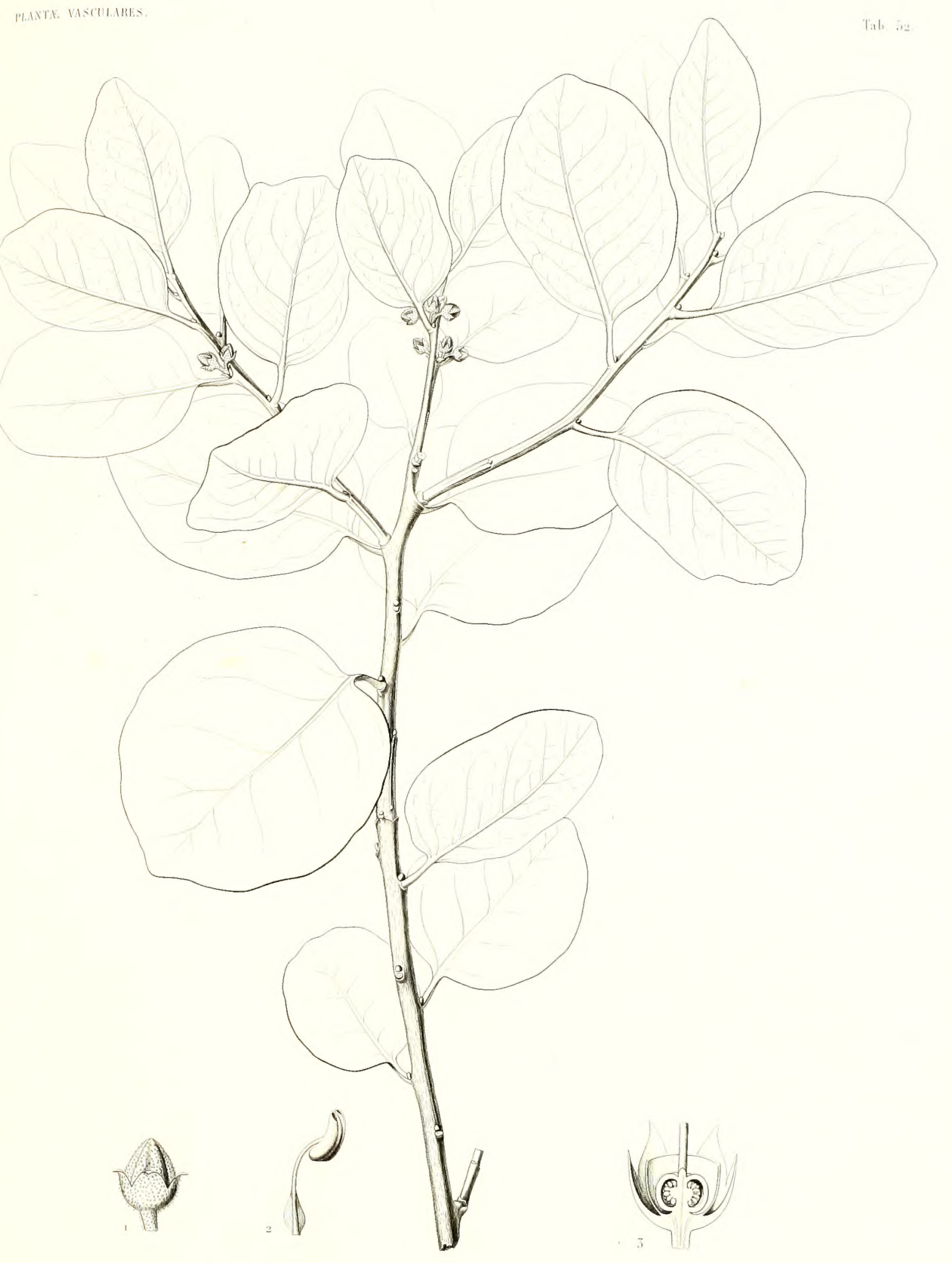



<smiles>CC1CCC(I)C1C</smiles> 



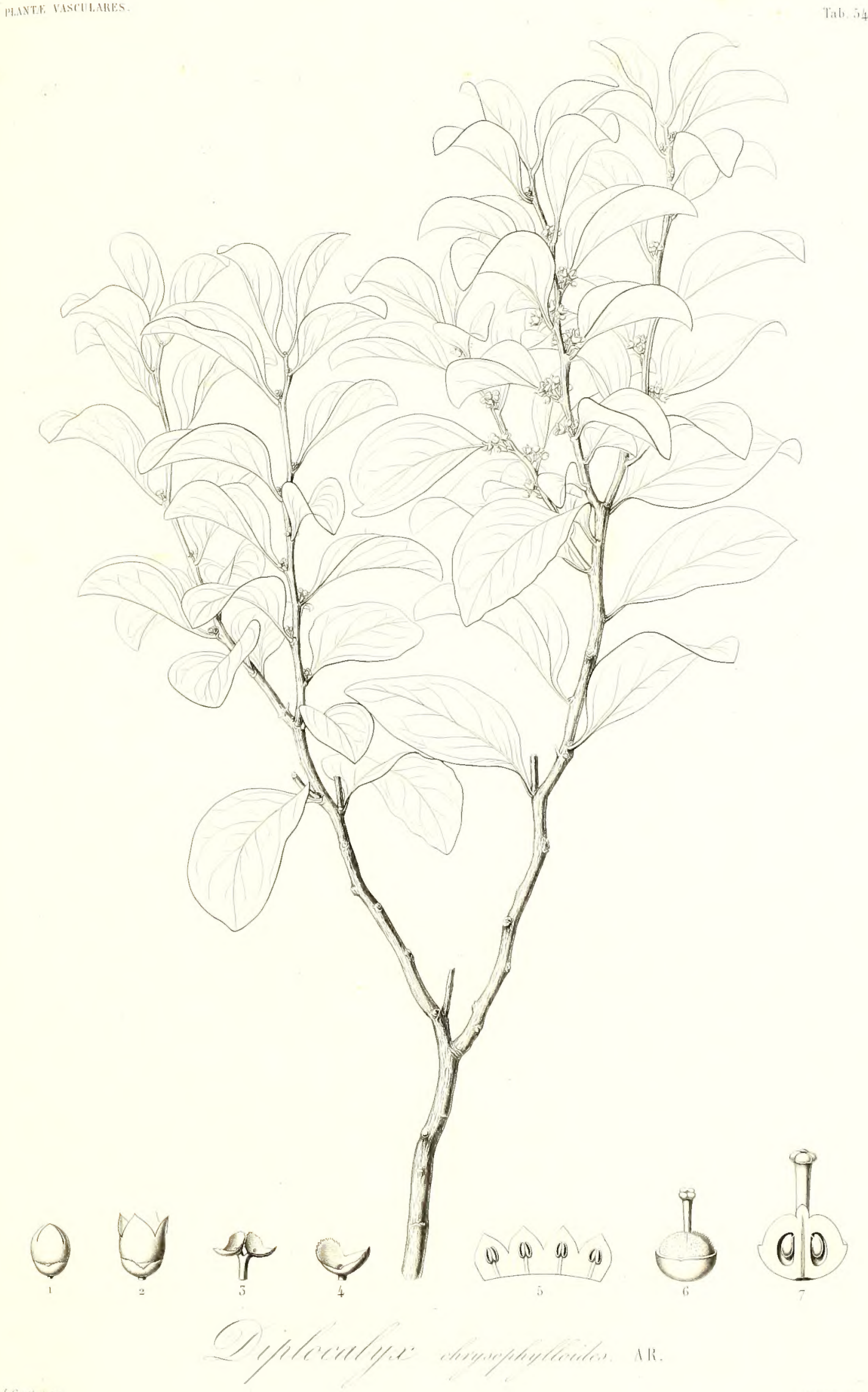





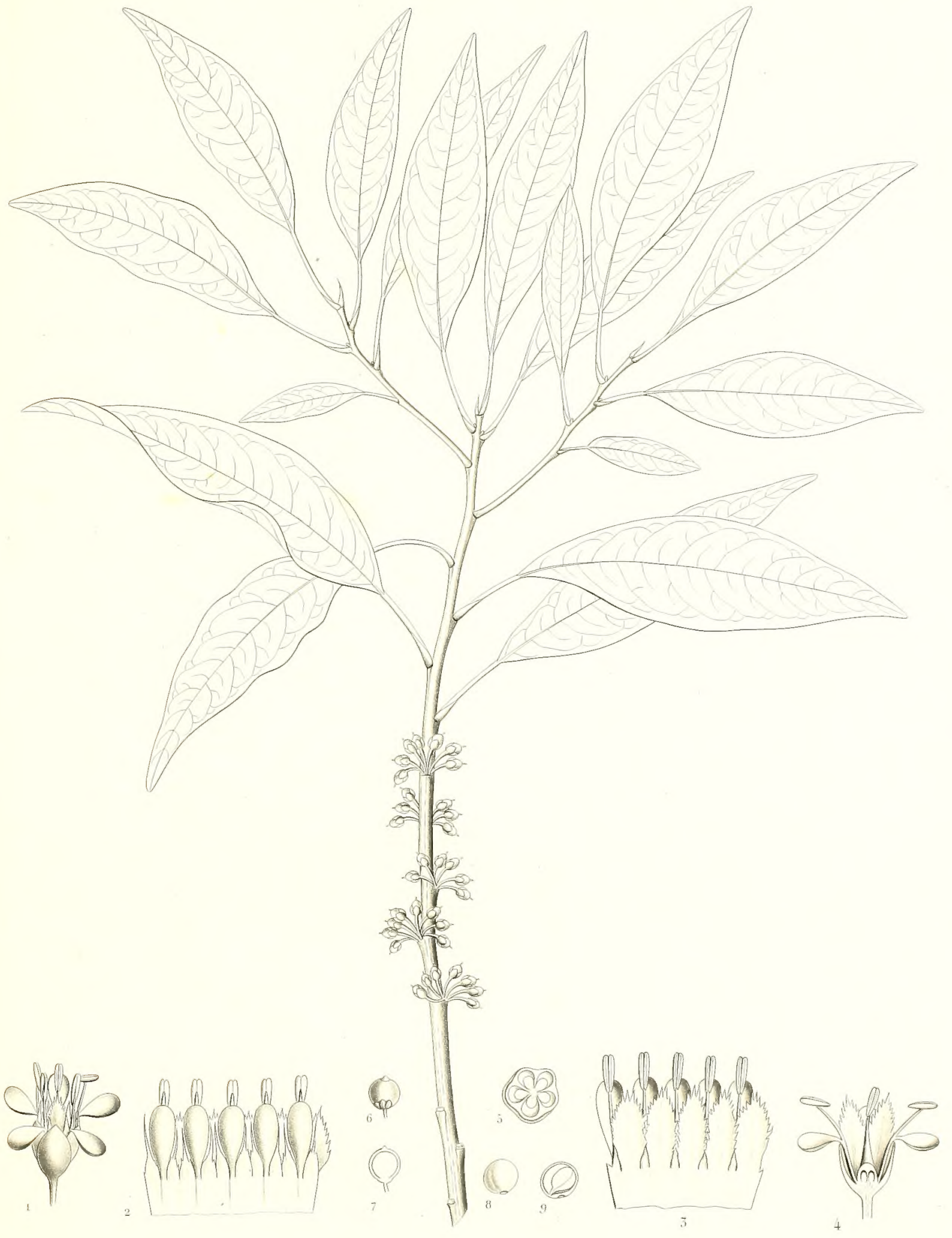

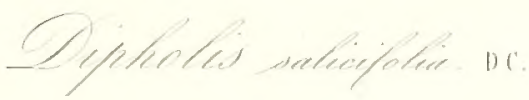





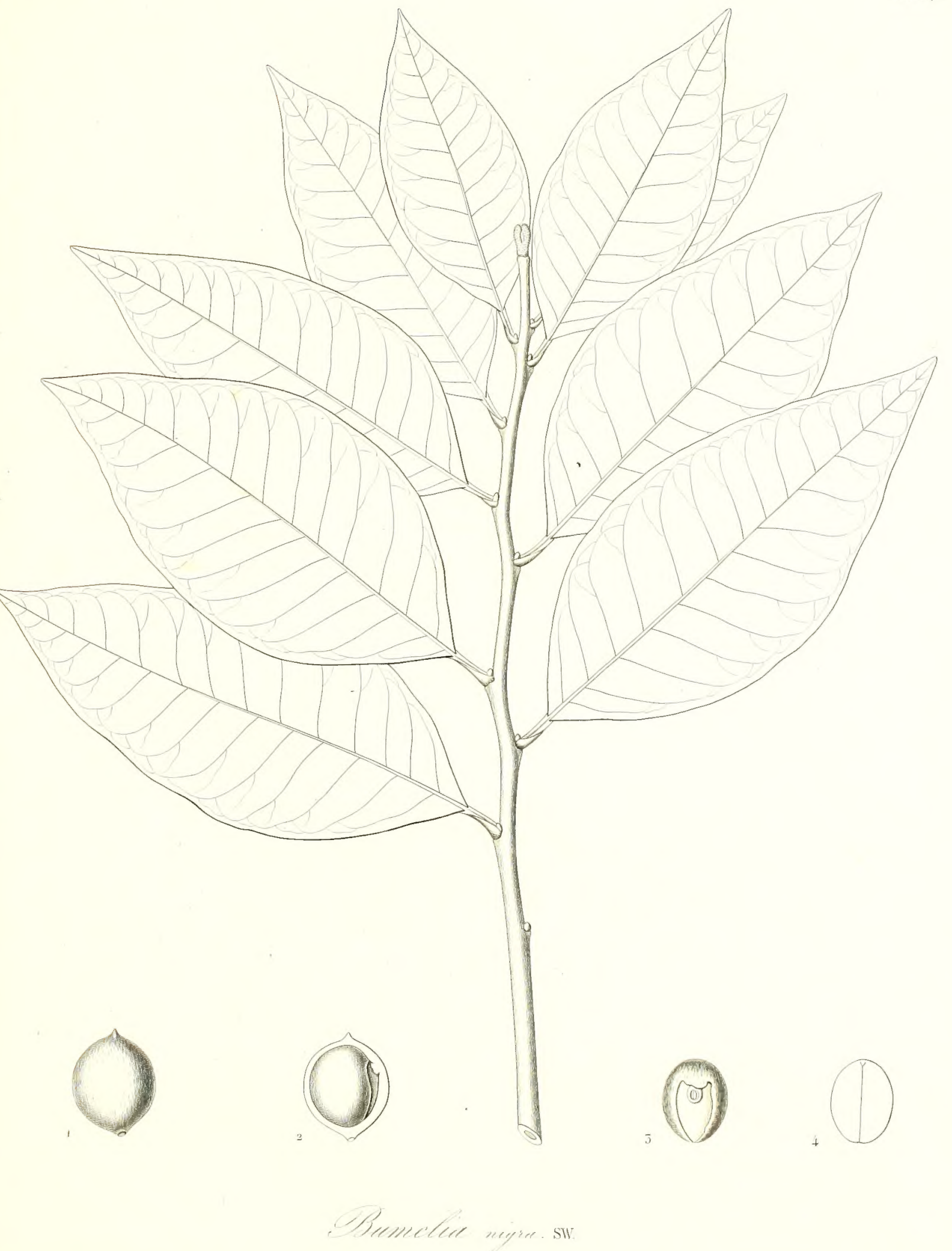







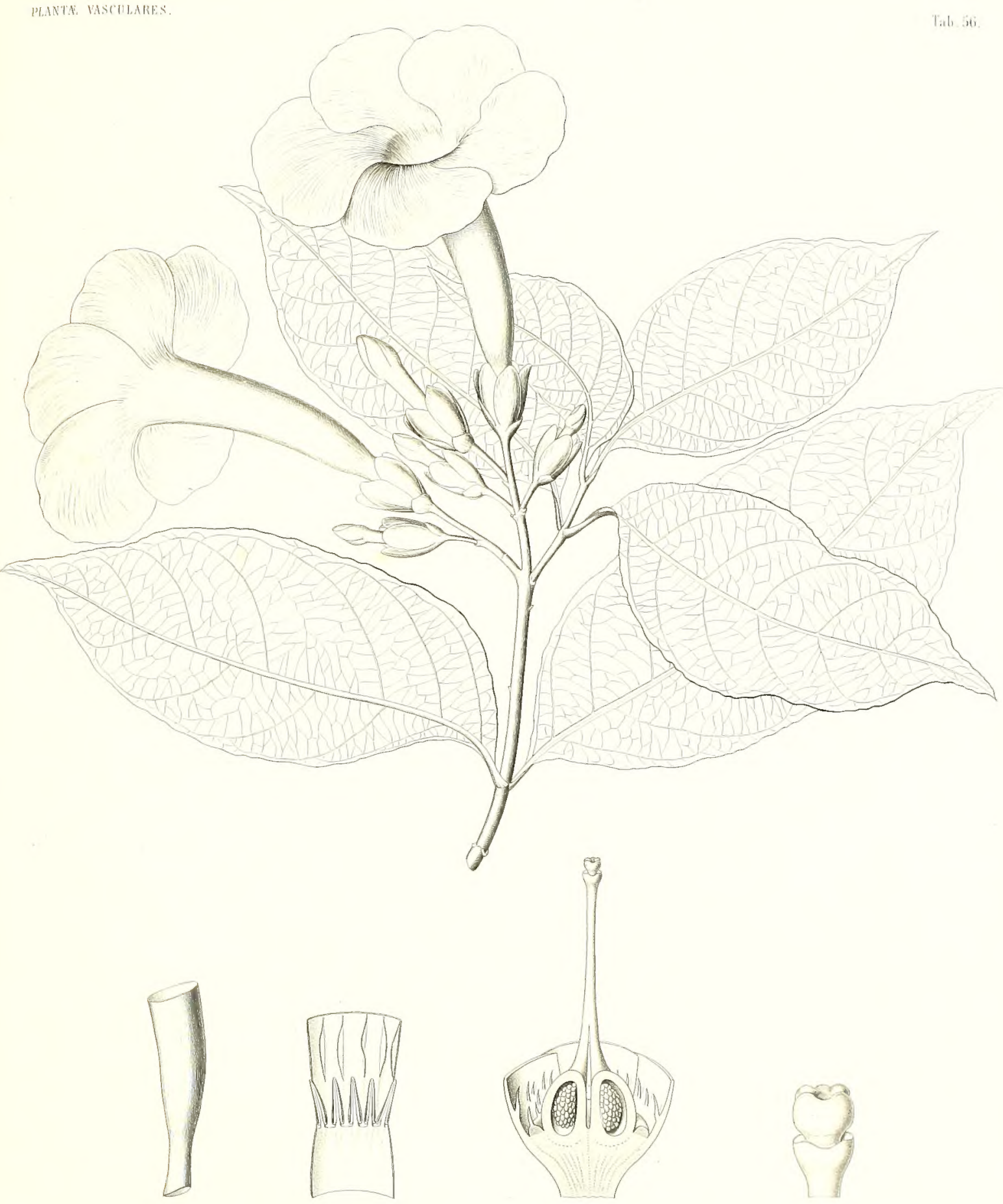

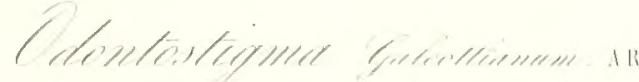




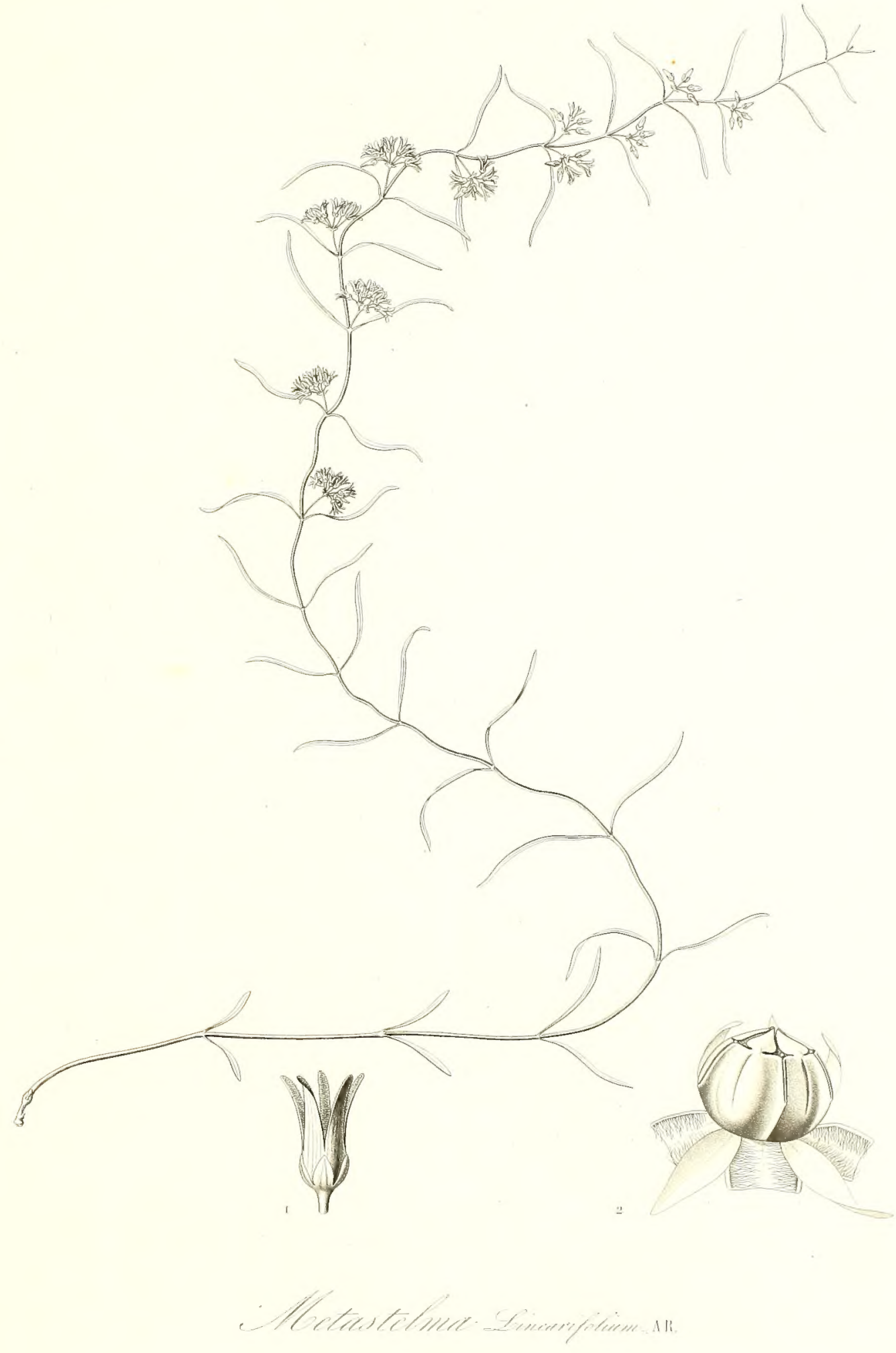





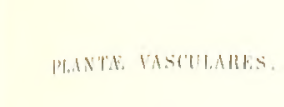

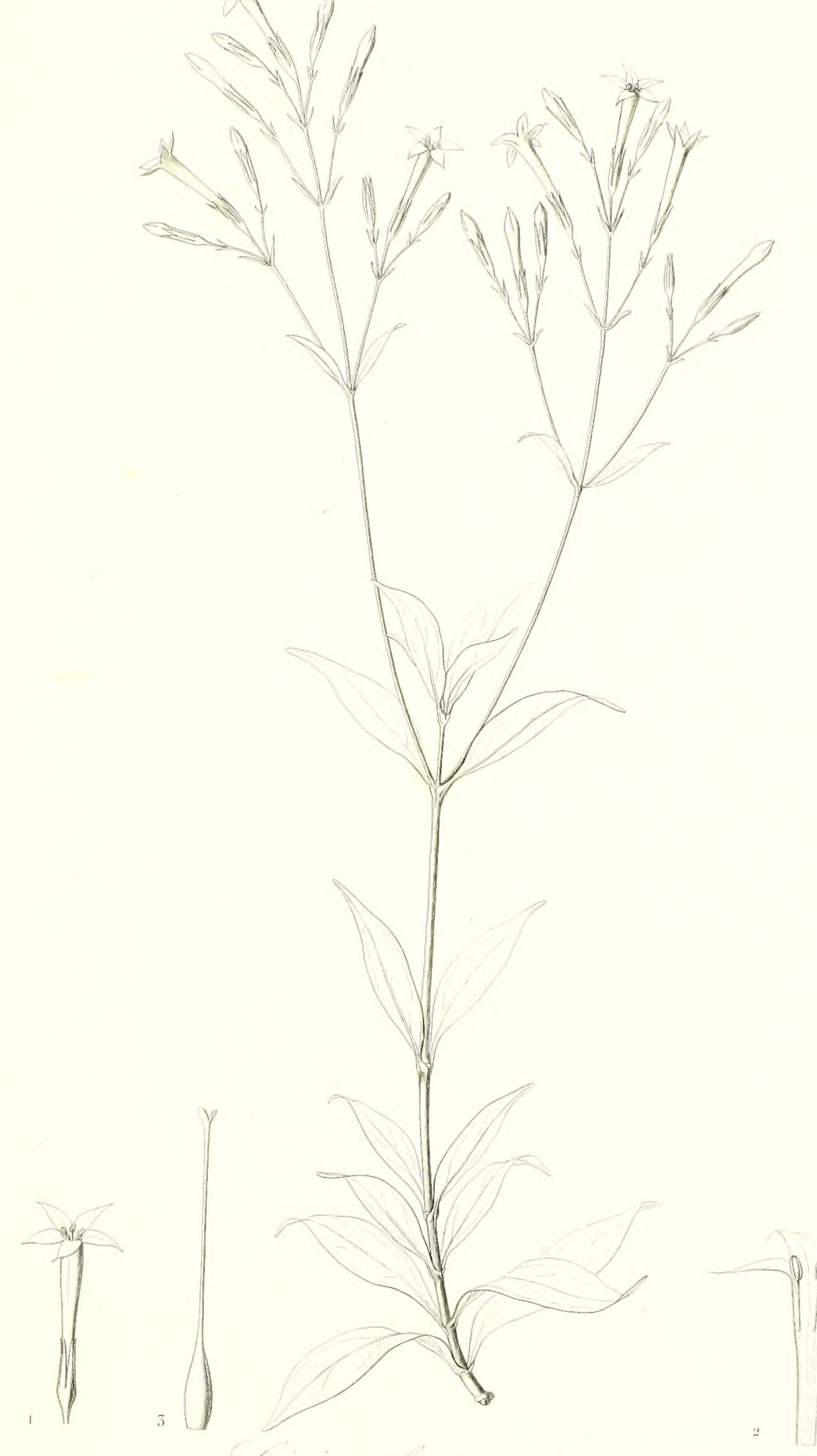




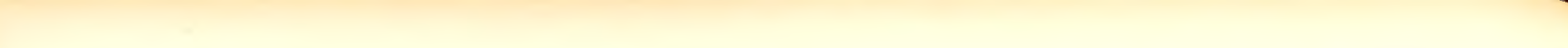




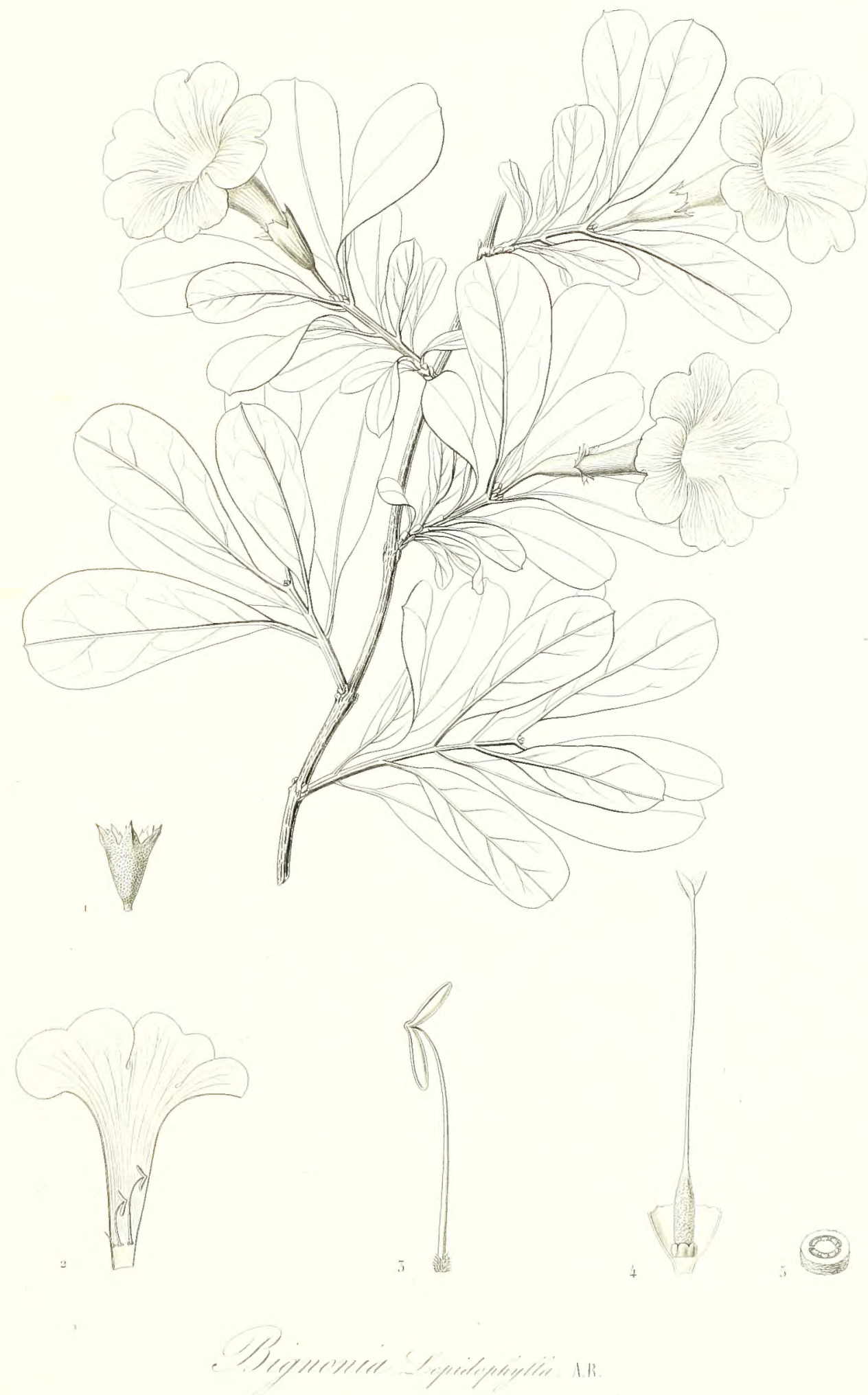


PIANLE MACULARLS

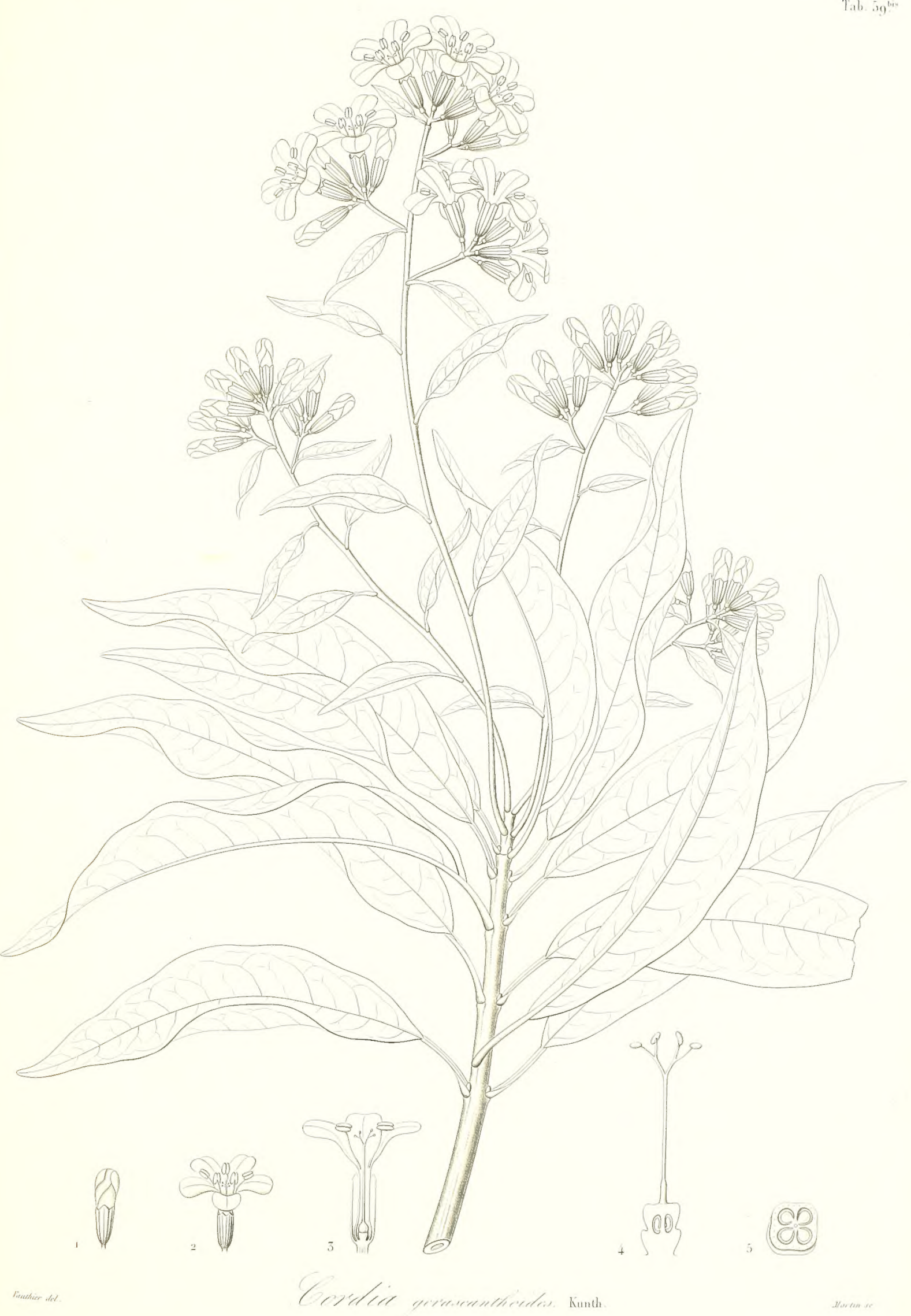




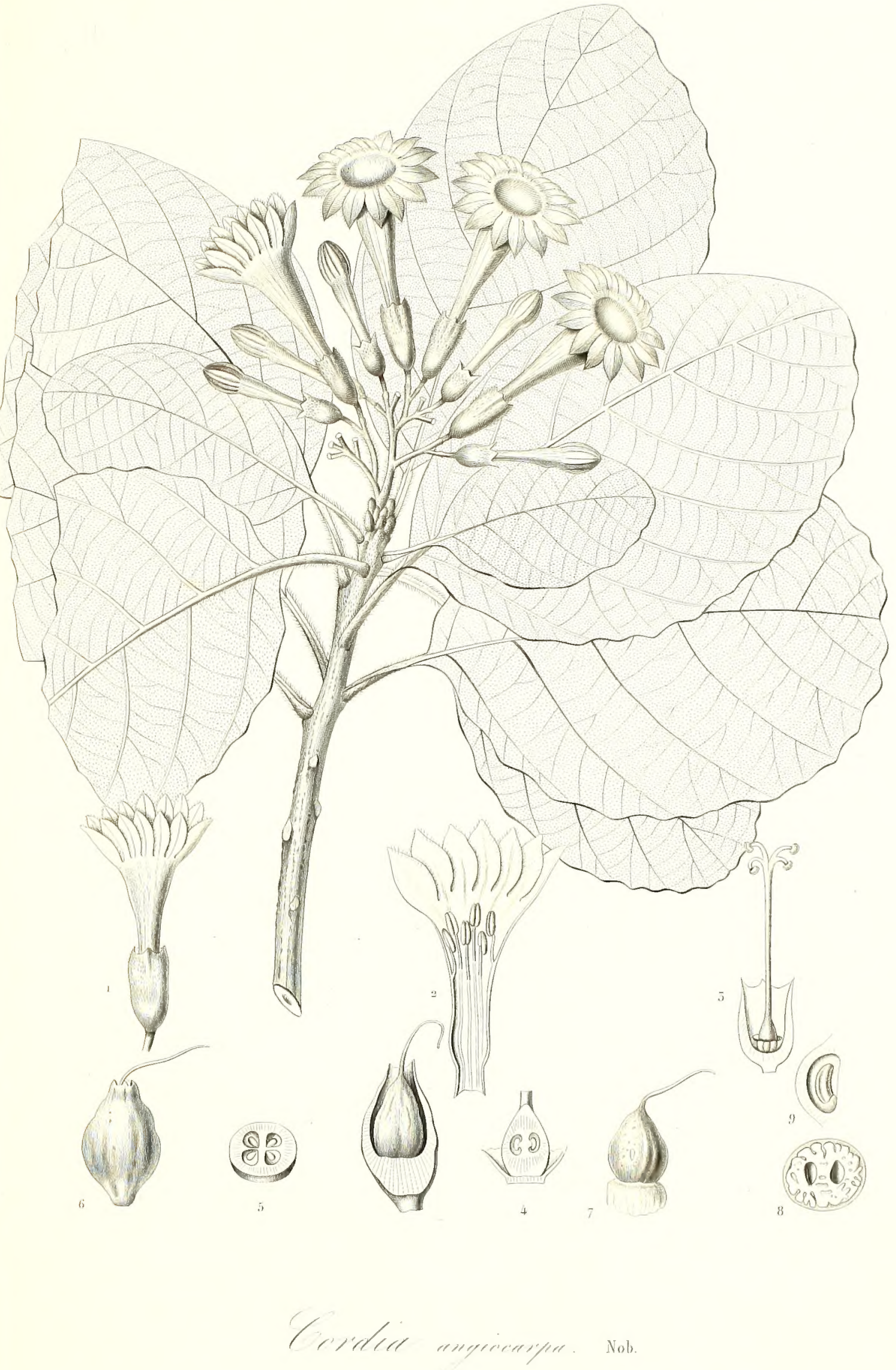





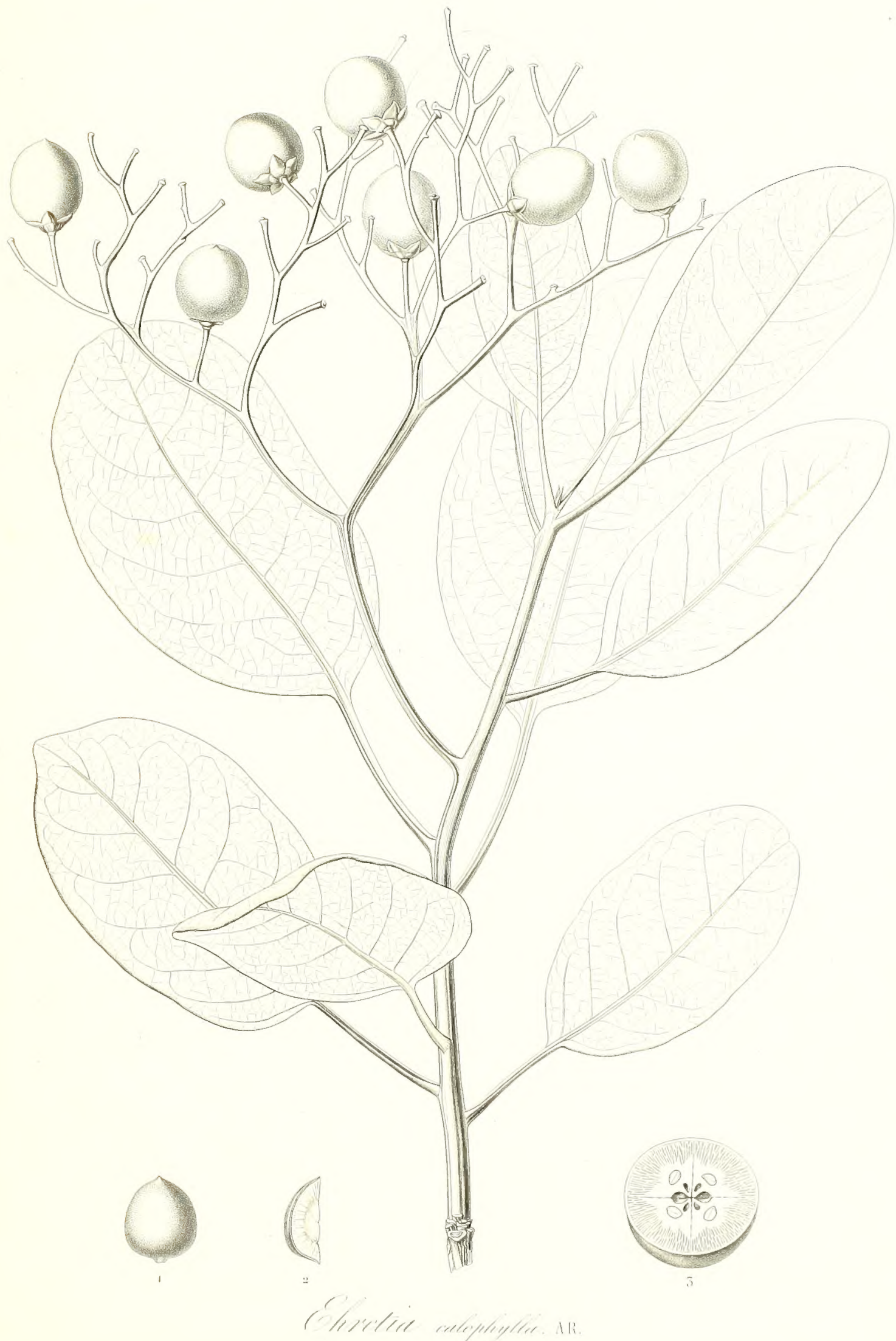






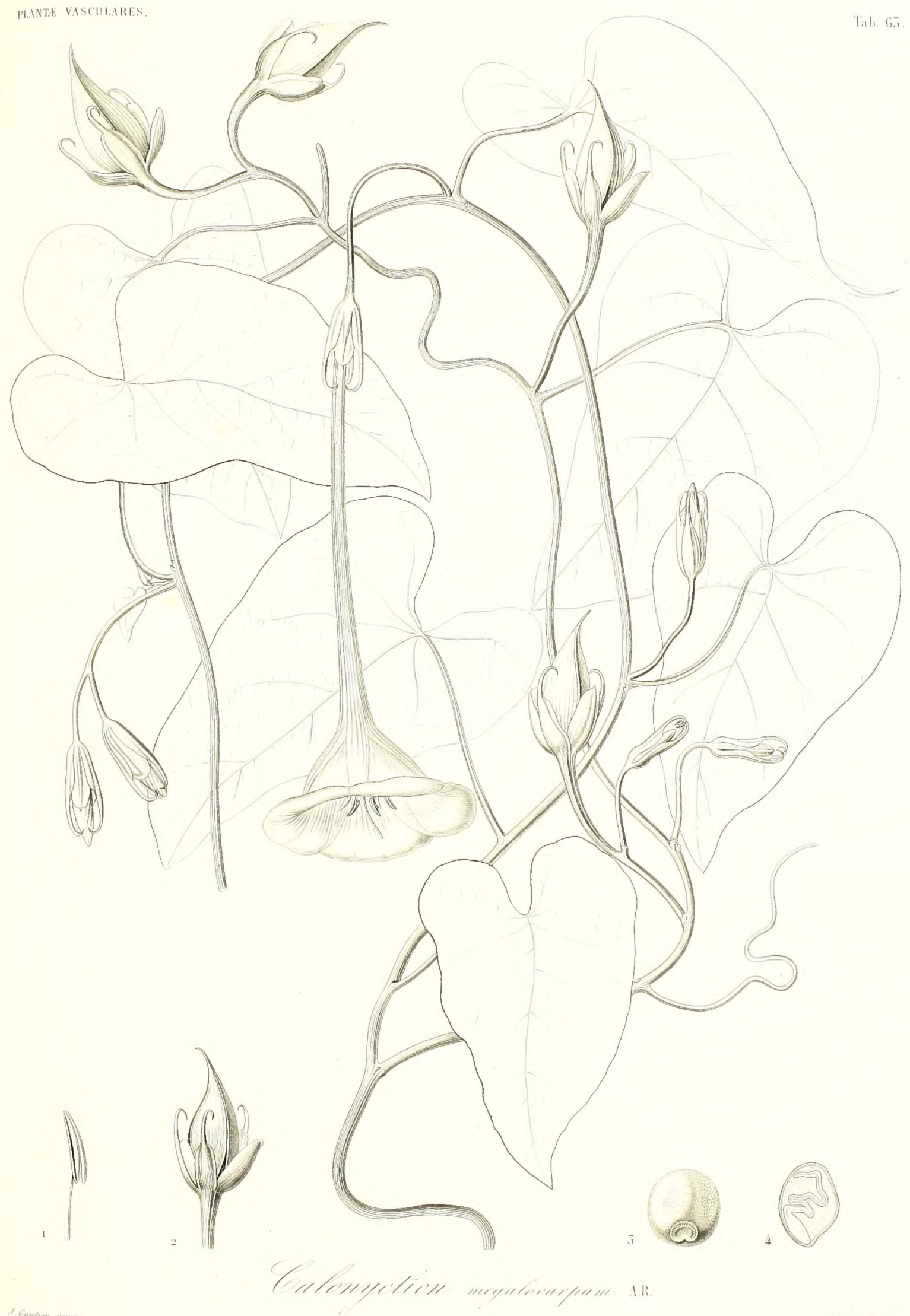


VITEX IJICIFOLIA. Nob. (P1.64.)

V.ramulis ferrugineo-subtomentosis, folits oppositis simpicibus brevissime petiolatis, lato-ovalibus apice subacutis basi obtusis ant subemarginato-cordatis coriaceis, margine sinuoso-Gentatis, dentibus spinosis, tenuissime reticulato-vemosis, praesertim subtus subpubentibus; crmis axillaribus longe pedunculatis, folio longioribus, ramoso-trichotomis pubenti-ferrugineis; calyce campanulato pulverulento, acute 5-dentato; corolla bilabiata, limbo explanato, obliquo; labio superiore erecto, emarginato; lobo medio lail inferiores productiore, enarEinato; arupa depressa obsolete et obtuse 4-Ioba, ferrugineo-tomentosa, calyce cupulaeformi nec aucto cincta, monopyrena, pyrena ossea 4-10culari, loculis monospermis.

orescit, in loois sylvaticis circa canasi, in insula cuba.

Observaciones. La belfa especie que venimos de describir con el nombre de V.ilicifolia, forma con la siguiente una tribu particular en este género á causa de sus hojas simples y coriaceas.

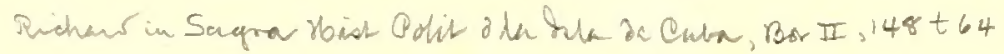

V. aviunniarias aioh le.p.14q. 


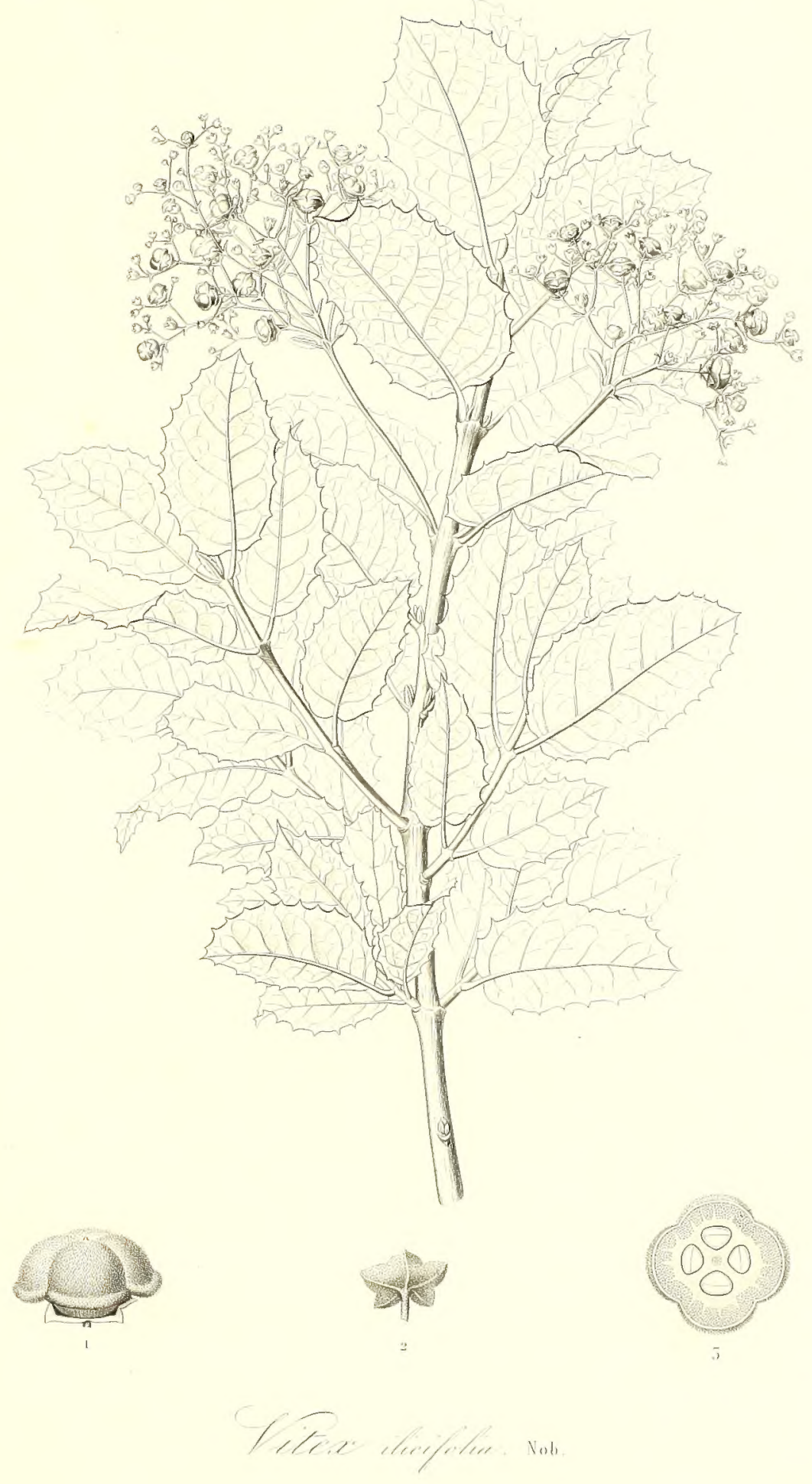


Tild 6,3

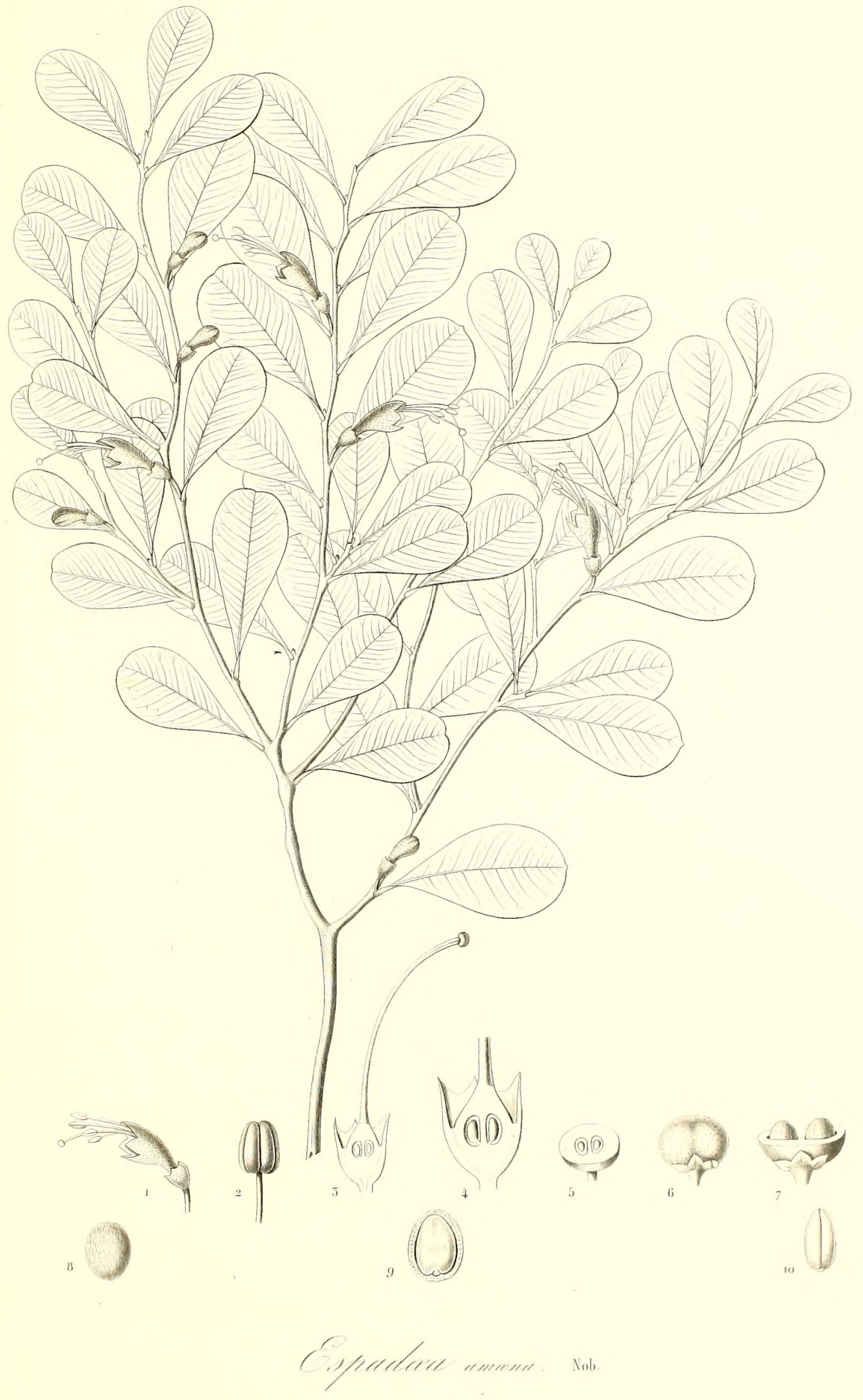




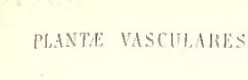

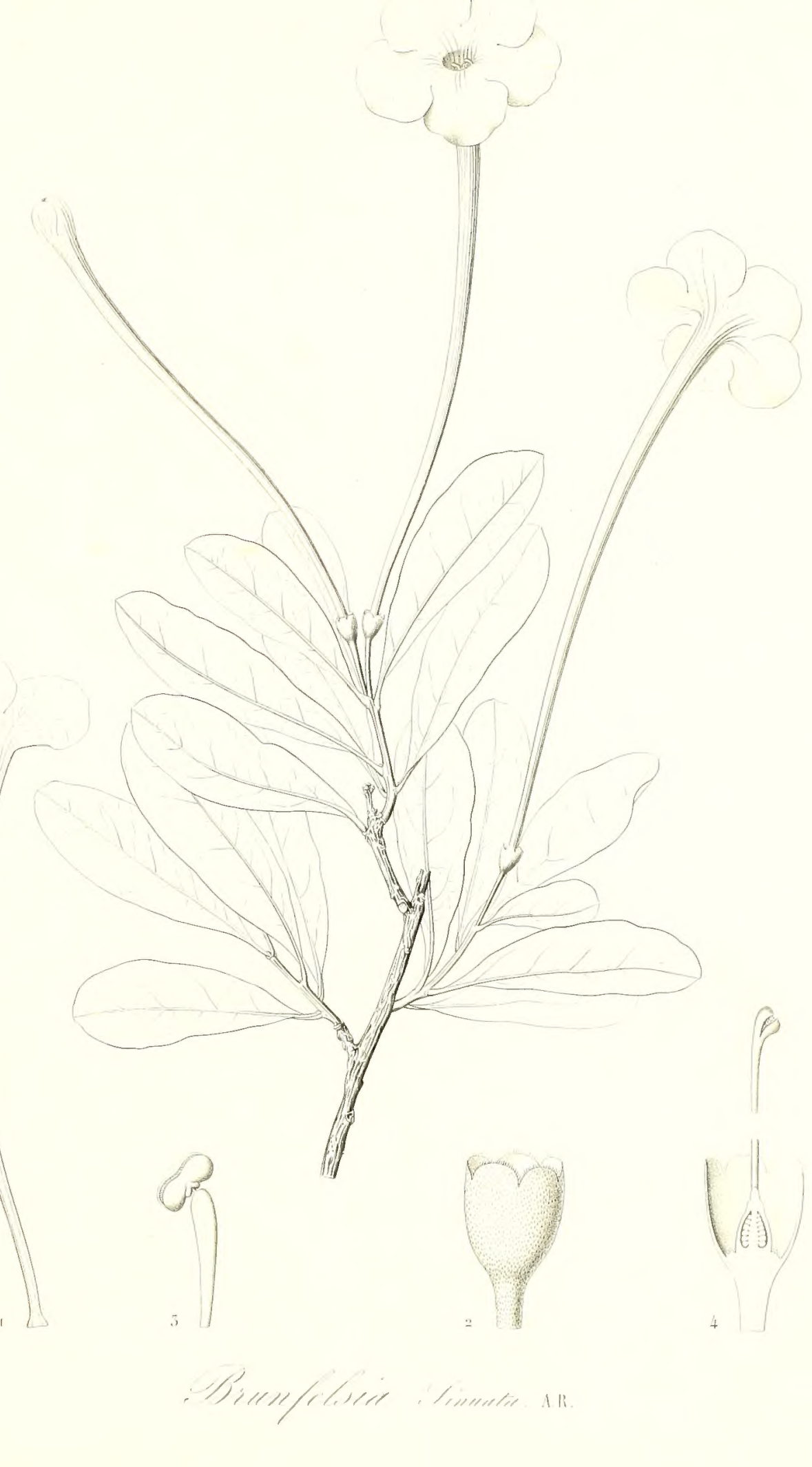




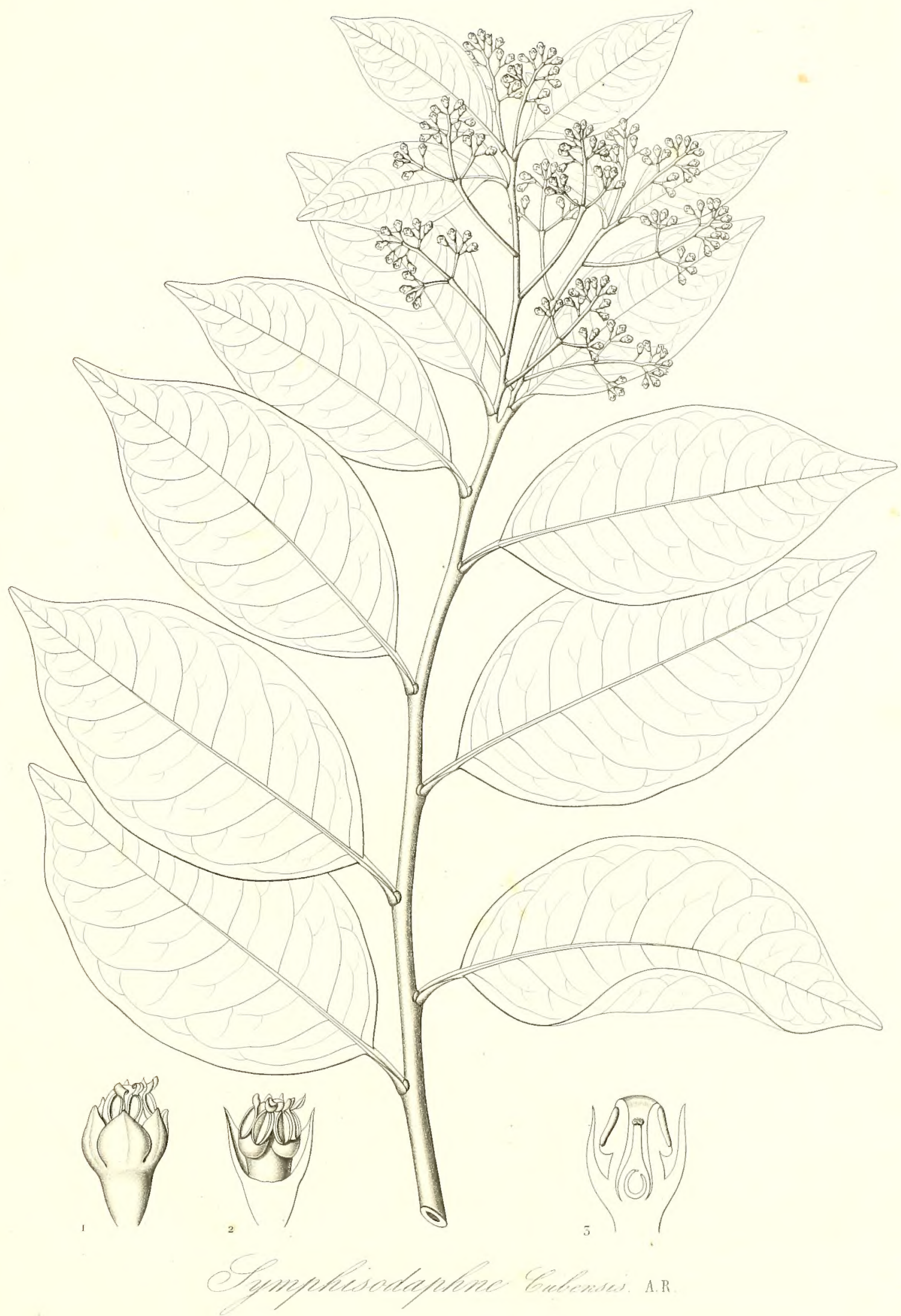




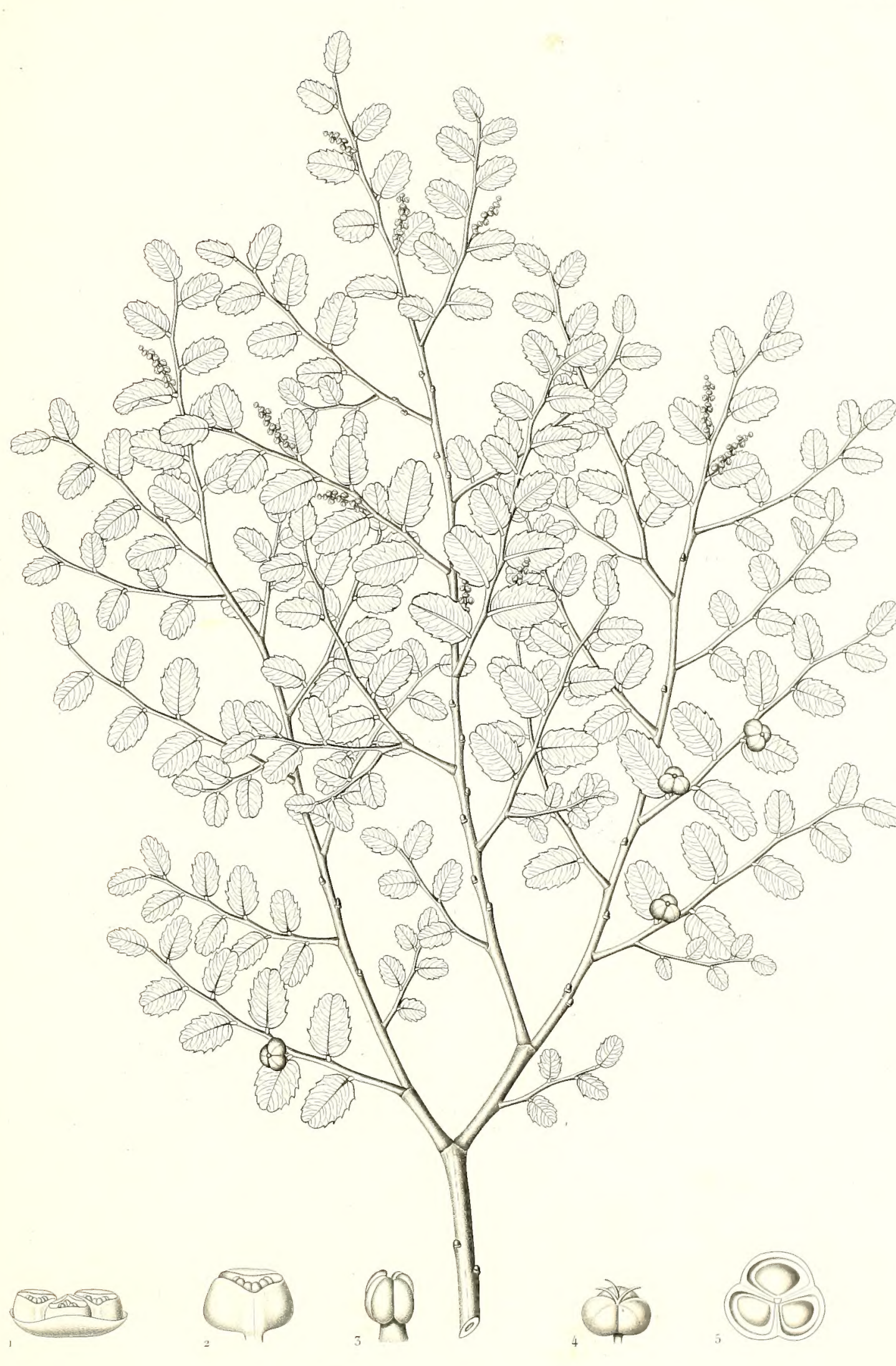





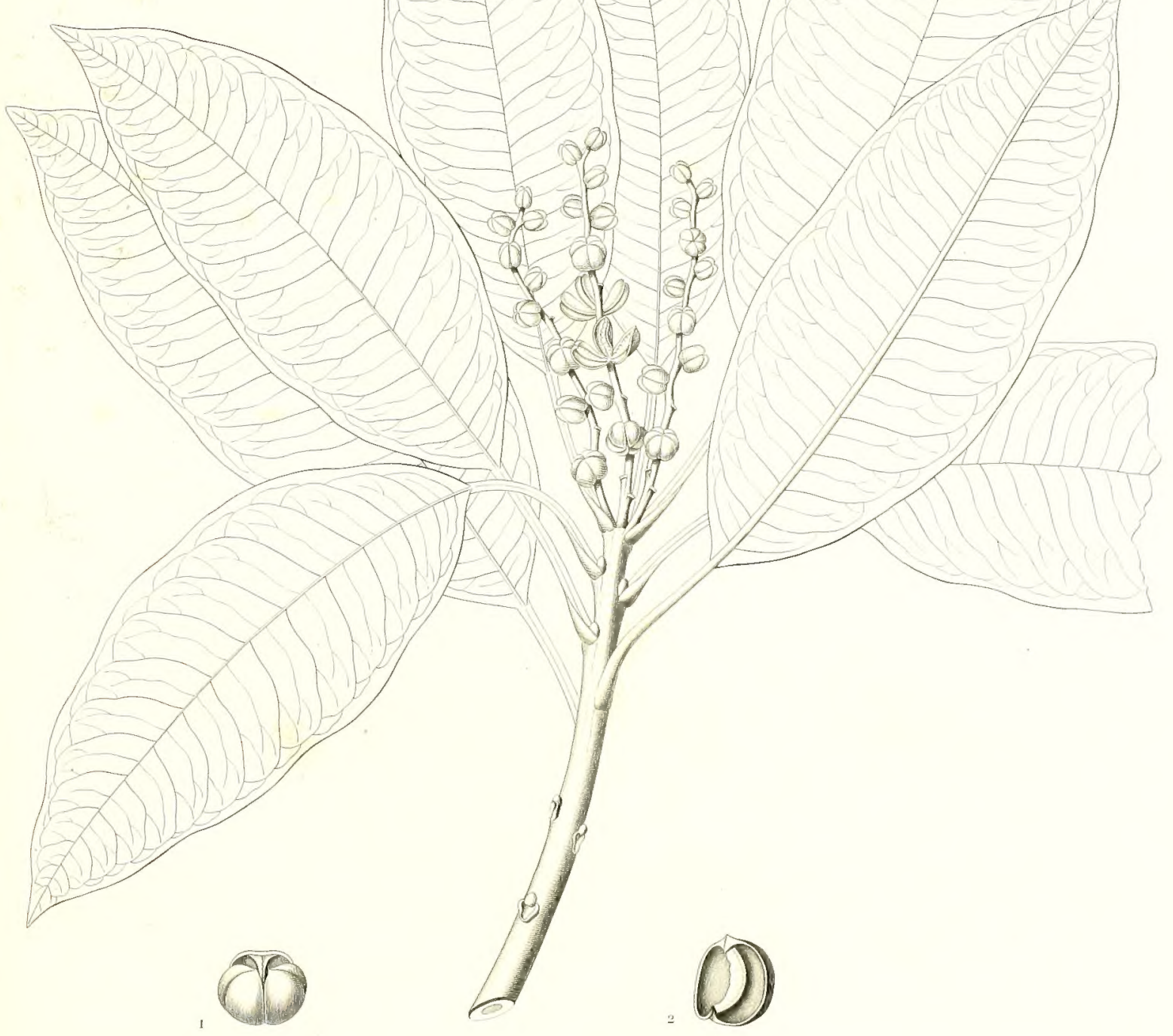

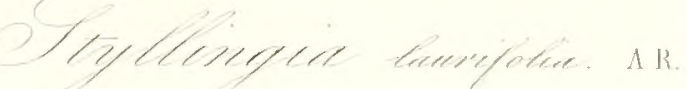


, 
PINTE VISCULALES
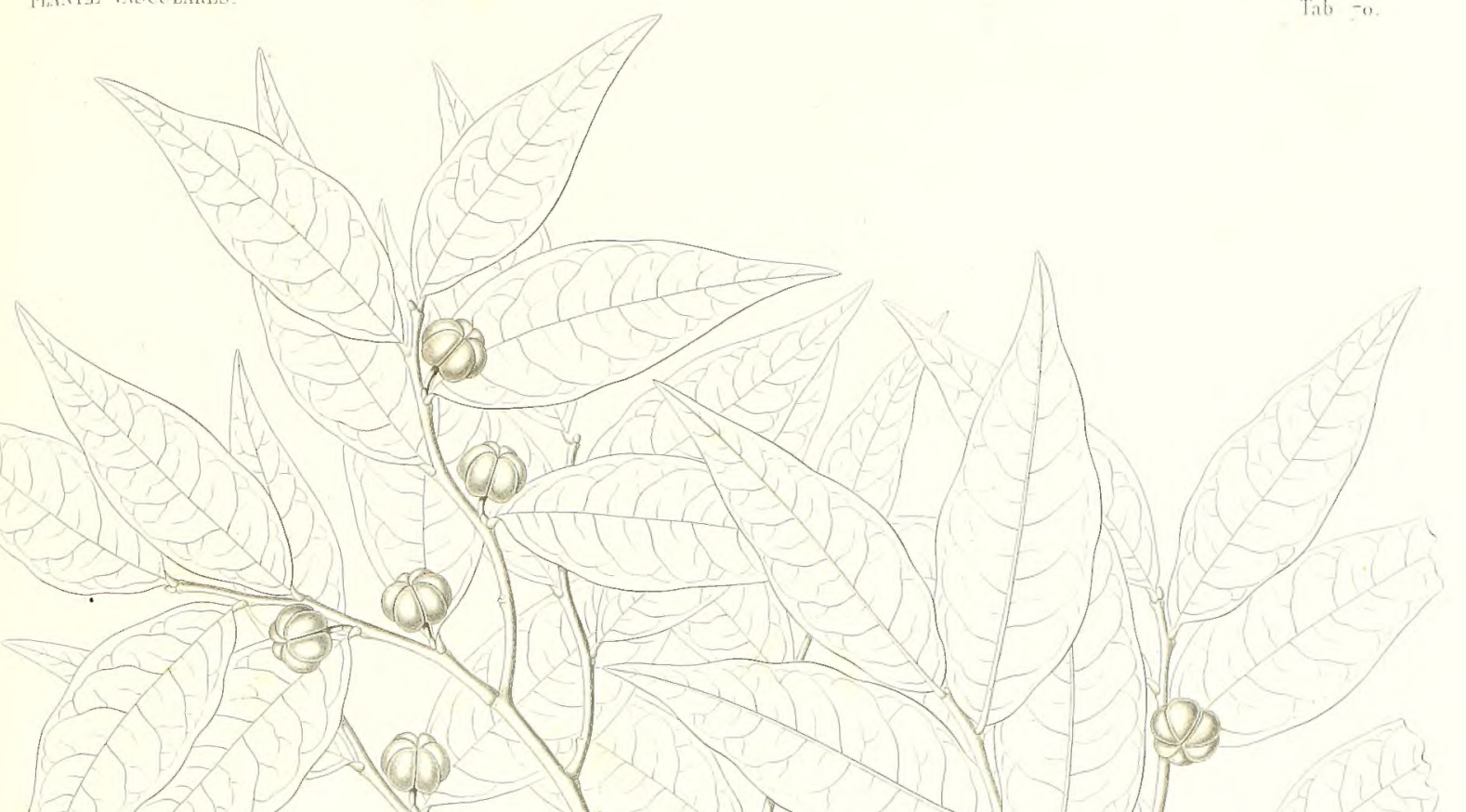

(1)
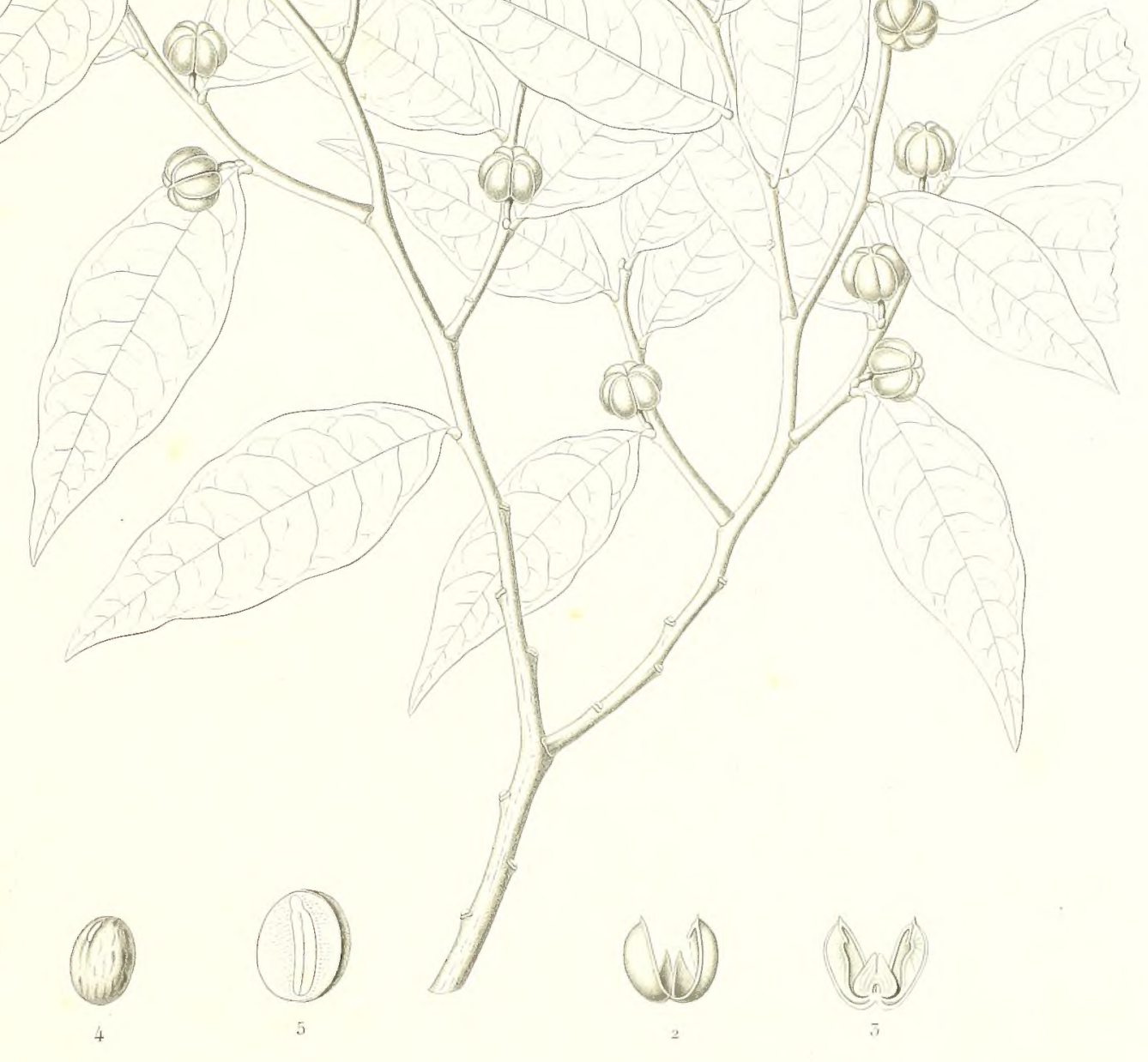

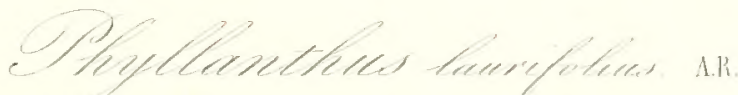


P'LANTE VASCLLARES

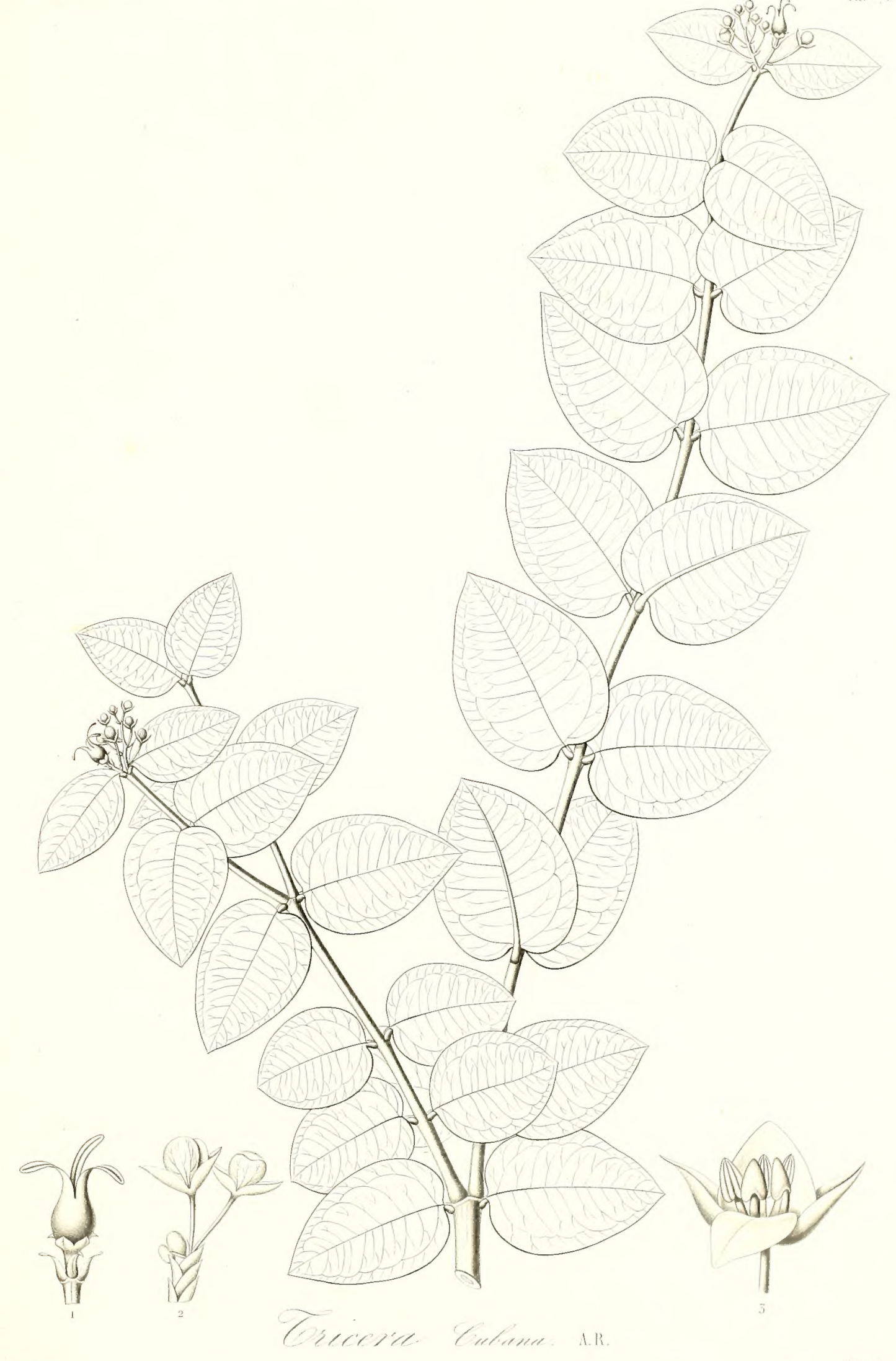



PLANEE MSCULARLS.

Til $1,-2$

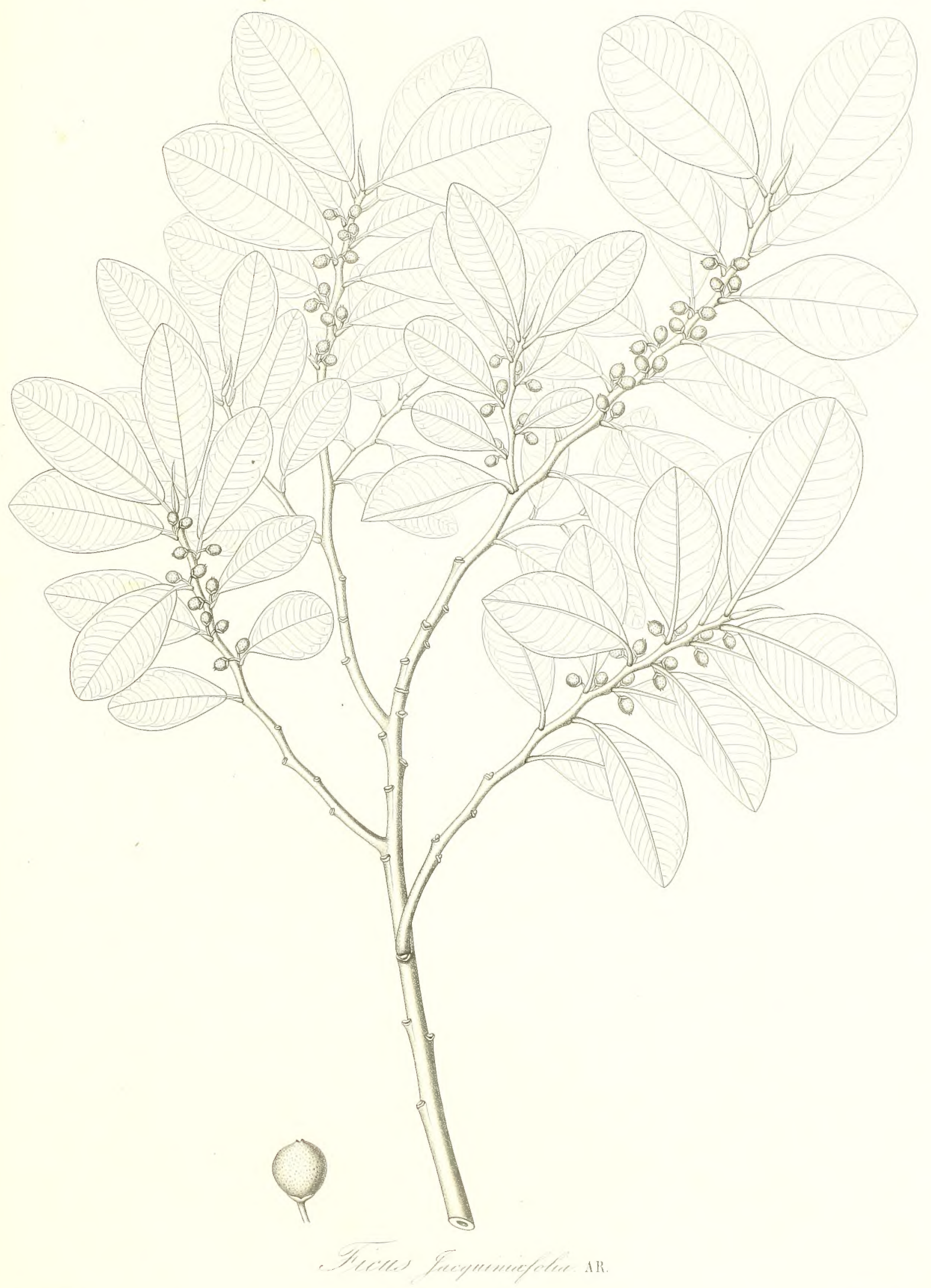

Wintheren ded 



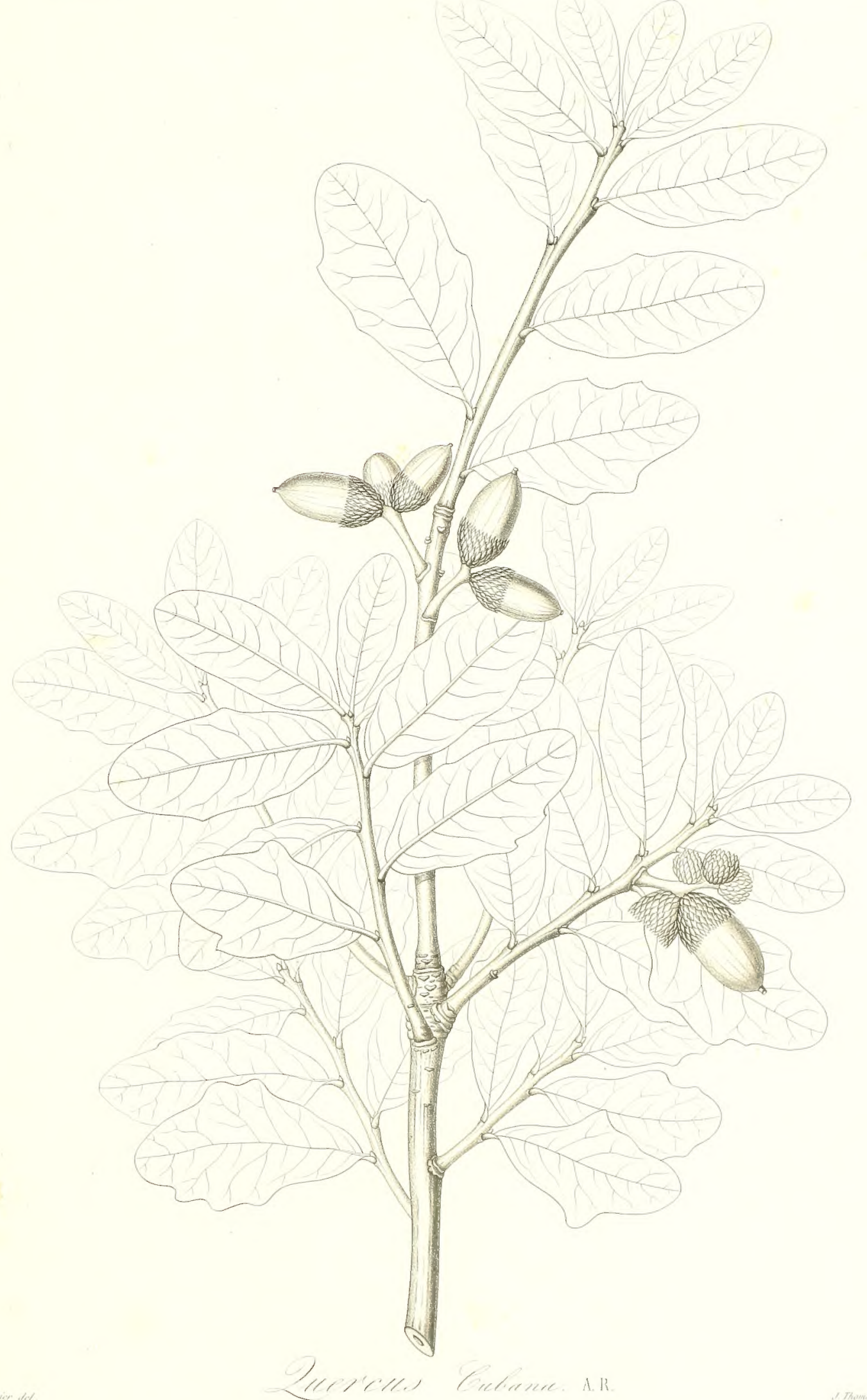



PUANTE VASCULARES

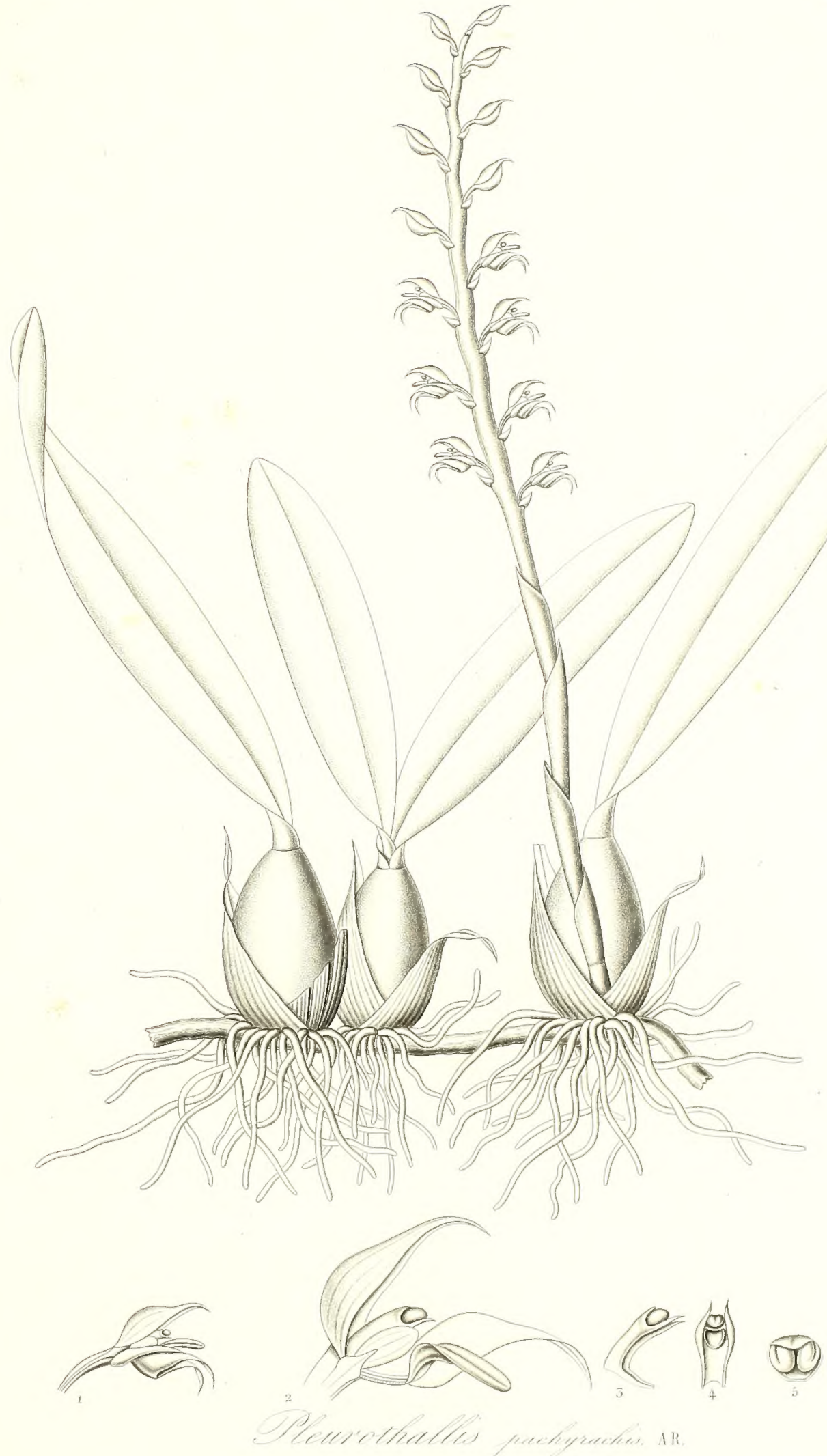





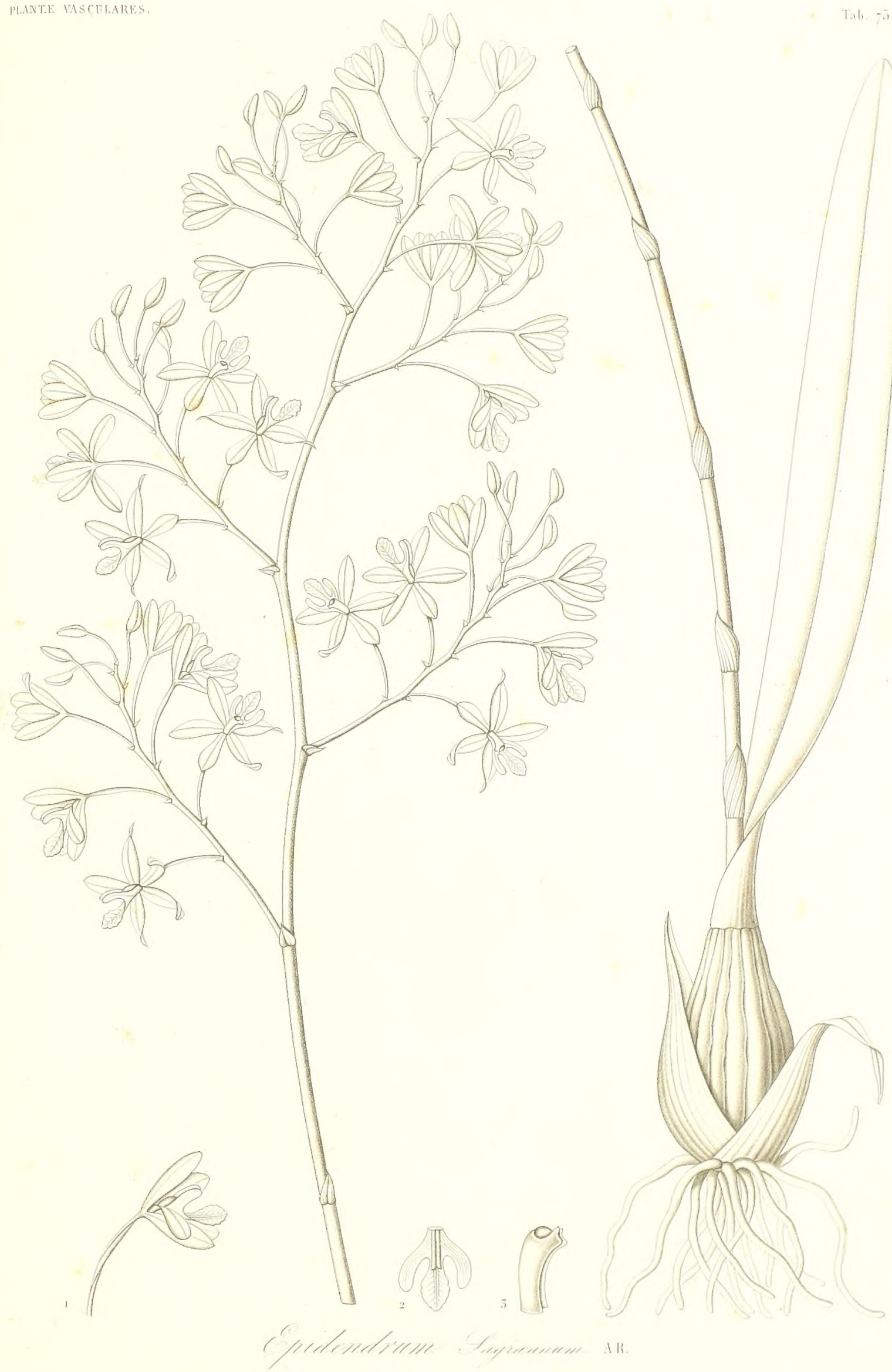



PMNR VASCULARES.

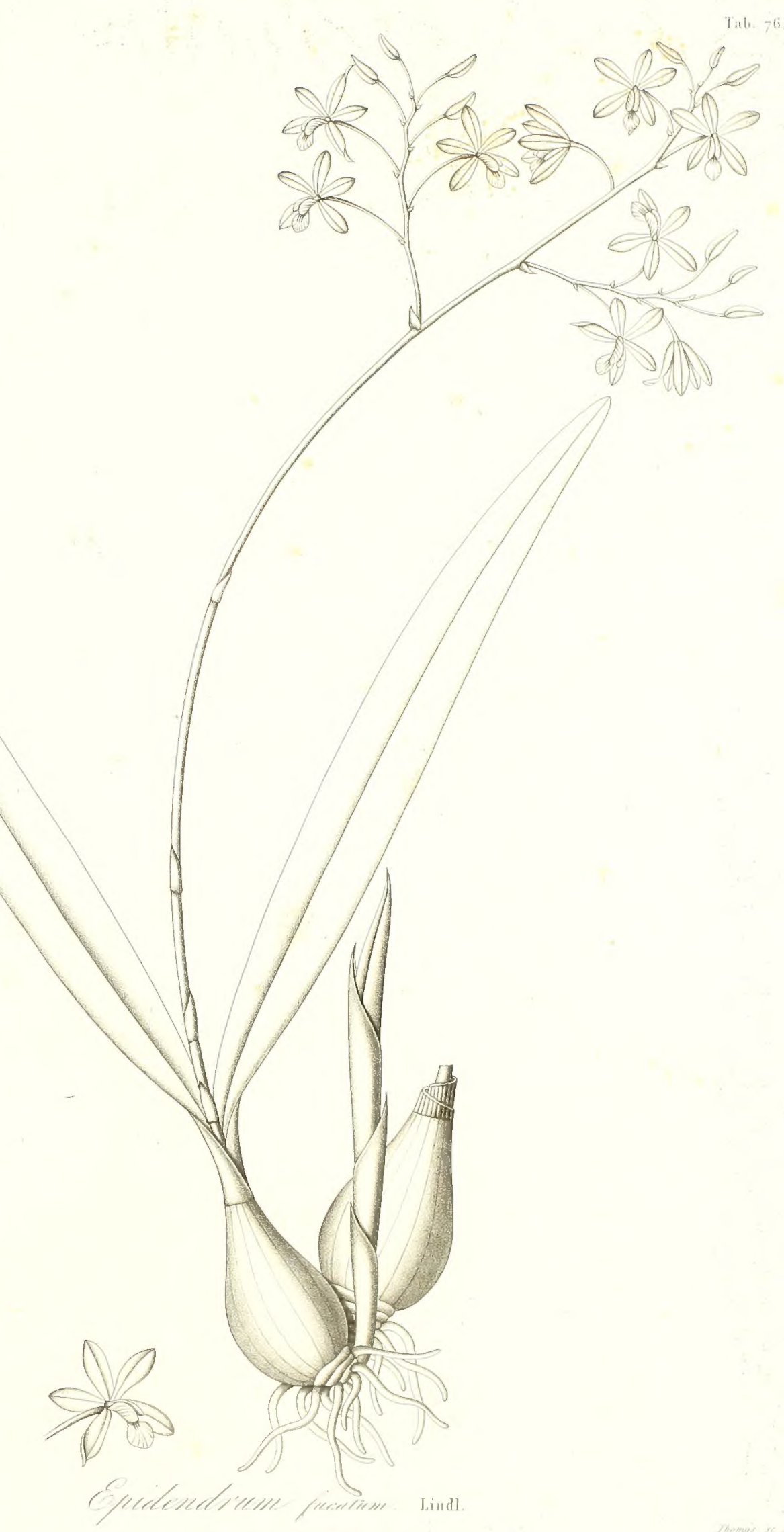





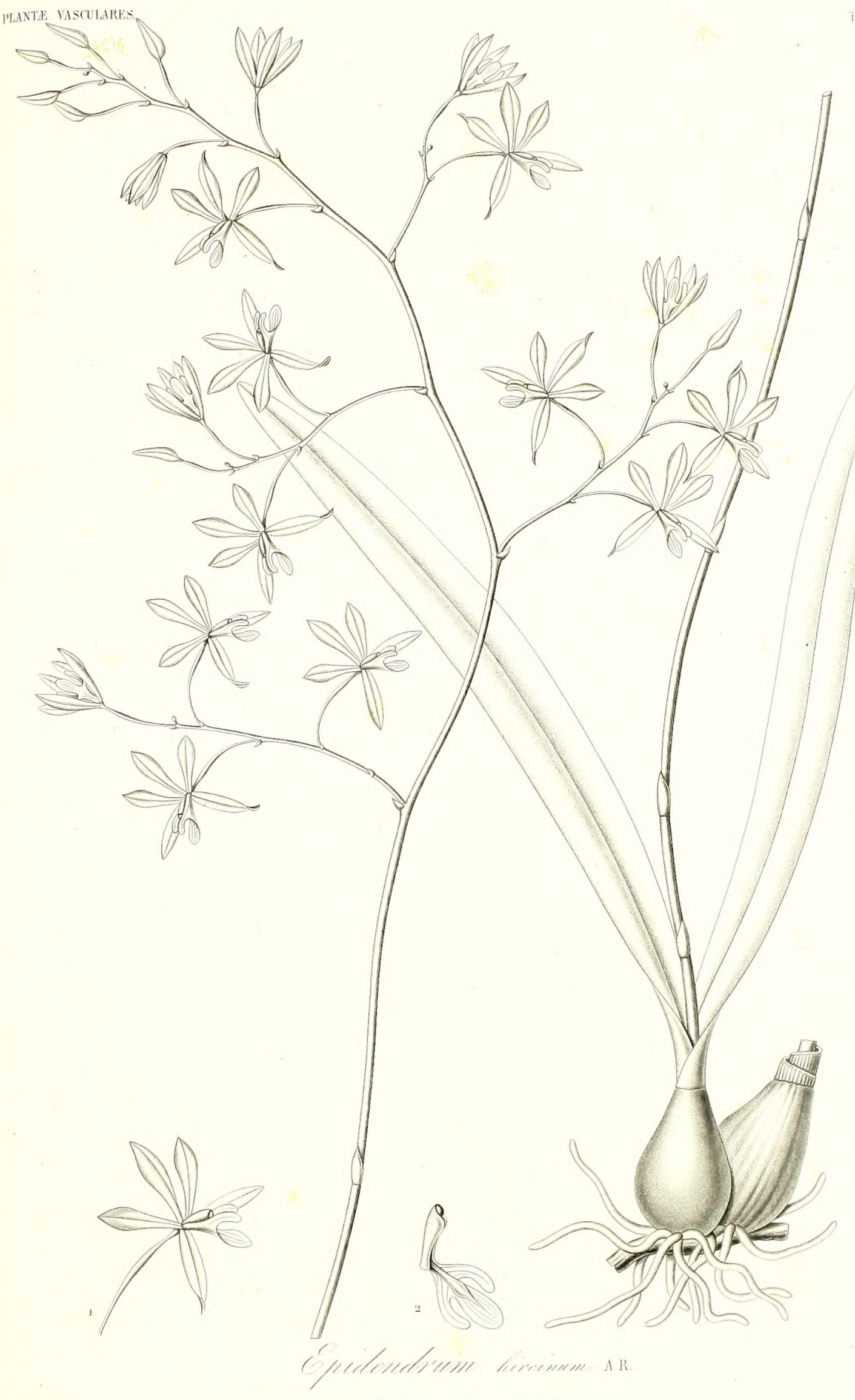





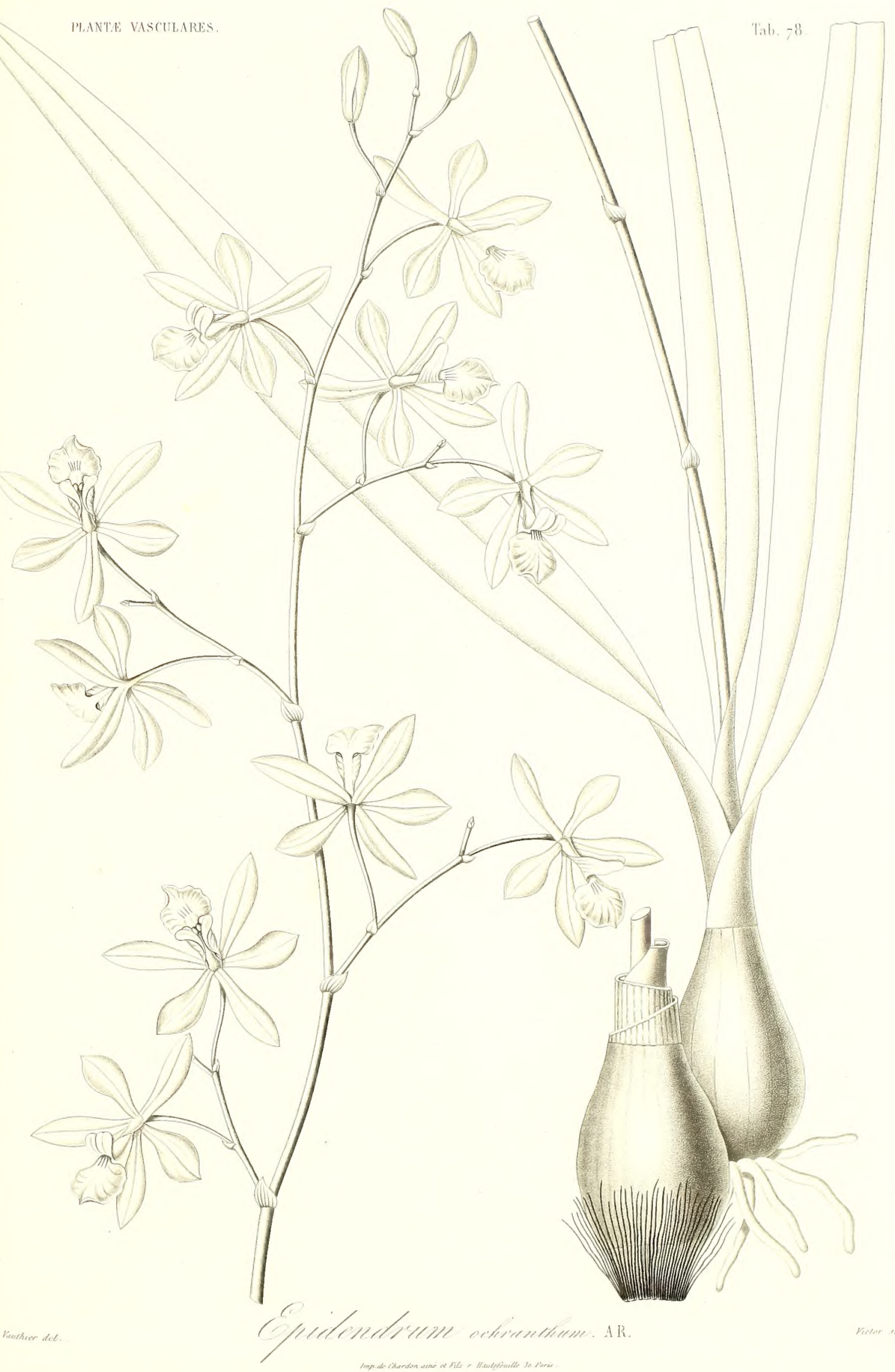





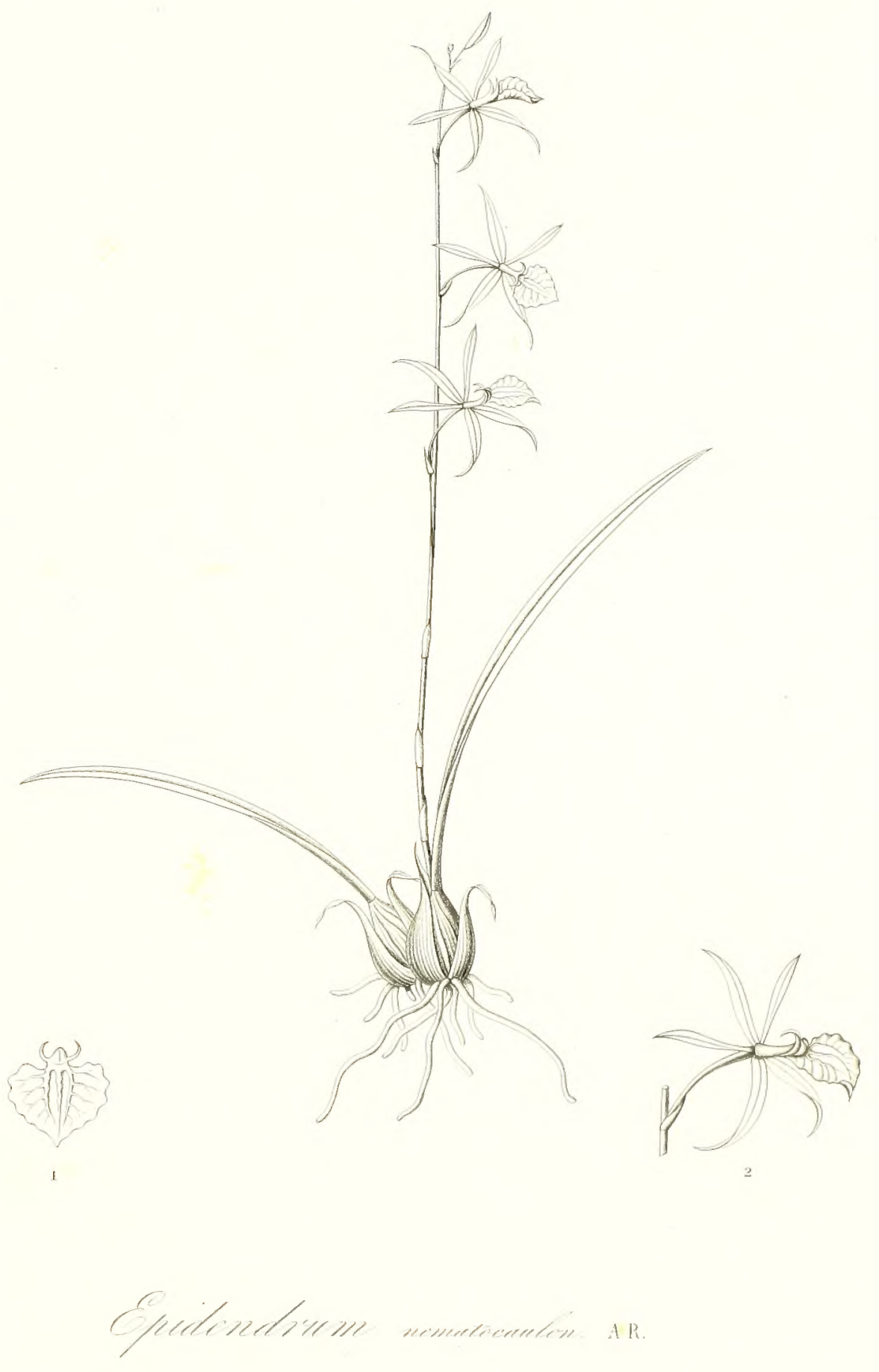



I'ANTE VASALARLS

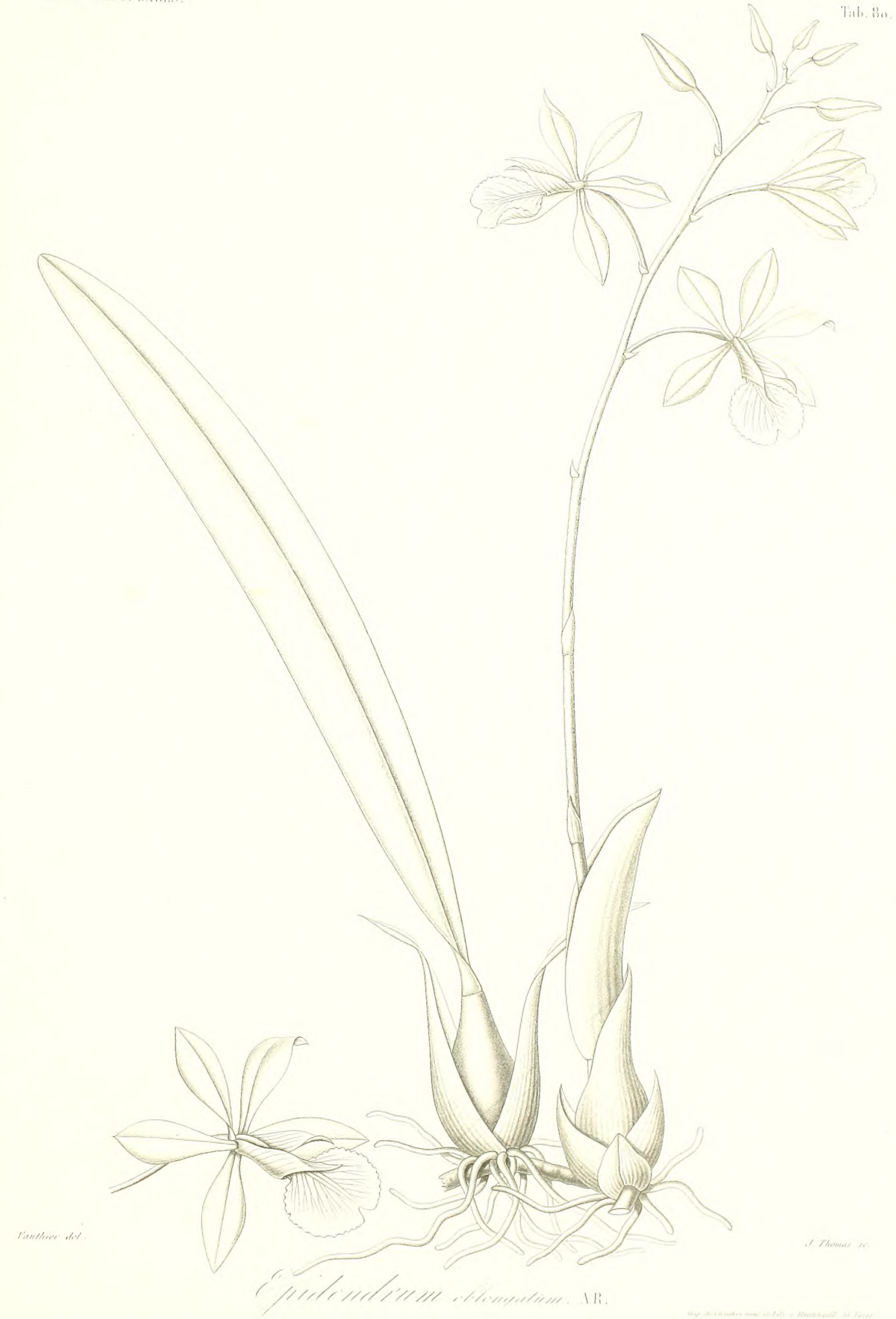



PLATTE VASCLLARES

Titis 81

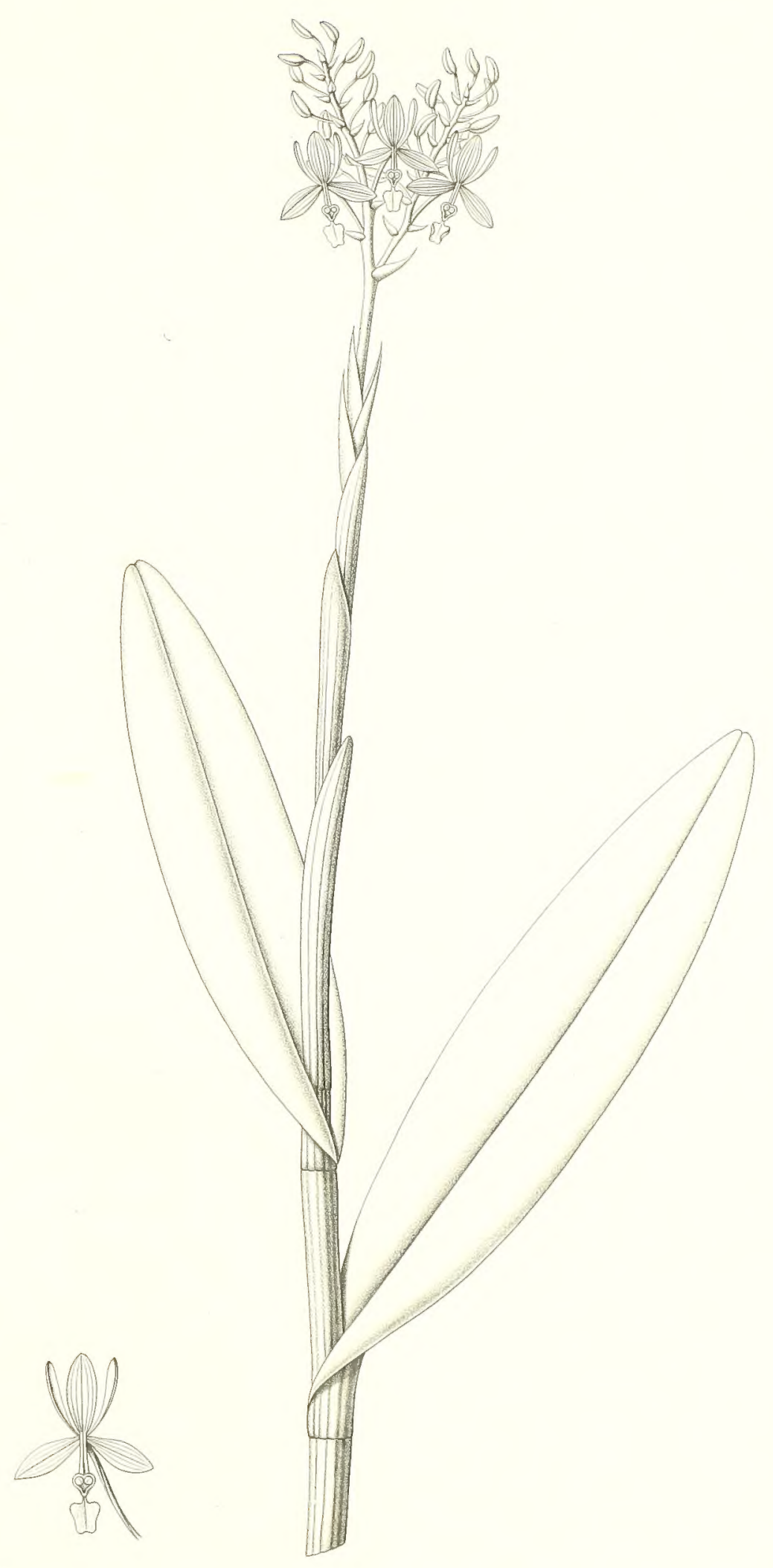

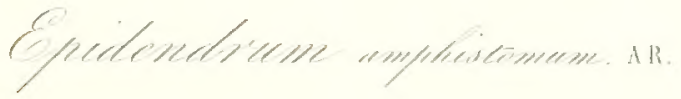





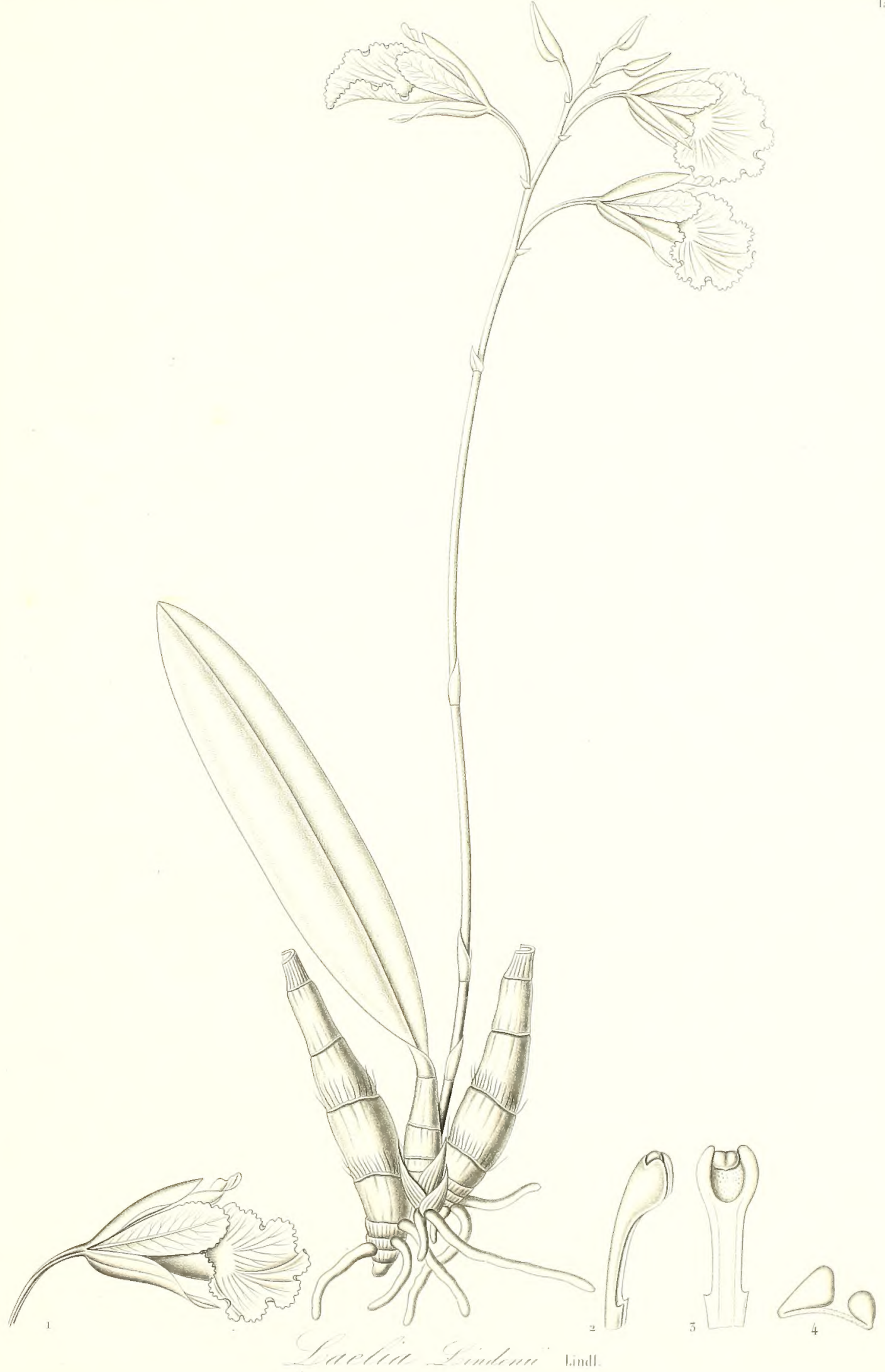





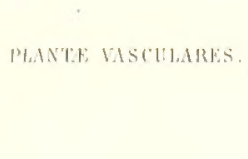

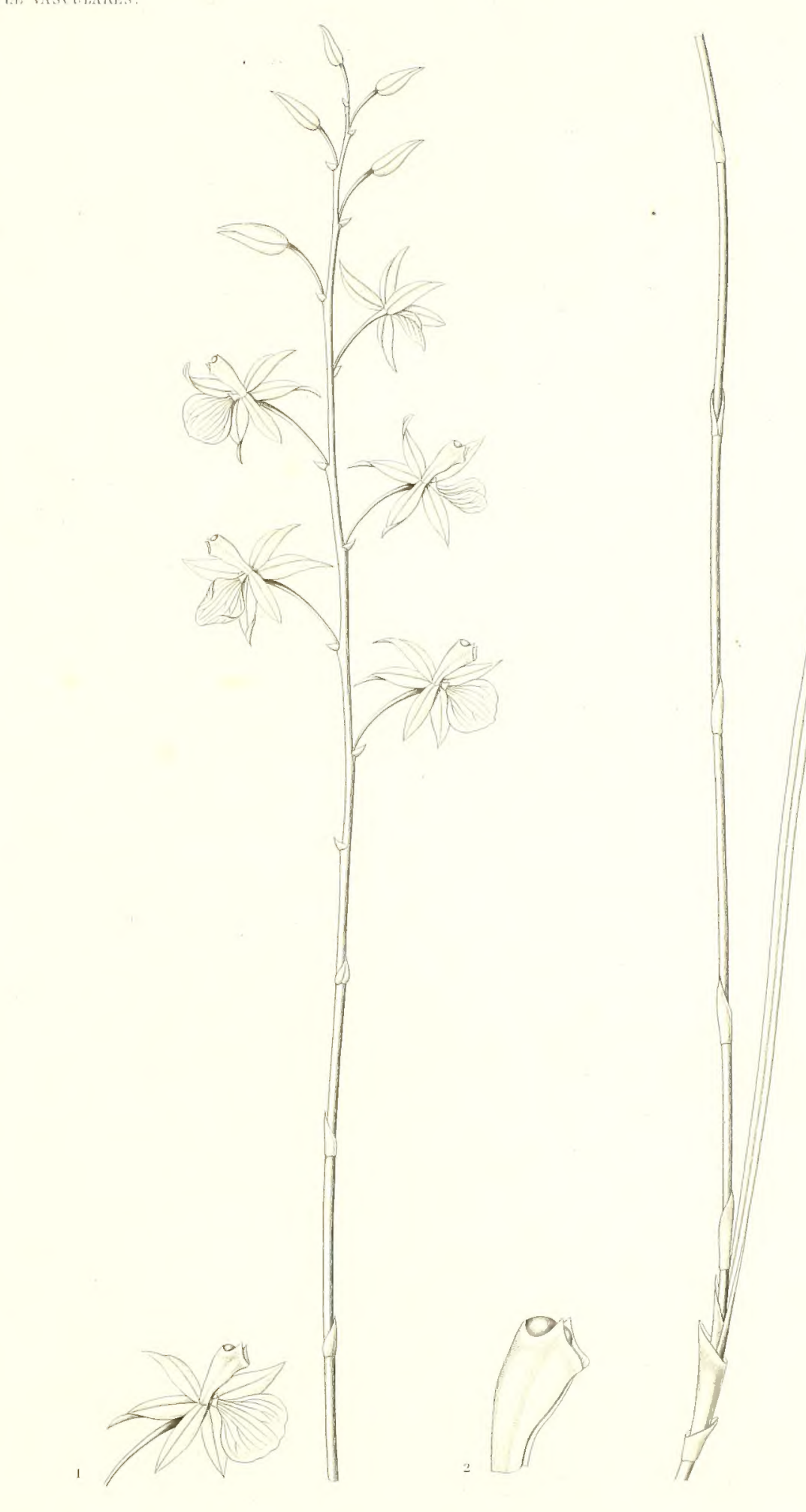





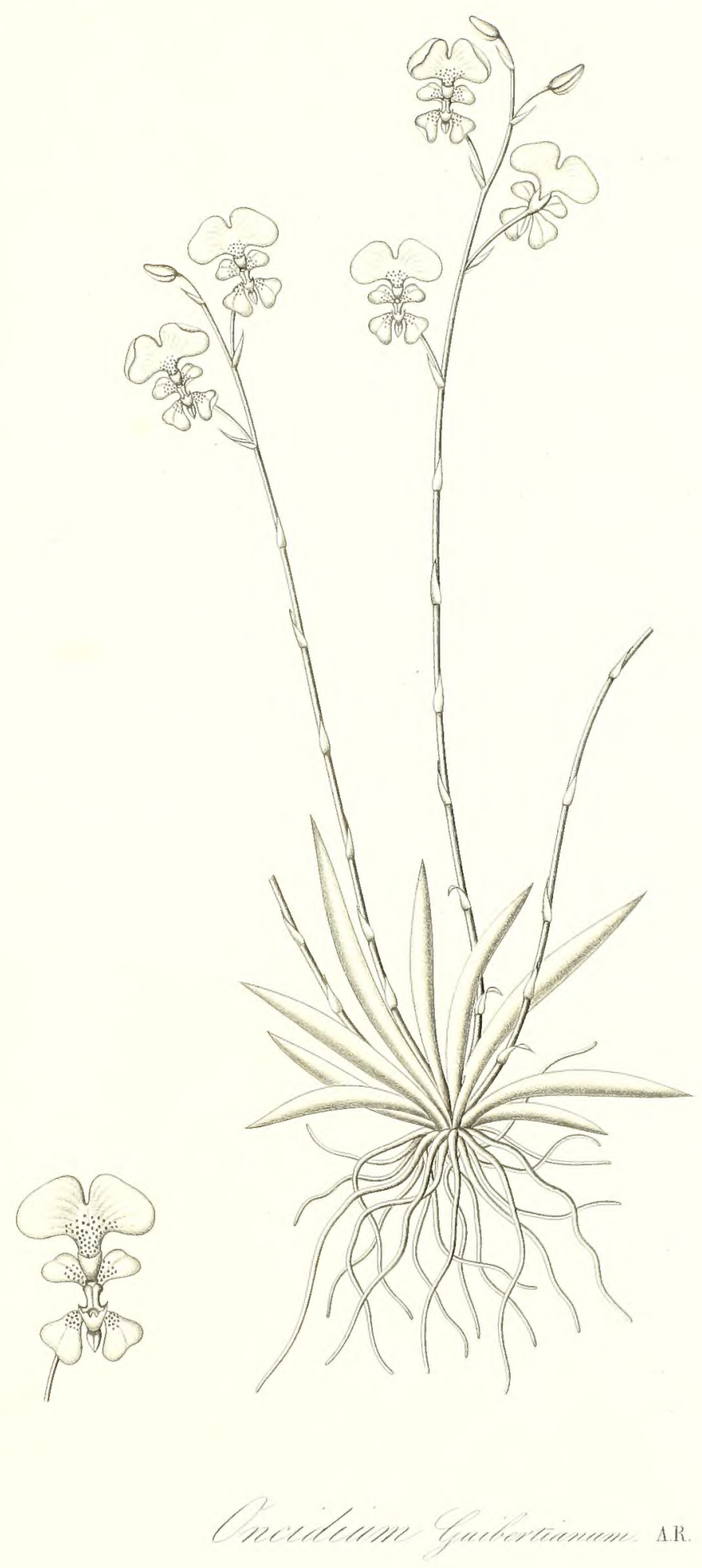




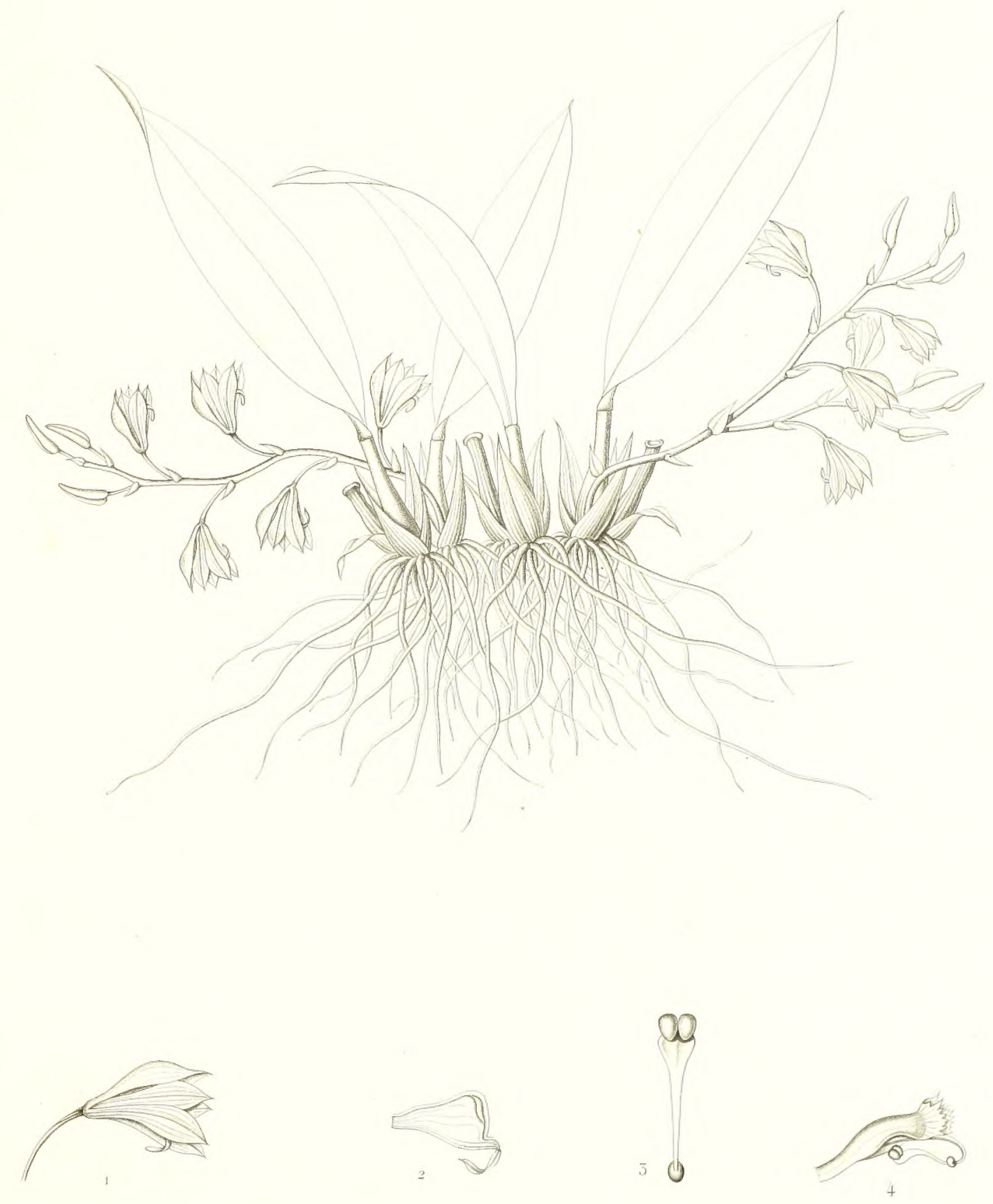

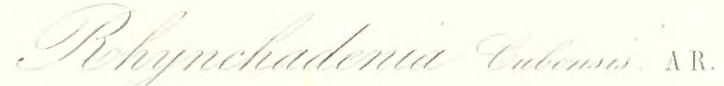




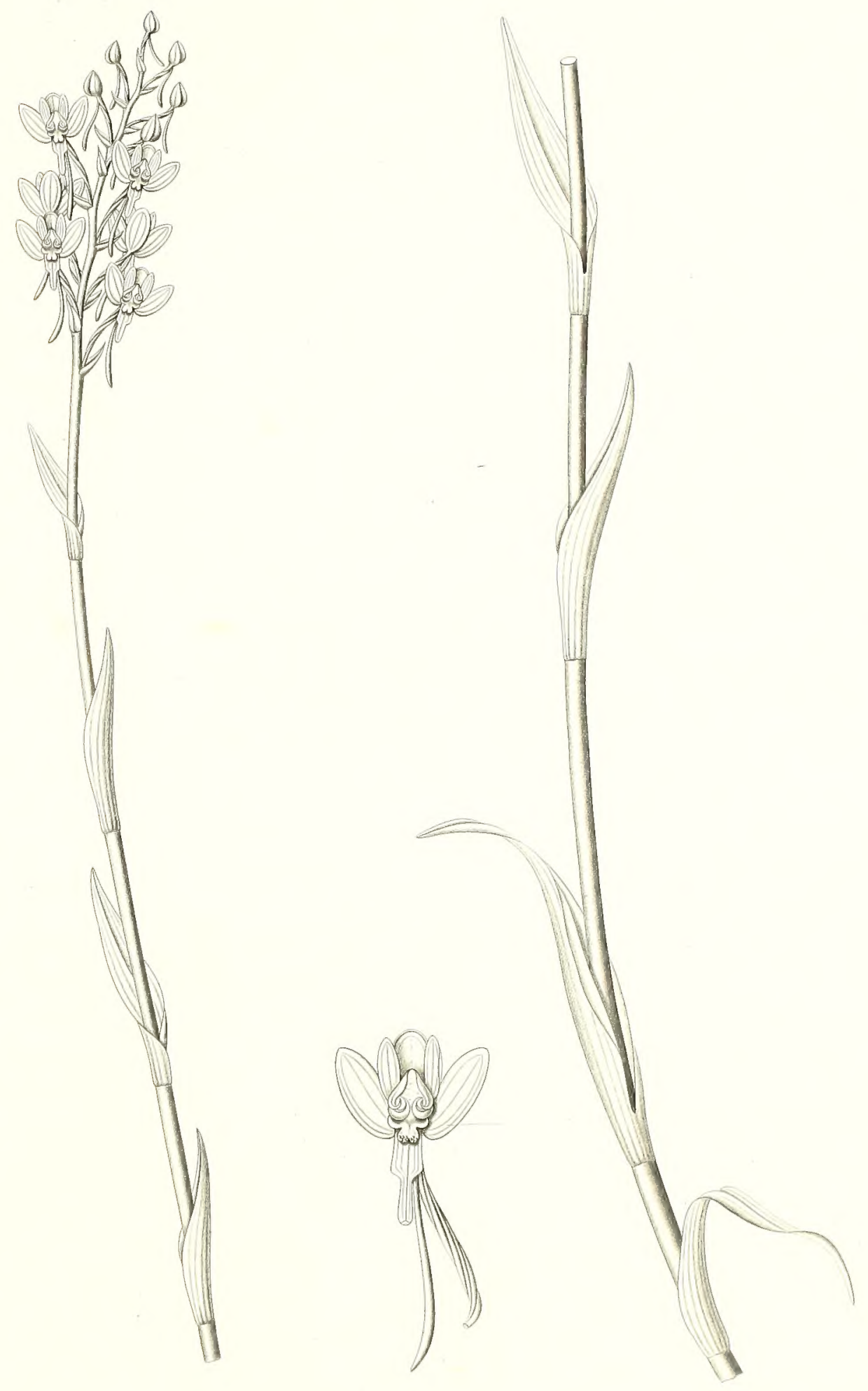

Aforticuenter 



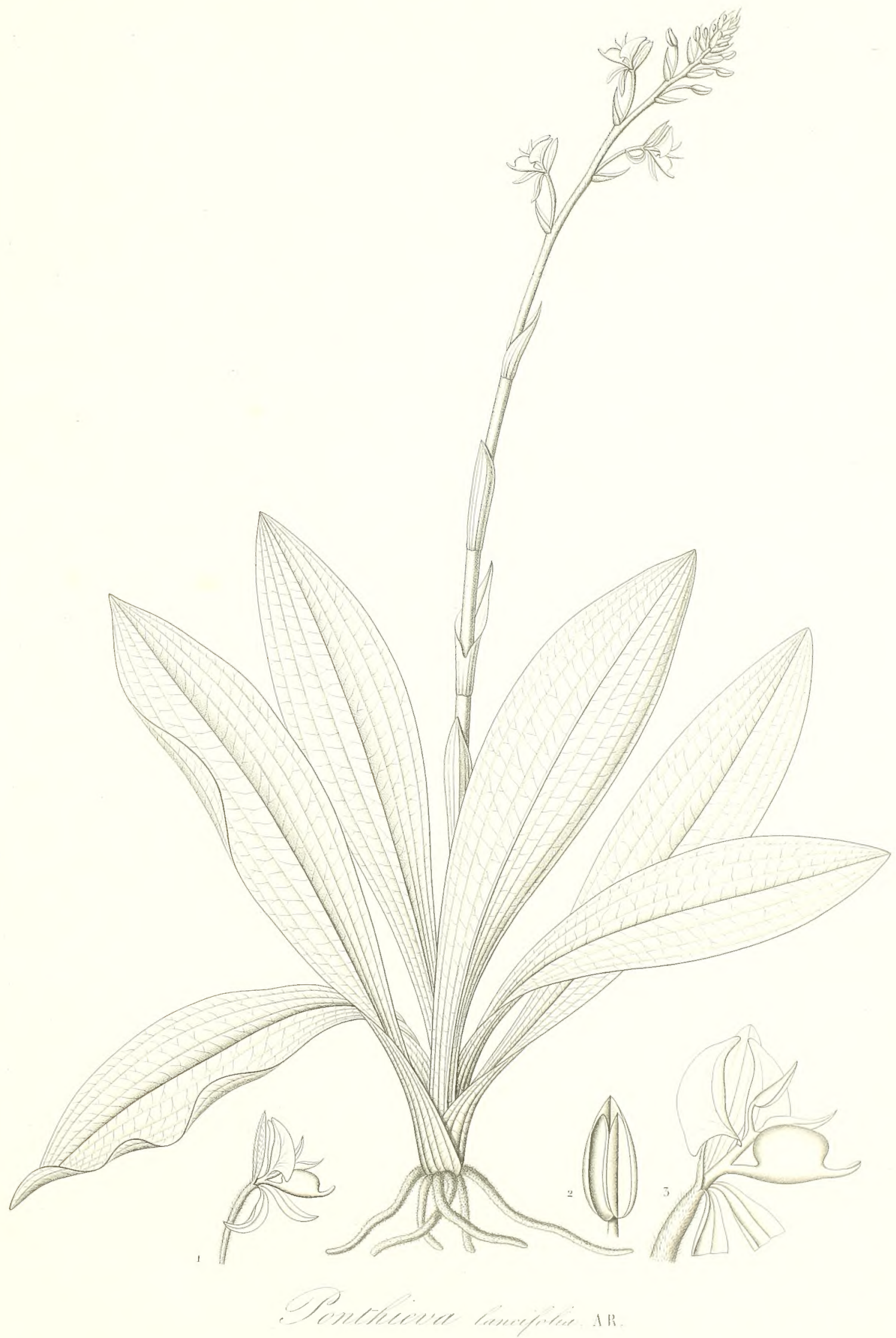


<smiles>C#CC(=C)C(C)C(C)C(C)CC</smiles> 



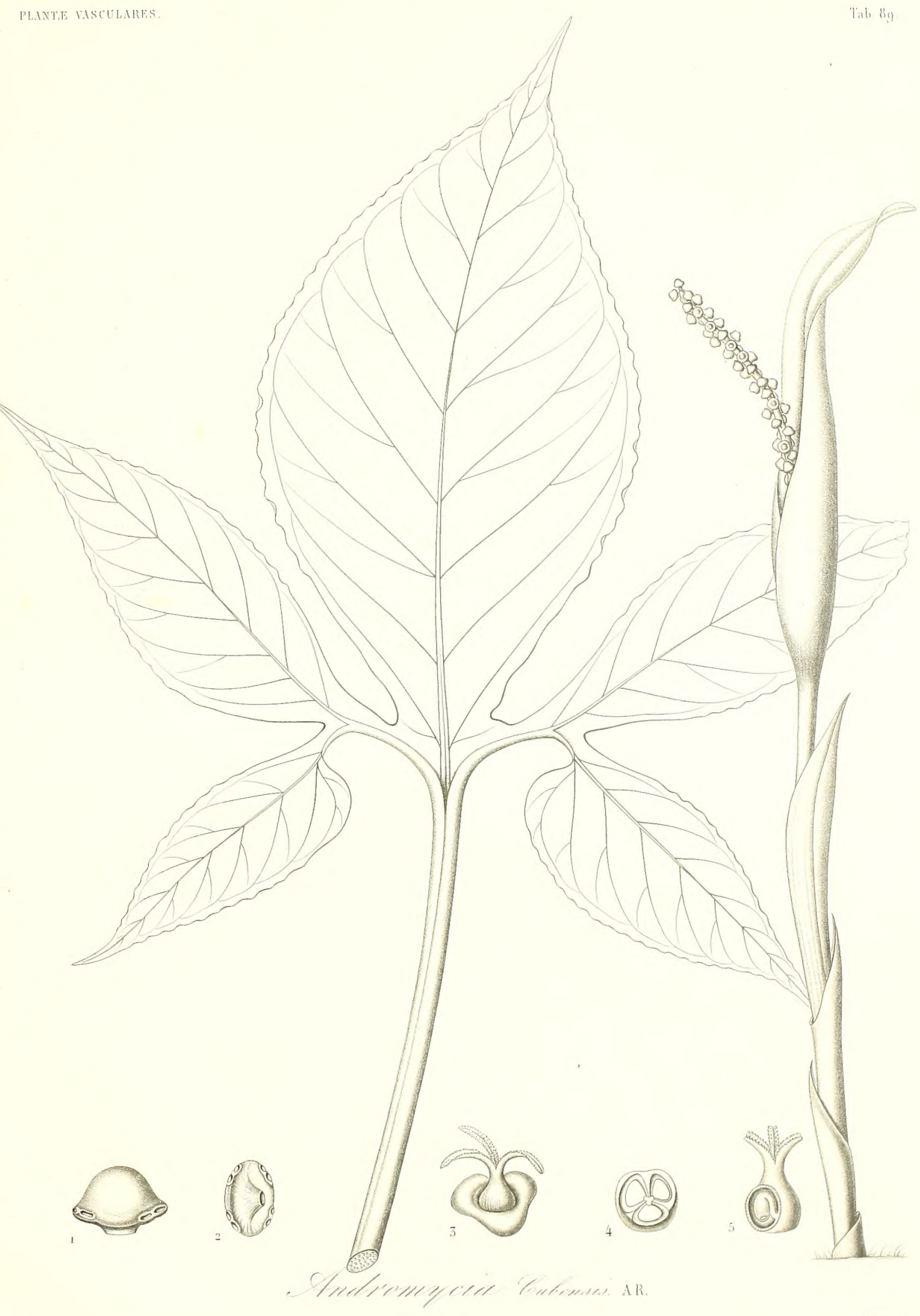




